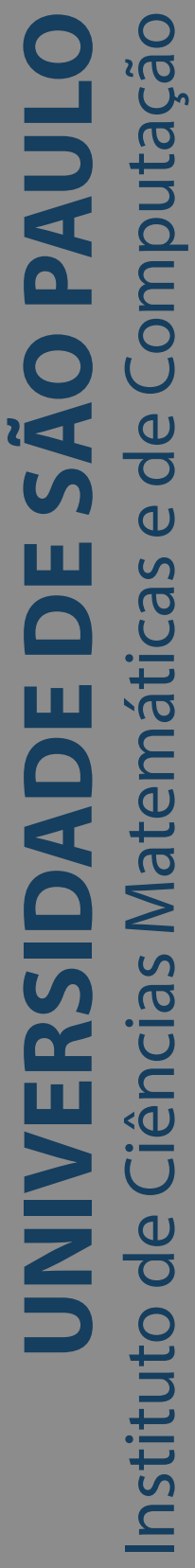

\title{
OntoSoft: um processo de desenvolvimento ágil para software baseado em ontologia
}

\section{Joice Basílio Machado Marques}

Tese de Doutorado do Programa de Pós-Graduação em Ciências de Computação e Matemática Computacional (PPG-CCMC) 

Assinatura:

\title{
Joice Basílio Machado Marques
}

\section{OntoSoft: um processo de desenvolvimento ágil para software baseado em ontologia}

\author{
Tese apresentada ao Instituto de Ciências \\ Matemáticas e de Computação - ICMC-USP, \\ como parte dos requisitos para obtenção do título \\ de Doutora em Ciências - Ciências de Computação e \\ Matemática Computacional. VERSÃO REVISADA \\ Área de Concentração: Ciências de Computação e \\ Matemática Computacional \\ Orientadora: Profa. Dra. Ellen Francine Barbosa
}


Ficha catalográfica elaborada pela Biblioteca Prof. Achille Bassi e Seção Técnica de Informática, ICMC/USP, com os dados fornecidos pelo(a) autor(a)

Machado Marques, Joice
OntoSoft: um processo de desenvolvimento ágil
para software baseado em ontologia / Joice Machado
Marques; orientadora Ellen Francine Barbosa. --
São Carlos, 2017 .
196 p.
Tese (Doutorado - Programa de Pós-Graduação em
Ciências de Computação e Matemática Computacional) --
Instituto de Ciências Matemáticas e de Computação,
Universidade de São Paulo, 2017.
1. Ontologia. 2. Engenharia de Software. 3.
Engenharia de Ontologias. 4. Scrum. 5. Processo de
desenvolvimento. I. Francine Barbosa, Ellen,
orient. II. Título.


Joice Basílio Machado Marques

OntoSoft: an agile development process for ontology-based software

Doctoral dissertation submitted to the Institute of Mathematics and Computer Sciences - ICMC-USP, in partial fulfillment of the requirements for the degree of the Doctorate Program in Computer Science and Computational Mathematics. FINAL VERSION

Concentration Area: Computer Science and Computational Mathematics

Advisor: Profa. Dra. Ellen Francine Barbosa

USP - São Carlos

December 2017 

Dedico esta tese para a minha primogênita Teresa e para os demais filhos que o Bom Deus quiser me dar. 

Agradeço ao Bom Deus pela oportunidade e por todas as graças recebidas ao longo desses 5 anos de doutorado. Se não fosse a sua Santa Vontade certamente eu não teria condições de fazer e concluir esta etapa tão importante em minha vida.

Agradeço à Santíssima Virgem Maria que providenciou tantos bens neste doutorado, que desde o início envolveu com seus méritos e virtudes as minhas ações para que eu pudesse conduzir e concluir cada atividade!

Agradeço à Ellen, minha cara orientadora, que durante o doutorado tanto me ensinou e foi tão paciente comigo. Sempre solícita e generosa, muitas vezes uma amiga compreensiva, especialmente no momento da gestação e após nascimento da minha filha Teresa. Muito obrigada por tudo!

Agradeço à minha mãe Cida, ao meu pai Jair e ao meu irmão Jean que fizeram tantos sacrifícios, especialmente na reta final da escrita desta tese. Vocês são meus primeiros grandes amigos, com os quais posso sempre contar! Muito obrigada!

Agradeço ao meu esposo, Leandro, que foi meu grande apoio ao longo deste tempo. Um pai excepcional que cuidou do nosso bem mais precioso quando eu não podia, que renunciou ao seu descanso para que eu pudesse trabalhar. Muito obrigada, meu amado esposo!

Agradeço aos amigos do laboratório de engenharia de software - LabES - pela convivência agradável e formativa. A todos que se tornaram tão especiais e fraternos! Aprendi muito com todos e ficarei feliz se em um futuro próximo nos encontrarmos nas instituições de ensino.

A todos os funcionários do ICMC, pelos serviços prestados.

À Universidade de São Paulo.

Ao CNPq e CAPES pelo apoio Financeiro. 

"Fazei tudo por Amor. Assim não há coisas pequenas: tudo é grande. A perseverança nas pequenas coisas, por Amor, é heroísmo." 



\section{RESUMO}

MARQUES, J. B. M. OntoSoft: um processo de desenvolvimento ágil para software baseado em ontologia. 2017. 195 p. Tese (Doutorado em Ciências - Ciências de Computação e Matemática Computacional) - Instituto de Ciências Matemáticas e de Computação, Universidade de São Paulo, São Carlos - SP, 2017.

A formalização e o compartilhamento do conhecimento tem incentivado cada vez mais o uso de ontologias em diversas áreas da computação. Na Engenharia de Software, por exemplo, elas são usadas em diferentes fases do ciclo de vida do software. Especificamente no desenvolvimento de software a ontologia pode ser considerada como um artefato de software que atua na formalização do conhecimento e requisitos, na geração automática de código, na integração contínua e na transformação de dados em conhecimento. No entanto, poucos estudos abordam esses fatores de maneira sistematizada na construção do software baseado em ontologia, ao associar os conceitos da Engenharia de Software à Engenharia de Ontologias. Além disso, as abordagens atuais não inserem princípios ágeis em suas definições. Portanto, este trabalho tem por objetivo definir um processo de desenvolvimento considerando os princípios e valores ágeis para o desenvolvimento de software baseado em ontologia. No processo, denominado OntoSoft, fases, atividades, tarefas, papeis e modelos de artefatos foram definidos de maneira detalhada para guiar as equipes de desenvolvimento. Ademais, foram especificados três cenários de desenvolvimento considerando a complexidade do software a ser desenvolvido, a fim de evidenciar possibilidades distintas na sequência das atividades durante o fluxo de desenvolvimento do software baseado em ontologia. Com base nos estudos de caso conduzidos em diferentes cenários de desenvolvimento, os resultados sugerem que o processo OntoSoft contribui positivamente na produção dos artefatos do software baseado em ontologia, colaborando para a efetividade e produtividade da equipe.

Palavras-chave: Ontologia, Engenharia de Software, Engenharia de Ontologias, Scrum, Processo de desenvolvimento. 



\section{ABSTRACT}

MARQUES, J. B. M. OntoSoft: an agile development process for ontology-based software. 2017. 195 p. Tese (Doutorado em Ciências - Ciências de Computação e Matemática Computacional) - Instituto de Ciências Matemáticas e de Computação, Universidade de São Paulo, São Carlos - SP, 2017.

Formalization and knowledge sharing have increasingly encouraged the use of ontologies in several areas of computing. In Software Engineering, for example, they have been used in different phases of the software life cycle. Specifically in software development, an ontology can be considered as a software artifact, which acts in the formalization of knowledge and requirements, automatic generation of code, continuous integration and data transformation into knowledge. However, few studies deal with these factors in a systematized way for the development of ontology based software, regarding to associating Software Engineering and Ontology Engineering concepts. In addition, current approaches do not address agile principles in their definitions. In this sense, this work aims to define a development process concerning the principles and agile values for ontology based software development. In the process, called OntoSoft, phases, activities, tasks, roles, and artifact models were defined in detail to guide development teams. In addition, three development scenarios were specified considering the complexity of the software to be developed, in order to demonstrate distinct possibilities of development flow of the ontology based software. Based on case studies conducted in different development environments, the results suggest that the OntoSoft process contributes positively to the development of ontology based software artifacts, contributing to the effectiveness and productivity of the team.

Keywords: Ontology, Software Engineering, Ontology Engineering, Scrum, Development process. 



\section{LISTA DE ILUSTRAÇÕES}

Figura 1 - O desenvolvimento de software ao longo do tempo (AßMANN et al., 2013). 30

Figura 2 - Interesse relativo aos últimos 10 anos com base em pesquisas no Google Trends e na base de dados Scopus. . . . . . . . . . . . . . . 38

Figura 3 - Scrum: principais atividades e artefatos. . . . . . . . . . . 39

Figura 4 - Processo de desenvolvimento de ontologias. . . . . . . . . . . . . . 44

Figura 5 - METHONTOLOGY: visão geral. . . . . . . . . . . . . . . 48

Figura 6 - Principais processos para o desenvolvimento e implantação de aplicativos na Gestão do Conhecimento. . . . . . . . . . . . . . . . . . . . . . . . . 61

Figura 7 - Atividades referentes ao processo de conhecimento. . . . . . . . . . 62

Figura 8 - Possíveis abordagens para o gerenciamento do conhecimento. . . . . . . . 62

Figura 9 - Quantidade de estudos incluídos e excluídos a partir dos critérios estabelecidos nas respectivas bases de busca. . . . . . . . . . . . . . . 66

Figura 10 - Linha do tempo considerando a definição dos processos para software baseado em ontologia nos últimos 12 anos. . . . . . . . . . . . . . 66

Figura 11 - Quatro aspectos do desenvolvimento de software considerando a interação e influência das novas tecnologias na qualidade do software. . . . . . . . 75

Figura 12 - Associação e integração dos aspectos de modelagem de software e das ontologias. . . . . . . . . . . . . . . . . 76

Figura 13 - Fluxo global do processo OntoSoft. . . . . . . . . . . . . . . . . 81

Figura 14 - Visão geral das principais fases e artefatos do processo OntoSoft. . . . . . . 82

Figura 15 - Fluxo das atividades entre as grandes fases do processo OntoSoft. . . . . . . 83

Figura 16 - Atividades definidas para o processo OntoSoft. . . . . . . . . . . . . 86

Figura 17 - Atividades que compõem a fase de Gerenciamento do processo OntoSoft. $\quad$ 88

Figura 18 - Fluxo das atividades e artefatos gerados no Gerenciamento do processo OntoSoft. . . . . . . . . . . . . . . . . . 92

Figura 19 - Atividades estabelecidas para a fase de Pré-Desenvolvimento do processo OntoSoft. . . . . . . . . . . . . . . . . 93

Figura 20 - Atividades relacionadas à fase de Desenvolvimento do processo OntoSoft. . 98

Figura 21 - Linha do tempo de desenvolvimento do software e da ontologia. . . . . . . 99

Figura 22 - Cenários de uso definidos no processo OntoSoft para software baseado em ontologia. . . . . . . . . . . . . . . . . . . 104

Figura 23 - Iteração entre as atividades referentes ao software e ontologia no decorrer do

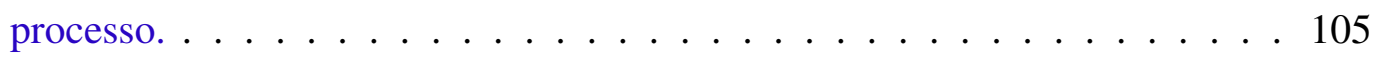


Figura 24 - Fluxo padrão das atividades no processo OntoSoft - Cenário i. . . . . . . . . 107

Figura 25 - Cenário i: fluxo de atividades na fase de Pré-Desenvolvimento do processo OntoSoft. . . . . . . . . . . . . . . . . . 108

Figura 26 - Cenário ii: fluxo de atividades na fase de Pré-Desenvolvimento do processo OntoSoft. . . . . . . . . . . . . . . . . . . 109

Figura 27 - Cenário iii: fluxo de atividades na fase de Pré-Desenvolvimento do processo OntoSoft. . . . . . . . . . . . . . . . . . 111

Figura 28 - Parte da ontologia da aplicação do Boa Moradia. . . . . . . . . . . . . . . . 114

Figura 29 - Fluxo iterativo de avaliação inicial do processo OntoSoft. . . . . . . . . . . 115

Figura 30 - Cenário proposto por Berners-Lee, Hendler e Lassila (2001) para a inserção de ontologias e tecnologias semânticas no desenvolvimento de software. . 118

Figura 31 - Nível de conhecimento dos participantes na primeira etapa do estudo de caso. 119

Figura 32 - Visão geral sobre a taxa de aprovação e de reprovação do processo OntoSoft com relação aos critérios estabelecidos na Tabela 20 . . . . . . . . . . . . . 122

Figura 33 - Número total de participantes para os critérios observados no estudo de caso. 127

Figura 34 - Evolução do cumprimento das atividades no decorrer do estudo. . . . . . . . 128

Figura 35 - Uso da ferramenta de gerenciamento SeeNowDo durante o estudo. . . . . . 129

Figura 36 - Análise da aceitação do processo OntoSoft no decorrer do estudo - Equipe A e Equipe B. . . . . . . . . . . . . . . . . . . . . . . . 129

Figura 37 - Análise do número de consultas dos participantes na aplicação do processo OntoSoft. . . . . . . . . . . . . . . . . 130

Figura 38 - Evolução das dificuldades encontradas no processo OntoSoft. . . . . . . . . 130

Figura 39 - Evolução dos benefícios identificados no processo OntoSoft durante o estudo. 131

Figura 40 - Experiência dos participantes em desenvolvimento de software. . . . . . . 136

Figura 41 - Experiência dos participantes em práticas e valores do Scrum. . . . . . . . . 136

Figura 42 - Análise das notas dadas ao processo pelos participantes. . . . . . . . . . . 139

Figura 43 - Observações sobre a coerência e a avaliação das atividades no processo OntoSoft. . . . . . . . . . . . . . . . . . . 140 
Tabela 1 - Comparação dos modelos de processo de software (SCHACH, 2011). . . . . 35

Tabela 2 - Principais diferenças entre desenvolvimento tradicional e ágil (DYBA; DINGSOYR, 2008). . . . . . . . . . . . . . . . . . 40

Tabela 3 - Benefícios e limitações das metodologias apresentadas. . . . . . . . . . 50

Tabela 4 - Comparação entre ferramentas de desenvolvimento de ontologias. . . . . . . 51

Tabela 5 - Comparação das principais fases da Engenharia de Software e Engenharia de Ontologias. . . . . . . . . . . . . . . . 5 55

Tabela 6 - Análise das forças, fraquezas, ameaças e oportunidades do uso de ontologias na Engenharia de Software. . . . . . . . . . . . . . . . 56

Tabela 7 - Termos usados na string de busca. . . . . . . . . . . . . . 65

Tabela 8 - Resultados parciais . . . . . . . . . . . . . . 65

Tabela 9 - Estudos selecionados na fase final. . . . . . . . . . . . . . 67

Tabela 10 - Definição e contexto de aplicação para cada processo identificado. . . . . . . 68

Tabela 11 - Metas e fases de desenvolvimento de software definidas nos processos. . . . 69

Tabela 12 - Aplicação das ontologias nos estudos e fases da Engenharia de Ontologias que são adaptadas/utilizadas em cada processo. . . . . . . . . . . . . . 70

Tabela 13 - Tipo de validação ou avaliação aplicado nos processos identificados. . . . . 70

Tabela 14 - Sumarização dos estudos identificados. . . . . . . . . . . . . . . . . . . 71

Tabela 15 - Análise das fases definidas pelos processos identificados. . . . . . . . . . 72

Tabela 16 - Diretrizes propostas para solucionar algumas das lacunas identificadas nos estudos para o desenvolvimento de software baseado em ontologia. . . . . . 73

Tabela 17 - Protocolo do primeiro estudo de caso estabelecido para a aplicação do processo OntoSoft. . . . . . . . . . . . . . . . . . . 116

Tabela 18 - Exemplo de algumas das avaliações feitas pelos desenvolvedores a partir da aplicação dos questionários. . . . . . . . . . . . . . . . . . 116

Tabela 19 - Características mais importantes do OntoSoft segundo o feedback dos participantes no estudo piloto.

Tabela 20 - Observações acerca da evolução do entendimento dos participantes durante a aplicação do processo OntoSoft nas sprints. . . . . . . . . . . . . . . . 121

Tabela 21 - Artefatos gerados no decorrer das duas sprints . . . . . . . . . . . . . . 123

Tabela 22 - Número de participantes em cada equipe e os respectivos questionários na condução do estudo de caso. . . . . . . . . . . . . . . . . . . . 126

Tabela 23 - Artefatos gerados e entregues ao final das sprints. . . . . . . . . . . . . 128 
Tabela 24 - Observação dos participantes sobre o maior aprendizado na disciplina. . . 132

Tabela 25 - Observação dos participantes acerca das críticas, limitações e contribuições para a disciplina. . . . . . . . . . . . . . . . . . . . 132

Tabela 26 - Protocolo para o estudo de caso conduzido na fábrica de software. . . . . . 134

Tabela 27 - Artefatos gerados pelas equipes A, B e C no final do estudo de caso conduzido na fábrica de software da Polícia Militar. . . . . . . . . . . . . . . . . 138

Tabela 28 - Observações extraídas dos questionários respondidos pelos participantes da Equipe C. . . . . . . . . . . . . . . . . . . . . 141 
INTRODUÇÃO $\ldots \ldots \ldots \ldots \ldots \ldots \ldots \ldots$

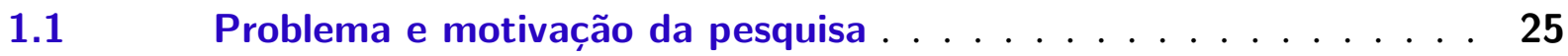

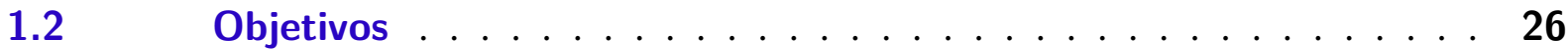

$1.3 \quad$ Organização da tese $\ldots \ldots \ldots \ldots \ldots \ldots \ldots \ldots \ldots$

2 ENGENHARIA DE SOFTWARE E ENGENHARIA DE ONTOLOGIA 29

2.1 Engenharia de software . . . . . . . . . . . . 29

2.1.1 Processo de desenvolvimento de software . . . . . . . . . . . 31

2.1.2 Modelos de processo de desenvolvimento . . . . . . . . . . . 32

2.1.3 Métodos ágeis . . . . . . . . . . . . . . . . . . . . . 34

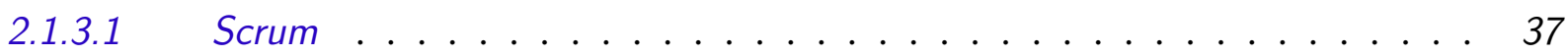

2.1.4 Métodos ágeis X Métodos tradicionais . . . . . . . . . . . 39

2.2 Ontologias e engenharia de ontologias . . . . . . . . . . . 40

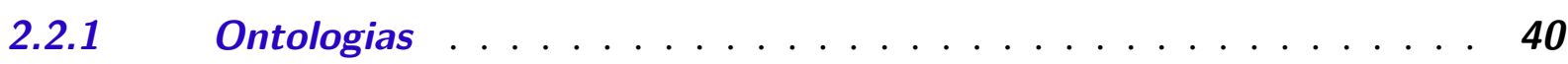

2.2.2 Tipos de ontologias . . . . . . . . . . . . . . . . . . 42

2.2.3 Engenharia de ontologias . . . . . . . . . . . . . . . . 43

$2.3 \quad$ Considerações finais . . . . . . . . . . . . . . . . . . 51

3 DESENVOLVIMENTO DE SOFTWARE BASEADO EM ONTOLO-

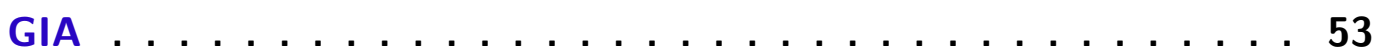

3.1 Ontologias aplicadas à engenharia de software . . . . . . . . . 54

3.2 Software baseado em ontologia . . . . . . . . . . . . . 57

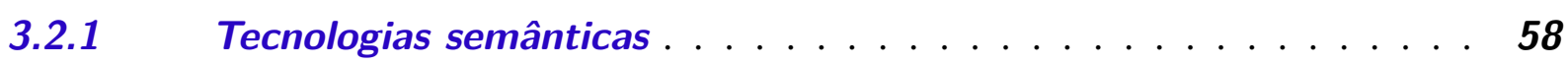

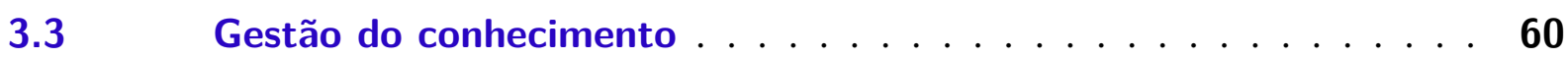

3.4 Processo de software baseado em ontologia: uma revisão sistemática 63

3.4.1 Protocolo da revisão sistemática . . . . . . . . . . . . . . . . . 64

3.4.2 Critérios de inclusão e exclusão . . . . . . . . . . . . . . . . . 64

3.4.3 Bases de pesquisa e estratégia de busca . . . . . . . . . 65

3.4.4 Condução da revisão sistemática . . . . . . . . . . . . . . . . 65

3.4.5 Análise e discussão dos resultados . . . . . . . . . . . . . . . . 67

3.5 Perspectivas para processo de desenvolvimento de software baseado em ontologia . . . . . . . . . . . . . . . . 74

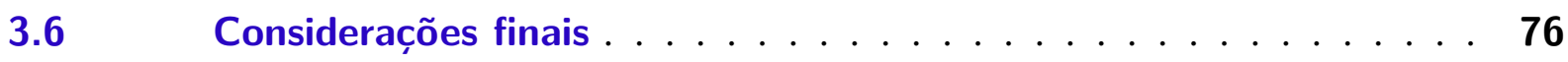



PARA SOFTWARE BASEADO EM ONTOLOGIA . . . . . . . . 79

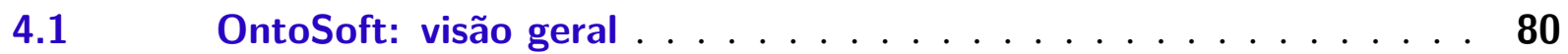

$4.2 \quad$ OntoSoft e Scrum . . . . . . . . . . . . . . . 83

4.3 OntoSoft: papeis ................ 84

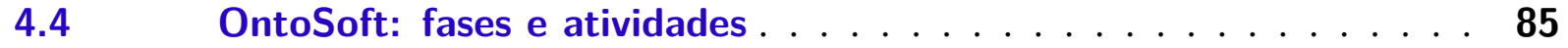

4.4.1 Gerenciamento . . . . . . . . . . . . . . . . 87

4.4.1.1 Preparação do backlog do produto . . . . . . . . . . . . . . 88

4.4.1.2 Definição dos papeis na equipe . . . . . . . . . . . . . . 88

4.4.1.3 Gestão do conhecimento . . . . . . . . . . . . . . . . . . . 89

4.4.1.4 Planejamento da sprint . . . . . . . . . . . . . . . . . . 89

4.4.1.5 Reunião diária da equipe (Daily Planning Meeting) . . . . . . . . . . . . . 90

4.4.1.6 Revisão da sprint (Sprint Review) . . . . . . . . . . . . . . . . . . 90

4.4.1.7 Retrospectiva da sprint (Sprint Restrospective) . . . . . . . . . . . . . 91

4.4.2 Artefatos gerados na fase de Gerenciamento . . . . . . . . . . . . . 91

4.4.3 Pré-desenvolvimento . . . . . . . . . . . . . 92

4.4.3.1 Elicitação de requisitos . . . . . . . . . . . . . . . . 94

4.4.3.2 Criação de cenários de uso . . . . . . . . . . . . . . . . . 94

4.4.3.3 Projeto de software . . . . . . . . . . . . . . . . . . 95

4.4.3.4 Especificação da ontologia . . . . . . . . . . . . . . . 95

4.4.3.5 Aquisição de conhecimento . . . . . . . . . . . . . . 96

4.4.3.6 Conceitualização . . . . . . . . . . . . . . . . . . 96

4.4.3.7 Análise de tecnologias semânticas . . . . . . . . . . . . . . . . . 97

4.4.4 Desenvolvimento . . . . . . . . . . . . . . . . . 97

4.4.4.1 Implementação do software . . . . . . . . . . . . . . . . 100

4.4.4.2 Teste de software . . . . . . . . . . . . . . . . 100

4.4.4.3 Implementação da ontologia . . . . . . . . . . . . . . . . 100

4.4.4.4 Teste da ontologia . . . . . . . . . . . . . . . . . . . 101

4.4.4.5 Inserção de tecnologias semânticas . . . . . . . . . . . . . . . . 101

4.4.4.6 Integração . . . . . . . . . . . . . . . . 102

4.4.5 Pós-Desenvolvimento . . . . . . . . . . . . . . . 102

4.4.5.1 Treinamento . . . . . . . . . . . . . . . 103

4.4.5.2 Implantação . . . . . . . . . . . . . . . . 103

4.4.5.3 Manutenção . . . . . . . . . . . . . . . . 103

4.5 Cenários para a aplicação do processo OntoSoft . . . . . . . . . 104

4.5.1 Cenário i . . . . . . . . . . . . . . . . . . 107

$4.5 .2 \quad$ Cenário ii . . . . . . . . . . . . . . . . . 108

$4.5 .3 \quad$ Cenário iii . . . . . . . . . . . . . . . . 110

4.6 Considerações finais . . . . . . . . . . . . . . 112 
5.1 Estudo de caso 1: UFAL - Boa Moradia . . . . . . . . . . . . . . 114

5.2 Estudo de caso 2: UFSCar - AppLucy . . . . . . . . . . . . 117

5.2.1 Estudo de caso piloto: desenvolvimento da AppLucy . . . . . . . . . 118

5.2.1.1 Preparação para a coleta de dados . . . . . . . . . . . . . . . . . . . . . 119

5.2.1.2 Análise dos dados . . . . . . . . . . . . . . . . . . . . . 120

5.2.2 Segunda parte do estudo de caso: projetos da disciplina . . . . . . 125

5.2.2.1 Preparação para a coleta de dados . . . . . . . . . . . . . . . . 125

5.2.2.2 Análise dos dados . . . . . . . . . . . . . . . . . 126

$5.3 \quad$ Estudo de caso 3: fábrica de software - AppLucy . . . . . . . 133

5.3.1 Preparação para a coleta de dados . . . . . . . . . . . . . . . . . 134

5.3.2 Análise e discussão dos resultados . . . . . . . . . . . . . . . 136

5.3.2.1 Aplicação do processo OntoSoft: equipes A e B . . . . . . . . . . . . . 137

5.3.2.2 Aplicação do processo OntoSoft: Equipe C . . . . . . . . . . . . . 140

5.4 Considerações finais . . . . . . . . . . . . . 142

6 CONCLUSÕES . . . . . . . . . . . . . . 145

6.1 Contribuições da pesquisa . . . . . . . . . . . . 146

$6.2 \quad$ Limitações e Trabalhos Futuros . . . . . . . . . . . . . . . 147

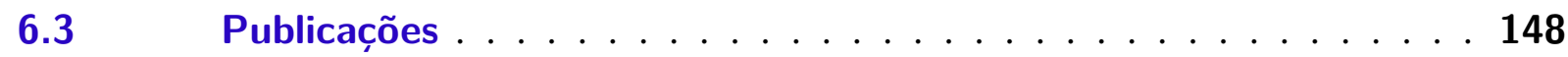

REFERÊNCIAS . . . . . . . . . . . . . . . . . . 151

APÊNDICE A ARTEFATOS PROPOSTOS NO PROCESSO ONTOSOFT ...................... 157

APÊNDICE B QUESTIONÁRIOS APLICADOS NOS ESTUDOS DE AVALIAÇÃO . . . . . . . . . . . . . . . . . 167

B.1 Estudo de caso 1: UFAL - Boa Moradia . . . . . . . . . . . . 167

B.2 Estudo de caso 2: UFSCar - AppLucy e Projeto Disciplina . . . . 175

B.3 Estudo de caso 3: fábrica de software - AppLucy . . . . . . . 186 



\section{1}

\section{INTRODUÇÃO}

$\mathrm{O}$

ntologias têm sido cada vez mais utilizadas no desenvolvimento de software, sobretudo em virtude de seus benefícios, tais como geração automática de código e maior precisão na definição de conceitos e requisitos de software. Nessa direção, Nadoveza e Kiritsis (2014) indicam que as ontologias possibilitam à modelagem do conhecimento vantagens como: (i) alto poder de expressividade; (ii) formalização dos conceitos; (iii) compartilhamento do conhecimento; (iv) reusabilidade; e (v) uso de raciocinadores para promover inferências.

Uma ontologia pode ser definida como a especificação formal de uma conceituação (GRUBER, 1995). A conceituação refere-se ao significado dos conceitos e suas relações em um contexto do mundo real e a especificação indica uma representação formal, declarativa e explícita dos conceitos (MACHADO et al., 2016; MIZOGUCHI, 2003; GOMEZ-PEREZ; CORCHOGARCIA; FERNANDEZ-LOPEZ, 2004). Nesse sentido, Ruiz e Hilera (2006) afirmam que há um grande potencial no uso de ontologias na gestão do conhecimento, as quais colaboram para: (i) facilitar a comunicação entre os envolvidos no projeto; (ii) evitar ambiguidades da linguagem natural; e (iii) filtrar o conhecimento ao definir modelos de sistemas a serem desenvolvidos.

Concernente à Engenharia de Software, a conceituação tem um papel primordial durante o ciclo de vida do software. No decorrer da análise, modelagem, projeto e desenvolvimento, por exemplo, são conceituadas todas as entidades relevantes do domínio de aplicação, com suas características e relacionamentos (BACHMANN; HESSE, 2007). A partir do uso de ontologias no desenvolvimento de software, dois aspectos principais podem ser observados: (i) minimização de erros na implementação; e (ii) redução do tempo para a entrega de um produto estável. Segundo Pan et al. (2013), estes são alguns dos fatores primordiais relacionados ao uso crescente de ontologias no desenvolvimento de software.

O desenvolvimento de software, de modo geral, requer várias fontes e formas de conhecimento explícito e implícito. Esse conhecimento é dinâmico e evolui constantemente, considerando a tecnologia, a cultura organizacional e as mudanças necessárias nas práticas 
de desenvolvimento da organização (LEVY; HAZZAN, 2009). As ontologias, por sua vez, podem ser usadas para tornar o conhecimento explícito e permitir seu compartilhamento em diferentes aplicações para uma variedade de domínios (SUÁREZ-FIGUEROA; GÓMEZ-PÉREZ; FERNÁNDEZ-LÓPEZ, 2016).

Guarino (1998) previu alguns destes benefícios e introduziu na pesquisa o termo "Sistema de Informação Dirigido a Ontologia" (Ontology-Driven Information System - ODIS). Nessa linha de pesquisa, as ontologias são usadas na aplicação final, não necessariamente sendo adotadas ao longo do desenvolvimento. Diferentemente, na "Engenharia de Software Dirigida à Ontologia" (Ontology Driven Software Engineering - ODSE), as ontologias são usadas em todo o processo de desenvolvimento da aplicação. Em termos gerais, a abordagem ODSE indica como ontologias e tecnologias semânticas podem contribuir para melhorar a Engenharia de Software, tanto no que se refere ao processo como aos artefatos produzidos (KATASONOV, 2012).

Além desses dois termos, muitos pesquisadores têm adotado o termo "Engenharia de Software Baseada em Ontologia" (Ontology Based Software Engineering - OBSE) (HESSE, 2005; HAPPEL; SEEDORF, 2006; BACHMANN; HESSE, 2007). OBSE diz respeito tanto ao domínio da aplicação, como às atividades de análise de requisitos, modelagem de domínio, integração, implantação e uso (HESSE, 2005). Ou seja, a ontologia é considerada um dos principais artefatos e representa uma parte central da lógica da aplicação.

$\mathrm{Na}$ abordagem OBSE, os projetos de software não são impulsionados apenas pelos requisitos e modelos, mas também por uma ou mais ontologias cobrindo seu domínio de aplicação (BACHMANN; HESSE, 2007). As ontologias são um dos principais artefatos do software e desempenham um papel importante na formalização e compartilhamento dos conceitos. Por meio da ontologia, o conhecimento pode ser inferido, em conjunto com as regras de negócios e o domínio de conhecimento.

Um software baseado em ontologia apresenta particularidades que ainda não estão presentes, de forma integrada, nas especificações dos processos de desenvolvimento atuais. As equipes dos desenvolvedores, até então, não possuem diretrizes para orientar as atividades no desenvolvimento dos artefatos, inclusive do artefato ontologia no decorrer das grandes fases do desenvolvimento do software. Esta lacuna será tratada no decorrer desta tese, uma vez que o propósito deste doutorado refere-se à definição de um processo sistemático considerando a abordagem OBSE.

De modo geral, existem diversas metodologias para a criação de ontologias, assim como existem vários processos de desenvolvimento de software já consolidados na literatura. Entretanto, tais metodologias atuam separadamente ou de maneira genérica no que diz respeito ao desenvolvimento de software baseado em ontologia. As abordagens são amplas, de forma que atividades e práticas não são detalhadas para guiar os desenvolvedores. Assim, a associação das tarefas relacionadas ao software às tarefas específicas na construção da ontologia pode ficar comprometida. Além disso, não são mencionados princípios ou práticas ágeis durante o 
desenvolvimento do software baseado em ontologia, conforme é abordado na presente pesquisa.

Ainda no contexto de desenvolvimento de ontologias surgiu o termo Engenharia de Ontologias, conceito presente em diversas áreas de conhecimento. De forma geral, trata-se da investigação dos princípios, métodos e ferramentas para gerenciamento, desenvolvimento e manutenção das ontologias (MIZOGUCHI, 2003; SURE; STAAB; STUDER, 2009). Em outras palavras, a Engenharia de Ontologias tem a finalidade de formalizar e padronizar o ciclo de desenvolvimento de ontologias, utilizando definições arraigadas na Engenharia de Software e adaptando alguns conceitos para o contexto ontológico (WIEBE; CHAN, 2012; SUAREZ-FIGUEROA, 2010).

Todavia, ao considerar o software baseado em ontologia, a maioria das abordagens não estabelece a associação do ciclo de vida do software aos benefícios da Engenharia de Ontologias, em um modelo de processo de desenvolvimento de software de maneira completa ou de forma prática (GASEVIC; DJURIC; DEVEDZIC, 2006; SURE; STAAB; STUDER, 2009). As pesquisas indicam que os trabalhos atuam em algumas partes do ciclo de vida do software, utilizando ontologias e tecnologias semânticas para solucionarem problemas específicos de uma fase do desenvolvimento, nem sempre utilizando o artefato ontologia na execução do software.

Com base no contexto mencionado, esta pesquisa tem como principal objetivo definir um processo de desenvolvimento para software baseado em ontologia, estabelecendo uma associação entre as boas práticas da Engenharia de Software e Engenharia de Ontologias. O processo deve proporcionar um gerenciamento ágil, a partir das atividades derivadas do método ágil Scrum (SCHWABER; SUTHERLAND, 2011). Além disso, a proposta é que o processo seja fácil de ser aplicado, factível de ser extensível, além de robusto, simples e adaptável para o contexto da aplicação.

\subsection{Problema e motivação da pesquisa}

Observa-se, nos últimos anos, uma busca pela formalização e automatização dos processos de software. Esta tendência deve-se a fatores relacionados à busca do aumento da produtividade, minimização de retrabalho das equipes e fomento da qualidade do desenvolvimento de software. Além disso, a aplicação desses fatores contribui para a diminuição da ambiguidade em diversas fases do ciclo de vida do software.

Um caminho para tornar essas ações factíveis refere-se ao uso de ontologias e tecnologias semânticas, em conjunto com boas práticas de desenvolvimento (AßMANN et al., 2013; RUIZ; HILERA, 2006). Trata-se de considerar as ontologias como um dos artefatos centrais para o sistema, apoiar as atividades e tarefas referentes ao desenvolvimento das ontologias em conjunto com os demais artefatos do software baseado em ontologia. No entanto, as metodologias atuais ainda não têm se mostrado suficientemente adequadas para guiar o desenvolvimento do software baseado em ontologias (BALIYAN; KUMAR, 2013). 
Concernente às práticas da Engenharia de Software, um conceito primordial para guiar o desenvolvimento de software e suas atividades refere-se ao estabelecimento de processos. Um princípio fundamental que rege as abordagens baseadas em processo é que a qualidade do processo pode influenciar na qualidade, custo e tempo do software, ao longo do gerenciamento (KROEGER; DAVIDSON; COOK, 2014).

Com base na investigação de metodologias e processos para o desenvolvimento de software baseado em ontologia, as principais tarefas e papeis dos desenvolvedores foram verificadas no decorrer da pesquisa deste doutorado. De modo geral, as diretrizes identificadas são genéricas e amplas, não tratando de práticas da Engenharia de Ontologia e Engenharia de Software em conjunto ou de forma específica no que se refere ao uso das ontologias.

Além disso, os trabalhos identificados não mencionam aspectos de desenvolvimento ágil (HSIEH; LU, 2006; DELINE et al., 2007; MAVETERA, 2011). Práticas indicando iteratividade, atividades graduais e colaborativas, por exemplo, não têm sido consideradas nos trabalhos relacionados. Portanto, a fim de inserir valores e práticas ágeis e fomentar o desenvolvimento incremental e gerenciado constantemente, neste trabalho o método ágil Scrum (SCHWABER; SUTHERLAND, 2011) é utilizado como base para as atividades de gerenciamento no processo.

A colaboração proporcionada pelas práticas do Scrum tende a fornecer uma elicitação mais rigorosa dos requisitos de software e a promover um melhor entendimento do negócio (ou do objetivo e escopo da aplicação) entre os envolvidos. Além disso, a ontologia contribui para formalizar os conceitos e os requisitos do software. No processo definido em cada iteração os artefatos são atualizados, de acordo com as necessidades do cliente, por meio do conhecimento extraído nas entregas e por meio da verificação dos cenários de aplicação.

Diante do contexto apresentado, neste trabalho é proposto um processo de desenvolvimento ágil para software baseado em ontologia, denominado OntoSoft. O processo associa características da Engenharia de Software, Engenharia de Ontologias, valores e práticas ágeis (Scrum) para guiar os desenvolvedores, definindo atividades, tarefas, artefatos e papeis para cada fase do ciclo de desenvolvimento. No processo também foram identificados cenários de desenvolvimento para guiar o fluxo das atividades, de acordo com a complexidade do domínio das ontologias e com o escopo da aplicação a ser desenvolvida. Os cenários consideram a ordem e a precedência no estabelecimento das atividades, enfatizando a integração das ontologias. Além disso, a aplicabilidade e a produtividade do processo OntoSoft foram avaliadas com base nos resultados de estudos de caso realizados em três ambientes distintos de desenvolvimento.

\subsection{Objetivos}

De acordo com o problema caracterizado na seção anterior, o objetivo principal desta tese refere-se à definição de um processo para guiar o desenvolvimento de software baseado em ontologia, considerando a associação das atividades da Engenharia de Software e Engenharia 
de Ontologias, bem como de valores e princípios ágeis. O processo, chamado OntoSoft, visa otimizar o desenvolvimento de software baseado em ontologia com base na definição de fases, atividades, tarefas, papeis e artefatos. Além disso, foram definidos cenários que especificam complexidade e características da ontologia para auxiliar as equipes de desenvolvimento de software no planejamento das sprints, visto que o processo OntoSoft também considera práticas do gerenciamento ágil.

Pretende-se, com isso, viabilizar a utilização de ontologias e promover a associação da Engenharia de Ontologias e Engenharia de Software, por meio da criação de diretrizes para o desenvolvimento de software baseado em ontologia. Os objetivos secundários, que compõem o objetivo principal deste trabalho de doutorado, são apresentados a seguir:

- Definição de cenários de uso do processo estabelecido: o objetivo é criar cenários de desenvolvimento com base nos principais tipos de uso das ontologias como um artefato essencial no desenvolvimento de software. O processo deve considerar diferentes fluxos de desenvolvimento das atividades das ontologias, de acordo com a complexidade do domínio e o objetivo das aplicações. Por meio de observação, do conhecimento de especialistas e do levantamento de aplicações que utilizam ontologias, objetiva-se indicar o fluxo das atividades em diferentes circunstâncias, guiando as ações dos desenvolvedores por meio das diretrizes do processo.

- Definição de modelos de artefatos: o objetivo é criar modelos de artefatos para utilização dos desenvolvedores na execução das atividades. Esses modelos devem contribuir para: (i) otimizar o tempo de desenvolvimento; (ii) auxiliar equipes que não tenham experiência com o desenvolvimento de ontologias; (iii) facilitar a padronização da documentação; e (iv) gerenciar a situação dos artefatos em diferentes estágios do desenvolvimento.

- Estabelecimento de diretrizes para guiar o desenvolvimento: o objetivo é fornecer aos desenvolvedores diretrizes práticas em cada atividade a ser elaborada, indicando os papeis adequados, as tarefas necessárias, os artefatos a serem gerados e as relações com as outras atividades. Essas diretrizes estão na composição do processo e são apresentadas às equipes a fim de colaborar para a melhor compreensão do mesmo.

- Planejamento e condução de avaliações para o processo proposto: o objetivo é aplicar estudos ao longo do estabelecimento do processo para avaliar sua aplicabilidade e produtividade, em especial a partir da visão dos desenvolvedores de software baseado em ontologia.

\subsection{Organização da tese}

Esta tese está organizada como segue. No Capítulo 2 é apresentada a fundamentação teórica das principais áreas de pesquisa envolvidas nesta tese de doutorado: (i) processo de 
desenvolvimento de software, e (ii) Engenharia de Ontologias. Conceitos relacionados aos modelos de processo atuais, metodologias ágeis, em particular o Scrum, também são discutidos a fim de extrair as melhores práticas para compor o processo OntoSoft. Além disso, é feita uma síntese sobre ontologias e algumas das principais metodologias de Engenharia de Ontologias, a fim de estabelecer as atividades relacionadas a ontologias no processo de desenvolvimento de software.

No Capítulo 3 são descritos os conceitos referentes a software baseado em ontologia, assim como os benefícios do uso de ontologias e tecnologias semânticas na Engenharia de Software. Também é traçado um paralelo entre as áreas de Gestão do Conhecimento e Engenharia de Ontologia. Por fim, é apresentada uma revisão sistemática sobre os processos de desenvolvimento para software baseado em ontologia identificados na literatura, a fim de extrair as perspectivas para compor o processo proposto nesta tese.

No Capítulo 4 é definido o processo OntoSoft, apresentando sua visão geral e principais características. Fases, atividades, tarefas e papeis definidos no processo são descritos. Além disso, são descritos os cenários para aplicação do processo, considerando peculiaridades da ontologia e do domínio a ser especificado, com a finalidade de instruir as equipes na escolha do fluxo das atividades a serem seguidas durante o processo de desenvolvimento.

No Capítulo 5 são apresentados os estudos de caso conduzidos no decorrer da avaliação do processo OntoSoft. Foram elaborados três estudos envolvendo a definição de aplicações baseadas em ontologia. $\mathrm{O}$ primeiro estudo foi realizado com uma equipe especialista de engenheiros de ontologias, o segundo estudo de caso do processo foi aplicado na realização de um projeto ao longo de uma disciplina de pós graduação, e no terceiro estudo de caso o processo foi aplicado em uma fábrica de software.

Finalmente, no Capítulo 6 são apresentadas as conclusões desta tese, sumarizando as principais contribuições alcançadas, limitações e perspectivas para pesquisas futuras. 


\title{
ENGENHARIA DE SOFTWARE E ENGENHARIA DE ONTOLOGIA
}

\begin{abstract}
Engenharia de Software surgiu por volta de 1968 com a finalidade de sistematizar, padronizar, criar processos, técnicas e ferramentas para desenvolver software com qualidade.
\end{abstract} As práticas do desenvolvimento de software estão em contínua evolução, de modo que os paradigmas de programação e os processos de desenvolvimento acompanham este crescimento, adaptando-se ao rápido desenvolvimento das tecnologias.

Ontologias e tecnologias semânticas têm contribuído fortemente para esta adaptação nas práticas do desenvolvimento de software. De maneira geral, as ontologias favorecem fatores como reúso, compartilhamento, interoperabilidade, recuperação da informação e extração do conhecimento. Em virtude desses indicativos, diversas pesquisas têm investigado e utilizado ontologias como um artefato no desenvolvimento de software, a fim de promover os benefícios supracitados.

Neste capítulo são apresentados os principais conceitos relacionados à Engenharia de Software e Engenharia de Ontologias, a fim de promover a associação e apresentar as características do software baseado em ontologia. Na Seção 2.1 são apresentados os conceitos referentes a modelos de processo de software na Engenharia de Software, discutindo também os principais conceitos de metodologias ágeis, em particular o método ágil Scrum. Na Seção 2.2 são sumarizados os principais conceitos de ontologias e as metodologias mais comumente utilizadas na Engenharia de Ontologias. Por fim, as considerações finais são discutidas na Seção 2.3.

\subsection{Engenharia de software}

A Engenharia de Software consiste na aplicação de uma abordagem sistemática, disciplinada e quantificável para o desenvolvimento, operação e manutenção de software (IEEE, 1990). Segundo Pressman (2010), a Engenharia de Software pode ser entendida também como o 
estabelecimento e uso de princípios da engenharia para obter software economicamente confiável e eficiente em máquinas reais.

Embora o desenvolvimento de software seja uma disciplina da engenharia sujeita a discussões, não há dúvida de que houve mudanças fundamentais durante as últimas décadas, tanto no que diz respeito ao surgimento de novas tecnologias quanto à sofisticação de metodologias (HAPPEL; SEEDORF, 2006).

A história do desenvolvimento de software tem sido repleta de evoluções e marcos. Antes de 1961, o conceito "Programação de Computadores" era comum em ambientes científicos e de engenharia a fim de resolver vários problemas em outras ciências (EMAMI; ITHNIN; IBRAHIM, 2010). Entre 1968 e 1970, houve um grande debate envolvendo os principais pesquisadores da computação no Comitê de Ciência da NATO (North Atlantic Treaty Organization). Nesse debate os membros da conferência tiveram opiniões muito diferentes sobre a gravidade da situação e a extensão das áreas problemáticas no desenvolvimento de software (NAUR; RANDELL, 1968). Após a conferência os pesquisadores denominaram tal situação como a "Crise do Software", a partir da qual surgiu o conceito de "Engenharia de Software". Este acontecimento é considerado uma revolução na computação e deu origem às metodologias de desenvolvimento de software (EMAMI; ITHNIN; IBRAHIM, 2010) como meio para solucionar os problemas identificados.

Além da criação e evolução dos métodos de desenvolvimento de software, vale ressaltar também a evolução das linguagens de programação, que apoiam diretamente as equipes de desenvolvedores. A evolução ao longo dos últimos anos é ilustrada na Figura 1.

Figura 1 - O desenvolvimento de software ao longo do tempo (AßMANN et al., 2013).

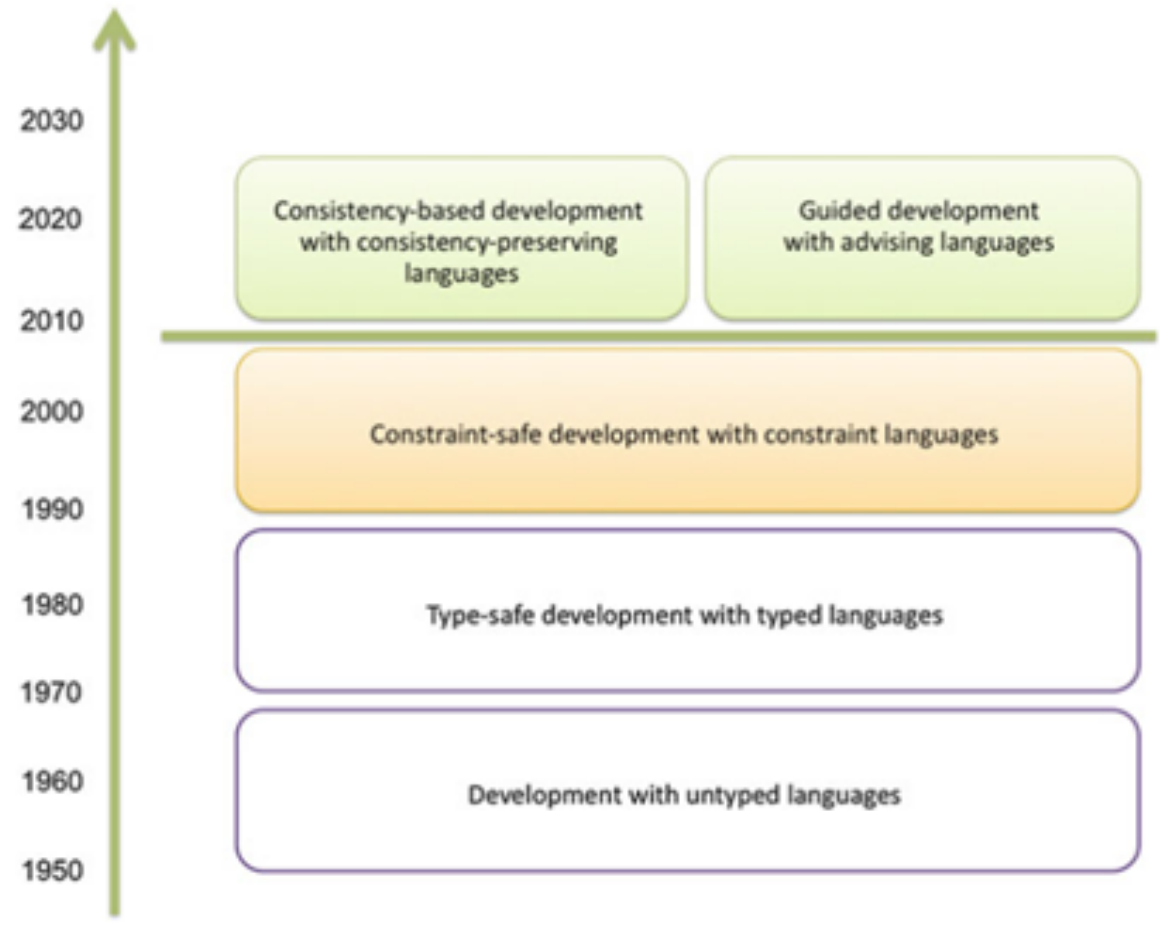


Na década de 1950, linguagens como Assembly praticamente não possuíam categorização (primeira camada - Figura 1), ou seja, os erros na programação eram descobertos durante ou após a execução do programa. Com o advento das linguagens de alto nível, foram introduzidos os tipos de dados, auxiliando os programadores a descobrirem erros em tempo de compilação (segunda camada - Figura 1). Ainda assim, os tipos de dados eram restritos a variáveis individuais, faziam a verificação de consistência e as linguagens de restrição permitiam especificações mais potentes, além de restrições sensíveis ao contexto (terceira e quarta camadas - Figura 1) (AßMANN et al., 2013).

Conforme evidenciado pela evolução dos paradigmas das linguagens de programação, uma tendência tem sido elevar o nível de abstração por meio da modelagem e linguagens de programação de alto nível, a fim de lidar com a complexidade inerente ao software. Uma das formas de se alcançar este propósito se dá por meio da utilização de ontologias como artefatos de software, que, entre outras contribuições, possibilitam a validação e geração de código de forma automática.

Nessa perspectiva, muitos problemas podem ser resolvidos, incluindo reúso de componentes, validação da informação, integração de aplicações, testes de software e fomento da qualidade do desenvolvimento do software e do produto. Estas são questões fundamentais que constituem a motivação para o surgimento de novas abordagens que complementam a Engenharia de Software (HAPPEL; SEEDORF, 2006).

No entanto, antes de tratar as novas abordagens e tendências de pesquisa, faz-se necessário apresentar conceitos já consolidados que são fundamentais na proposta deste doutorado, a saber processo de software. Pressman (2010) afirma que a base para a Engenharia de Software é a camada de processo, que reúne a camada de tecnologia e permite o desenvolvimento do software. Os processos de software são indispensáveis para o controle gerencial de projetos de software e estabelecem o contexto no qual os métodos são aplicados, os produtos de trabalho são produzidos, os marcos são estabelecidos, a qualidade é assegurada e as modificações são geridas adequadamente.

De fato, a qualidade de software está intimamente ligada ao processo de software (BIYANG; MIN, 2010) pois, ao selecionar o modelo de processo apropriado, os erros podem ser efetivamente reduzidos ao longo do desenvolvimento. Nas próximas seções são sumarizados os conceitos dos principais modelos de processo de desenvolvimento de software encontrados na literatura.

\subsubsection{Processo de desenvolvimento de software}

Para compreender a distinção entre termos similares na Engenharia de Software é preciso que estes sejam definidos claramente. A IEEE (1990) define um processo como uma sequência de passos, composta por atividades, desenvolvido para uma determinada proposta. 
Um processo de desenvolvimento de software é o processo por meio do qual as necessidades dos usuários são traduzidas em um produto de software. Este processo envolve a tradução das necessidades dos usuários em requisitos de software, transformando os requisitos em projeto, implementando o projeto em código, testando o código e, por fim, instalando e verificando o uso operacional do software resultante (IEEE, 1990).

Tyrrell (2000) apresenta algumas consequências no desenvolvimento quando o projeto é dependente do desenvolvedor (ou da equipe de desenvolvedores), a saber: (i) dificuldade para manter o software; (ii) dificuldade para avaliar a qualidade do produto com precisão; e (iii) sobrecarga para quem trabalha individualmente e de maneira ad-hoc. Esses fatores demonstram a necessidade da aplicação de um processo de software, a fim de guiar a equipe de desenvolvedores e manter o software.

Somerville (2010) define processo de software como um conjunto de atividades e resultados associados que produz um produto de software, elencando quatro atividades fundamentais, que são comuns a todos os processos de software, a saber:

1. Especificação de software: clientes e engenheiros definem o software a ser produzido e as restrições para a sua operação.

2. Desenvolvimento de software: o software é projetado e programado.

3. Validação de software: o software é verificado para garantir o que o cliente deseja.

4. Evolução de software: o software é modificado para se adaptar às mudanças dos requisitos dos clientes e do mercado.

Já um modelo de processo de software pode ser definido como uma descrição e/ou visão simplificada do processo de software. Os modelos de processo incluem as atividades que fazem parte do processo de software, os produtos de software e os papeis das pessoas envolvidas na Engenharia de Software (SOMERVILLE, 2010).

Nessa perspectiva, vários modelos de processo na Engenharia de Software têm sido desenvolvidos nas últimas décadas na tentativa de construir ferramentas de apoio que facilitem e tornem o processo de desenvolvimento de sistemas de software mais controláveis e rastreáveis (VALIENTE; GARCIA-BARRIOCANAL; SICILIA, 2012). Na próxima seção são apresentados os principais modelos de processo utilizados na Engenharia de Software, os quais contribuíram para a proposta do processo OntoSoft.

\subsubsection{Modelos de processo de desenvolvimento}

Um modelo de processo de software consiste em uma estratégia de desenvolvimento e em uma descrição abstrata sobre o processo de software (BIYANG; MIN, 2010). Os principais modelos de processos utilizados na Engenharia de Software são sumarizados a seguir. 
- Modelo cascata: sugere uma abordagem sistemática e sequencial para o desenvolvimento de software que começa com a especificação dos requisitos pelo cliente e progride ao longo do planejamento, modelagem, construção e implantação, culminando na manutenção progressiva do software finalizado. Trata-se de uma abordagem disciplinada em que a documentação desempenha um papel fundamental (SOMERVILLE, 2010; PRESSMAN, 2010). O modelo cascata é o paradigma mais antigo da Engenharia de Software. No entanto, nas últimas décadas, devido às muitas mudanças no desenvolvimento, o modelo tem sido considerado inadequado. Ainda assim, ele é indicado para situações nas quais os requisitos são fixos e o trabalho deve prosseguir até o fim de modo linear (PRESSMAN, 2010).

- Modelo de prototipação: auxilia o engenheiro de software e o cliente a entenderem o que deve ser construído quando os requisitos estão confusos (PRESSMAN, 2010). A prototipagem pode ser usada de maneira independente, ou como uma técnica implementada dentro do contexto de outro modelo de processo. O paradigma de prototipação começa com a comunicação. $\mathrm{O}$ engenheiro de software e o cliente encontram-se e definem os objetivos gerais do software, identificam as necessidades e as áreas que precisam de definições. Uma iteração de prototipação é planejada rapidamente e então ocorre a modelagem, na forma de um projeto rápido. O projeto rápido leva à construção de um protótipo, que é implantado e avaliado pelo cliente/usuário. Idealmente, o protótipo serve como um mecanismo para identificação dos requisitos do software (SOMERVILLE, 2010).

- Modelo incremental e iterativo: combina elementos do modelo cascata de maneira iterativa, aplicando sequências lineares de uma forma racional com o passar do tempo. Cada sequência linear produz incrementos do software passíveis de serem entregues (PRESSMAN, 2010). Diferentemente do modelo de prototipação, o modelo incremental tem o objetivo de apresentar um produto operacional a cada incremento. Os primeiros incrementos são versões simplificadas do produto final, mas oferecem funcionalidades que servem ao usuário, além de uma plataforma para a validação do usuário. $\mathrm{O}$ desenvolvimento incremental é particularmente útil quando não há mão de obra disponível para uma implementação completa, dentro do prazo comercial de entrega estabelecido para o projeto (PRESSMAN, 2010).

- Modelo espiral: é um modelo evolucionário que combina a natureza iterativa do modelo de prototipação com os aspectos controlados e sistemáticos do modelo em cascata. Ele fornece o desenvolvimento rápido de versões de software cada vez mais completas. Durante as primeiras iterações, as versões podem ser um modelo em papel ou protótipo; já nas últimas iterações são produzidas versões cada vez mais completas de artefatos do software (PRESSMAN, 2010). Cada passagem no modelo resulta frequentemente em um produto final, tais como especificação, protótipo e assim por diante. Além disso, um dos 
principais diferenciais do modelo espiral é que ele incorpora uma abordagem orientada a risco ao processo de software (EMAMI; ITHNIN; IBRAHIM, 2010).

- Modelo RUP (Rational Unified Process) - Processo Unificado da Rational (JACOBSON; BOOCH; RUMBAUGH, 1999): é um modelo de processo derivado da UML Unified Modeling Language e do Processo Unificado. Pode ser considerado um modelo híbrido de processo, pois apresenta elementos de todos os modelos genéricos de processo, apoia iteração e ilustra boas práticas de especificação e projeto (SOMERVILLE, 2010). O RUP é um modelo construído por fases que identificam quatro etapas discretas no processo de software, a saber: concepção, elaboração, construção e transição. No entanto, ao contrário do modelo cascata, no qual as fases coincidem com as atividades do processo, as fases do RUP estão relacionadas mais estritamente aos negócios do que a assuntos técnicos (SOMERVILLE, 2010),

Além dos modelos sumarizados anteriormente, há muitos outros modelos de processo de desenvolvimento, sobretudo devido à diversidade de aplicações de software. De fato, diferentes organizações têm processos de software distintos, pois adaptam os processos da literatura em conformidade com as suas necessidades. Por exemplo, ao abordar a fase de documentação, algumas organizações consideram o software que produzem como auto-documentável. Outras organizações, no entanto, elaboram especificações e verificam a documentação metodicamente (SCHACH, 2011).

Conforme Biyang e Min (2010), os requisitos para a seleção do modelo adequado devem estar de acordo com as práticas de desenvolvimento do projeto. Independentemente do procedimento adotado, normalmente o processo de desenvolvimento de software está estruturado em torno de cinco fluxos básicos de trabalho (SCHACH, 2011): requisitos, análise (especificação), projeto, implementação e testes.

Na Tabela 1 são sumarizadas as principais vantagens e desvantagens dos modelos de processo de software apresentados, seguindo o escopo mais apropriado para sua utilização (SCHACH, 2011).

Além dos modelos de processos apresentados, chamados prescritivos, destacam-se ainda os métodos ágeis, que enfatizam a adaptação e a flexibilidade do desenvolvimento de software. Neste trabalho, como base para guiar as atividades de gerenciamento do processo definido, foi utilizado o método ágil Scrum (SCHACH, 2011).

Na próxima seção são discutidos e sumarizados os principais métodos ágeis na literatura.

\subsubsection{Métodos ágeis}

Métodos de desenvolvimento ágil constituem em um conjunto de práticas formado a partir das experiências dos desenvolvedores. Esses métodos podem ser vistos como uma reação 
Tabela 1 - Comparação dos modelos de processo de software (SCHACH, 2011).

\begin{tabular}{|c|c|c|}
\hline Modelo & Vantagens & Desvantagens \\
\hline Cascata & $\begin{array}{l}\text { Abordagem disciplinada. } \\
\text { Dirigido à documentação. }\end{array}$ & $\begin{array}{l}\text { O produto fornecido pode não atender às } \\
\text { necessidades do cliente. }\end{array}$ \\
\hline Prototipação & $\begin{array}{l}\text { Garante que o produto entregue atende às ne- } \\
\text { cessidades do cliente. }\end{array}$ & $\begin{array}{l}\text { O desenvolvedor pode fazer muitas con- } \\
\text { cessões de implementação para que um } \\
\text { protótipo seja colocado em funcionamento } \\
\text { rapidamente. }\end{array}$ \\
\hline $\begin{array}{l}\text { Incremental e } \\
\text { Iterativo }\end{array}$ & $\begin{array}{l}\text { O custo de realizar as mudanças é reduzido. } \\
\text { Há maior facilidade na obtenção de } \\
\text { feedback do cliente. } \\
\text { Entrega e implementação rápida de parte do } \\
\text { software ao cliente. }\end{array}$ & $\begin{array}{l}\text { O processo não é visível, o que gera } \\
\text { dificuldade para mensurar o projeto. } \\
\text { A estrutura do sistema tende a se degradar } \\
\text { com a adição dos novos incrementos. }\end{array}$ \\
\hline Espiral & Impulsionado a risco. & $\begin{array}{l}\text { Pode ser usado apenas para produtos em } \\
\text { grande escala. } \\
\text { Os desenvolvedores devem ser compe- } \\
\text { tentes em análise e resolução de risco. }\end{array}$ \\
\hline RUP & $\begin{array}{l}\text { Processo robusto, bem definido e que tem uma } \\
\text { boa gerência de riscos. }\end{array}$ & $\begin{array}{l}\text { Pode ser complexo e trabalhoso para proje- } \\
\text { tos de pequeno porte. }\end{array}$ \\
\hline
\end{tabular}

aos métodos tradicionais de desenvolvimento de software, que enfatizam uma abordagem baseada na engenharia, afirmando que os problemas são totalmente determináveis e que existem soluções previsíveis para cada problema (DYBA; DINGSOYR, 2008). Além disso, a receptividade às mudanças nos requisitos e a colaboração com o cliente são dois fatores fundamentais nos processos ágeis (SCHACH, 2011). Por isso, a essência de um processo ágil considera três principais dificuldades (PRESSMAN, 2010):

i. Previsão dos requisitos e das prioridades do cliente.

ii. Separação da fase de projeto da fase de desenvolvimento.

iii Previsão das fases de análise, projeto, desenvolvimento e testes.

Assim como aconteceu a Crise do Software em 1968 e que deu origem à Engenharia de Software, houve em 2001 um movimento requisitando maior agilidade para o desenvolvimento de software. Neste movimento foi constituído o Manifesto Ágil, que fundamentou os métodos ágeis. Dentre os resultados do Manifesto Ágil ${ }^{1}$ foram definidos quatro principais valores que regem o desenvolvimento ágil:

- Indivíduos e interações são mais importantes que processos e ferramentas.

- Software funcionando é mais importante do que documentação completa e detalhada.

- Colaboração dos clientes é mais importante do que negociação de contratos.

- Adaptação às mudanças é mais importante do que seguir um plano.

1 O manifesto para o desenvolvimento ágil de software pode ser acessado em: manifestoagil.com.br/ 
Embora os projetos ágeis sejam baseados no paradigma incremental, eles propõem diferentes processos para alcançar tal objetivo. No entanto, compartilham um conjunto de princípios comuns com base nas indicações do Manifesto Ágil, a saber (SOMERVILLE, 2010):

- Envolvimento com o cliente: os clientes devem estar envolvidos no processo de desenvolvimento, fornecendo e priorizando novos requisitos do sistema.

- Entrega incremental: o software é desenvolvido em incrementos com o cliente, especificando os requisitos para serem incluídos em cada um.

- Foco nas pessoas: as habilidades da equipe de desenvolvimento devem ser reconhecidas e exploradas.

- Aceitação das mudanças: os requisitos do sistema podem mudar e, para isso, deve-se projetar o sistema de maneira a acomodar essas mudanças.

- Manter a simplicidade: priorizar a simplicidade, tanto do software a ser desenvolvido quanto do processo de desenvolvimento.

A seguir os principais métodos de desenvolvimento ágil encontrados na literatura são sumarizados (DYBA; DINGSOYR, 2008):

- Extreme programming (XP, XP2) (BECK, 2000): é um método ágil para o desenvolvimento de software focado em projetos cujos requisitos mudam frequentemente. $\mathrm{O}$ método concentra-se nas melhores práticas para o desenvolvimento, a saber: jogo de planejamento, pequenas releases, metáforas, projeto simples, testes, refatoração, programação em par, propriedade coletiva, integração contínua, 40 horas semanais, clientes no local e padrão de codificação. O XP2 revisado consiste nas seguintes práticas primárias: sentar junto, espaço de trabalho informativo, trabalho energizado, programação em pares, histórias, ciclo semanal, ciclo trimestral, slack, reunião de 10 minutos, integração contínua, primeiro teste de programação e projeto incremental.

- Metodologias Crystal (COCKBURN, 2004): é uma família de métodos para equipes de diferentes tamanhos e cujos níveis de dificuldade variam de acordo com as cores Clear, Yellow, Orange, Red, Blue. O método mais ágil, Crystal Clear, enfatiza a comunicação de pequenas equipes de desenvolvimento de software. O desenvolvimento Clear tem sete características: (i) entrega frequente; (ii) melhoria reflexiva; (iii) comunicação osmótica; (iv) segurança pessoal; (v) foco; (vi) fácil acesso a usuários experientes; e (vii) requisitos para o ambiente técnico.

- Desenvolvimento de Software Enxuto (Lean Software Development) (POPPENDIECK; POPPENDIECK, 2003): é uma adaptação de princípios de produção "enxuta", 
baseando-se no sistema de produção da Toyota para desenvolvimento de software. Consiste em sete princípios: (i) eliminar o desperdício; (ii) aumentar a aprendizagem; (iii) decidir o mais tarde possível; (iv) entregar o mais rápido possível; (v) capacitar a equipe; (vi) construir integridade; e (vii) ver o todo.

Além dos métodos citados anteriormente, merece destaque o Scrum (SCHWABER; SUTHERLAND, 2011), amplamente utilizado em diferentes contextos de aplicação. Neste projeto de doutorado, o Scrum foi utilizado como base para as atividades de gerenciamento do processo OntoSoft. Na próxima seção são apresentadas as principais características do método.

\subsubsection{Scrum}

Scrum é um método ágil dentro do qual vários processos ou técnicas podem ser aplicados (SCHWABER; SUTHERLAND, 2013). Além disso, o Scrum evidencia a eficácia das práticas de gerenciamento e desenvolvimento de produtos, permitindo sua melhoria.

Em linhas gerais, o Scrum emprega a abordagem iterativa e incremental para aperfeiçoar a previsibilidade e o controle de riscos. Para tal, os valores de comprometimento, coragem, foco, transparência e respeito devem ser assumidos pela equipe (SCHWABER; SUTHERLAND, 2013). Nessa direção, três pilares apoiam a implementação do controle do processo empírico, a saber (SCHWABER; SUTHERLAND, 2013):

- Transparência: aspectos significativos do processo devem estar visíveis aos responsáveis pelos resultados.

- Inspeção: os usuários devem, frequentemente, inspecionar os artefatos Scrum e o progresso em direção a detectar variações.

- Adaptação: se um inspetor determina que um ou mais aspectos de um processo estão fora dos limites aceitáveis, e que o produto resultante será inaceitável, o processo ou o material sendo produzido deve ser ajustado.

Recentemente, Dingsoyr e Lassenius (2016) realizaram um levantamento indicando as tendências de algumas práticas de desenvolvimento nos últimos dez anos. Os pesquisadores investigaram o interesse nos últimos dez anos para os temas Scrum, XP, DevOp ${ }^{2}$ e Integração Contínua ${ }^{3}$.

2 DevOps podem ser entendidos como uma comunidade de prática interdisciplinar dedicada ao estudo da construção, evolução e operação de sistemas resilientes de rápida mudança em escala. Fonte: $<$ https://theagileadmin.com/what-is-devops/>

3 Integração contínua é uma prática de desenvolvimento de software em que o software é integrado continuamente durante o desenvolvimento. A integração contínua requer pelo menos uma integração diária e a verificação por compilação e testes automatizados (DINGSOYR; LASSENIUS, 2016). 
Figura 2 - Interesse relativo aos últimos 10 anos com base em pesquisas no Google Trends e na base de dados Scopus.

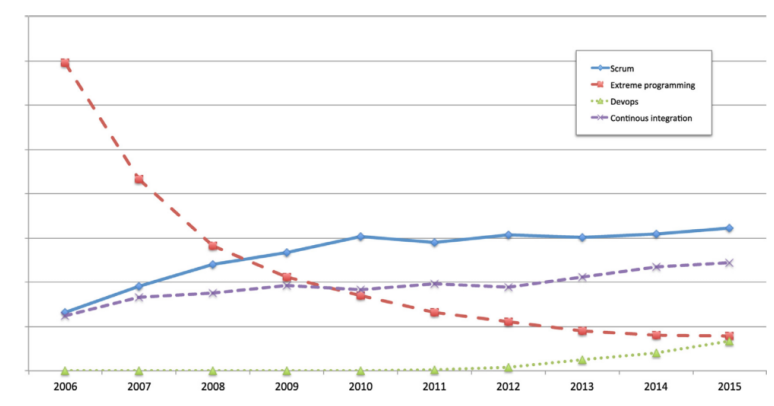

(a) Pesquisas no Google Trends.

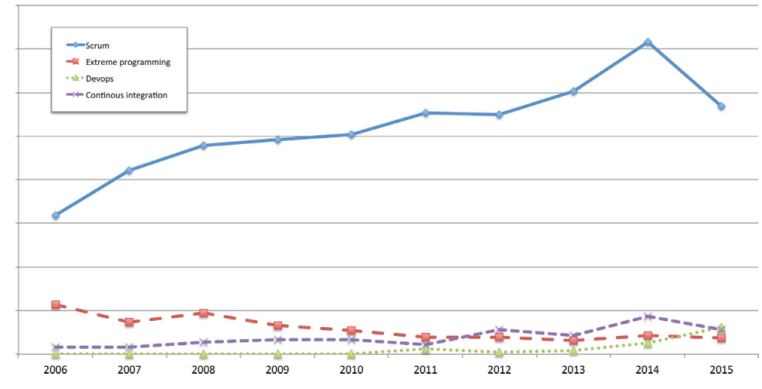

(b) Publicações da base de dados Scopus.

Fonte: Dingsoyr e Lassenius (2016).

Na Figura 2(a) é indicado o interesse relativo entre desenvolvedores com base no Google Trends e na Figura 2(b) demonstrado o interesse entre os pesquisadores. O Scrum se destaca e tem sido crescente o uso e interesse ao longo do tempo. Provavelmente a queda em 2015 entre os pesquisadores é relacionada à indexação tardia de artigos na base de dados (DINGSOYR; LASSENIUS, 2016).

Os papeis são bem definidos no Scrum, de modo que a equipe (Time Scrum) é composta pelo Product Owner, time de desenvolvimento e Scrum Master. A documentação sugere que o time de desenvolvimento tenha entre três e nove membros, a fim de facilitar o gerenciamento das sprints.

A sprint é uma iteração ou ciclo que dura de duas a quatro semanas, a partir da qual deve ser gerado algo de valor tangível para o cliente ou usuário. Uma nova sprint inicia imediatamente após a conclusão da sprint anterior (RUBIN, 2012). O Scrum define quatro eventos formais que acontecem dentro da sprint e são necessários para inspeção e adaptação (SCHWABER; SUTHERLAND, 2013): reunião de planejamento da sprint, reunião diária, reunião de revisão da sprint e retrospectiva da sprint. Na Figura 3 são apresentadas as principais atividades e artefatos do método.

Os artefatos definidos para o Scrum são especificamente projetados para maximizar a transparência das informações. De forma geral, o Scrum propõe três artefatos principais (SCHWABER; SUTHERLAND, 2013; RUBIN, 2012):

- Backlog do produto: trata-se de uma lista priorizada (ou ordenada) dos recursos necessários para atender à visão do proprietário do produto. Para o desenvolvimento contínuo do produto, o backlog do produto também pode conter novos recursos, alterações nos recursos existentes, defeitos que precisam ser reparados, melhorias técnicas e assim por diante.

- Backlog da sprint: descreve por meio de um conjunto de tarefas detalhadas, como a equipe deve planejar, projetar, construir, integrar e testar o subconjunto selecionado do backlog 
Figura 3 - Scrum: principais atividades e artefatos.

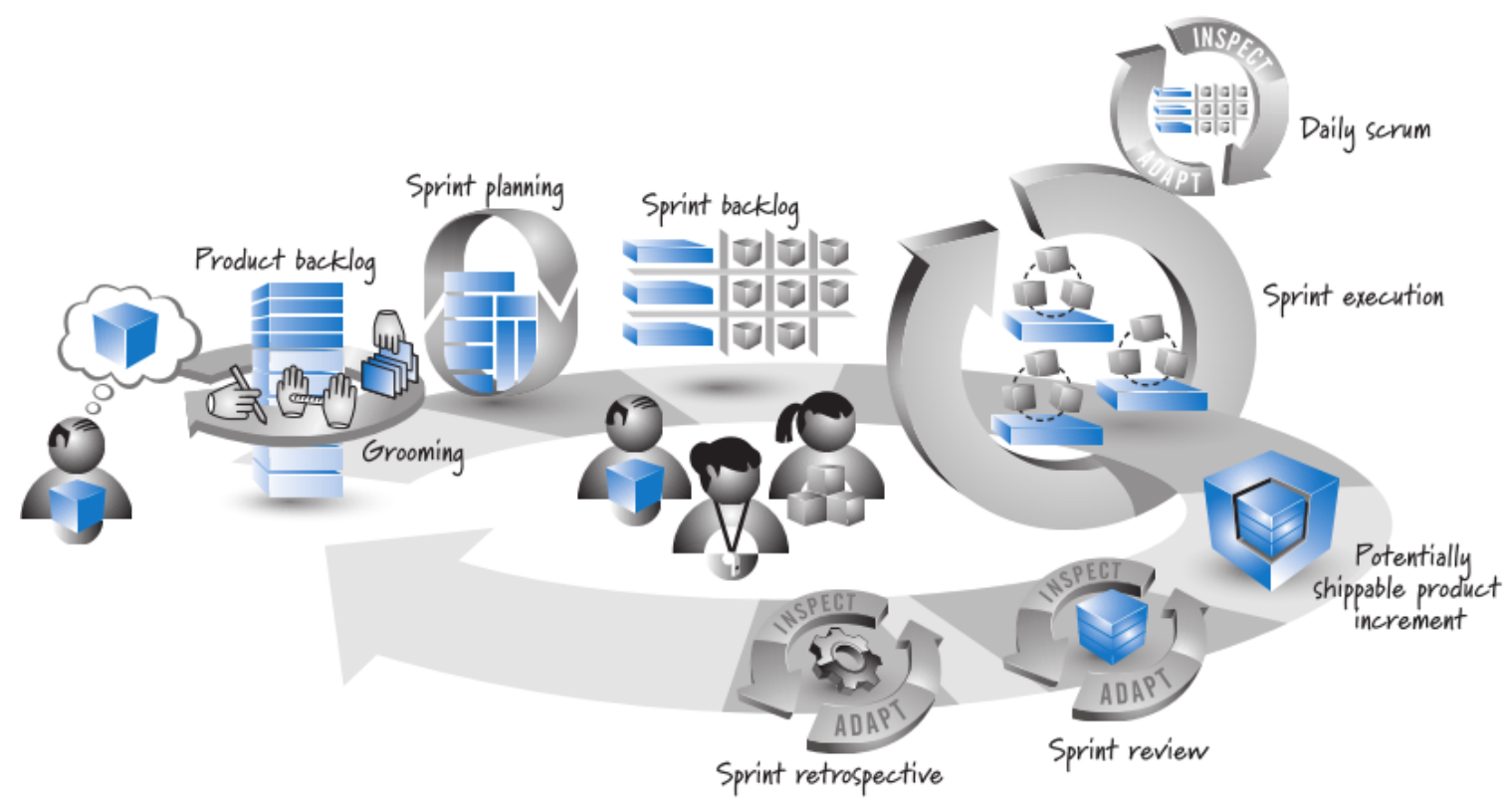

Fonte: Rubin (2012).

do produto durante a execução de uma sprint em particular.

- Incremento do produto: é a soma de todos os itens do Product Backlog finalizados durante a sprint e o valor dos incrementos de todas as sprints anteriores. Ao final da sprint um novo incremento deve estar pronto, o que significa que deve estar em condição de uso.

\subsubsection{Métodos ágeis $X$ Métodos tradicionais}

Métodos tradicional e ágil podem ser combinados ou aplicados separadamente; no entanto, em ambos espera-se como resultado um software de qualidade, em conformidade com os requisitos e entregue no tempo determinado. O método de desenvolvimento utilizado pela equipe depende do contexto de cada projeto e da respectiva organização.

Dyba e Dingsoyr (2008) identificaram características relacionadas ao gerenciamento e modelo de processo de desenvolvimento, comparando os desenvolvimentos tradicional e ágil. Tais características podem orientar a escolha dos desenvolvedores na aplicação de métodos que sejam coerentes às suas realidades. A sumarização dos principais pontos a serem observados é ilustrada na Tabela 2.

De forma geral, os métodos ágeis concentram-se nas pessoas, na comunicação e no relacionamento constante com o cliente. Estas são práticas importantes que influenciam diretamente na garantia da corretitude dos requisitos.

Apresentados alguns dos principais modelos de processo de desenvolvimento na Engenharia de Software, faz-se necessário descrever também os pontos fundamentais relacionados à 
Tabela 2 - Principais diferenças entre desenvolvimento tradicional e ágil (DYBA; DINGSOYR, 2008).

\begin{tabular}{|c|c|c|}
\hline & Desenvolvimento Tradicional & Desenvolvimento Ágil \\
\hline $\begin{array}{l}\text { Premissa funda- } \\
\text { mental }\end{array}$ & $\begin{array}{l}\text { Sistemas são totalmente especificáveis, } \\
\text { preditos e são construídos por meio de } \\
\text { planejamento meticuloso e extensivo. }\end{array}$ & $\begin{array}{l}\text { Software adaptativo de alta qualidade é } \\
\text { desenvolvido por pequenas equipes, por } \\
\text { meio de princípios de projeto contínuo. }\end{array}$ \\
\hline $\begin{array}{l}\text { Estilo de gerencia- } \\
\text { mento }\end{array}$ & Comando e controle. & Liderança e colaboração. \\
\hline $\begin{array}{l}\text { Gerenciamento do } \\
\text { conhecimento }\end{array}$ & Explícito. & Tácito. \\
\hline Conhecimento & Formal. & Informal. \\
\hline $\begin{array}{l}\text { Modelo de desenvol- } \\
\text { vimento }\end{array}$ & $\begin{array}{l}\text { Modelo de ciclo de vida (cascata, espiral } \\
\text { ou alguma variação). }\end{array}$ & Modelo evolucionário. \\
\hline $\begin{array}{l}\text { Estrutura organiza- } \\
\text { cional }\end{array}$ & $\begin{array}{l}\text { Mecanicista (burocrático com alta for- } \\
\text { malização), visando a grandes organiza- } \\
\text { ções. }\end{array}$ & $\begin{array}{l}\text { Orgânica (incentivando a ação so- } \\
\text { cial, cooperativa, flexível e participa- } \\
\text { tiva), destinado a pequenas e médias } \\
\text { empresas. }\end{array}$ \\
\hline $\begin{array}{l}\text { Controle de quali- } \\
\text { dade }\end{array}$ & $\begin{array}{l}\text { Planejamento extenso e controle rigo- } \\
\text { roso. Posteriormente são feitos testes } \\
\text { extensos. }\end{array}$ & $\begin{array}{l}\text { Controle contínuo de requisitos, projeto } \\
\text { e soluções. Teste contínuo. }\end{array}$ \\
\hline
\end{tabular}

Engenharia de Ontologias, uma vez que este projeto de doutorado está na intersecção das duas áreas de pesquisa.

\subsection{Ontologias e engenharia de ontologias}

Nas duas últimas décadas, ontologias têm sido investigadas, desenvolvidas e aplicadas por diferentes grupos de pesquisa na área de Ciência da Computação. Na Engenharia de Software, em particular, ontologias relacionadas a métricas de software, gerência de riscos, teste de software e qualidade de software, entre outras sub-áreas, também têm sido desenvolvidas (CORCHO; FERNANDEZ-LOPEZ; GOMEZ-PEREZ, 2006; MORO; FALBO, 2009; BHATIA; KUMAR; BENIWAL, 2016a).

Nas próximas seções são apresentados os principais conceitos e tipos de ontologias, assim como metodologias de desenvolvimento propostas na Engenharia de Ontologias.

\subsubsection{Ontologias}

Ontologias têm sido utilizadas com diferentes objetivos, em comunidades e aplicações distintas. As ontologias são um meio para modelar formalmente a estrutura de um sistema, isto é, as entidades e relações relevantes que emergem da observação e que são úteis para um determinado propósito (GUARINO, 2009). Gruber (1995) definiu ontologia como uma especificação explícita de uma conceituação. Borst (1997) definiu uma ontologia como uma especificação formal de uma conceituação compartilhada. Esta definição exigia ainda que a conceituação deveria expressar uma visão compartilhada entre várias partes, um consenso e não 
uma visão individual. Além disso, essa conceituação deve ser expressa em um formato (formal) legível por máquina (GUARINO, 2009).

Studer, Benjamins e Fensel (1998) unificaram essas duas definiçõos afirmando que: "uma ontologia é uma especificação formal e explícita de uma conceitualização compartilhada". Nessa direção, Noy e McGuinness (2001) pormenorizaram a definição de ontologia incluindo classes, propriedades, atributos e restrições de conceitos. Os autores enfatizam também que a ontologia com um conjunto de instâncias individuais de classes constitui uma base de conhecimento, alertando que existe uma linha tênue na qual termina a ontologia e começa a base de conhecimento.

As ontologias podem ser classificadas em (RUIZ; HILERA, 2006; ISOTANI; BITTENCOURT, 2015): (i) leves (lightweight ontologies), que definem a taxonomia para representar a relação hierárquica entre conceitos; e (ii) pesadas ou densas (heavyweight ontologies), as quais enfatizam não apenas a taxonomia, mas também a representação rigorosa da semântica entre os conceitos.

O nível de formalidade das ontologias leves e pesadas pode ser categorizado da seguinte forma (GOMEZ-PEREZ; CORCHO-GARCIA; FERNANDEZ-LOPEZ, 2004): (1) altamente informais, expressas em linguagem natural; (2) semi-informais, expressas de maneira mais estruturada e restrita; (3) semi-formais, formalmente definidas; e (4) rigorosamente formais, preveem termos meticulosamente definidos com semânticas formais, teoremas e provas de propriedades.

Independentemente do nível de formalismo da ontologia, existem diversos componentes para sua formalização e implementação na representação do conhecimento. Cada representação fornece diferentes componentes que podem ser usados para a construção de suas tarefas. Embora exista uma ampla variedade de representações, há um conjunto mínimo de componentes que estão inclusos e são essenciais, a saber (CORCHO; FERNANDEZ-LOPEZ; GOMEZ-PEREZ, 2006):

- Classes: representam conceitos que são retirados de um domínio amplo e são organizados em taxonomias por meio de herança.

- Relações: representam um tipo de associação entre os conceitos do domínio. Elas são formalmente definidas como um subconjunto de um produto de $n$ conjuntos. As ontologias contêm relações binárias que são usadas para expressar atributos de conceitos. Atributos são usualmente diferenciados das relações porque suas extensões são tipos de dados, enquanto a extensão da relação é o próprio conceito.

- Axiomas formais: servem para modelar sentenças que são sempre verdade (GRUBER, 1995). São usados, normalmente, para representar o conhecimento que não pode ser definido formalmente por outros componentes. Axiomas formais também verificam a 
consistência da própria ontologia ou a consistência do conhecimento armazenado. Além disso, são muito usados para inferir novos conhecimentos.

- Instâncias: representam elementos ou indivíduos em uma ontologia.

Para que tais conceitos e relações sejam bem construídos, os aspectos de desenvolvimento de ontologias devem ser observados e bem estabelecidos de acordo com o domínio de conhecimento da aplicação. Esses aspectos incluem classificações, princípios, linguagens, metodologias e ferramentas descritas na literatura (GOMEZ-PEREZ; CORCHO-GARCIA; FERNANDEZLOPEZ, 2004; MIZOGUCHI, 2003; CORCHO; FERNANDEZ-LOPEZ; GOMEZ-PEREZ, 2006).

Alguns benefícios identificados por Guarino (1998) quanto ao uso das ontologias são: (i) capacitam o ambiente para a prática do alto nível de reúso, usando um vocabulário comum por meio de plataformas de software heterogêneas; e (ii) capacitam o ambiente para se concentrar na estrutura do domínio, protegendo-o de preocupações iniciais e de detalhes de implementação. Marietto et al. (2002) também identificaram vantagens para o uso de ontologias, complementando os pontos anteriores:

- Propiciam uma melhor compreensão do domínio abordado.

- Possibilitam o compartilhamento do conhecimento, considerando termos de um determinado domínio.

- Oferecem apoio à interoperabilidade entre sistemas computacionais, considerando o relacionamento de diferentes paradigmas, métodos, linguagens, etc.

- Auxiliam na manutenção e documentação de sistemas computacionais.

\subsubsection{Tipos de ontologias}

Existem várias classificações de ontologias na literatura (GUARINO, 1998). Nesta seção são apresentadas algumas delas. Mizoguchi, Vanwelkenhuysen e Ikeda (1995) caracterizam quatro tipos de ontologias:

\section{- Ontologias de conteúdo}

1. Ontologias de domínio: definem e caracterizam o domínio no qual as tarefas ocorrem. Essas ontologias fornecem vocabulários sobre conceitos e seus relacionamentos, sobre atividades, teorias desenvolvidas e princípios elementares que governam o domínio.

2. Ontologias de tarefa: fornecem um vocabulário sistemático dos termos usados para resolver os problemas associados às tarefas que podem ou não pertencer ao mesmo 
domínio. Elas representam os processos e as atividades para resolver um determinado problema abstraindo o contexto do domínio (ISOTANI; BITTENCOURT, 2015).

3. Ontologias gerais ou comuns: usadas para representar conhecimento reusável de senso comum para vários domínios.

- Ontologias de comunicação: usadas para conhecimento compartilhado.

- Ontologias de indexação: usadas em casos de recuperação de dados.

- Meta-ontologias: são equivalentes às ontologias de representação do conhecimento.

Outra classificação foi feita por Noy e McGuinness (2001), na qual as ontologias foram categorizadas de acordo com a informação necessária para expressar e enriquecer suas estruturas internas, apontando as seguintes categorias: vocabulários controlados, glossários, hierarquia informal do tipo é-um, instâncias formais, frames, restrição de valores e restrições de lógica geral.

As ontologias podem, ainda, ser classificadas de acordo com suas estruturas internas, por exemplo: ontologias de representação do conhecimento, ontologias de alto-nível, ontologias de domínio, ontologias de tarefa, ontologias de tarefa de domínio, ontologias de métodos e ontologias de aplicação (CORCHO; FERNANDEZ-LOPEZ; GOMEZ-PEREZ, 2006).

As classificações sintetizadas são importantes para orientar o desenvolvimento ontológico, pois apontam as características e particularidades atribuídas a cada categoria e, portanto, a cada domínio. Dessa forma, a categorização direciona alguns aspectos relevantes no processo de construção, como o nível de restrições e de formalidade, colaborando de forma direta na definição da ontologia e de suas especificidades.

Assim como a Engenharia de Software, a Engenharia de Ontologia estabelece processos e diretrizes, indicando e descrevendo os passos do ciclo de vida e de desenvolvimento das ontologias. Algumas das principais metodologias são sumarizadas a seguir.

\subsubsection{Engenharia de ontologias}

A partir das definições de engenharia do conhecimento e de ontologias, bem como sua relação com a Engenharia de Software na criação de sistemas de gerenciamento do conhecimento, surge o conceito de Engenharia de Ontologias, que pode ser entendido como o conjunto de tarefas relacionadas ao desenvolvimento das ontologias (OSMAN; HO; HAW, 2011).

De maneira mais completa, segundo Mizoguchi e Kitamura (2001), a Engenharia de Ontologias corresponde ao conjunto de princípios de projeto, processos e atividades de desenvolvimento, tecnologias de apoio e metodologias sistemáticas que facilitam o desenvolvimento e uso de ontologias em todo o seu ciclo de vida, isto é, projeto, implementação, avaliação, validação, manutenção, implantação, mapeamento, integração, compartilhamento e reúso. 
Santhosh (2010) indica que a Engenharia de Ontologias é um campo emergente da Ciência da Computação que visa tornar o conhecimento implícito, contido dentro de aplicativos de software, explícito para um dado domínio nas organizações. A Engenharia de Ontologias também oferece uma direção para resolver os problemas de interoperabilidade gerados por obstáculos semânticos, ou seja, os obstáculos relacionados às definições de termos de negócios e classes de software, por exemplo.

Conforme Corcho, Fernandez-Lopez e Gomez-Perez (2006), o ciclo de vida das ontologias produz diversos cenários com diferentes requisitos tecnológicos. Dentre os cenários mais comuns destacam-se: (1) avaliação e importação; (2) conceituação, integração e avaliação da conceituação; (3) conceituação e aquisição do conhecimento; (4) construção semiautomática de ontologias; (5) avaliação e importação de um conjunto de ontologias e seus ajustes; (6) avaliação e importação de um conjunto de ontologias e sua intercalação; (7) tradução da ontologia em linguagem natural; (8) gerenciamento da evolução da ontologia; e (9) atividades de apoio.

O processo de desenvolvimento de ontologias proposto por Corcho, Fernandez-Lopez e Gomez-Perez (2006) incorpora as atividades referentes à construção da ontologia, classificadas em três categorias - Gerenciamento, Desenvolvimento e Apoio - conforme ilustrado na Figura 4. A proposta foi baseada no padrão de desenvolvimento de ontologia da metodologia METHONTOLOGY (FERNANDEZ-LOPEZ; GOMEZ-PEREZ; JURISTO, 1997). As fases e respectivas atividades do processo de desenvolvimento são descritas resumidamente na sequência (CORCHO; FERNANDEZ-LOPEZ; GOMEZ-PEREZ, 2006).

Figura 4 - Processo de desenvolvimento de ontologias.

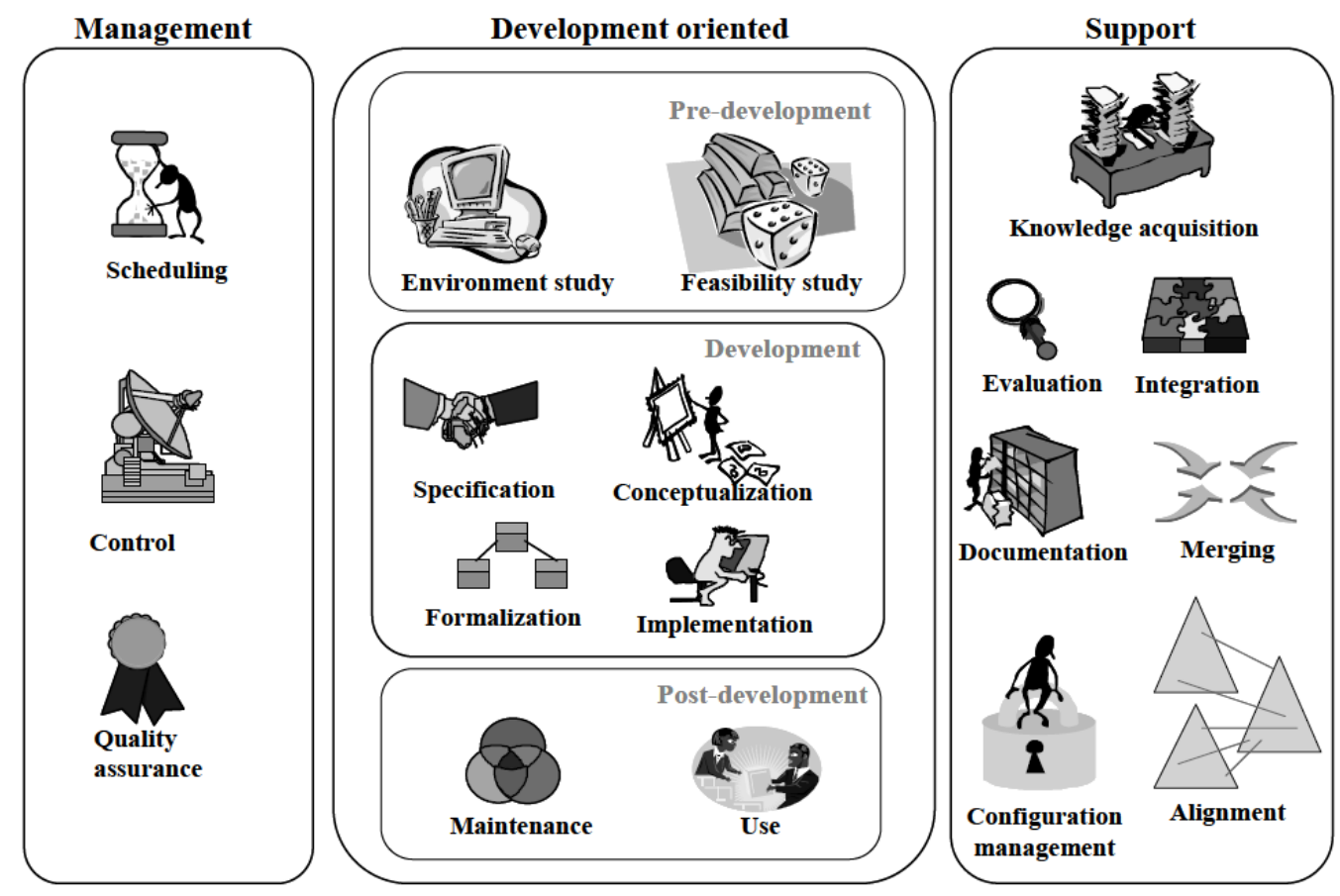

Fonte: Corcho, Fernandez-Lopez e Gomez-Perez (2006). 
- Atividades de gerenciamento da ontologia: incluem atividades de listagem, controle e de garantida de qualidade.

- Atividades orientadas ao desenvolvimento da ontologia: são um grupo de atividades que englobam o pré-desenvolvimento (estudos do ambiente e de viabilidade), o desenvolvimento (especificação, conceituação, formalização e implementação) e o pós-desenvolvimento (manutenção e uso).

- Atividades de apoio à ontologia: incluem atividades que podem ser desempenhadas durante a fase de desenvolvimento, a saber: aquisição do conhecimento, avaliação, integração, documentação, união, gerenciamento de configuração e alinhamento.

A escolha dos cenários, da metodologia, da linguagem e da ferramenta para o desenvolvimento da ontologia é dependente do escopo do projeto envolvido e é inerente ao processo de desenvolvimento (CORCHO; FERNANDEZ-LOPEZ; GOMEZ-PEREZ, 2006). A seguir são apresentadas algumas das principais metodologias utilizadas na literatura para o processo de desenvolvimento de ontologias.

\section{Metodologia On-To-Knowledge}

A metodologia On-To-Knowledge (STAAB et al., 2001) foi desenvolvida na University of Karlsruhe com base na arquitetura two-loop, na qual o processo de conhecimento e o de meta-conhecimento são baseados na ontologia.

De acordo com a metodologia, o desenvolvimento de ontologias é composto por cinco passos, a saber (CORCHO; FERNANDEZ-LOPEZ; GOMEZ-PEREZ, 2006; MIZOGUCHI, 2003):

1. Estudo de viabilidade: é aplicado para identificar e completar os detalhes da aplicação.

2. Kick-off: os requisitos da ontologia são capturados e especificados, as questões de competência são identificadas, possíveis ontologias reutilizáveis são estudadas e uma primeira versão da ontologia é construída.

3. Refinamento: a ontologia é produzida e orientada à aplicação, de acordo com a especificação proposta na fase anterior.

4. Avaliação: os requisitos e as questões de competência são conferidas e a ontologia é testada no ambiente da aplicação.

5. Manutenção da ontologia: esclarece o papel responsável por manter as definições e os passos que são necessários para que ocorra a manutenção. 
Segundo Staab et al. (2001), a metodologia On-To-Knowledge pode ser aplicada a todos os cenários do processo de desenvolvimento. No entanto, a metodologia não define uma ordem das atividades para diferentes cenários de desenvolvimento (CORCHO; FERNANDEZ-LOPEZ; GOMEZ-PEREZ, 2006).

\section{Metodologia Ontology 101}

Noy e McGuinness (2001) definiram a Ontology 101, descrevendo uma abordagem iterativa com base em questões gerais para compor o processo de desenvolvimento da ontologia. As fases que compõem a metodologia são descritas na sequência (NOY; MCGUINNESS, 2001):

1. Determinar o domínio e o escopo da ontologia: identificar o domínio que a ontologia deve cobrir, para que uso será a ontologia, quais os tipos de questões devem ser feitas, quem vai usar e manter a ontologia.

2. Considerar o reúso de ontologias existentes: verificar se existem outras ontologias que devem ser estendidas e se são necessárias para uma dada ontologia ou para vocabulários controlados.

3. Enumerar termos importantes na ontologia: identificar e listar os termos e suas propriedades no domínio do conhecimento.

4. Definir as classes e suas hierarquias: definir as classes dos conceitos e suas hierarquias (top-down, bottom-up ou combination).

5. Definir as propriedades das classes: descrever as estruturas internas das classes, ou seja, inserir as propriedades dos conceitos.

6. Definir as propriedades: especificar tipos e características das propriedades dos conceitos (atributos, tipo de atributos, cardinalidade, entre outros).

7. Criar instâncias das classes: definir os requisitos de uma instância da classe: (i) escolha da classe; (ii) criação de uma instância individual da classe; e (iii) inserção dos valores das propriedades.

Além dessas atividades, a metodologia Ontology 101 implementa atividades referentes à avaliação e importação de ontologias no processo de desenvolvimento. Por fim, Noy e McGuinness (2001) afirmam que após seguir as regras e sugestões para a construção de ontologias, é importante observar que não existe uma única ontologia correta para qualquer domínio. De fato, diferentes ontologias podem ser construídas para o mesmo domínio de conhecimento. 


\section{Metodologia METHONTOLOGY}

METHONTOLOGY (FERNANDEZ-LOPEZ; GOMEZ-PEREZ; JURISTO, 1997) é uma metodologia criada pelo grupo de Engenharia de Ontologias da Technical University of Madrid (UPM) para construção, reúso e reengenharia de Ontologias.

A metodologia tem um formato similar à norma ISO/IEC 12207 (ISO, 2008), estabelecendo as atividades a serem realizadas no desenvolvimento da ontologia. As atividades (Figura 4) são divididas em três grupos: (1) desenvolvimento, (2) gerenciamento; e (3) apoio. As atividades de gerenciamento e de apoio são realizadas durante todo o processo, auxiliando as atividades ao longo do desenvolvimento. As atividades de desenvolvimento, por sua vez, estabelecem o núcleo de desenvolvimento da ontologia e são descritas a seguir (CORCHO; FERNANDEZ-LOPEZ; GOMEZ-PEREZ, 2006):

- Especificação: definir o domínio a ser representado, o propósito da ontologia e os usuários finais da mesma.

- Conceituação: uma vez que o primeiro protótipo foi construído, estrutura-se o conhecimento adquirido por meio de um modelo conceitual ou de uma hierarquia descrevendo os conceitos, propriedades e restrições do domínio de conhecimento. A atividade de conceituação merece atenção especial, já que determina o restante da construção da ontologia. Essa fase organiza e converte uma visão informal do domínio em uma especificação semi-formal usando um conjunto de notações facilmente compreendidas. Inclui uma série de tarefas para estruturar o conhecimento, tais como: (1) construir glossário de termos, taxonomias de conceito, diagramas de relações binárias e dicionário de conceitos; (2) descrever as relações binárias, atributos de instâncias, atributos de classes, constantes, axiomas formais, regras e instâncias. Estas tarefas não precisam ser realizadas necessariamente nesta ordem, porém alguma ordem deve ser seguida para assegurar a consistência e a completude do conhecimento representado.

- Formalização: transformar a descrição conceitual da fase anterior em um modelo formal. É importante observar que, quando utilizados editores de ontologias, o modelo conceitual pode ser automaticamente implementado em várias linguagens de ontologias usando tradutores.

- Implementação: implementar a ontologia em uma linguagem de representação de conhecimento, ou seja, uma linguagem para construção de ontologias.

- Manutenção: corrigir ou atualizar (caso tenha ocorrido alguma mudança no domínio de conhecimento) a ontologia desenvolvida.

Além das atividades de desenvolvimento, a METHONTOLOGY propõe atividades de gerenciamento, garantindo qualidade e controle, e atividades de apoio, como aquisição de co- 
nhecimento, integração com outras ontologias, validação, documentação e gerenciamento de configuração, entre outras. A integração com outras ontologias deve ocorrer antes da implementação e o modelo conceitual deve ser avaliado para evitar que erros se propaguem para outros estágios dentro do ciclo (FERNANDEZ-LOPEZ; GOMEZ-PEREZ; JURISTO, 1997; CORCHO; FERNANDEZ-LOPEZ; GOMEZ-PEREZ, 2006).

Todo o processo deve ser gerenciado e documentado para facilitar a manutenção e o reúso da ontologia, além de facilitar a compreensão por parte dos usuários finais. Os processos macros da METHONTOLOGY serviram de base para algumas definições das fases do processo OntoSoft. A Figura 5 ilustra as fases e as atividades propostas pela METHONTOLOGY.

Figura 5 - METHONTOLOGY: visão geral.

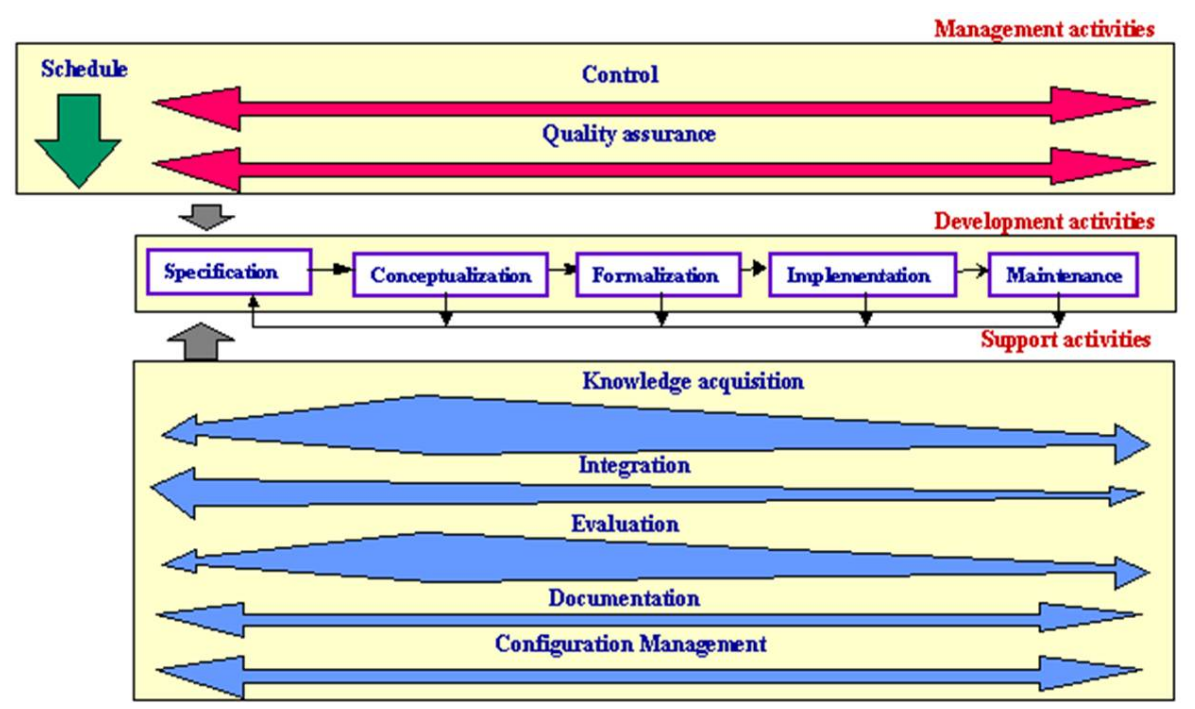

Fonte: Fernandez-Lopez, Gomez-Perez e Juristo (1997).

\section{Metodologia $\mathrm{NeOn}$}

A metodologia $\mathrm{NeOn}$ define um processo de desenvolvimento e ciclo de vida para redes de ontologias por meio de um framework com base no projeto $\mathrm{NeOn}^{4}$, que envolve 14 parceiros europeus e é co-financiado por um Programa da Comissão Europeia. O projeto tem como objetivo avançar o estado da arte na utilização de ontologias para aplicações semânticas em larga escala nas organizações distribuídas.

A metodologia detalha as diretrizes para o processo de desenvolvimento das ontologias, tendo sido definida especialmente com base na METHONTOLOGY. NeOn apresenta diversos estudos de casos e modelos, enfatizando a especificação, o planejamento e o reúso das ontologias e de redes de ontologias.

As grandes etapas do processo são: gerenciamento, desenvolvimento e apoio às redes de ontologias. O conjunto completo de processos e atividades abrange todo o ciclo de vida 
da rede de ontologias. Os grupos fornecem uma classificação administrativa que apresenta os processos e atividades de uma forma mais coerente (SUAREZ-FIGUEROA, 2010). A fase de desenvolvimento é dividida em três partes:

- Pré-desenvolvimento: envolve estudo de viabilidade e de ambiente.

- Desenvolvimento: envolve alinhamento, anotação, comparação, reengenharia, reúso, transformação, busca, seleção, atualização de ontologias, entre outras atividades.

- Pós-desenvolvimento: envolve aquisição de conhecimento, gerenciamento de configuração, elicitação, avaliação, validação, verificação, entre outras atividades.

\section{Metodologia HCOME}

A metodologia HCOME visa capacitar os trabalhadores do conhecimento a gerenciar continuamente suas conceitualizações formais em suas atividades cotidianas e a modelar seu espaço de informação por estarem ativamente envolvidas no ciclo de vida da ontologia (KOTIS; VOUROS, 2006). Trata-se de uma metodologia centrada no usuário.

HCOME fornece uma distinção clara entre as fases do ciclo de vida da ontologia, os objetivos que devem ser alcançados e as tarefas que podem ser executadas para atingir esses objetivos. As atividades são apresentadas a seguir (KOTIS; VOUROS, 2006):

- Especificação da ontologia: os engenheiros de conhecimento discutem os requisitos, produzem os documentos de especificação e chegam a um acordo sobre o objetivo e o escopo da nova ontologia.

- Conceitualização: envolve (i) a aquisição de conhecimento (discussão de requisitos, produção de documentos, identificação de colaboradores, especificação do escopo e objetivo da ontologia), e (ii) o desenvolvimento e manutenção da ontologia (importação de ontologias, consulta de ontologias genéricas e especialistas do domínio).

- Exploração: corresponde ao uso e avaliação das ontologias. Nesta fase são realizadas atividades como inspeção das ontologias (acordadas ou compartilhadas por indivíduos em seu espaço pessoal), para revisar, avaliar e criticar as conceitualizações especificadas; comparação de versões compartilhadas de uma ontologia e lançamento de outras versões.

eXtreme Design - XD

O eXtreme Design (XD) é um método colaborativo, incremental e iterativo para o projeto de ontologias que se baseia em padrões de projeto de ontologia (Ontology Design Patterns ODP) (PRESUTTI et al., 2009). XD foi inspirado no método ágil XP, sendo assim é orientado a testes, e aplica a abordagem de "dividir para conquistar". 
Na metodologia XD o projeto de desenvolvimento da ontologia é caracterizado por dois grupos principais de atividades (PRESUTTI et al., 2009): (i) definição do espaço do problema, que é composto por questões de modelagem reais, para criar um conjunto de dados RDF, a fim de modelar papeis que podem ser desempenhados por pessoas em períodos de tempo determinados; (ii) definição de um espaço de solução, o qual é constituído por soluções de modelagem, por exemplo, uma prática de reengenharia reutilizável para associar microformatos de atributos às relações de um certo vocabulário RDF Resource Description Framework. O desenvolvimento da ontologia é parte de um quadro maior, em que normalmente um projeto de software está em desenvolvimento.

Em linhas gerais, as metodologias apresentadas propõem um conjunto de atividades que devem ser executadas visando a construção de uma ontologia de qualidade. Analisando tais metodologias pode-se concluir que a maioria delas enfatiza atividades de desenvolvimento, especialmente conceituação e implementação de ontologias. Por outro lado, aspectos importantes como gestão, aprendizagem, integração, evolução e avaliação de ontologias ainda são pouco explorados. Na Tabela 3 são sumarizados os principais benefícios e limitações das metodologias apresentadas.

Tabela 3 - Benefícios e limitações das metodologias apresentadas.

\begin{tabular}{l|ll}
\hline Metodologias & Benefícios & Limitações \\
\hline Onto-To-Knowledge & Apresenta fases bem definidas. & $\begin{array}{l}\text { Não estabelece uma ordem para as ativi- } \\
\text { dades em diferentes cenários de desen- } \\
\text { volvimento. }\end{array}$ \\
\hline Ontology 101 & $\begin{array}{l}\text { Abordagem iterativa para desenvolver } \\
\text { ontologias. }\end{array}$ & $\begin{array}{l}\text { Não indica atividades de manutenção e } \\
\text { avaliação da ontologia. }\end{array}$ \\
\hline METHONTOLOGY & $\begin{array}{l}\text { Proporciona construção, reúso e reenge- } \\
\text { nharia de ontologias. }\end{array}$ & $\begin{array}{l}\text { A metodologia pode ser considerada ex- } \\
\text { tensa. }\end{array}$ \\
\hline NeOn & $\begin{array}{l}\text { Identifica e define processos e ativida- } \\
\text { des para nove cenários na construção de } \\
\text { redes de ontologias. }\end{array}$ & $\begin{array}{l}\text { A metodologia pode ser considerada ex- } \\
\text { tensar herdar características do mo- } \\
\text { delo cascata de desenvolvimento. }\end{array}$ \\
\hline XDOME & $\begin{array}{l}\text { Propõe uma abordagem centrada no ser } \\
\text { humano para desenvolver ontologias. }\end{array}$ & $\begin{array}{l}\text { Atingir um domínio consensual e con- } \\
\text { ceituações compreensíveis é uma tarefa } \\
\text { difícil e exigente. }\end{array}$ \\
\hline \hline & $\begin{array}{l}\text { É uma metodologia colaborativa, incre- } \\
\text { mental e iterativa para o projeto de onto- } \\
\text { logias baseada em padrões. }\end{array}$ & $\begin{array}{l}\text { A metologia ainda não foi avaliada } \\
\text { rigonamente. }\end{array}$ \\
\hline \hline
\end{tabular}

Também é importante ressaltar que, a partir das abordagens criadas, alguns grupos de pesquisa construíram editores de ontologias com base nas suas metodologias. Por exemplo, a On-To-Knowledge deu origem ao editor OntoEdit e METHONTOLOGY ao editor WebODE.

Segundo Corcho, Fernandez-Lopez e Gomez-Perez (2006) e Mizoguchi (2003), as ferramentas possibilitam a criação e integração de ontologias, apoiando a maioria das atividades do ciclo de vida de desenvolvimento. De modo geral, os editores são extensíveis, permitindo que novos módulos sejam facilmente adicionados. Além disso, permitem modelar o conheci- 
mento independentemente da linguagem utilizada. Alguns editores são Hozo (KOZAKI et al., 2002), OntoStudio ${ }^{5}$ e Protégé. Na Tabela 4 são apresentadas algumas das ferramentas utilizadas na construção de ontologias encontradas na literatura e as linguagens que são utilizadas respectivamente.

Tabela 4 - Comparação entre ferramentas de desenvolvimento de ontologias.

\begin{tabular}{|c|c|c|c|c|c|c|}
\hline & Hozo & OntoStudio & OntoEdit & Protégé & TopBraid & WebODE \\
\hline Licença & $\begin{array}{l}\text { Software } \\
\text { proprietário }\end{array}$ & $\begin{array}{l}\text { Software } \\
\text { proprietário }\end{array}$ & $\begin{array}{l}\text { Software } \\
\text { livre }\end{array}$ & $\begin{array}{l}\text { Software } \\
\text { livre }\end{array}$ & $\begin{array}{l}\text { Software } \\
\text { proprietário }\end{array}$ & $\begin{array}{l}\text { Software } \\
\text { livre }\end{array}$ \\
\hline Extensibilidade & Não & Plugins & Plugins & Plugins & Plugins & Servidor \\
\hline $\begin{array}{l}\text { Importação/ } \\
\text { Exportação }\end{array}$ & $\begin{array}{l}\text { XML(S), } \\
\text { RDF(S), } \\
\text { OWL, } \\
\text { outros. }\end{array}$ & $\begin{array}{l}\text { XML(S), } \\
\text { RDF(S), } \\
\text { OWL, Dia- } \\
\text { grama UML, } \\
\text { outros. }\end{array}$ & $\begin{array}{l}\text { OXML, } \\
\text { RDF(S), } \\
\text { Flogic, } \\
\text { DAML+OIL }\end{array}$ & $\begin{array}{l}\text { XML(S), } \\
\text { RDF(S), } \\
\text { OWL, Excel, } \\
\text { outros. }\end{array}$ & $\begin{array}{l}\text { RDFa, WOL, } \\
\text { RDF(S), } \\
\text { XHTML, } \\
\text { Excel, } \\
\text { outros. }\end{array}$ & $\begin{array}{l}\text { XML, } \\
\text { RDF(S), } \\
\text { DAM+OIL, } \\
\text { OWL, OIL, } \\
\text { Flogic, Jess, } \\
\text { Java. }\end{array}$ \\
\hline $\begin{array}{l}\text { Taxonomia } \\
\text { gráfica }\end{array}$ & Sim & Sim & Sim & Sim & Não & Sim \\
\hline $\begin{array}{l}\text { Trabalho cola- } \\
\text { borativo }\end{array}$ & Sim & Sim & Não & Sim & Sim & Sim \\
\hline
\end{tabular}

Fonte: Adaptada de Isotani e Bittencourt (2015).

Neste Capítulo foram abordados conceitos da Engenharia de Software, especificamente modelos de processo e Engenharia de Ontologias. Tais conceitos são importantes para o estabelecimento das diretrizes propostas para o desenvolvimento de software baseado em ontologia.

\subsection{Considerações finais}

Neste capítulo foram sumarizados os principais tópicos de pesquisa relacionados à Engenharia de Software e Engenharia de Ontologias. Atualmente, ontologias têm sido inseridas no contexto de desenvolvimento de software e, de forma promissora, influenciando fatores como compartilhamento, formalização do conhecimento, manutenção de artefatos de maneira automatizada, interoperabilidade e reúso. Em virtude destes benefícios, vários trabalhos têm investigado a associação entre as áreas de Engenharia de Software e Engenharia de Ontologias.

A associação dos conceitos destas duas grandes áreas apoia o desenvolvimento de software baseado em ontologia, o objeto de estudo desta tese. No entanto, ainda existem muitos desafios e lacunas no que tange o alinhamento destas atividades. Nesse cenário, destaca-se a necessidade de associar os conceitos da Engenharia de Software aos da Engenharia de Ontologias, a fim de orientar e direcionar os desenvolvedores nestas novas perspectivas, por intermédio da definição de um modelo de processo para software baseado em ontologia.

5 OntoStudio: www.semafora-systems.com/en/products/ontostudio/ 
No próximo capítulo são discutidos os benefícios e limitações de ontologias aplicadas à Engenharia de Software, bem como as características que constituem um software baseado em ontologia. Além disso, uma revisão sistemática é apresentada, a qual tem o objetivo de identificar os trabalhos relacionados ao desenvolvimento de software baseado em ontologia. 


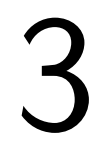

\section{DESENVOLVIMENTO DE SOFTWARE BASEADO EM ONTOLOGIA}

$\mathrm{O}$

desenvolvimento de software baseado em ontologia ou, em outras palavras, software que possui uma ontologia como um dos seus principais artefatos, tem sido alvo de crescente pesquisa na academia e nas organizações. De fato, em virtude do surgimento das tecnologias semânticas e da necessidade de transformar a informação em conhecimento, ontologias têm sido utilizadas em diversas fases do desenvolvimento das aplicações.

No decorrer deste projeto de doutorado diversos trabalhos foram estudados a fim de verificar a inserção das ontologias em aplicações de software. De modo geral, observa-se que a maioria dos estudos abordam as ontologias nas fases iniciais do ciclo de vida do software mas, por outro lado, não mencionam atividades relacionadas às práticas para desenvolver ontologias.

Nesse sentido, neste capítulo são apresentados conceitos referentes a software baseado em ontologia, bem como perspectivas para os processos de desenvolvimento, a partir da importância da gestão do conhecimento e da inserção de tecnologias semânticas.

O capítulo está organizado como segue. Na Seção 3.1 são sintetizados os benefícios do uso de ontologias na Engenharia de Software. Na Seção 3.2 são sumarizadas questões a respeito de software baseado em ontologia e, consequentemente, sobre o uso de ontologias como artefato de software. Na Seção 3.3 é discutido de que forma os conceitos de gestão do conhecimento e Engenharia de Ontologias estão relacionados. Na Seção 3.4 é apresentada uma revisão sistemática conduzida para identificar os processos de desenvolvimento para software baseado em ontologia. Na Seção 3.5 são sumarizadas algumas perspectivas com base no levantamento dos estudos e literatura. Finalmente, na Seção 3.6 são sumarizados os principais pontos abordados no capítulo. 


\subsection{Ontologias aplicadas à engenharia de software}

Uma das grandes preocupações da Engenharia de Software é o tempo despendido no desenvolvimento. Por isso, fatores como reutilização de componentes de software, integração e compartilhamento da informação se fazem necessários para otimizar o desenvolvimento das aplicações. Essas contribuições podem ser alcançadas com a utilização de abordagens ontológicas (GRIMM; ABECKER; VO, 2011).

Ontologias podem ser usadas para facilitar os processos de desenvolvimento de software a longo prazo e construir sistemas mais homogêneos (HESSE, 2005). Nesse sentido, Happel e Seedorf (2006) propuseram soluções para as fases de: (i) análise e projeto; (ii) implementação; (iii) desenvolvimento e tempo de execução; e (iv) manutenção envolvendo ontologias.

Especificamente no que se refere à área de análise e projeto de software, a engenharia de requisitos pode ser beneficiada com o uso de ontologias para automatizar e auxiliar a representação de conhecimento. Outros benefícios das ontologias no desenvolvimento de software que se destacam são (HAPPEL; SEEDORF, 2006): contribuição para abordagens evolucionárias e rastreabilidade; validação automática e checagem de consistência; background para execução de consultas; flexibilidade em cenários dinâmicos; redução da ambiguidade de linguagem; e representação unificada para o domínio.

Além disso, diferentes tipos de ontologias podem ser utilizados em aplicações distintas, conforme apresentam Gasevic, Kaviani e Milanovic (2009): ontologias de domínio, ontologias de nível superior, ontologias para a documentação, para código fonte, para verificação de erros, ontologias baseada em modelos, e padrões de projeto. Estas aplicações são usadas para tarefas na Engenharia de Software, como adição de mais semântica aos artefatos, melhoria das ligações de rastreabilidade, verificação de consistência entre modelos, geração de transformações de modelos e métricas de software, entre outras.

Face ao exposto, as pesquisas têm integrado Engenharia de Software e Engenharia de Ontologias, com a finalidade de facilitar e otimizar o desenvolvimento de software, para obter os benefícios das tecnologias semânticas ao longo do desenvolvimento. Diversas abordagens da Engenharia de Ontologias são provenientes de uma adaptação das metodologias da Engenharia de Software (MAVETERA, 2011; HESSE, 2005). Na Tabela 5 são sumarizadas algumas semelhanças entre os processos de Engenharia de Ontologias e Engenharia de Software.

Na Tabela 5 pode-se perceber que o produto (ou saída, como aponta a primeira linha da tabela) difere nas duas engenharias: para a Engenharia de Software tem-se o produto de software e para a Engenharia de Ontologias a própria ontologia. São dois resultados distintos que se complementam e tornam o software baseado em ontologia mais robusto.

No que diz respeito ao ciclo de vida, atividades de apoio e métricas de qualidade, as atividades são parcialmente adaptadas, possuindo tarefas específicas e distintas nas engenharias. Já a reusabilidade e o projeto ocorrem de maneira diferente para a Engenharia de Ontologias e 
Tabela 5 - Comparação das principais fases da Engenharia de Software e Engenharia de Ontologias.

\begin{tabular}{|c|c|}
\hline Características & Engenharia de Ontologias \\
\hline Produto (Saída) & $\begin{array}{ll}\text { Função do conhecimento: produto de } & \begin{array}{l}\text { Representação do conhecimento: } \\
\text { ontologias. }\end{array}\end{array}$ \\
\hline Ciclo de vida & $\begin{array}{l}\text { Especificação de requisitos, conceitualização, formalização, implementação e } \\
\text { manutenção. }\end{array}$ \\
\hline $\begin{array}{l}\text { Atividades de } \\
\text { apoio }\end{array}$ & $\begin{array}{l}\text { Atividades de gerenciamento de projetos e aquisição de conhecimento de } \\
\text { programação, ou seja, programação, garantia de qualidade, integração, } \\
\text { documentação e gerenciamento de configuração. }\end{array}$ \\
\hline Reusabilidade & $\begin{array}{l}\text { Ontologias podem ser importadas em } \\
\text { outras ontologias e podem ser usadas } \\
\text { em qualquer aplicação. }\end{array}$ \\
\hline Projeto & $\begin{array}{llll}\begin{array}{l}\text { Envolver os usuários ao projetar siste- } \\
\text { mas. }\end{array} & \begin{array}{l}\text { Envolver } \\
\text { ontologia. }\end{array} & & \text { usuários ao conceituar } \\
& \end{array}$ \\
\hline $\begin{array}{l}\text { Métricas de com- } \\
\text { plexidade }\end{array}$ & $\begin{array}{l}\text { Dificuldade de realizar tarefas, ou seja, codificação, depuração, teste e } \\
\text { modificação. }\end{array}$ \\
\hline $\begin{array}{l}\text { Medidas de quali- } \\
\text { dade }\end{array}$ & $\begin{array}{l}\text { Métricas de ontologias, como número } \\
\text { de conceitos, nível de profundidade e } \\
\text { capacidade para abordar questões de } \\
\text { competência. }\end{array}$ \\
\hline
\end{tabular}

Fonte: Adaptada de Osman, Ho e Haw (2011).

para a Engenharia de Software, conforme é especificado na tabela.

Hesse (2005) também descreveu diversas características sobre as fases do ciclo de vida do software e da ontologia. No que se refere aos paradigmas de desenvolvimento, Hesse (2005) afirma que os processos incremental, baseado em componentes e evolucionário são os mais adequados para o desenvolvimento de ontologias. Concomitantemente, estes também são altamente recomendados para o desenvolvimento de software, por meio das metodologias ágeis.

Ainda segundo a categorização de Hesse (2005), a maioria das atividades da Engenharia de Ontologias concentra-se na fase inicial de elicitação dos requisitos e construção do modelo conceitual do sistema. Estas também são atividades cruciais no desenvolvimento de software e podem ser melhoradas ou refinadas, a partir da construção da ontologia. Além disso, com o uso de técnicas de gestão do conhecimento as ontologias podem contribuir na qualidade do projeto do software.

Em virtude dos benefícios apresentados, nota-se o crescimento na utilização de ontologias por parte dos desenvolvedores de software em diversos segmentos. Nesse sentido, Bhatia, Kumar e Beniwal (2016b) fizeram um levantamento do uso de ontologias na Engenharia de Software, considerando a visão organizacional, a fim de avaliar o uso prático das ontologias. Os fatores identificados foram representados de acordo com a análise das forças, fraquezas, oportunidades e ameaças, conforme a Tabela 6. 
Tabela 6 - Análise das forças, fraquezas, ameaças e oportunidades do uso de ontologias na Engenharia de Software.

\begin{tabular}{l}
\hline Forças: \\
(i.) Plataforma para compartilhar e reusar conhecimento. \\
(ii.) Disponibilizar o conhecimento humano na área de Engenharia de Software, bem como \\
por meio de fomulários compreensíveis por máquina. \\
(iii.) Plataformas para gerar informação consistente. \\
(iv.) Canal de comunicação eficaz. \\
Fraquezas: \\
(i.) Definir uma maneira padrão para gerar ontologias na Engenharia de Software. \\
(ii.) Gerar uma ontologia pode consumir muito tempo. \\
(iii.) O processo pode ter custo extra inicialmente. \\
Oportunidades: \\
(i.) Criar ferramentas inteligentes que facilitem a comunicação e o compartilhamento de \\
informação. \\
(ii.) Desenvolver ferramentas inteligentes para gerenciar efetivamente as diferentes fases do \\
ciclo de vida no desenvolvimento de software. \\
(iii.) Desenvolver métodos, técnicas e ambientes para facilitar o desenvolvimento de software \\
semântico utilizando abordagens interdisciplinares. \\
Ameaças: \\
(i.) Questões sociais, legais e éticas (Há violação da propriedade intelectual?). \\
(ii.) Fornecer uma solução específica. \\
(iii.) Dificuldade em encontrar a equipe chave.
\end{tabular}
Fonte: Adaptada de Bhatia, Kumar e Beniwal (2016b).

As forças indicadas na Tabela 6 já foram discutidas ao longo desta seção, a saber: o compartilhamento e reúso do conhecimento e a associação das ontologias às atividades da Engenharia de Software. Estas contribuições impulsionam o uso de ontologias e tecnologias semânticas em aplicações na Engenharia de Software, pois colaboram para a resolução de problemas relacionados à comunicação entre os envolvidos, para a formalização do conhecimento e para a automatização do desenvolvimento.

Com relação às fraquezas, o primeiro item da tabela refere-se à falta de uso de metodologias da Engenharia de Ontologias, que podem facilitar o entendimento e o desenvolvimento padronizado de ontologias, conforme foi discutido no Capítulo 2. O segundo item é algo crítico e inerente ao processo de gestão e aquisição do conhecimento, consequentemente da construção das ontologias, assim como na definição do domínio e dos requisitos do software. Além disso, por se tratar de algo emergente a ser aplicado em uma equipe de desenvolvimento de software, a construção da ontologia pode gerar custos extras.

Quanto às oportunidades, os dois primeiros itens são tendências de pesquisa e atuam na colaboração e automatização das atividades para o compartilhamento da informação e o desenvolvimento. $\mathrm{O}$ terceiro item aborda a definição de métodos e ambientes para facilitar a integração das áreas e o desenvolvimento de software baseado em ontologia. Este ponto refere-se ao escopo deste trabalho, em que é feita a definição de um processo para facilitar o desenvolvimento de software e da ontologia de maneira integrada. 
As ameaças indicadas revelam questões recentes e que estão em discussão na academia. Por exemplo, esclarecimentos a respeito de propriedade intelectual e questões sociais são pertinentes na área de pesquisa, pois delimitam o limiar entre a extração da informação, por meio de raciocinadores e inferências, e a privacidade dos usuários. Além disso, ainda é difícil encontrar especialistas em Engenharia de Ontologias ou tecnologias semânticas.

Com base nessas direções da pesquisa e dadas as contribuições das ontologias para a Engenharia de Software, o termo software baseado em ontologia também tem se destacado. Na próxima seção, o termo é discutido e algumas das suas definições são apresentadas.

\subsection{Software baseado em ontologia}

O uso das ontologias no desenvolvimento das aplicações fez surgir vários termos relacionados ao software e sua relação com a ontologia. Um dos termos é software baseado em ontologia, o qual é abordado ao longo desta tese.

No que diz respeito a este doutorado, a ontologia é um dos artefatos principais do software a ser desenvolvido. Ela não guia o processo de desenvolvimento, mas é um dos artefatos a ser desenvolvido no processo. Por isso, o termo software baseado em ontologia é aplicado a esta pesquisa. Há um grande potencial no uso de ontologias como artefatos do conhecimento, para facilitar a comunicação entre os atores do projeto e para evitar as ambiguidades da linguagem natural, bem como para filtrar o conhecimento ao definir modelos e metamodelos de sistemas a serem desenvolvidos (RUIZ; HILERA, 2006).

Ruiz e Hilera (2006) fazem a distinção do uso das ontologias como artefatos em duas categorias: em tempo de desenvolvimento e tempo de execução. No primeiro caso, as ontologias em tempo de desenvolvimento são vistas como um artefato utilizado em uma parte específica do processo de desenvolvimento. Consequentemente, no desenvolvimento e nos processos de engenharia, as ontologias podem ser usadas como artefatos para especificação de requisitos, modelagem conceitual, programação, projeto de banco de dados ou geração automática de código.

No caso de "ontologias como artefatos de software em tempo de execução", seguindo o mesmo raciocínio de Guarino (1998), são definidas duas situações distintas:

i. Ontologias como artefatos arquiteturais: as ontologias são parte do sistema; como um componente adicional, cooperando com o resto do sistema em tempo de execução para atingir o objetivo de software (software baseado em ontologia).

ii. Ontologias como recursos (de informação): são utilizadas pelo software durante o tempo de execução para uma finalidade específica, como um recurso de informação, normalmente remoto, sobre o qual o software opera (software de reconhecimento de ontologia) realizando, por exemplo, consultas específicas. 
Neste trabalho a ontologia é um artefato arquitetural, segundo a definição de Guarino (1998) e Ruiz e Hilera (2006). A ontologia coopera com o sistema para atingir o objetivo do software, de forma que o núcleo da aplicação e o conhecimento inferido tem essencialmente uma ou mais ontologias associadas. Em outras palavras, a ontologia desempenha um papel de extrema importância e armazena, propaga e atualiza o conhecimento do domínio do sistema.

Conforme apresentado anteriormente, os benefícios do uso de ontologias na Engenharia de Software têm proporcionado a automatização de diversas atividades e facilitado a gestão e aquisição do conhecimento no desenvolvimento das aplicações. A partir do alinhamento das atividades da Engenharia de Ontologias e da Engenharia de Software, as aplicações podem ser construídas utilizando também algumas tecnologias semânticas, as quais facilitam a formalização e o compartilhamento do conhecimento de maneira automatizada.

A fim de ilustrar o uso de tais tecnologias no desenvolvimento de software, na próxima seção são apresentados conceitos, definições e tendências da inserção de tecnologias semânticas no desenvolvimento de software baseado em ontologia.

\subsubsection{Tecnologias semânticas}

De acordo com o domínio da aplicação, um software baseado em ontologia pode utilizar uma ou mais tecnologias semânticas. De maneira geral, as tecnologias semânticas fornecem descrições de dados, programas e infraestrutura que são compreensíveis ou processáveis por máquina, permitindo que os computadores utilizem esses artefatos (DOMINGUE; FENSEL; HENDLER, 2011).

Em sua interação com outras tecnologias, as tecnologias semânticas são consideradas para atingir o objetivo da pesquisa em diversas áreas de aplicação, não somente na computação, por exemplo (NIXON et al., 2011): gerir a energia de forma mais inteligente, aumentar a flexibilidade e a eficácia da produção, permitir novas formas de interação na mídia e entretenimento, melhorar a vida urbana, por meio da otimização do fluxo de tráfego, entre outras aplicações.

Ainda segundo Nixon et al. (2011), as principais tecnologias semânticas são do tipo: anotação semântica, extração de conhecimento, pesquisa, modelagem e raciocínio:

- Anotação: é um pré-requisito vital para o uso da tecnologia semântica. A maioria dos dados produzidos por ferramentas e serviços não são anotados semanticamente, levando à necessidade de extrair descrições semânticas com antecedência ou durante a execução de dados legados antes que eles possam ser usados em sistemas baseados em semântica. As anotações semânticas podem ser divididas entre abordagens automática e manual, bem como baseadas ou não em texto.

- Contexto: refere-se à necessidade de capturar, se possível formalmente, as circunstâncias em que o conhecimento está sendo obtido, modelado, alterado, usado, a fim de permitir 
que um sistema semântico use essa informação ao interagir com outros usuários, sistemas, ou dados, isto é, para fins de personalização, adaptação, filtro, classificação ou seleção.

- Modelagem: refere-se a ferramentas e técnicas que tornam possível aos especialistas de conhecimento capturarem o conhecimento de um domínio sob a forma de uma ontologia. Isso engloba meios para formalizar o conhecimento, construir a ontologia, avaliá-la e refiná-la, bem como mantê-la e desenvolvê-la.

- KDD (Knowledge Discovery and Data Mining - Descoberta de Conhecimento e Mineração de Dados): refere-se ao ato de extrair conhecimento útil de dados usando técnicas analíticas, estatísticas e de mineração.

- Raciocinadores: referem-se aos meios para inferir novos conhecimentos a partir de instâncias de base de dados semântica, ou seja, ontologias e axiomas. Os raciocinadores formam uma parte crítica da arquitetura do aplicativo, sempre que a inferência ou validação semântica é necessária.

De forma geral, a anotação e os raciocinadores são inclusos nos editores de desenvolvimento de ontologias e facilitam a geração da semântica necessária para formalizar e extrair o conhecimento. As técnicas de modelagem também fazem parte do desenvolvimento de ontologias, desde que a equipe utilize uma metodologia com atividades de aquisição de conhecimento. Portanto, estas características são intrínsecas ao desenvolvimento de ontologias e estão presentes na definição do processo OntoSoft.

Tais tecnologias interagem com outras tecnologias para permitir a criação de aplicações na resolução de novos problemas do mundo real. Além disso, tais conceitos são parte da Web Semântica, na qual é dado um significado bem definido para a informação, a fim de melhorar a cooperação entre os programas de computador (DOMINGUE; FENSEL; HENDLER, 2011). Por meio das Web Semântica e suas tecnologias espera-se extrair o significado dos dados, transformando informações em conhecimento.

Nessa direção, as subáreas de representação do conhecimento e aquisição do conhecimento, que posteriormente foram chamadas de Engenharia do Conhecimento, foram criadas para fornecer métodos e técnicas para representar o conhecimento humano ou tácito de forma compreensível por máquina e fornecer o contexto histórico a partir do qual a tecnologia semântica foi desenvolvida (DOMINGUE; FENSEL; HENDLER, 2011).

Portanto, o uso das tecnologias semânticas e ontologias se faz presente no desenvolvimento de soluções para problemas de diferentes áreas, em aplicações reais e atuais. No contexto de software baseado em ontologia tais tecnologias colaboram sobremaneira na checagem de consistência dos conceitos da ontologia e requisitos de software definidos, assim como na otimização de atividades de implementação, e em outras atividades no desenvolvimento dos artefatos do software. 
Dada a correlação entre as atividades de aquisição do conhecimento e a área de Gestão do Conhecimento no desenvolvimento de software baseado em ontologia, na próxima seção são apresentados fundamentos e características para gerenciar o conhecimento, partindo do ponto de vista da Web Semântica e das ontologias.

\subsection{Gestão do conhecimento}

A tecnologia da informação constitui um fator crucial para muitos aspectos da Gestão do Conhecimento. Nesse cenário, as ontologias frequentemente são ativos valiosos que orientam questões como busca, integração de informações e mapeamento dos ativos de conhecimento. Consequentemente, a gestão do conhecimento é um assunto intrinsecamente interdisciplinar e no qual as ontologias desempenham um papel central (SURE; STAAB; STUDER, 2009).

Os avanços na gestão do conhecimento com base na tecnologia da informação fornecem meios importantes para aumentar a produtividade e alcançar a eficácia da equipe. Isto é possível em virtude dos métodos e ferramentas que capturam, compreendem, compartilham e facilitam o acesso e reutilização de conhecimento pelos membros da equipe para criar valor (MEZGHANI; EXPOSITO; DRIRA, 2015).

Uma definição clara sobre a gestão do conhecimento, proposta por Abecker e Elst (2009) diz: "Gestão do conhecimento é uma atividade organizacional gerenciada sistematicamente, que vê o conhecimento implícito e explícito como um recurso estratégico chave de uma organização. O objetivo é melhorar o manejo do conhecimento no nível individual, de equipe, de organização e inter-organizacional, para alcançar objetivos organizacionais, como melhor inovação, maior qualidade, maior custo-efetividade ou menor tempo de lançamento no mercado."

A maioria das bases conceituais de ontologias está em vigor há um longo tempo, sem usufruir de uma adoção generalizada por engenheiros de software. $\mathrm{O}$ advento corrente de formalismo no contexto da Web Semântica é um fator importante, de modo que ações de grupos como W3C ${ }^{1}$ ajudaram a definir padrões como RDF e OWL. Em certo sentido, a importância da normalização pode ser comparada com a situação da modelagem visual na Engenharia de Software antes dos modelos da UML (HAPPEL; SEEDORF, 2006).

Para desenvolver e implantar um aplicativo de Gestão do Conhecimento, é preciso considerar diferentes processos. Segundo Sure, Staab e Studer (2009), destacam-se três processos: (i) processo de meta conhecimento, que corresponde à identificação do conhecimento; (ii) problemas humanos, que são relacionados ao ambiente cultural relacionado às organizações; e (iii) Engenharia de Software, que acompanha os requisitos de software provenientes dos processos de conhecimento, os quais precisam ser refletidos no planejamento, na gestão da

1 World Wide Web Consortium (W3C) é uma comunidade internacional que desenvolve padrões abertos para garantir o crescimento a longo prazo da Web. <https://www.w3.org/> 
concepção geral do sistema e na implementação. Estes processos não são disjuntos, mas se sobrepõem e se complementam, conforme é apresentado na Figura 6.

Figura 6 - Principais processos para o desenvolvimento e implantação de aplicativos na Gestão do Conhecimento.

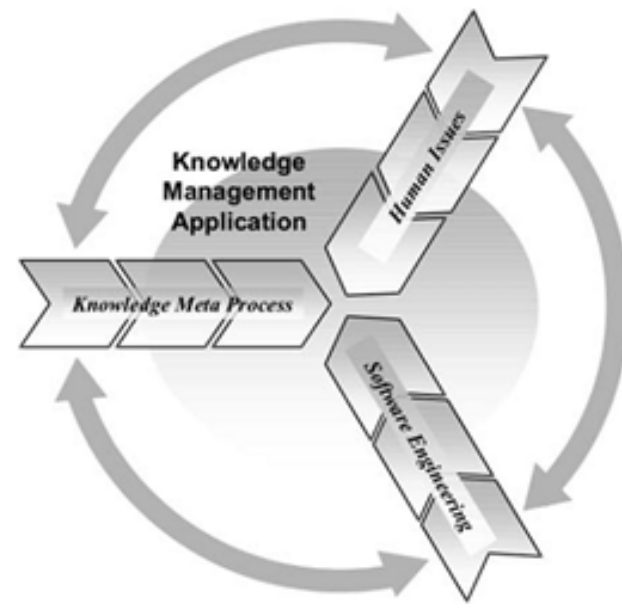

Fonte: Sure, Staab e Studer (2009).

A partir da Figura 6 é possível observar a interdisciplinaridade e a complementaridade das áreas no desenvolvimento de aplicações que contemplem a Gestão do Conhecimento. Assim como a elicitação dos requisitos é importante para construir sistemas que satisfaçam as necessidades dos usuários, utilizando e processando, de fato, o conhecimento tácito, também os sistemas de informação devem utilizar o potencial do conhecimento extraído nos processos e inferir novos conhecimentos.

Uma vez que a aplicação da Gestão do Conhecimento é implementada em uma organização, e sabendo que o processo do conhecimento tem como núcleo as ontologias, a Gestão do Conhecimento caracteriza-se por ser essencialmente cíclica em torno dos seguintes passos (SURE; STAAB; STUDER, 2009): criação ou importação do conhecimento; captura dos itens do conhecimento; recuperação e acesso do conhecimento; e processamento do conhecimento para estabelecer seu uso pela organização, como é ilustrado na Figura 7.

No entanto, alguns fatores culturais e sociais podem dificultar o progresso deste processo, especialmente se os membros intuírem que o compartilhamento de conhecimento requer muito tempo e os esforços poderiam ser investidos em outras atividades mais benéficas para si mesmos. Além disso, cada membro tem seus próprios traços de personalidade e características, o que torna complexa a gestão de um grupo de pessoas, em particular se os conflitos aparecem (MEZGHANI; EXPOSITO; DRIRA, 2015).

Desde o início das atividades na Gestão do Conhecimento, podem ser identificados dois fluxos de pesquisa e aplicações, a partir da visão centrada no processo e da visão centrada no produto respectivamente (ABECKER; ELST, 2009), como pode ser visto na Figura 8. 
Figura 7 - Atividades referentes ao processo de conhecimento.

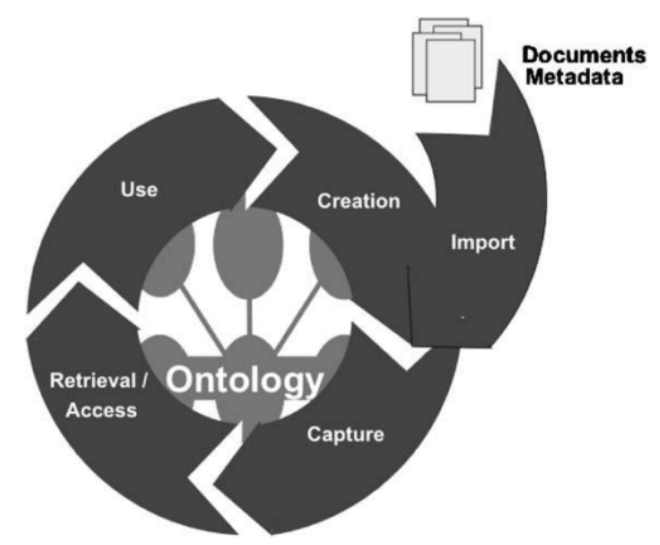

Fonte: Sure, Staab e Studer (2009).

Figura 8 - Possíveis abordagens para o gerenciamento do conhecimento.

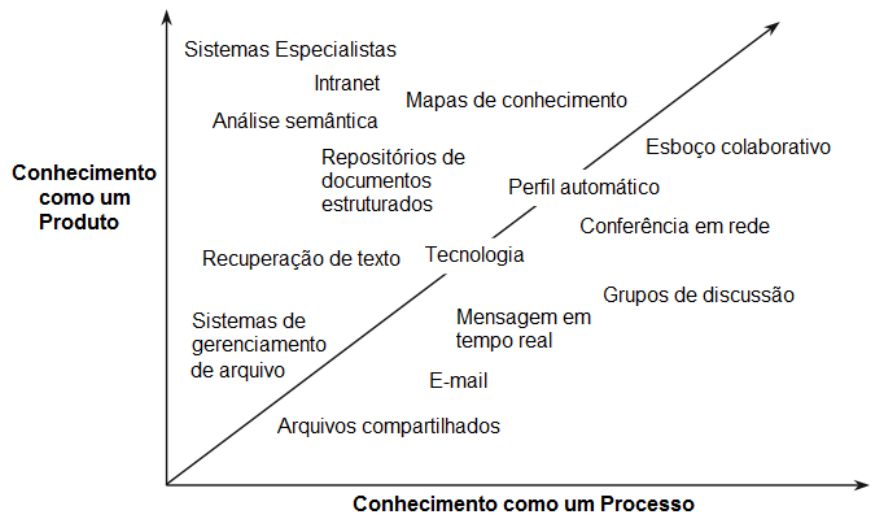

Fonte: Adaptada de Abecker e Elst (2009).

A visão centrada no processo compreende, principalmente, o gerenciamento do conhecimento como processo de comunicação. Essa visão assume que a fonte de conhecimento mais importante de uma organização são seus funcionários, e não a solução de problemas (ABECKER; ELST, 2009). Por sua vez, a visão centrada no produto pressupõe que o conhecimento pode existir fora das pessoas e pode ser tratado como um objeto dentro dos sistemas. Essa visão se concentra em documentos de conhecimento, sua criação, armazenamento e reutilização em memórias organizacionais baseadas em computador (ABECKER; ELST, 2009).

Para uma abordagem satisfatória faz-se necessário utilizar práticas das duas visões apresentadas. Tanto o conhecimento tácito quanto o conhecimento nos documentos de uma organização são necessários para construir a base de conhecimento. As tecnologias semânticas têm um papel fundamental na otimização da coleta e aquisição deste conhecimento.

Conforme foi visto nas seções anteriores, o software baseado em ontologia tem como diferencial as ações referentes à manutenção, integração e compartilhamento do conhecimento. A fim de caracterizar os estudos relacionados a esta pesquisa, uma revisão sistemática foi conduzida 
no intuito de identificar e investigar os processos de desenvolvimento para software baseado em ontologia. A revisão sistemática conduzida e os principais resultados obtidos são sumarizados na próxima seção.

\subsection{Processo de software baseado em ontologia: uma re- visão sistemática}

Devido à falta de conhecimento dos desenvolvedores sobre metodologias de desenvolvimento de ontologia, a maioria dos estudos relacionados ao uso de ontologias no desenvolvimento de software abordam os conceitos da Engenharia de Software e poucos conceitos de Engenharia de Ontologias. Esse fator pode influenciar o tempo de desenvolvimento e a qualidade do produto, pois a falta de um processo tende a prejudicar o desempenho da equipe e causar dificuldades no desenvolvimento do software.

Nesta seção é descrita e discutida uma revisão sistemática da literatura, que foi conduzida a fim de identificar trabalhos relacionados à Engenharia de Ontologias e Engenharia de Software, além de extrair características no que se refere ao desenvolvimento de software baseado em ontologia. A análise dos estudos revelou a identificação de fases, atividades do ciclo de vida do software e o produto de software resultante em cada processo de desenvolvimento proposto na literatura.

Esta revisão sistemática contribuiu para a pesquisa no processo de desenvolvimento de software baseado em ontologia da seguinte forma: (i) identificando os processos de desenvolvimento; (ii) sumarizando as características de cada processo e evidenciando a associação entre Engenharia de Software e Engenharia de Ontologias; (iii) indicando diretrizes e boas práticas nos processos de desenvolvimento para software baseado em ontologia; e (iv) oferecendo orientações para pesquisas futuras.

De acordo com Deline et al. (2009), a associação entre desenvolvimento de software e ontologia pode garantir uma atualização constante e contínua das ontologias, além de agregar regras de negócios e conhecimento, considerando as atividades do ciclo de vida do software. Com base em indicativos como acima referido, a utilização de metodologias e processos é de extrema importância, pois contribuem para formalizar, padronizar, orientar e dirigir o desenvolvimento de software durante o ciclo de vida do software para todos os envolvidos em um projeto.

Nesse sentido, para um processo de desenvolvimento de software baseado em ontologia, os pesquisadores integram características da Engenharia de Software tradicional e Engenharia de Ontologia para estabelecer diretrizes a fim de guiar o desenvolvedor. Este é o principal objetivo deste trabalho de doutorado, conforme será apresentado no Capítulo 4. Portanto, a fim de fundamentar as decisões tomadas e identificar necessidades reais e emergentes esta revisão foi conduzida. 
Basicamente, o processo de revisão sistemática pode ser descrito como um conjunto bem definido e planejado de etapas de acordo com um protocolo previamente estabelecido (KITCHENHAM et al., 2009), composto de planejamento, condução e análise dos resultados, que serão apresentados nas próximas seções.

\subsubsection{Protocolo da revisão sistemática}

A revisão sistemática conduzida visou identificar processos de desenvolvimento para software baseado em ontologia; além de verificar o contexto e a associação entre as atividades da Engenharia de Software e Engenharia de Ontologias. A partir deste objetivo a seguinte questão de pesquisa foi levantada: como é feita a associação das atividade de Engenharia de Software e Engenharia de Ontologias nos processos de desenvolvimento de software baseado em ontologia?

A partir da questão de pesquisa foram derivados dois pontos de observação que foram utilizados no decorrer da análise dos estudos identificados:

a: Quais fases do ciclo de desenvolvimento de software são encontradas nos processos para software baseado em ontologia?

b: Como a Engenharia de Ontologia é aplicada ao software baseado em ontologia?

\subsubsection{Critérios de inclusão e exclusão}

Os critérios de inclusão e exclusão foram estabelecidos com base na questão de pesquisa definida. Os estudos selecionados na revisão foram classificados de acordo com dois critérios de inclusão (CI), para que pudessem ser identificados estudos no âmbito de processos de desenvolvimento para software baseado em ontologia.

- CI-1: Estudos que definem um processo de desenvolvimento para software baseado em ontologia.

- CI-2: Estudos que adaptam um processo de desenvolvimento a um software baseado em ontologia.

Foram definidos os seguintes critérios de exclusão (CE) para refinar a pesquisa e análise dos estudos:

- CE-1: Estudos que não apresentam um processo de desenvolvimento.

- CE-2: Estudos que não estão escritos em inglês ou português.

- CE-3: Estudos não disponíveis e páginas que descrevem eventos, como editoriais e notas de abertura. 


\subsubsection{Bases de pesquisa e estratégia de busca}

De acordo com os artigos indicados pelos especialistas e o objetivo desta revisão sistemática, foram identificadas como palavras-chave da pesquisa: software development process e ontology based software. As fontes de pesquisa escolhidas foram: IEEE Xplore, Biblioteca Digital ACM, Science Direct, Scopus e Web of Science. Essas fontes foram selecionadas por serem consideradas as principais bases de pesquisa em Engenharia de Software.

Alguns sinônimos foram definidos para compor a sequência de busca e os termos foram divididos em duas partes. Conforme mostrado na Tabela 7, o termo A refere-se à Engenharia de Ontologias e desenvolvimento baseado em ontologia e o termo B está relacionado ao desenvolvimento de software e à Engenharia de Software. Portanto, a sequência de pesquisa resultante é (A AND B).

Tabela 7 - Termos usados na string de busca.

\begin{tabular}{|c|c|}
\hline Termo & Sinônimos \\
\hline $\mathrm{A}$ & $\begin{array}{l}\text { "ontology-based" OR "ontology engineering" OR "ontology-driven"OR "ontology } \\
\text { driven" OR "ontology paradigm" OR "semantic application" OR "semantic develop- } \\
\text { ment" OR "semantic process" OR "semantic approach" OR "semantic technologies" } \\
\text { OR "semantic based" OR "semantic web enabled" }\end{array}$ \\
\hline B & $\begin{array}{l}\text { "software process" OR "process model" OR "software engineering" OR "software } \\
\text { development" }\end{array}$ \\
\hline String & (A AND B) \\
\hline
\end{tabular}

\subsubsection{Condução da revisão sistemática}

Após a busca foram selecionados 765 estudos relacionados a processo de desenvolvimento para software baseado em ontologia. O resultado para cada base de dados é apresentado na Tabela 8.

Tabela 8 - Resultados parciais

\begin{tabular}{lc}
\hline \hline Base de dados & Resultado \\
\hline \hline IEEE Xplore & 89 \\
ACM Digital Library & 28 \\
Science Direct & 42 \\
Scopus & 390 \\
Web of Science & 216 \\
\hline Total de estudos: & $\mathbf{7 6 5}$ \\
\hline \hline
\end{tabular}

A revisão sistemática foi conduzida seguindo a abordagem proposta por Kitchenham et al. (2009). Após a análise de títulos e abstracts 668 estudos foram excluídos, pois abordavam somente partes do processo. Embora a maioria dos estudos fizesse referência ao uso de ontologias para apoiar o desenvolvimento de software, estes não definiram um processo de desenvolvimento para software baseado em ontologia. Os critérios e os respectivos números podem ser vistos na Figura 9. 
Figura 9 - Quantidade de estudos incluídos e excluídos a partir dos critérios estabelecidos nas respectivas bases de busca.

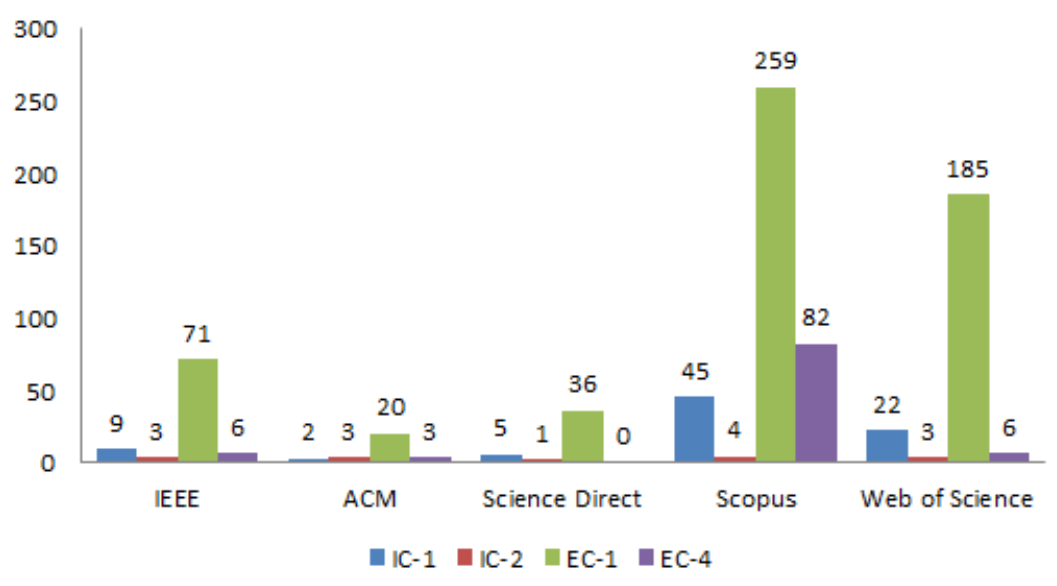

571 estudos se enquadram no primeiro critério de exclusão, ou seja, eram estudos que aplicavam a ontologia em diversas partes do desenvolvimento de software, como análise de requisitos, processo de manutenção de software, desenvolvimento orientado a modelos, gerenciamento de processos de negócios, agentes e arquitetura orientada a serviços. A ontologia não era utilizada como um artefato arquitetural do desenvolvimento, ou seja, como um dos artefatos essenciais na aplicação desenvolvida, por isso os trabalhos não foram considerados na revisão.

A partir da aplicação dos critérios de inclusão e exclusão, 97 estudos indicaram associações entre processos de desenvolvimento e software baseado em ontologia, tendo sido selecionados para uma análise aprofundada. No entanto, apenas 11 estudos abordaram dez diferentes processos de desenvolvimento e foram incluídos na fase final da revisão sistemática. Os demais estudos (86) ou eram repetidos em algumas bases ou não consideravam a ontologia como um dos principais artefatos do software. Na Figura 10 são destacados os estudos concernentes a software baseado em ontologia nos últimos 12 anos.

Figura 10 - Linha do tempo considerando a definição dos processos para software baseado em ontologia nos últimos 12 anos.

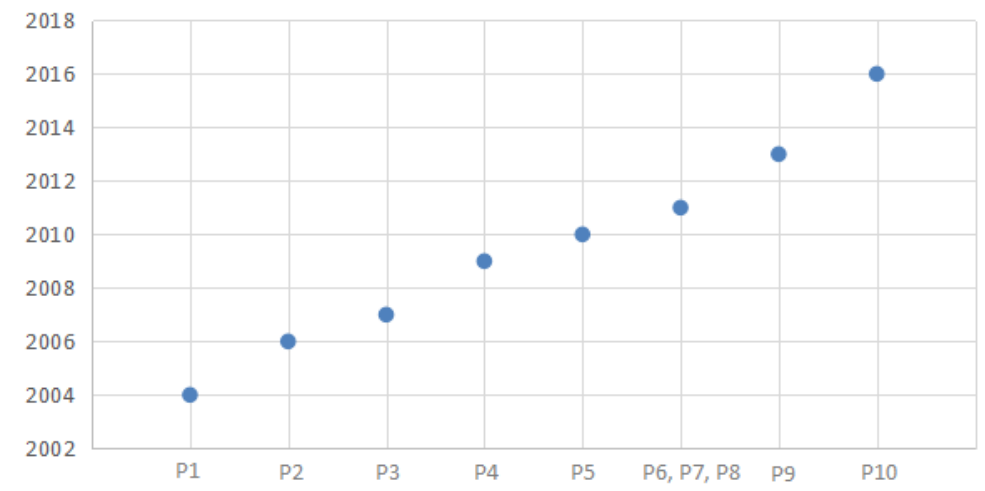

Na Tabela 9 são apresentados o ano da publicação e o título de cada estudo respectiva- 
mente. O primeiro processo para software baseado em ontologia foi identificado em 2004 e o último em $2016^{2}$. Nesta direção, vários autores (SHEN et al., 2014; ABROWSKA-KUBIK, 2015) apontam vantagens do uso de ontologias no desenvolvimento de software.

Tabela 9 - Estudos selecionados na fase final.

\begin{tabular}{lll}
\hline \hline Id & Ano & Título da publicação \\
\hline \hline P1 & 2004 & Ontology-based skills management \\
P2 & 2006 & Collaborative engineering software development: Ontology-based approach \\
P3 & 2007 & OBSE - an approach to Ontology-based Software Engineering in the practice \\
P4 & 2009 & A case study of ontology-driven development of intelligent educational systems \\
P5 & 2010 & A process framework for semantics-aware tourism information systems \\
P6 & 2011 & Towards a Comprehensive Ontology-Driven Software Development Approach \\
P7 & 2011 & NextGen and SESAR moving towards ontology-based software development \\
P8 & 2012 & Software engineering approach to enterprise-strength ontology engineering \\
P9 & 2013 & A MDE Framework for semi-automatic development of web applications \\
P10 & 2016 & OntoSoft Process: Towards an agile process for ontology-based software \\
\hline \hline
\end{tabular}

Na próxima seção, são apresentadas e discutidas as principais características dos processos propostos nos estudos identificados por meio da revisão sistemática.

\subsubsection{Análise e discussão dos resultados}

Com base na questão de pesquisa elaborada, as características dos processos foram extraídas e analisadas. Definições, contexto de aplicação, características e outras questões também são sumarizadas em tabelas ao longo desta seção. Os fatores observados nos estudos referem-se às fases de Engenharia de Software, Engenharia de Ontologia, utilização de inferência e produto resultante do processo.

A pesquisa revelou que a combinação de práticas de Engenharia de Software e ontologias oferece vantagens em relação ao tempo de desenvolvimento de software, diminuição da ambiguidade de conceitos, agilidade na correção de requisitos, reutilização, geração automática de código e garantia de qualidade do software.

Os processos fazem parte de contextos específicos e distintos, por exemplo em sistemas baseados em conhecimento, para sistemas relacionados a construções de dobradiças plásticas, sistema educacional, sistema de turismo e sistema de informação da aeronáutica. Os detalhes da definição e o contexto de aplicação são apresentados para cada processo na Tabela 10. As legendas P1 a P10 referem-se aos processos identificados na revisão sistemática.

A meta relacionada ao uso das ontologias em cada processo identificado também foi analisada. De forma geral, na maioria dos processos, a ontologia permite a criação de um modelo de representação do conhecimento para possibilitar a interoperabilidade entre sistemas. $\mathrm{Na}$ Tabela 11 as metas definidas em cada estudo são sumarizadas e apresentadas.

$\overline{2}$ Esta revisão sistemática já foi atualizada após a publicação de um artigo (MACHADO et al., 2016) em que o OntoSoft, processo definido neste trabalho de doutorado, foi publicado. Em virtude desse fato, o trabalho definido nos próximos capítulos é apresentado de forma sucinta nesta revisão. 
Tabela 10 - Definição e contexto de aplicação para cada processo identificado.

\begin{tabular}{|c|c|c|}
\hline Processo & Definição & Contexto de Aplicação \\
\hline P1 & $\begin{array}{l}\text { Modelo de Processo Kowien (Cooperative Kno- } \\
\text { wledge Management in Engineering Networks) } \\
\text { é uma junção de projetos de pesquisa na área } \\
\text { de sistemas baseados em conhecimento. }\end{array}$ & 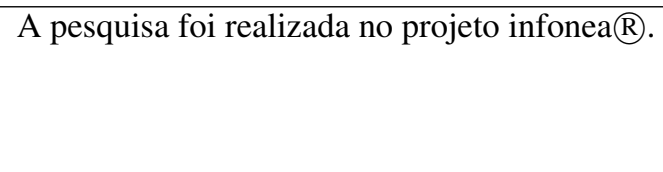 \\
\hline $\mathrm{P} 2$ & $\begin{array}{l}\text { O processo é uma abordagem baseada em onto- } \\
\text { logias para desenvolvimento de software cola- } \\
\text { borativo. }\end{array}$ & $\begin{array}{l}\text { O processo foi utilizado no desenvolvimento } \\
\text { de um protótipo de sistema para a construção } \\
\text { de dobradiças plásticas, denominado ambiente } \\
\text { OneApp (Ontology- based Engineering Appli- } \\
\text { cation Integration Environment). }\end{array}$ \\
\hline$\overline{\mathrm{P} 3}$ & $\begin{array}{l}\text { Processo OBSE (Ontology-based Software En- } \\
\text { gineering) é uma combinação de ciclos de de- } \\
\text { senvolvimento de software e ontologias. }\end{array}$ & $\begin{array}{l}\text { A abordagem não mostra nenhuma aplicação } \\
\text { ou estudo de caso. }\end{array}$ \\
\hline $\mathrm{P} 4$ & $\begin{array}{l}\text { Propõe um desenvolvimento de software ori- } \\
\text { entado a ontologia baseado em três níveis de } \\
\text { detalhe. }\end{array}$ & $\begin{array}{l}\text { Foi definido um sistema educacional (E- } \\
\text { Advisor) que facilita a supervisão dos alunos. }\end{array}$ \\
\hline$\overline{\mathrm{P} 5}$ & $\begin{array}{l}\text { PLOSATIS é uma nova forma de integrar a } \\
\text { linha de produtos de software, ontologias de } \\
\text { engenharia e computação semântica para o de- } \\
\text { senvolvimento de sistemas de informação turís- } \\
\text { tica. }\end{array}$ & $\begin{array}{l}\text { Uma estrutura desenvolvida para sistemas de } \\
\text { turismo. }\end{array}$ \\
\hline P6 & $\begin{array}{l}\text { É uma metodologia genérica para o desenvolvi- } \\
\text { mento orientado a ontologia. }\end{array}$ & $\begin{array}{l}\text { Foi estabelecido para desenvolvedores de En- } \\
\text { genharia de Software. }\end{array}$ \\
\hline P7 & $\begin{array}{l}\text { ONTOCOR é uma aproximação do desenvolvi- } \\
\text { mento de software baseado em ontologia que } \\
\text { permite a reutilização elevada de código e o } \\
\text { desenvolvimento mais rápido. }\end{array}$ & $\begin{array}{l}\text { Define uma aplicação semântica para a gestão } \\
\text { da informação aeronáutica. }\end{array}$ \\
\hline P8 & $\begin{array}{l}\text { A metodologia ESOE identifica as semelhanças } \\
\text { entre os modelos da Engenharia de Software e } \\
\text { Engenharia de Ontologias. }\end{array}$ & $\begin{array}{l}\text { A abordagem não mostra nenhuma aplicação } \\
\text { ou estudo de caso. }\end{array}$ \\
\hline P9 & $\begin{array}{l}\text { A proposta utiliza desenvolvimento dirigido a } \\
\text { modelo e ontologias para construir o projeto } \\
\text { semântico, sendo uma plataforma de desenvol- } \\
\text { vimento ágil. }\end{array}$ & $\begin{array}{l}\text { Ilustra um exemplo genérico de um construtor } \\
\text { de web semântica. }\end{array}$ \\
\hline $\mathrm{P} 10$ & $\begin{array}{l}\text { OntoSoft (Ontology based Software) é um pro- } \\
\text { cesso ágil que integra práticas de Engenharia } \\
\text { de Software e Engenharia de Ontologias para o } \\
\text { desenvolvimento de software baseado em onto- } \\
\text { logia. }\end{array}$ & $\begin{array}{l}\text { As atividades do OntoSoft foram discutidas e } \\
\text { melhorias foram feitas a partir da condução de } \\
\text { estudos de caso. }\end{array}$ \\
\hline
\end{tabular}

Na Tabela 11 também são apresentadas as fases advindas da Engenharia de Software que são abordadas nos processos. A maioria das abordagens define atividades de planejamento, análise e projeto e elicitação de requisitos. Nota-se que por mais que as atividades sejam denominadas de maneira distinta nos estudos, estas por sua vez possuem tarefas semelhantes ou idênticas.

Também foram analisados aspectos relacionados ao uso de ontologias e às atividades de Engenharia de Ontologias. O objetivo foi identificar como as metodologias de Engenharia de Ontologias são incluídas nos processos, se a equipe de desenvolvimento segue uma determinada abordagem. Nas tabelas 12 e 13 esses aspectos são sumarizados, apresentam as fases cobertas pelos processos e a avaliação realizada, respectivamente. 
Tabela 11 - Metas e fases de desenvolvimento de software definidas nos processos.

\begin{tabular}{|c|c|c|}
\hline Processo & Meta relacionada ao uso da ontologia. & Fases do desenvolvimento de software. \\
\hline $\mathrm{P} 1$ & $\begin{array}{l}\text { Fornece sugestões para os usuários que vi- } \\
\text { sam elaborar a conceituação, desenvolvi- } \\
\text { mento e avaliação de um sistema de infor- } \\
\text { mação baseado em ontologia. }\end{array}$ & $\begin{array}{l}\text { Global (documentação e gerenciamento de pro- } \\
\text { jetos) e sucessivos (elicitação de requisitos, } \\
\text { aquisição de conhecimento, conceituação, im- } \\
\text { plementação e avaliação). }\end{array}$ \\
\hline $\mathrm{P} 2$ & $\begin{array}{l}\text { Utiliza ontologias para representar explici- } \\
\text { tamente conceitos importantes e suas rela- } \\
\text { ções entre problemas do domínio e Enge- } \\
\text { nharia de Software no desenvolvimento de } \\
\text { software. }\end{array}$ & $\begin{array}{l}\text { Análise e projeto, projeto detalhado e imple- } \\
\text { mentação, e integração. }\end{array}$ \\
\hline $\mathrm{P} 3$ & $\begin{array}{l}\text { Oferece oportunidades e benefícios seme- } \\
\text { lhantes para reengenharia e reutilização } \\
\text { nos estágios iniciais do desenvolvimento } \\
\text { de software. }\end{array}$ & $\begin{array}{l}\text { Requisitos, domínio do conhecimento, modela- } \\
\text { gem e implementação. }\end{array}$ \\
\hline $\mathrm{P} 4$ & $\begin{array}{l}\text { Facilita a orientação acadêmica e o pro- } \\
\text { grama de planejamento para estudantes de } \\
\text { pós-graduação de Sistemas de Informação } \\
\text { da Universidade do Athabasca. }\end{array}$ & $\begin{array}{l}\text { Planejamento de atividades, preparação e exe- } \\
\text { cução. }\end{array}$ \\
\hline P5 & $\begin{array}{l}\text { Apoio a sistemas de informação de turismo } \\
\text { usando tecnologias semânticas e linhas de } \\
\text { produto. }\end{array}$ & $\begin{array}{l}\text { Requisitos e análise de processo, engenharia de } \\
\text { ontologia, engenharia de domínio e engenharia } \\
\text { de produto web. }\end{array}$ \\
\hline P6 & $\begin{array}{l}\text { Fornece diretrizes gerais para o ciclo de } \\
\text { desenvolvimento de um processo. }\end{array}$ & $\begin{array}{l}\text { Atividades genéricas de desenvolvimento de } \\
\text { software são apenas discutidas. }\end{array}$ \\
\hline P7 & $\begin{array}{l}\text { Aprimora o desenvolvimento de software } \\
\text { com tecnologias semânticas e também per- } \\
\text { mite um intercâmbio de domínios diferentes } \\
\text { com tipos semelhantes de tarefas. }\end{array}$ & $\begin{array}{l}\text { A abordagem não indica as fases de desenvol- } \\
\text { vimento de software. }\end{array}$ \\
\hline P8 & $\begin{array}{l}\text { Utiliza os princípios e práticas de Engenha- } \\
\text { ria de Software para o desenvolvimento, im- } \\
\text { plementação e manutenção das ontologias. }\end{array}$ & $\begin{array}{l}\text { A metodologia ESEO tem } 19 \text { atividades (pro- } \\
\text { jeto, desenvolvimento, testes, manutenção, en- } \\
\text { tre outras) divididas em três processos princi- } \\
\text { pais, seguindo os modelos de maturidade. }\end{array}$ \\
\hline P9 & $\begin{array}{l}\text { Auxilia na geração automática de código a } \\
\text { partir da ontologia. }\end{array}$ & $\begin{array}{l}\text { Conceitualização do problema, geração auto- } \\
\text { mática de código e implementação. }\end{array}$ \\
\hline P10 & $\begin{array}{l}\text { Define um processo para software baseado } \\
\text { em ontologia, associando engenharia de on- } \\
\text { tologia, Engenharia de Software e práticas } \\
\text { Scrum. }\end{array}$ & $\begin{array}{l}\text { OntoSoft tem } 23 \text { atividades divididas em ge- } \\
\text { renciamento, pré-desenvolvimento, desenvolvi- } \\
\text { mento e pós-desenvolvimento. }\end{array}$ \\
\hline
\end{tabular}

Os dados foram apresentados no formato de tabela com a finalidade de indicar as principais características dos dez processos para desenvolvimento de software baseado em ontologia de maneira sucinta. Por meio da sumarização realizada, observa-se que embora a pesquisa para apoiar o desenvolvimento de software baseado em ontologia esteja crescendo, poucas orientações têm facilitado a associação entre os artefatos do software e o artefato ontologia. No que concerne à resposta para a questão de pesquisa desta revisão sistemática, as principais contribuições dos processos identificados são:

- Engenharia de software: todos os processos abordam algumas das principais fases do ciclo de vida do software, em especial análise, projeto e manutenção.

- Uso de ontologias: todos os processos utilizam ontologias em estágios específicos, de 
Tabela 12 - Aplicação das ontologias nos estudos e fases da Engenharia de Ontologias que são adaptadas/utilizadas em cada processo.

\begin{tabular}{lll}
\hline \hline Processo & Aplicação das ontologias & Engenharia de ontologias: fases \\
\hline \hline P1 & $\begin{array}{l}\text { As ontologias são o núcleo do processo de desen- } \\
\text { volvimento. }\end{array}$ & $\begin{array}{l}\text { Aquisição de conhecimento, conceitua- } \\
\text { lização e implementação. }\end{array}$ \\
\hline P2 & $\begin{array}{l}\text { O especialista em domínio define a ontologia de } \\
\text { domínio e a essência do conhecimento do domí- } \\
\text { nio. }\end{array}$ & $\begin{array}{l}\text { Ontologias são usadas em todas as fa- } \\
\text { ses. }\end{array}$ \\
\hline P3 & $\begin{array}{l}\text { A criação das ontologias é definida na fase inicial } \\
\text { do projeto. }\end{array}$ & $\begin{array}{l}\text { Análise, projeto, implementação e inte- } \\
\text { gração. }\end{array}$ \\
\hline P4 & $\begin{array}{l}\text { As ontologias são aplicadas para atualizar o mo- } \\
\text { delo de regras de negócios. }\end{array}$ & Análise, arquitetura e implementação. \\
\hline P5 & $\begin{array}{l}\text { A ontologia permite a interoperabilidade entre } \\
\text { plataformas heterogêneas e serve como um mo- } \\
\text { delo de representação do conhecimento. }\end{array}$ & $\begin{array}{l}\text { Modelagem, projeto e e desenvolvi- } \\
\text { mento. }\end{array}$ \\
\hline P6 & $\begin{array}{l}\text { A ontologia de domínio é usada como um modelo } \\
\text { de software para capturar o conhecimento válido } \\
\text { para um determinado tipo de domínio. }\end{array}$ & $\begin{array}{l}\text { Preparação, requisitos e implementa- } \\
\text { ção projeto. }\end{array}$ \\
\hline P7 & $\begin{array}{l}\text { O uso de ontologias fornece alta flexibilidade } \\
\text { para a integração de aplicativos legados, novos } \\
\text { sistemas e serviços. }\end{array}$ & $\begin{array}{l}\text { Desenvolvimento, raciocinadores e } \\
\text { combinação de ontologias. }\end{array}$ \\
\hline P8 & $\begin{array}{l}\text { Metodologia embasada nos modelos de maturi- } \\
\text { dade em três níveis, a saber, engenharia, foco do } \\
\text { projeto e foco da organização. }\end{array}$ & $\begin{array}{l}\text { Especificação, formalização, imple- } \\
\text { mentação e manutenção. Aquisição, } \\
\text { avaliação e documentação do conheci- } \\
\text { mento são atividades auxiliares. }\end{array}$ \\
\hline P9 & $\begin{array}{l}\text { A ontologia mantém o modelo e o conhecimento } \\
\text { do domínio nos requisitos do sistema. }\end{array}$ & Fases não são definidas na abordagem. \\
\hline P10 & $\begin{array}{l}\text { A ontologia é considerada como um artefato cen- } \\
\text { tral do software. }\end{array}$ & $\begin{array}{l}\text { Especificação, conceituação, aquisição } \\
\text { de conhecimento, implementação e ava- } \\
\text { liação. }\end{array}$ \\
\hline \hline
\end{tabular}

Tabela 13 - Tipo de validação ou avaliação aplicado nos processos identificados.

\begin{tabular}{ll}
\hline \hline Processo & Avaliação \\
\hline \hline P1 & O processo foi validado no contexto de uma empresa. \\
\hline P2 & $\begin{array}{l}\text { Um protótipo de aplicação do processo foi desenvolvido para verificar o fluxo } \\
\text { de trabalho. }\end{array}$ \\
\hline P3 & Não apresenta avaliação. \\
\hline P4 & Um sistema foi definido e aplicado na Universidade de Athabasca. \\
\hline P5 & $\begin{array}{l}\text { O processo foi avaliado por meio da aplicação de } 32 \text { questões, considerando } \\
\text { Engenharia de Ontologias e características da linha de produtos. }\end{array}$ \\
\hline P6 & Não apresenta avaliação. \\
\hline P7 & $\begin{array}{l}\text { Foi desenvolvido um estudo de caso utilizando a abordagem, mas as avaliações } \\
\text { são incompletas. }\end{array}$ \\
\hline P8 & Não apresenta avaliação. \\
\hline P9 & A abordagem e o framework foram aplicados em sites do governo mexicano. \\
\hline P10 & Foram desenvolvidos três estudos de caso utilizando o processo. \\
\hline \hline
\end{tabular}


acordo com as definições e o escopo de cada domínio de aplicação. De maneira geral, elas são consideradas um artefato central e são aplicadas para gerenciar o conhecimento e o modelo de negócio do domínio.

- Engenharia de ontologias: os processos P1 e P5 abordam parte da Engenharia de Ontologias, enfatizando a criação de ontologias nas fases de requisitos e análise. No entanto, não descrevem associações nas fases de atualização e manutenção. O processo P10 apresenta as fases do ciclo de vida de desenvolvimento da ontologia em diferentes cenários de aplicação.

- Inferência: os processos P1 e P5 mencionaram algumas características no fluxo do processo. P1 usa o mecanismo de inferência para acessar a ontologia e a base de conhecimento e P5 refere-se ao motor de raciocínio para as ontologias utilizando JESS.

- Software semântico: os processos P1, P2, P4, P5, P9 e P10 indicam que o software resultante é semântico, isto é, as ontologias automatizam o desenvolvimento de software e a extração de conhecimento por meio de personalização, recomendação ou uso de inferência para derivar novos conhecimentos no sistema.

Em relação à avaliação, a maioria dos estudos estabeleceu um framework ou uma aplicação para avaliar os processos. No entanto, as avaliações foram restritas a um contexto específico e a generalização do processo não foi proposta para outros cenários. A Tabela 14 sumariza as principais informações extraídas dos estudos.

Tabela 14 - Sumarização dos estudos identificados.

\begin{tabular}{lllllll}
\hline \hline Processo & $\begin{array}{l}\text { Engenharia de } \\
\text { Software }\end{array}$ & Ontologias & $\begin{array}{l}\text { Engenharia de } \\
\text { Ontologia }\end{array}$ & Inferência & $\begin{array}{l}\text { Software } \\
\text { mântico }\end{array}$ & Se- \\
\hline P1 & $\checkmark$ & $\checkmark$ & $\checkmark$ & $\checkmark$ & $\checkmark$ & $\checkmark$ \\
P2 & $\checkmark$ & $\checkmark$ & $x$ & $x$ & $\checkmark$ & $\checkmark$ \\
P3 & $\checkmark$ & $\checkmark$ & $x$ & $x$ & $x$ & $x$ \\
P4 & $\checkmark$ & $\checkmark$ & $x$ & $x$ & $\checkmark$ & $\checkmark$ \\
P5 & $\checkmark$ & $\checkmark$ & $\checkmark$ & $\checkmark$ & $\checkmark$ & $\checkmark$ \\
P6 & $\checkmark$ & $\checkmark$ & $x$ & $x$ & $x$ & $x$ \\
P7 & $\checkmark$ & $\checkmark$ & $\checkmark$ & $\checkmark$ & $\checkmark$ & $x$ \\
P8 & $\checkmark$ & $\checkmark$ & $\checkmark$ & $x$ & $x$ & $x$ \\
P9 & $\checkmark$ & $\checkmark$ & $x$ & $x$ & $x$ & $\checkmark$ \\
P10 & $\checkmark$ & $\checkmark$ & $\checkmark$ & $\checkmark$ & $\checkmark$ & $\checkmark$ \\
\hline \hline
\end{tabular}

A partir da análise percebe-se que metade dos estudos definiu algum tipo de associação entre Engenharia de Software e práticas de Engenharia de Ontologias. Todos processos utilizaram ontologias, mas apenas 50\% definiram práticas da Engenharia de Ontologias. A maioria das abordagens não definiu etapas para a criação de ontologias ou metodologia específica, mas apenas sugeriu as atividades de desenvolvimento mais comuns e gerais (conceituação, especificação e implementação). 
Aßmann et al. (2013) propuseram uma associação entre modelagem de software estrutural e modelagem ontológica que pode ser considerada um pré-requisito para o desenvolvimento de software baseado em ontologias. Eles combinam desenvolvimento de software e engenharia de ontologia para garantir que os benefícios computacionais das ontologias possam ser usados para minimizar esforço, tempo e custos no desenvolvimento de software, conforme observado por Uschold (2008).

Com base nessa tendência, as atividades dos processos identificados foram elencadas a fim de visualizar a relação da construção dos artefatos. Na Tabela 15 são ilustradas as fases do ciclo de vida, a área de conhecimento (Engenharia de Software - ES ou Engenharia de Ontologia - EO) e os respectivos processos.

Tabela 15 - Análise das fases definidas pelos processos identificados.

\begin{tabular}{llll}
\hline \hline Fases & Área & Processo & $\%$ \\
\hline \hline Análise (Documentação, Planejamento) & ES & $\begin{array}{l}\text { P1, P2, P4, P5, P6, P8, P9, } \\
\text { P10 }\end{array}$ & 80 \\
\hline Requisitos & ES & P1, P3, P5, P6, P8, P9, P10 & 70 \\
\hline Aquisição de conhecimento & ES & P1, P5, P8, P9, P10 & 50 \\
\hline Conceitualização (base de conhecimento do domínio) & EO & P1, P3, P5, P10 & 40 \\
\hline Modelagem (Projeto) & ES & P2, P3, P5, P6, P7, P8, P10 & 70 \\
\hline Arquitetura & ES & P4, P5, P8, P10 & 40 \\
\hline Engenharia de Ontologia & EO & P1, P5, P7, P10 & 40 \\
\hline Implementação & EO & P8, P9, P10 & 30 \\
\hline Integração & EO & P2, P8, P10 & 30 \\
\hline Gerenciamento de projeto & ES & P1, P8, P10 & 30 \\
\hline \hline
\end{tabular}

Por exemplo, cerca de $80 \%$ dos processos enfatizam a inserção de ontologias na etapa de análise e planejamento e especificação de requisitos para uma maior formalização do domínio, propagação de mudanças e estabelecimento de definições, de acordo com o andamento do projeto. Já fases como arquitetura, integração e gerenciamento de projetos são tratadas por poucos processos e de forma simplificada.

Na fase de implementação, o principal benefício refere-se à capacidade que as ontologias possuem para a extração de informações computacionalmente. Ontologias também podem auxiliar a criação de consultas, automação de manutenção e atualização de outros artefatos no desenvolvimento de software, além de permitir a geração automática de códigos. Somente os trabalhos, P8, P9 e P10 especificam tarefas para o uso das ontologias na implementação do software.

Em relação à Engenharia de Ontologias, de forma geral, os estudos abordam conceituação, especificação e aquisição de conhecimento. No entanto, estas fases não estão relacionadas com as atividades e tarefas do desenvolvimento de software. Esta lacuna deve-se principalmente ao fato de que a aquisição de conhecimento não é uma tarefa trivial.

Vale ressaltar que, no decorrer do desenvolvimento deste trabalho de doutorado estes fatores foram considerados a fim de associar as tarefas para o desenvolvimento dos artefatos 
descrevendo os papeis dos desenvolvedores e cenários de aplicação das ontologias. Concomitantemente a esses aspectos, Pan et al. (2013) apresentam dois desafios: (i) associar modelos de Engenharia de Software e ontologias; e (ii) reduzir problemas da Engenharia de Software por meio do uso de raciocinadores e consultas sobre ontologias.

Estes dois desafios também são tratados neste trabalho de doutorado. Por exemplo, o processo OntoSoft considera as atividades iniciais de elicitação dos requisitos do software e aquisição de conhecimento em sub-equipes. A partir das reuniões diárias e de revisão da sprint, que ocorrem durante o projeto, as atividades são verificadas, a fim de promover a conformidade entre os requisitos e conceitos estabelecidos. Não somente as atividades de gerenciamento supracitadas, mas os raciocinadores dos editores de desenvolvimento da ontologia proporcionam a checagem de consistência e a criação de axiomas e restrições, gerando a visualização de conhecimento implícito nas consultas elaboradas pelo engenheiro de ontologias.

Além de identificar os processos, por meio da revisão também foi possível indicar algumas diretrizes para auxiliar pesquisadores e desenvolvedores de software quando a ontologia é um dos artefatos centrais, com base nas limitações encontradas nos estudos. Na Tabela 16 são sumarizadas algumas soluções propostas para as principais limitações dos estudos que foram discutidas ao longo desta seção.

Tabela 16 - Diretrizes propostas para solucionar algumas das lacunas identificadas nos estudos para o desenvolvimento de software baseado em ontologia.

\begin{tabular}{ll}
\hline \hline Limitação & Solução proposta \\
\hline \hline Generalidade dos processos & $\begin{array}{l}\text { Criar diretrizes mais objetivas e que especifiquem atividades } \\
\text { e tarefas para cada fase definida, tanto para Engenharia de } \\
\text { Software quanto para Engenharia de Ontologias. }\end{array}$ \\
\hline Associação de tarefas & $\begin{array}{l}\text { Guiar o desenvolvimento das atividades por meio de tarefas } \\
\text { bem definidas associando as atividades de Engenharia de } \\
\text { Software e Engenharia de Ontologias. }\end{array}$ \\
\hline Uso de metodologias para atividades & Permitir que nas atividades relacionadas à Engenharia de \\
de Engenharia de Ontologias & $\begin{array}{l}\text { Ontologias o desenvolvedor possa empregar tarefas de meto- } \\
\text { dologias consolidadas e adequadas para o desenvolvimento } \\
\text { das aplicações. }\end{array}$ \\
\hline Avaliação do processo & $\begin{array}{l}\text { Elaborar estudos de caso e experimentos que formalizem as } \\
\text { abordagens definidas em diferentes cenários de aplicação. }\end{array}$ \\
\hline \hline
\end{tabular}

A partir da revisão sistemática conduzida, observou-se que há diversas oportunidades para pesquisas futuras. Três objetivos importantes circundam tanto o desenvolvimento de software quanto o de ontologias, a saber: prover maior qualidade de software, minimizar o tempo de codificação e reduzir custos na equipe de desenvolvimento.

As propostas supracitadas convergem para estes objetivos, pois uma das tendências apresentadas refere-se ao uso das ontologias na geração automática de código, por meio de raciocinadores e inferências. Todos esses desafios de pesquisa têm como objetivo otimizar o tempo de desenvolvimento da equipe por intermédio de tarefas bem distribuídas e da flexibilidade entre atividades no processo de desenvolvimento. 
A partir da revisão sistemática conduzida e das discussões apresentadas, a próxima seção tem o objetivo de sumarizar perspectivas sobre processos de desenvolvimento para software baseado em ontologia, a fim de fundamentar o processo definido neste trabalho de doutorado.

\subsection{Perspectivas para processo de desenvolvimento de software baseado em ontologia}

Conforme discutido neste capítulo, ontologias podem ser usadas por aplicações que exigem um maior nível de formalidade em sua definição. Por exemplo, a catalogação de recursos ou de mapeamento de vocabulários de diferentes fontes de informação necessitam de definições precisas, ou caracterizações importantes que auxiliem na tomada de decisão dos termos para que possam ser utilizados em situações práticas. Nesse sentido, as ontologias permitem adicionar semântica aos dados de modo que diferentes componentes de software possam compartilhar informações de forma homogênea (RODRIGUEZ et al., 2010).

Nessa mesma perspectiva, Aßmann et al. (2013) propuseram a extensão do processo Desenvolvimento de Software Orientado a Modelo (Model-Driven Software Development MDSD) com o uso integrado de ontologias, resultando no desenvolvimento de software orientado a ontologia (Ontology Driven Software Development - ODSD). Nesse processo, modelos de software e ontologias são aliados: as ontologias não são apenas utilizadas na modelagem estrutural, mas também empregadas para tarefas avançadas no desenvolvimento de software. Surge então o software baseado em ontologia, no qual as ontologias são artefatos centrais que mantêm a base de conhecimento.

Aßmann et al. (2013) também afirmam que mais tecnologias podem ser adicionadas a estas fases de desenvolvimento de software, por exemplo, verificação de modelos em tempo real, verificação de modelo probabilístico, interpretações abstratas, e outras técnicas de verificação estática com base em estruturas formais. Essas abordagens não são concorrentes entre si, mas contribuem conjuntamente para o desenvolvimento de software que requer maior consistência. Além disso, a combinação de ontologias e tais tecnologias é similar a ligação entre ontologias e modelos de software. Esta ligação pode colaborar na obtenção de software mais compreensível, com menos erros e mais rápido para o mercado. Na Figura 11 são apresentados quatro aspectos que influenciam no desenvolvimento de software considerando a interação das novas tecnologias na qualidade do software.

Segundo Aßmann et al. (2013), quatro papeis no desenvolvimento são primordiais para desenvolver o software com qualidade: especialista do domínio, engenheiro de software, especialistas em semântica estática (ontologias) e semântica dinâmica. O alinhamento entre as atividades do engenheiro de software e demais papeis é essencial na composição do software baseado em ontologia. Desde o nível do código, as ontologias de domínio e outras ontologias, tais como aquelas que representam as regras de negócios ou modelos de negócios, podem ser 
Figura 11 - Quatro aspectos do desenvolvimento de software considerando a interação e influência das novas tecnologias na qualidade do software.

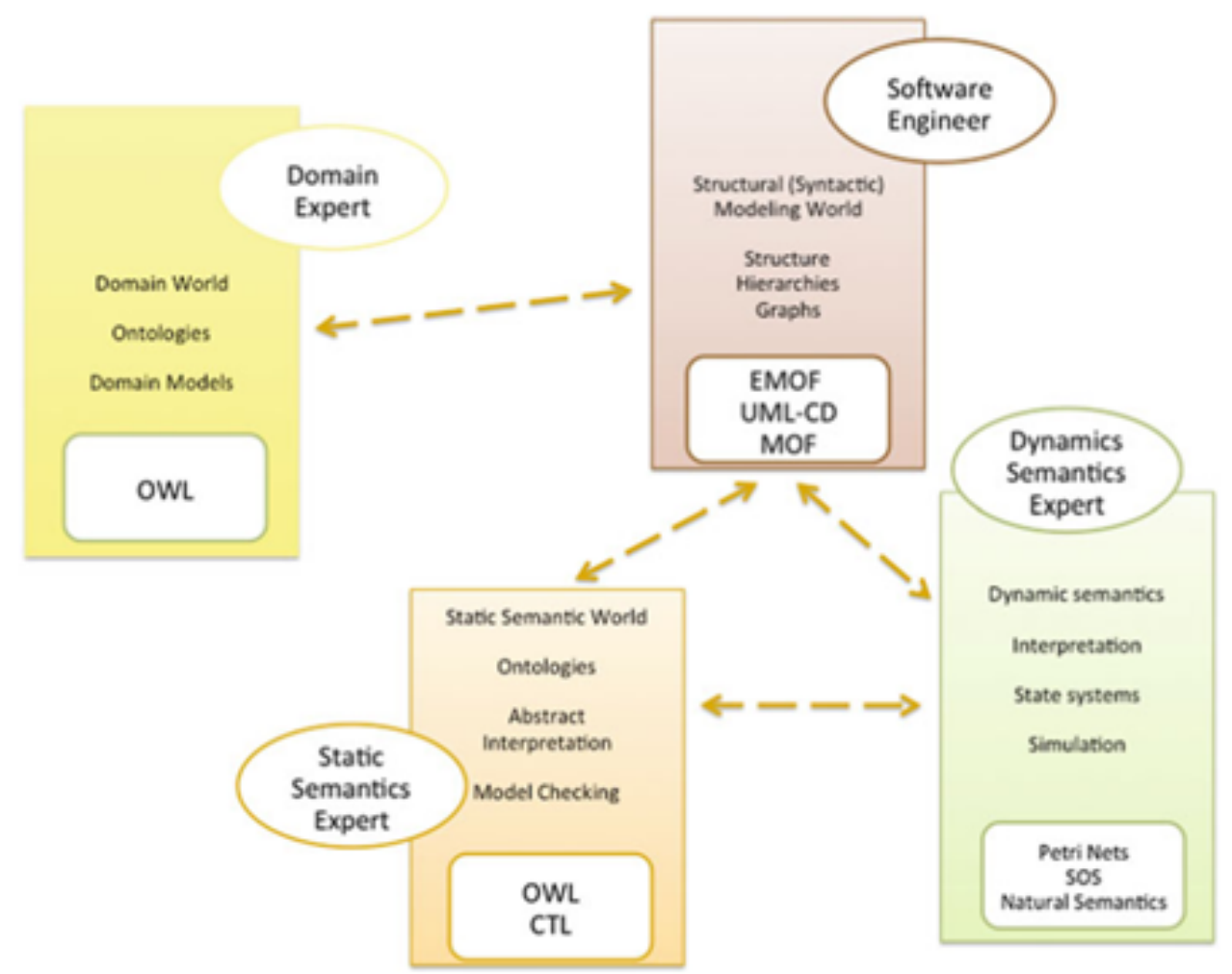

Fonte: Aßmann et al. (2013).

consultadas. Para este fim, os raciocinadores ( reasoners) oferecem interfaces de programação de aplicativo (APIs) para acessar a ontologia e para prestar serviços de raciocínio, inclusive nos editores de ontologias.

No entanto, algumas limitações precisam ser sanadas até que as ontologias possam ser integradas com a modelagem dos artefatos do software. O ideal é que os serviços fornecidos pela ontologia sejam acessíveis, de uma forma simples e integrada. Espera-se que, eventualmente, os serviços da ontologia possam ser utilizados em diversos modelos da cadeia do desenvolvimento do software baseado em ontologia. Para esta integração ocorrer deve ser construída a ligação entre a modelagem de software e da ontologia. Assim, os modelos do "mundo do software" podem ser automaticamente transportados para o "mundo da ontologia", de forma que os serviços das ontologias possam ser executados. Essa correlação e integração são ilustradas na Figura 12.

Aßmann et al. (2013) indicam que aproximar os dois espaços tecnológicos, a modelagem de software e a modelagem de ontologias, é um pré-requisito para o desenvolvimento de software baseado em ontologia. Contudo, a revisão apresentada neste capítulo mostrou que as abordagens atuais ainda não tratam este elo de ligação entre as áreas de pesquisa. Este é um campo de pesquisa emergente, em que muitas empresas procuram adaptar-se à dinamicidade do surgimento das tecnologias e ontologias para conquistarem mais clientes e solucionarem problemas recentes. 
Figura 12 - Associação e integração dos aspectos de modelagem de software e das ontologias.

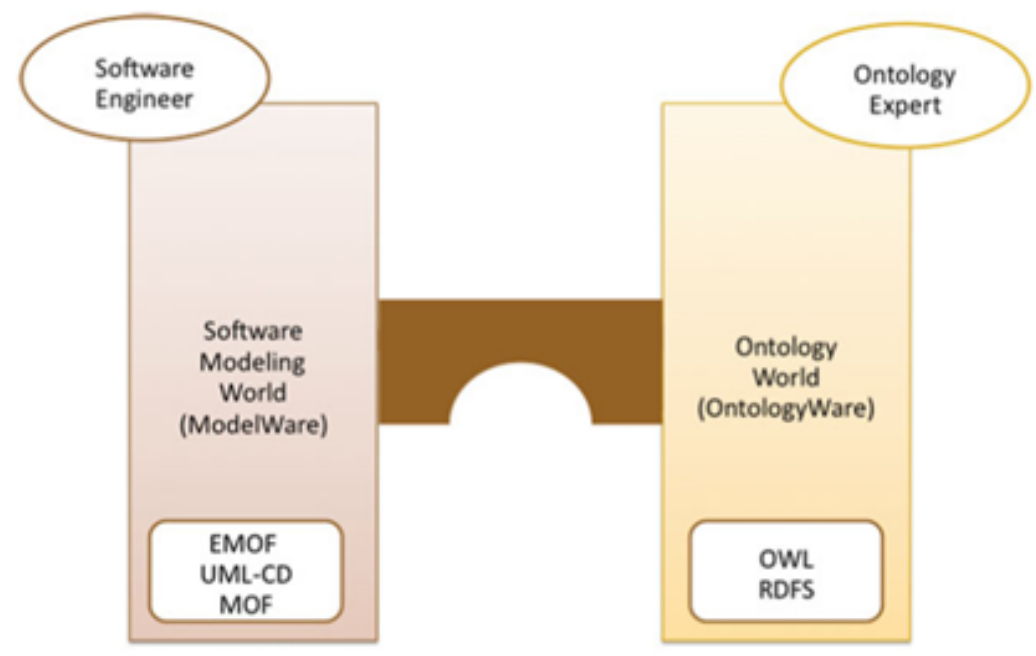

Fonte: Aßmann et al. (2013).

De modo geral, os pesquisadores atuam investigando as tecnologias e como unir o tradicional (processos e modelos da Engenharia de Software) e a novidade tecnológica (as ontologias e as tecnologias semânticas) de forma a prover a qualidade das aplicações e satisfazer as novas necessidades das empresas e de seus clientes. Esta lacuna é tratada neste trabalho de doutorado, em que é proposto um processo de desenvolvimento para software baseado em ontologia considerando os elementos indicados. O processo OntoSoft, apresentado no próximo capítulo, foi definido para suprir algumas dessas necessidades, considerando os desafios, os benefícios e as limitações identificadas na literatura.

\subsection{Considerações finais}

Conforme foi apresentado no decorrer deste capítulo, muitos trabalhos têm definido ontologias para apoiar o desenvolvimento de software. Este fato é decorrente dos desafios para desenvolver software que atenda à evolução das tecnologias atuais. Utilizar ontologias como artefatos de software potencializa as chances para se prover maior formalização, compartilhamento, reúso e integração durante o desenvolvimento, entre outras vantagens.

Nessa direção, ontologias e tecnologias semânticas aplicadas à Engenharia de Software têm proporcionado benefícios como maior qualidade das aplicações, minimização do tempo de implementação, por meio da geração automática de código e, consequentemente, redução de custos. Aliada a esses fatores, a gestão do conhecimento atua diretamente na composição da ontologia e dos demais artefatos de software, conforme foi apresentado no detalhamento dos estudos identificados na revisão sistemática.

Com base nas perspectivas indicadas e na necessidade emergente de auxiliar os desenvolvedores de ontologias e guiar os demais papeis na equipe de desenvolvimento, este trabalho visa 
a definir um processo com atividades e tarefas detalhadas para o desenvolvimento de software baseado em ontologia. Nesta tese de doutorado é descrito o processo OntoSoft, que tem como objetivo associar as tarefas de Engenharia de Software e Engenharia de Ontologias, para guiar os desenvolvedores por meio da definição de cenários, atividades, tarefas, papeis e artefatos ao longo do desenvolvimento do software baseado em ontologia. A definição do processo OntoSoft é descrita no próximo capítulo. 

CAPÍTULO

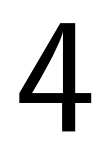

(1)

\section{ONTOSOFT: UM PROCESSO DE DESENVOLVIMENTO ÁGIL PARA SOFTWARE BASEADO EM ONTOLOGIA}

$\mathrm{O}$ ntologias possibilitam geração automática de código e maior acurácia na definição de conceitos e requisitos do software baseado em ontologia. Tais características motivam o uso e revelam o seu impacto em alguns dos principais componentes de um sistema de informação (GUARINO, 1998). Além disso, as ontologias promovem a redução de erros de implementação e minimização do tempo de entrega do produto. Segundo Pan et al. (2013), estes são os principais fatores relacionados ao aumento do uso de ontologias na Engenharia de Software.

Neste trabalho foi definido um processo de desenvolvimento ágil para software baseado em ontologia, o processo OntoSoft, cuja finalidade é guiar o desenvolvimento do software e da ontologia de maneira integrada. O OntoSoft visa reduzir as dificuldades de comunicação entre a equipe e de integração das atividades de desenvolvimento dos artefatos do software, visto que a ontologia é um dos artefatos primordiais neste tipo de aplicação. Adicionalmente, visa minimizar o tempo de desenvolvimento, por meio da definição sistemática de cenários de aplicação, atividades, tarefas, papeis e artefatos relacionados ao software e à ontologia durante o desenvolvimento.

Neste capítulo é apresentada a definição do processo OntoSoft e seus cenários de aplicação. O capítulo está organizado como se segue. Na Seção 4.1 é apresentada a proposta do processo, seguida de uma visão geral da sua criação. Na Seção 4.2 é apresentada a relação do processo OntoSoft com as práticas e valores do método ágil Scrum. Na Seção 4.3 são discutidos e elencados os papeis de desenvolvimento que compõem a equipe no processo. Na Seção 4.4 as fases e atividades do processo são descritas. Na Seção 4.5 os cenários de uso são apresentados e exemplificados para ilustrar o fluxo das atividades do processo. Por fim, as considerações finais 
são discutidas na Seção 4.6.

\subsection{OntoSoft: visão geral}

Durante a condução deste doutorado, algumas das principais atividades do ciclo de vida do software e da ontologia foram consideradas para estabelecer o processo OntoSoft. De maneira geral, as fases propostas foram derivadas de processos utilizados na Engenharia de Software (PRESSMAN, 2010; SOMERVILLE, 2010), da norma ISO 12207 (ISO, 2008) e do núcleo das metodologias mais utilizadas na Engenharia de Ontologias (GOMEZ-PEREZ; CORCHOGARCIA; FERNANDEZ-LOPEZ, 2004; SUÁREZ-FIGUEROA et al., 2012; MIZOGUCHI; VANWELKENHUYSEN; IKEDA, 1995; GUARINO, 1998). Além disso, os princípios ágeis e os valores do método Scrum (SCHWABER; SUTHERLAND, 2011) também foram estudados e considerados no estabelecimento do processo OntoSoft.

O OntoSoft é um processo incremental e iterativo, de modo que os incrementos (ou pequenas partes do software) são gerados ao final de cada sprint e podem ser revisados e atualizados de acordo com o parecer da equipe. Essa característica é facilitada devido ao uso do método ágil Scrum, que auxilia na verificação e validação das entregas de forma contínua.

Associar práticas ágeis ao desenvolvimento de ontologias é um grande desafio, devido à complexidade inerente ao processo de criação de ontologias. A tarefa de estabelecer um domínio compartilhado e gerar conhecimento a partir de uma grande quantidade de informação, em si mesma, é complexa e requer tempo e esforço da equipe, assim como ocorre no processo de elicitação de requisitos e na construção de um software, por exemplo.

Devido a esses fatores, durante a definição do processo OntoSoft foram identificados três principais cenários de uso, que dizem respeito à sequência das atividades propostas para guiar o desenvolvimento da ontologia durante a execução das atividades dos demais artefatos do software. Os cenários foram descritos a fim de minimizar as dificuldades para estabelecer o fluxo de atividades e para otimizar o tempo de desenvolvimento da equipe, conforme é apresentado na Seção 4.5. Ademais, durante a pesquisa e a execução dos estudos de caso neste doutorado, observou-se que as práticas ágeis podem ser adaptadas e utilizadas com êxito no desenvolvimento de ontologias. Atividades de conceituação do domínio e aquisição do conhecimento, por exemplo, também podem ser fragmentadas em tarefas menores e gerar resultados incrementais.

De maneira geral, o fluxo do processo OntoSoft é iniciado com a elicitação dos requisitos do software e dos principais conceitos da ontologia. Em uma primeira reunião de discussão com a equipe e o cliente são identificados os itens do produto de backlog, considerado um dos primeiros artefatos do processo, como pode ser visto na Figura 13. Esses itens, relacionados à concepção do software, à conceitualização e formalização da ontologia, são extraídos pela equipe, a qual define a precedência de cada item a fim de priorizar as funcionalidades no planejamento da sprint. 
Figura 13 - Fluxo global do processo OntoSoft.

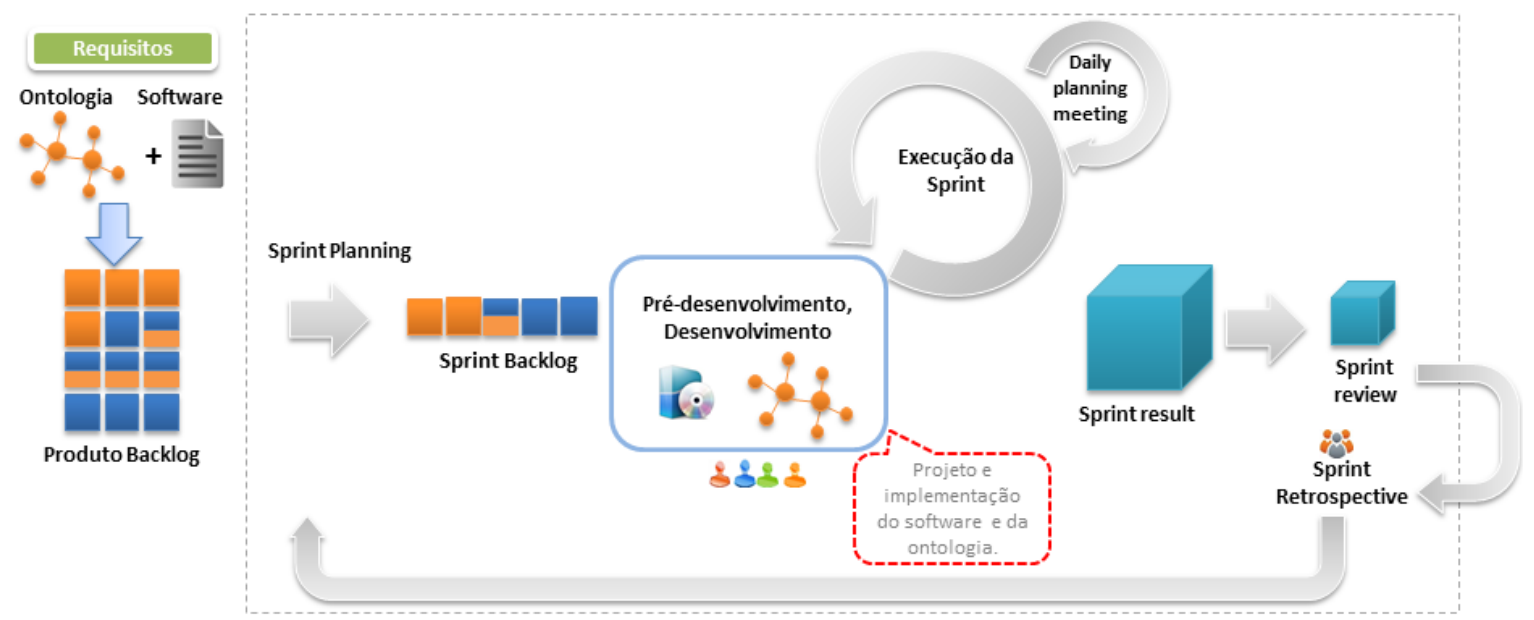

Fonte: Elaborada pela autora.

Após a construção do produto de backlog é feita uma reunião para planejar a sprint (Sprint Planning). Após a identificação dos itens de backlog, ora relacionados à ontologia, ora ao software e ora ao software e à ontologia, são realizadas as atividades de pré-desenvolvimento e desenvolvimento. As atividades são seguidas da reunião de planejamento diária (Daily Planning Meeting) e ao final da execução de cada sprint acontecem a revisão e a retrospectiva da sprint (Sprint Review e Sprint Retrospective).

O OntoSoft é composto por quatro fases principais: (i) Gerenciamento; (ii) PréDesenvolvimento; (iii) Desenvolvimento; e (iv) Pós-Desenvolvimento. As fases do processo estão destacadas na Figura 14, na qual também são indicados os papeis correlacionados e alguns artefatos gerados ao longo das fases do processo.

Além disso, podem ser vistas as iterações graduais e constantes das atividades de Gerenciamento que ocorrem em paralelo ao Pré-Desenvolvimento e Desenvolvimento, fases centrais para desenvolver a ontologia e o software. Também podem ser identificados os principais artefatos gerados no decorrer do processo, como o Sprint Backlog, o projeto do software e da ontologia e, por fim, a ontologia e o software implementados.

As atividades relacionadas ao Pré-desenvolvimento e Desenvolvimento, por exemplo, podem ocorrer de maneira adjacente, de acordo com o Cenário de uso indicado para a aplicação. Independentemente do Cenário, ao final de cada sprint um resultado é incrementado. Dada essa característica incremental, é de suma importância que o Scrum Master tenha em vista os resultados desejados em cada sprint, identificando suas prioridades, para facilitar a evolução do software ao longo de sua execução.

Como parte do processo OntoSoft também foram definidas diretrizes envolvendo atividades e tarefas para cada fase do ciclo de vida do software e da ontologia. Para cada atividade, o processo estabelece as tarefas, os papeis e os artefatos esperados. Dessa forma, os desenvolvedo- 
Figura 14 - Visão geral das principais fases e artefatos do processo OntoSoft.



Fonte: Elaborada pela autora.

res têm maior previsibilidade para planejar as sprints e podem visualizar grandes e pequenas atividades a médio e longo prazo.

Um ponto importante a ser observado refere-se aos casos em que as entregas não estão de acordo com o esperado. Caso seja necessário adaptar ou melhorar o que foi entregue, o ajuste deve ser realizado o mais breve possível para minimizar desvios. No entanto, dada a natureza incremental do processo OntoSoft e o ciclo curto e transparente de desenvolvimento, grandes mudanças têm menor probabilidade de ocorrerem.

Na Figura 15 são apresentadas algumas possíveis sequências de execução para as atividades. Os itens de backlog dão início ao ciclo de vida do software; ao final do ciclo têm-se os artefatos do software e a ontologia finalizados. Caso isso ocorra em um cenário de muitas mudanças, os princípios do Scrum consideram a previsibilidade de problemas, que devem ser solucionados pela equipe com transparência e rapidez a fim de mitigar riscos. Além disso, as atividades de gerenciamento permeiam as demais fases que podem se relacionar iterativamente no processo OntoSoft.

Entre os principais benefícios práticos do processo OntoSoft destacam-se: (i) definir atividades e tarefas claras, objetivas e específicas para cada atividade; (ii) estabelecer papeis para cada atividade; (iii) melhorar a comunicação entre a equipe; (iv) definir cenários de aplicações e fluxo de desenvolvimento; e (v) oferecer entregas mais rápidas e menores a cada iteração do processo. 
Figura 15 - Fluxo das atividades entre as grandes fases do processo OntoSoft.

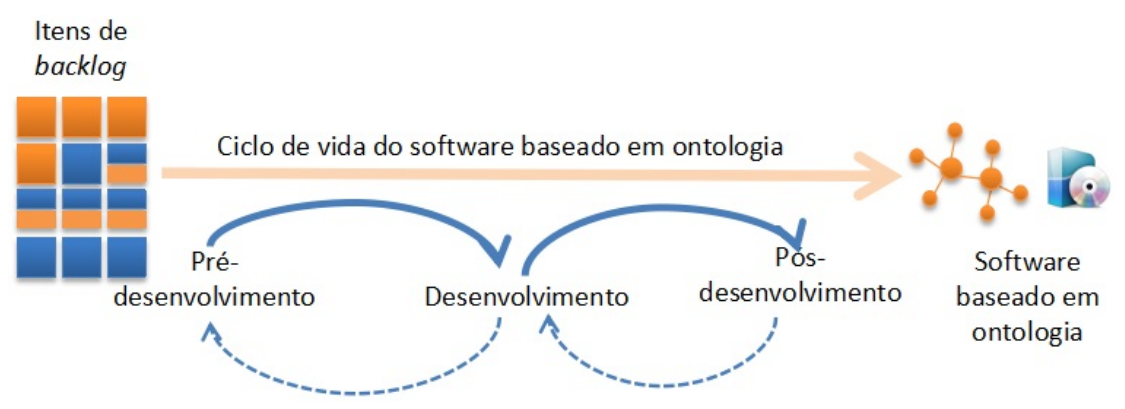

Fonte: Elaborada pela autora.

\subsection{OntoSoft e Scrum}

A escolha do método ágil Scrum (SCHWABER; SUTHERLAND, 2011) para o processo OntoSoft foi motivada em virtude dos benefícios como: entregas rápidas, gerenciamento iterativo e constante, além de prover atividades flexíveis e facilitar a adaptação da equipe. De modo geral, Scrum possibilita a leveza na definição das iterações e propicia a adaptação do processo à realidade da equipe (SCHWABER; SUTHERLAND, 2011). Estas vantagens estão em consonância com os objetivos de empresas e equipes de desenvolvimento de software e podem ser determinantes na escolha de um processo.

Ao utilizar o método ágil Scrum tem-se o objetivo de diminuir a granularidade das tarefas, tornando os ciclos das tarefas menores, podendo ser concluídas entre duas a quatro semanas, conforme a definição de sprint no método (SCHWABER; SUTHERLAND, 2013). Ao fragmentar as atividades tem-se a possibilidade de identificar e prevenir erros ou inconsistências que podem surgir ao longo do desenvolvimento. Nesse sentido, o processo OntoSoft herda tais características, possuindo ciclos curtos de desenvolvimento e planejamento incremental, a fim de aumentar a capacidade de resposta às necessidades de negócio.

Além disso, a inspeção e a adaptação são dois pilares do Scrum (SCHACH, 2011), também empregados no processo OntoSoft. Trata-se de um dos diferenciais de se utilizar métodos ágeis, pois, à medida em que os incrementos são entregues, avaliações são realizadas para verificar a conformidade do produto com os requisitos esperados, com as regras de negócio e com as características do domínio de conhecimento. Esses fatores contribuem para a obtenção de software com qualidade.

Outro aspecto relevante refere-se à complexidade de definir o entendimento comum sobre um determinado domínio, o que é inerente ao processo de construção da ontologia, como analogamente ocorre na especificação de requisitos. Para contornar estas dificuldades iniciais no desenvolvimento da ontologia, o processo OntoSoft propõe uma adaptação na composição da execução das sprints iniciais. Tratam-se das sprints referentes à formalização dos conceitos do domínio, como forma de manter e promover os princípios ágeis na integração das atividades do 
software e da ontologia, bem como evitar discussões desnecessárias para os outros papeis da equipe.

Com respeito à equipe de desenvolvimento, o processo OntoSoft estabelece sua divisão em duas sub-equipes: engenheiros de software e engenheiros responsáveis pelo estabelecimento da ontologia. Dessa forma, atividades específicas e que são independentes entre si podem ocorrer em sprints distintas e seus resultados podem ser discutidos a cada revisão com a equipe completa, já que a Sprint Review acontece no final das sprints.

Essa divisão é estendida ao formato da reunião diária de planejamento. Particionar as equipes proporciona maior agilidade e especificidade às primeiras atividades referentes às ontologias (discussões e reuniões para conceitualização e aquisição de conhecimento). O particionamento das equipes favorece o caráter iterativo das reuniões e não interfere no andamento das demais atividades de projeto do software. Essa divisão entre equipes se faz necessária até que os principais conceitos da ontologia sejam estabelecidos.

A partir do momento em que a conceitualização esteja acordada e as sprints relacionadas finalizadas, os desenvolvedores da ontologia podem ser alocados em outras atividades. Nesse momento não se fazem mais necessárias as sub-equipes para a reunião diária. A equipe deve identificar este momento de acordo com a maturidade da ontologia e as precedências entre as atividades para a aplicação, considerando também o cenário definido.

Nas próximas seções são descritas as fases e as atividades do processo OntoSoft em detalhes, dando ênfase às principais características, tarefas, papeis e artefatos produzidos.

\subsection{OntoSoft: papeis}

No processo OntoSoft, a equipe deve ser composta por papeis multi-disciplinares, a fim de reunir conhecimento e competências para o desenvolvimento do software baseado em ontologia. Conforme foi descrito na revisão sistemática, a maioria das abordagens na literatura não definem os papeis da equipe e suas respectivas funções. No OntoSoft tais papeis foram definidos com base em três categorias, considerando as três áreas que compõem o desenvolvimento de software baseado em ontologia, a saber: (i) engenheiros de ontologias e do conhecimento; (ii) engenheiros de software; e (iii) papeis do Scrum. Desse modo, os papeis estabelecidos no OntoSoft são: cliente, engenheiro de software, engenheiro de ontologias, engenheiro de conhecimento ou especialista do domínio e desenvolvedor. Além disso, também são considerados os papeis específicos do Scrum (SCHWABER; SUTHERLAND, 2011): Product Owner, Time de Desenvolvimento e Scrum Master. Os papeis e suas funções são descritos na sequência:

- Engenheiro de ontologia: responsável por formalizar, construir, manipular e avaliar a ontologia. Auxilia também na formalização do conhecimento e dos requisitos do software, colaborando para a construção da base de conhecimento. 
- Engenheiro de conhecimento ou Especialista do domínio: responsável por definir o domínio da aplicação, por compartilhar o seu conhecimento tácito, por transferir as informações necessárias na elicitação dos requisitos e do domínio de conhecimento para compor os artefatos referentes à ontologia e aos requisitos.

- Engenheiro de software: responsável por construir o software em conformidade com os requisitos esperados e que funcione corretamente. O engenheiro de software acompanha todo o ciclo de desenvolvimento do software baseado em ontologia, contribuindo na geração de artefatos de qualidade e coerentes com os requisitos especificados.

- Time de Desenvolvimento: responsável por determinar como entregar o que o proprietário do produto solicitou. O Time de Desenvolvimento consiste de profissionais que realizam o trabalho de entregar uma versão usável que potencialmente incrementa o produto ao final de cada sprint.

- Product Owner: responsável pelo produto que será desenvolvido e por estabelecer a ordem de prioridade dos itens de backlog a serem entregues. O Product Owner pode representar o desejo de um comitê no backlog do produto. No entanto, é importante observar que se trata de uma pessoa e não de um comitê.

- Scrum Master: responsável por orientar a equipe na criação e acompanhamento de seu próprio processo. Além disso, é responsável por garantir que o Scrum seja entendido e aplicado, sendo também um servo-líder para o time de desenvolvimento Scrum.

\subsection{OntoSoft: fases e atividades}

O processo OntoSoft associa boas práticas da Engenharia de Software e da Engenharia de Ontologias, assim como práticas de gerenciamento do método ágil Scrum (SCHWABER; SUTHERLAND, 2011), para guiar o desenvolvimento de software baseado em ontologia. Estas práticas fornecem diretrizes que consideram o conhecimento dos especialistas e a junção das atividades relacionadas ao desenvolvimento do software e da ontologia de forma integrada.

As atividades de Gerenciamento são responsáveis por: (i) obter os itens de backlog da aplicação; (ii) associar as competências e habilidades aos papeis da equipe; e (iii) guiar as demais atividades na execução do projeto. O Gerenciamento é contínuo e diário, de maneira que a equipe pode fazer as adaptações que forem necessárias a cada reunião diária, assim como na revisão das sprints.

As atividades de Pré-Desenvolvimento e Desenvolvimento correspondem ao núcleo da execução do processo, pois tratam do projeto e do desenvolvimento do software e da ontologia. Elas são apoiadas pelas atividades de Gerenciamento, que fomentam o desenvolvimento das iterações, a fim de garantir maior consistência dos requisitos e artefatos, assim como possibilitar o 
controle de mudanças. Por fim, as atividades de Pós-Desenvolvimento referem-se ao treinamento dos usuários/clientes, atualização e manutenção do software. As atividades para cada fase são ilustradas na Figura 16.

Figura 16 - Atividades definidas para o processo OntoSoft.

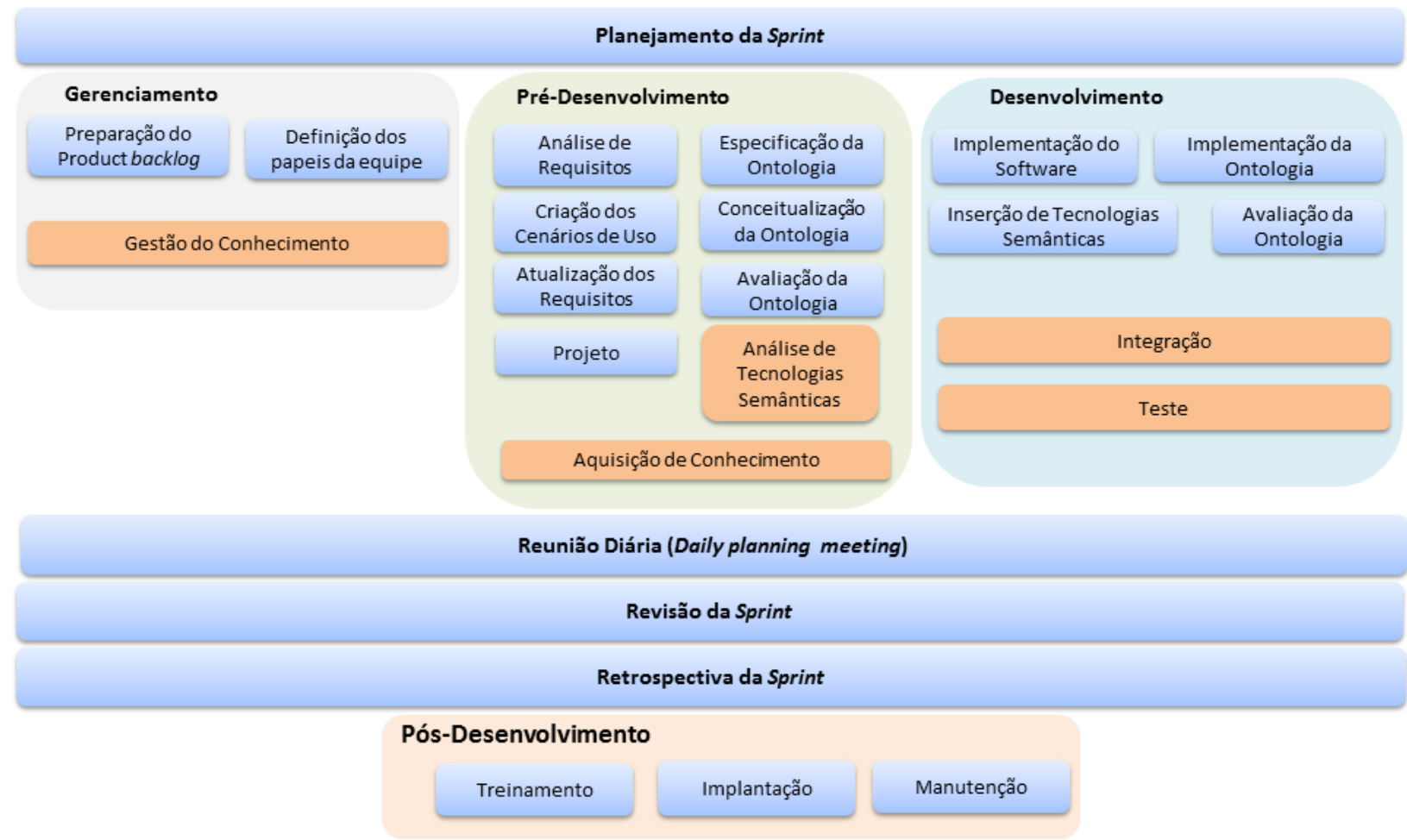

Fonte: Elaborada pela autora.

Além das atividades definidas para cada fase do processo OntoSoft, também foram estabelecidas atividades contínuas, que acontecem ao longo de todo o ciclo do software. São as atividades de gerenciamento vindas do método Scrum e outras cinco atividades que ocorrem em diversos momentos do processo e de maneira continuada, que estão destacadas na Figura 16 e são descritas na sequência.

- Gestão do Conhecimento (Gerenciamento) e Aquisição de Conhecimento (Pré-Desenvolvimento): são atividades contínuas e similares. Segundo Mezghani, Exposito e Drira (2015), o sucesso da Gestão do Conhecimento, especialmente o que se baseia no conhecimento de especialistas, depende fortemente da aceitação das pessoas envolvidas neste processo. Nesse sentido, a colaboração e a participação humanas são necessárias para sustentar a transferência e o compartilhamento de conhecimento de maneira eficiente. Isso é comum também durante a Aquisição de Conhecimento, que pode ser considerada a continuação na Gestão do Conhecimento na fase de Pré-Desenvolvimento. Além disso, essas são atividades que perduram em todo o ciclo de vida do software e na criação de todos os seus artefatos, inclusive a ontologia. 
- Análise de Tecnologias Semânticas (Pré-Desenvolvimento): A tecnologia semântica fornece descrições de dados, programas e infra-estrutura processáveis por máquinas, permitindo que os computadores compreendam sobre esses artefatos (DOMINGUE; FENSEL; HENDLER, 2011). Em outras palavras, são ferramentas e tecnologias como anotação semântica, extração de conhecimento, pesquisa, modelagem e raciocínio (NIXON et al., 2011), que auxiliam na solução de problemas reais. Os desenvolvedores podem elicitar e analisar as tecnologias mais pertinentes no Pré-Desenvolvimento, em conjunto com o levantamento de requisitos e com a formalização do domínio da ontologia. As tecnologias selecionadas servem de apoio para a implementação do software baseado em ontologia.

- Integração (Desenvolvimento) e Teste (Desenvolvimento): Estas atividades ocorrem não somente no Desenvolvimento, mas desde o início do ciclo de vida do software e da ontologia. À medida em que os itens de backlog são identificados e as sprints são definidas, as tarefas podem ser cruzadas e os artefatos gerados servem de entrada para a composição de outros artefatos, em outras atividades. Assim, a atividade de Integração acontece quando os engenheiros de ontologia indicam as tecnologias necessárias para facilitar o desenvolvimento da ontologia e sua manipulação, por exemplo. De maneira análoga, ocorre com a atividade de Teste, que pode ser iniciada desde o início na construção dos primeiros artefatos.

Após apresentar as especificidades das atividades contínuas, que dizem respeito ao domínio de software baseado em ontologia, ao uso de tecnologias semânticas e ao caráter incremental do processo proposto, as grandes fases são descritas com mais detalhes, sumarizando cada atividade e suas respectivas tarefas.

\subsubsection{Gerenciamento}

Esta fase é composta pelas atividades que abrangem o ciclo de vida do software e da ontologia. Especificamente, as atividades referentes ao Scrum (Sprint Planning, Daily Planning Meeting, Sprint Review e Sprint Retrospective) acompanham as demais fases do processo OntoSoft de maneira iterativa e contínua. Estas atividades permeiam todo o desenvolvimento do software e gerenciam as iterações e as atualizações necessárias em cada fase.

As atividades de Gestão do Conhecimento e Daily Planning Meeting são contínuas, ocorrendo em todas as fases do processo. As demais atividades, com exceção da Preparação do Produto de Backlog e da Definição dos Papeis na Equipe, são semicontínuas, ou seja, são executadas em determinados momentos da execução das sprints. A sequência das atividades é apresentada na Figura 17.

A sumarização de cada atividade foi feita com base nas definições propostas no processo OntoSoft e em conformidade com a documentação do Scrum (SCHWABER; SUTHERLAND, 
Figura 17 - Atividades que compõem a fase de Gerenciamento do processo OntoSoft.

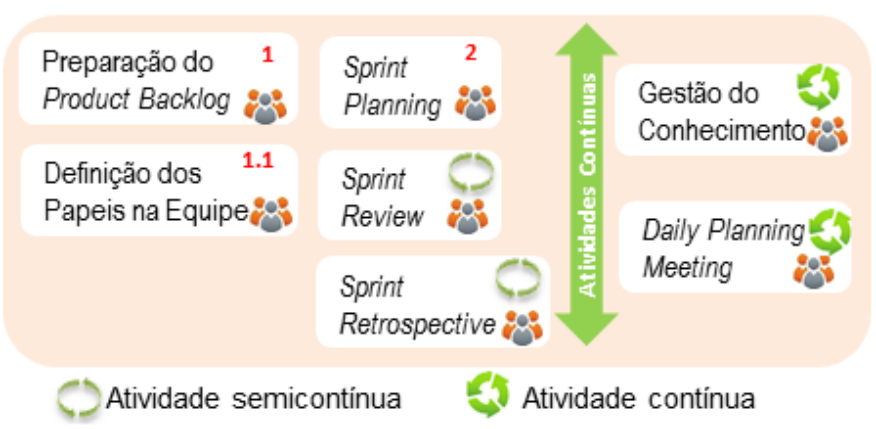

Fonte: Elaborada pela autora.

2011), no que se refere às atividades. A seguir, a descrição de cada atividade e suas respectivas tarefas são apresentadas.

\subsubsection{Preparação do backlog do produto}

A Preparação do backlog do produto é uma reunião em que as funcionalidades requeridas para o produto são identificadas e elencadas em uma lista de prioridades, cujos itens são classificados em ordem de valores estabelecidos pelo cliente. Segundo o manual do Scrum (SUTHERLAND, 2010), o Backlog do Produto evolui ao longo do tempo de vida do projeto e os itens são continuamente adicionados, removidos ou recategorizados.

\section{Tarefas:}

(i) Identificar as principais necessidades do cliente e funcionalidades do software.

(ii) Listar os itens de backlog e associar prioridade a cada item identificado.

\subsubsection{Definição dos papeis na equipe}

Esta atividade é responsável pela definição dos papeis para a equipe, de maneira que as habilidades e competências sejam analisadas durante a escolha. Devem ser considerados na equipe papeis como: especialista do domínio, engenheiro de ontologia e engenheiro de software. Além dos papeis oriundos do Scrum, a saber: Product Owner, Scrum Master e Equipe de Desenvolvimento ou Time Scrum. A documentação do processo OntoSoft disponibiliza um modelo para este artefato, conforme apresentado no Apêndice (??), a fim de facilitar o trabalho dos desenvolvedores.

\section{Tarefas:}

(i) Definir os papeis e as funções necessárias para a execução do projeto.

(ii) Atribuir os papeis aos respectivos membros da equipe. 


\subsubsection{Gestão do conhecimento}

Uma das principais funções da gestão do conhecimento é melhorar a produtividade por meio do compartilhamento e transferência de conhecimento de forma eficaz (LEVY; HAZZAN, 2009). Neste sentido, o Processo OntoSoft insere esta atividade a fim de ressaltar a importância de identificar, além do contexto da aplicação, o conhecimento que envolve esse contexto. Trata-se do conhecimento tácito, que consiste em perspectivas, percepções e valores que tem um papel central na captação e assimilação do conhecimento explícito (LEVY; HAZZAN, 2009).

As subáreas da representação do conhecimento e a Aquisição do Conhecimento foram criadas para fornecer métodos e técnicas para tornar o conhecimento humano compreensível por máquina (DOMINGUE; FENSEL; HENDLER, 2011). Por conseguinte, a Gestão do Conhecimento acontece continuamente nas demais fases do Processo, não somente no Gerenciamento. A Gestão de Conhecimento é composta pela elicitação, empacotamento, gerenciamento e reutilização do conhecimento em todas as suas diferentes formas e, em particular, em artefatos de Engenharia de Software como código, projeto, requisitos, modelos e dados (LEVY; HAZZAN, 2009).

Em virtude de tais características, esta atividade abrange todas as fases do processo OntoSoft. A seguir as principais tarefas correlacionadas são sumarizadas.

\section{Tarefas:}

(i) Identificar o conhecimento envolvido no domínio da aplicação por meio de entrevistas e observação com os stakeholders que dominam o conhecimento a ser formalizado.

(ii) Transformar o conhecimento implícito em explícito, por meio da construção de artefatos do software.

(iii) Definir como mapear e incrementar este conhecimento via software.

(iv) Identificar as prováveis tecnologias semânticas que serão utilizadas no projeto.

\subsubsection{Planejamento da sprint}

No início de cada sprint ocorre a reunião de Planejamento da Sprint para definir as tarefas a serem realizadas. O Product Owner e o Time Scrum, com a facilitação do Scrum Master, reveem o Produto de Backlog, discutem os objetivos e o contexto para definir os itens da sprint (SUTHERLAND, 2010). O Time Scrum seleciona os itens do Produto de Backlog que deverão ser concluídos até ao final da sprint. Por fim, a lista de tarefas é registrada em um documento chamado sprint backlog. As tarefas são apresentadas a seguir, seguindo a documentação do Scrum (SCHWABER; SUTHERLAND, 2011):

\section{Tarefas:}

(i) Reunir a equipe de desenvolvimento e o Product Owner. 
(ii) Escolher os itens de backlog que deverão ser implementados.

(iii) Especificar as tarefas relacionadas ao software e à ontologia que devem ser feitas.

(iv) Definir a prioridade e as procedências nas tarefas da sprint.

\subsubsection{Reunião diária da equipe (Daily Planning Meeting)}

Durante todos os dias de execução da sprint é feita uma reunião diária e breve (aproximadamente 15 minutos) da equipe de desenvolvimento (SCHWABER; SUTHERLAND, 2011). No processo OntoSoft, em que é indicada a divisão da equipe considerando o especialista de domínio e o(s) engenheiro(s) de ontologias, serão duas reuniões, de modo que os engenheiros de software e engenheiros de ontologias discutam separada e paralelamente. Desse modo, pretende-se que os valores de adaptação e inspeção sejam garantidos no projeto, conforme proposto pelo Scrum.

\section{Tarefas:}

(i) Identificar o que foi feito desde a última reunião.

(ii) Planejar o que deve ser feito até a próxima reunião.

(iii) Identificar os problemas e formas de preveni-los para não atrapalhar o progresso do projeto.

(iv) Observar a consistência entre os requisitos e a ontologia.

(v) Gerenciar os riscos identificados.

\subsubsection{Revisão da sprint (Sprint Review)}

Esta é uma reunião que acontece na finalização de cada sprint, com a finalidade de inspecionar e adaptar o produto que está sendo construído. Esta atividade é feita com toda a equipe, incluindo o Time Scrum e os stakeholders convidados pelo Product Owner (SCHWABER; SUTHERLAND, 2013). Todos colaboram indicando o que deve ser feito, fornecendo informações relevantes para a Reunião de Planejamento da próxima sprint. Na sequência as atividades para a equipe de desenvolvimento são descritas, seguindo a documentação do Scrum (SCHWABER; SUTHERLAND, 2011).

\section{Tarefas}

(i) Discutir o que foi bem sucedido durante a sprint, quais problemas e como estes foram resolvidos.

(ii) Apresentar o trabalho que foi finalizado e responder às questões sobre o incremento.

(iii) O Product Owner deve discutir o produto de backlog tal como está. Deve projetar as prováveis datas de conclusão baseando-se no progresso até a data.

(iv) Analisar as mudanças do mercado e o que deve ser feito para mitigar prováveis problemas. 
(v) Analisar a linha do tempo, orçamento, capacidades e mercado para a próxima versão esperada do produto.

\subsubsection{Retrospectiva da sprint (Sprint Restrospective)}

Esta atividade ocorre após a Sprint Review e antes do planejamento da próxima sprint, com o objetivo de inspecionar e adaptar o processo de desenvolvimento. Trata-se de uma oportunidade para o Time Scrum inspecionar a si próprio e criar um plano para melhorias a serem aplicadas na próxima sprint (SCHWABER; SUTHERLAND, 2013). Esta é uma reunião de aproximadamente três horas para sprints de duas a quatro semanas.

\section{Tarefas:}

(i) Inspecionar como a última sprint aconteceu em relação às pessoas, aos relacionamentos, aos processos e às ferramentas.

(ii) Identificar e ordenar os principais itens que foram desenvolvidos e as potenciais melhorias.

(iii) Criar um plano para implementar melhorias de modo que o Time Scrum possa continuar seu trabalho.

\subsubsection{Artefatos gerados na fase de Gerenciamento}

Os artefatos gerados na fase de Gerenciamento servem como base para os artefatos das demais fases do processo OntoSoft. Como são atividades gerenciais, não há obrigatoriedade na geração de artefatos. No entanto, as tarefas podem atualizar os artefatos existentes, de acordo com as necessidades da equipe.

Conforme ilustrado na Figura 18, as atividades de reunião diária, revisão e retrospectiva podem atualizar ou modificar artefatos existentes, mas não produzem novos resultados. A atividade de Preparação do backlog do produto gera o backlog do produto e o documento de visão; a Definição dos Papeis da Equipe gera o documento com essas informações; e a Sprint planning gera o backlog da sprint, ou seja, tratam-se das tarefas referentes aos itens de backlog que devem ser implementados na sprint correspondente.

A fim de facilitar e otimizar os esforços da equipe de desenvolvimento, alguns modelos de artefatos foram propostos e são disponibilizados no processo OntoSoft, conforme pode ser visto no Apêndice A. Além disso, é possível promover a padronização e coerência na documentação do software e da ontologia. No entanto, a equipe pode utilizar seu próprio padrão para os artefatos, caso seja necessário, desde que os modelos possuam o mínimo de descrição para posteriores avaliações e atualizações.

As atividades definidas na fase de Gerenciamento acompanham todo o ciclo de vida do software baseado em ontologia. De modo especial, destaca-se a atividade de Gestão do 
Figura 18 - Fluxo das atividades e artefatos gerados no Gerenciamento do processo OntoSoft.

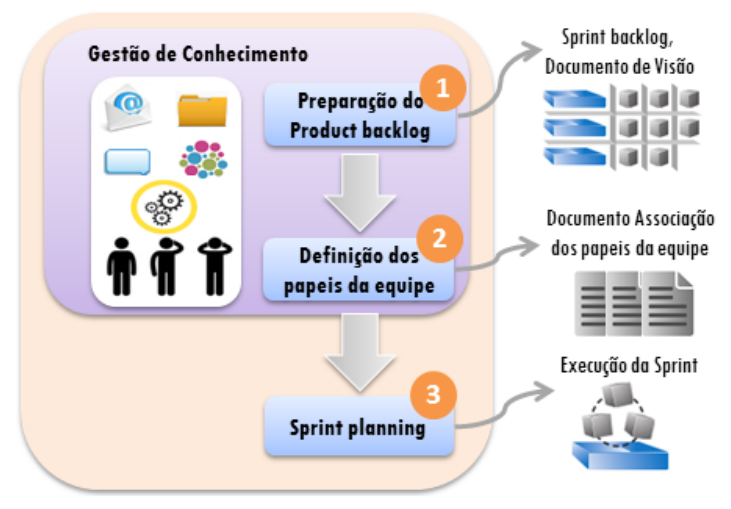

Fonte: Elaborada pela autora.

Conhecimento, que desempenha um papel fundamental e se relaciona com atividades das outras fases. Esta atividade representa um dos diferenciais do processo OntoSoft na formalização e no compartilhamento do conhecimento ao longo do desenvolvimento dos artefatos. Além disso, as atividades referentes ao método ágil Scrum também ocorrem continuamente no decorrer de todas as fases do OntoSoft.

\subsubsection{Pré-desenvolvimento}

No Pré-Desenvolvimento os conceitos chaves da aplicação e os requisitos são identificados, sendo também iniciado o projeto do software e da ontologia. As atividades podem acontecer simultaneamente em uma mesma sprint, em sub-equipes de desenvolvimento distintas ou em mais de uma sprint, em conformidade com a complexidade do domínio da aplicação e do cenário indicado pelo OntoSoft.

As atividades foram escolhidas e definidas de acordo com o núcleo de desenvolvimento de grandes processos na Engenharia de Software (PRESSMAN, 2010; SOMERVILLE, 2010), considerando os princípios e valores do método ágil Scrum (transparência, adaptação e flexibilidade). No que diz respeito às tarefas relacionadas à Engenharia de Ontologias, estas foram elaboradas com base em metodologias como NeOn (SUAREZ-FIGUEROA, 2010), METHONTOLOGY (FERNANDEZ-LOPEZ; GOMEZ-PEREZ; JURISTO, 1997), HCOME (KOTIS; VOUROS, 2006), entre outras, a fim de extrair as atividades comuns e mais importantes para compor as diretrizes do processo. O OntoSoft utiliza, ainda, conceitos relacionados a Ontology Design Patterns (PRESUTTI et al., 2009) para favorecer o reúso e boas práticas no desenvolvimento das ontologias. Na Figura 19 estas atividades são ilustradas.

Conforme é apresentado na Figura 19, as atividades são agrupadas considerando a relação com a Engenharia de Software e a Engenharia de Ontologias. Estas atividades interagem umas com as outras, tendo em vista o papel na equipe de desenvolvimento, os artefatos desenvolvidos e os que são pré-requisitos ou utilizados para as tarefas na execução das sprints. 
Figura 19 - Atividades estabelecidas para a fase de Pré-Desenvolvimento do processo OntoSoft.

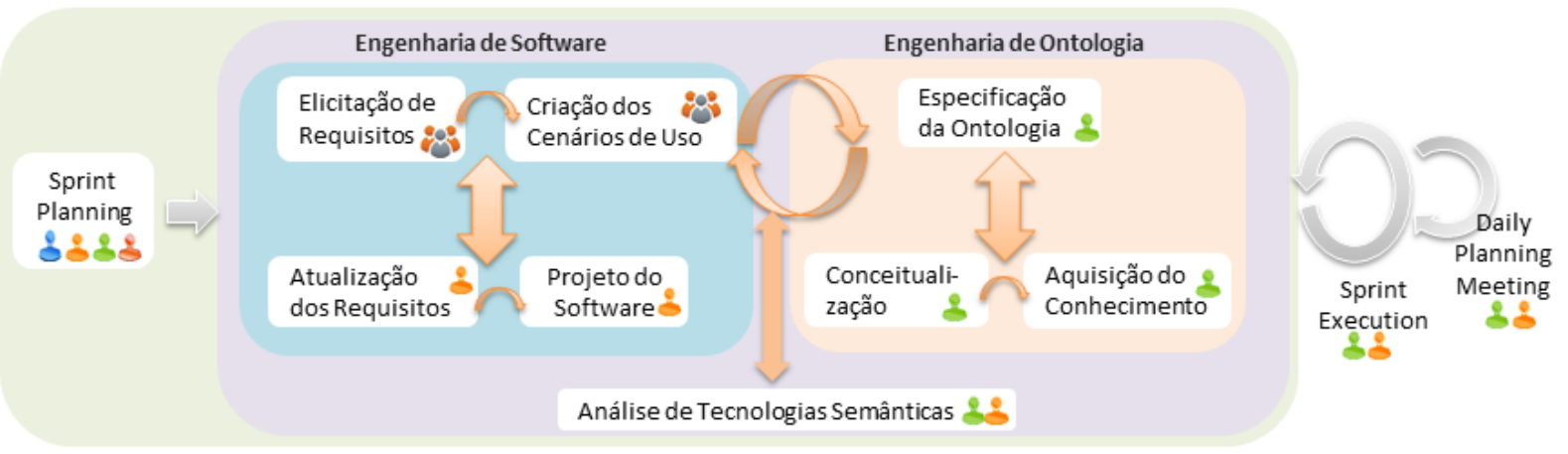

Fonte: Elaborada pela autora.

As atividades de Especificação de Requisitos, Atualização dos Requisitos, Criação de Cenários de Uso e do Projeto do Software são responsáveis por definir o escopo e os requisitos do software, sendo estas funções atribuídas aos engenheiros de software. Tais atividades em conjunto referem-se à concepção do software, desde a definição do projeto e requisitos do software até a conceitualização da ontologia.

A atividade de Projeto do Software merece destaque, pois está relacionada à Análise de Tecnologias Semânticas. Devem ser identificadas tecnologias semânticas e outras tecnologias necessárias para o domínio da aplicação. Inclusive no que concerne à inserção de tarefas relacionadas à pesquisa, escolha, uso e integração destas tecnologias ao software e à ontologia. Além disso, nesta atividade, a equipe pode construir os diagramas de acordo com o escopo da aplicação, tais como: diagrama de caso de uso, diagrama de sequência, de atividades, de componentes.

As atividades de Especificação da Ontologia, Conceitualização e Aquisição do Conhecimento são relacionadas à ontologia e podem acontecer simultaneamente às atividades referentes ao software, de acordo com o cenário especificado. Adicionalmente, as atividades iniciais do desenvolvimento da ontologia colaboram diretamente para a elicitação e definição dos requisitos do software.

O processo OntoSoft indica as principais atividades da formalização e construção da ontologia. No entanto, caso a equipe utilize uma metodologia específica e produza os artefatos básicos para apoiar outras atividades, esta metodologia pode substituir as atividades de Engenharia de Ontologias propostas no OntoSoft. É importante, no entanto, que os passos da metodologia escolhida sejam descritos nas tarefas e nas atividades, de modo que os artefatos correspondentes também sejam indicados.

Duas atividades merecem destaque, a Aquisição do Conhecimento e a Conceitualização, que ocorrem simultaneamente, permitindo o reuso de ontologias, caso seja necessário e em conformidade com o cenário da aplicação. O engenheiro de conhecimento armazena as ontologias relacionadas ao domínio em uma biblioteca de ontologias. Estas poderão ser reutilizadas 
e readaptadas para compor a ontologia da aplicação. O artefato gerado nesta etapa é o esboço da ontologia, o qual pode conter os conceitos relacionados às ontologias importadas na fase de Conceitualização.

A seguir é apresentada a descrição das atividades e suas tarefas do Pré-Desenvolvimento do processo OntoSoft.

\subsubsection{Elicitação de requisitos}

Esta atividade visa definir o escopo e o objetivo do software, a fim de extrair os principais requisitos do software.

\section{Tarefas:}

(i) Investigar as necessidades do cliente.

(ii) Identificar as características do domínio de aplicação.

(iii) Especificar o objetivo e o escopo do software.

(iv) Documentar os requisitos do sistema considerando os conceitos extraídos em um documento, nos Cenários de Uso e no glossário de termos.

\subsubsection{Criação de cenários de uso}

Nesta atividade é possível identificar, junto ao cliente, os prováveis Cenários de Uso do software, com o intuito de facilitar a extração de conhecimento tácito e de requisitos. Nesta atividade diversas ações podem ser tomadas, por exemplo: (i) construção de storyboards de acordo com as discussões realizadas; (ii) elaboração de diagramas de caso de uso para ilustrar os requisitos; (iii) criação de estrutura de tópicos e prioridades das funcionalidades; e (iv) lista de considerações e observações feitas durante a interação com o cliente.

\section{Tarefas:}

(i) Discutir com o cliente quais as principais características esperadas para o software, a fim de identificar as funcionalidades.

(ii) Elaborar Cenários de Uso, diagramas, estrutura de tópicos e/ou storyboards durante as reuniões com o cliente.

(iii) Associar os cenários descritos às funcionalidades requeridas e especificadas na atividade de Elicitação de Requisitos.

(iv) Validar os cenários identificados com a equipe e posteriormente com o cliente. 


\subsubsection{Projeto de software}

As atividades de projeto envolvem a especificação dos casos de uso identificados, bem como a consulta dos Cenários de Uso e do glossário de termos e da ontologia, se necessário. Nesta etapa, os engenheiros de software elaboram diagramas para auxiliar na comunicação da equipe e no desenvolvimento da aplicação. Estes diagramas podem incluir: diagramas de classes, de atividade, de sequência, de colaboração (entre outros), conforme a complexidade do problema e a necessidade da equipe.

Os desenvolvedores também podem consultar o artefato relacionado à Análise de Tecnologias Semânticas, visto que, as tecnologias a serem utilizadas podem impactar no Projeto do Software e as relações entre as tarefas e os artefatos devem ser mapeadas.

\section{Tarefas:}

(i) Definir a linguagem e o ambiente de programação da equipe.

(ii) Modelar o domínio e as regras de negócio da aplicação.

(iii) Especificar os casos de uso do sistema, já identificados nas atividades anteriores.

(iv) Construir os diagramas solicitados pelos engenheiros.

(v) Selecionar os editores adequados para construir os diagramas.

(vi) Analisar as tecnologias semânticas que são indicadas para a aplicação, considerando o Cenário de Uso.

As atividades e tarefas descritas servem de base umas para as outras na fase de Desenvolvimento e, consequentemente, os artefatos resultantes colaboram para a criação de novos artefatos. A consulta de artefatos, associada às reuniões diárias, promove a atualização (quando necessária) dos artefatos e auxilia na manutenção da consistência dos requisitos do domínio da aplicação em desenvolvimento. Por exemplo, o artefato produzido na atividade de Elicitação de Requisitos pode ser consultado (e até mesmo validado) na atividade de Criação dos Cenários de Uso.

As atividades descritas anteriormente são relacionadas ao software; porém, podem consultar atividades e/ou artefatos da ontologia. A seguir são apresentadas as atividades e tarefas relativas ao Pré-Desenvolvimento da ontologia.

\subsubsection{Especificação da ontologia}

Esta atividade é responsável por identificar o domínio e o escopo, assim como o objetivo e o nível de formalização proposto para a(s) ontologia(s).

\section{Tarefas:}

(i) Identificar o objetivo da ontologia. 
(ii) Definir o escopo da ontologia.

(iii) Definir o nível de formalização desejado para construir a ontologia.

\subsubsection{Aquisição de conhecimento}

Essa atividade é uma continuação da Gestão de Conhecimento na fase de Gerenciamento e acompanha o processo em todo o seu ciclo. Segundo Levy e Hazzan (2009), esse conhecimento é dinâmico e evolui de acordo com a tecnologia, a cultura organizacional e as mudanças nas necessidades das práticas de desenvolvimento de software da organização.

A Aquisição de Conhecimento e a Conceitualização acontecem simultaneamente, pois são complementares. Faz-se a definição dos conceitos de acordo com o domínio da aplicação. Especialistas, livros, manuais, figuras, tabelas e outras ontologias são consultados, pois são considerados fontes de conhecimento. Além disso, técnicas como brainstorming, entrevistas, análise formal e informal de documentos podem ser utilizadas para extrair conhecimento (FERNANDEZLOPEZ; GOMEZ-PEREZ; JURISTO, 1997).

\section{Tarefas:}

(i) Mapear as relações entre os conceitos.

(i) Consultar/pesquisar ontologias existentes.

(iii) Analisar os cenários de aplicação sugeridos pelo cliente.

(iv) Importar ontologias, se necessário.

(v) Fazer o esboço da ontologia.

\subsubsection{Conceitualização}

Esta atividade consiste em identificar os conceitos relacionados ao objetivo da ontologia. Essa etapa organiza e converte uma visão informal do domínio em uma especificação semi-formal usando um conjunto de notações facilmente compreendidas (CORCHO; FERNANDEZ-LOPEZ; GOMEZ-PEREZ, 2006). Deve-se consultar ontologias relacionadas ao domínio e, se necessário, a partir das consultas e versões encontradas, criar uma biblioteca de ontologias.

\section{Tarefas:}

(i) Identificar os conceitos e defini-los de acordo com as especificidades do domínio.

(ii) Pesquisar e consultar ontologias existentes.

(iii) Anexar ao esboço da ontologia itens de informação com comentários. 


\subsubsection{Análise de tecnologias semânticas}

Nesta fase os engenheiros de ontologia devem analisar as tecnologias semânticas adequadas para o domínio e o cenário da aplicação. A partir das necessidades identificadas, a equipe define a(s) tecnologia(s) mais adequada(s) para a aplicação. A partir das tecnologias definidas, a equipe investiga e estabelece as ferramentas e aplicações de apoio a serem utilizadas durante o desenvolvimento do software baseado em ontologia.

\section{Tarefas:}

(i) Investigar ferramentas para o desenvolvimento tanto do software quanto da ontologia.

(ii) Analisar as tecnologias indicadas e disponíveis que serão utilizadas para o domínio da aplicação.

(iii) Levantar as características do software que indicam as necessidades e restrições que devem ser associadas à aplicação.

A fase de Pré-Desenvolvimento do processo OntoSoft é composta pelas atividades iniciais e primordiais que dizem respeito à identificação dos conceitos chaves e dos requisitos do software e da ontologia. Os artefatos gerados nessa fase são entrada para a construção dos artefatos nas atividades do Desenvolvimento, a saber: backlog da sprint, modelo de domínio, cenários de uso, especificação de requisitos, glossário de termos, esboço da ontologia, diagrama de casos de uso e demais diagramas necessários.

\subsubsection{Desenvolvimento}

A fase de Desenvolvimento refere-se à implementação do software e da ontologia, bem como à integração de ambos. O processo OntoSoft estabelece as principais atividades que devem ser realizadas, indicando ao desenvolvedor as tarefas necessárias em cada atividade e o fluxo de execução de tais tarefas por meio da definição dos Cenários de Uso no processo. Esse conjunto de tarefas, instruções e recomendações compõe as diretrizes do OntoSoft, as quais descrevem e disponibilizam também modelos de artefatos para a equipe de desenvolvimento. A Figura 20 representa o fluxo global da fase de Desenvolvimento.

Esta fase equivale ao núcleo de desenvolvimento do software baseado em ontologia. Atividades como Implementação, Teste e Integração ocorrem iterativa e continuamente no OntoSoft. Além disso, algumas atividades na fase de Desenvolvimento do software necessitam de vários artefatos de entrada, inclusive para a implementação da ontologia, que desempenha um papel essencial no software.

A atividade de Integração acontece desde o Pré-Desenvolvimento, de maneira que nas atividades de Aquisição de Conhecimento e na Análise de Tecnologias Semânticas os desenvolvedores, ontologistas e engenheiros de conhecimento já investigam e indicam prováveis soluções tecnológicas para apoiar o uso da ontologia e de tecnologias na aplicação. 
Figura 20 - Atividades relacionadas à fase de Desenvolvimento do processo OntoSoft.

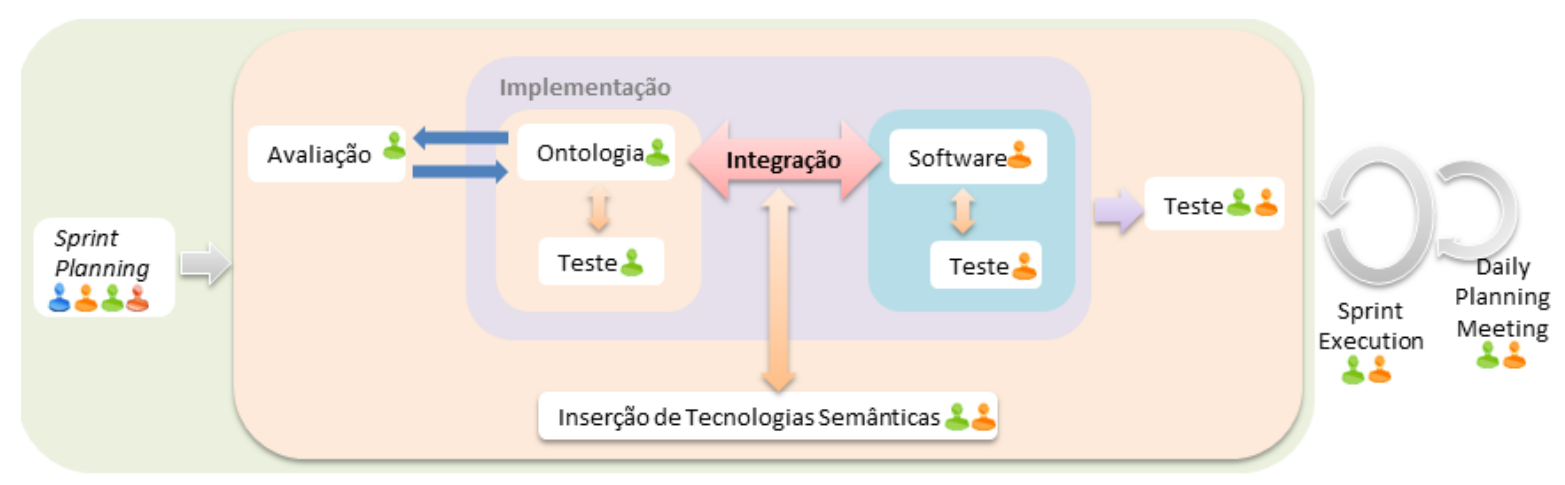

Fonte: Elaborada pela autora.

Essa investigação possibilita aos desenvolvedores identificarem as ferramentas mais apropriadas para o domínio da aplicação, com a finalidade de facilitar a aprendizagem e de prever algumas das configurações técnicas (instalação, adaptação, ferramentas entre outros aspectos envolvidos). Tais tecnologias semânticas, já disponíveis e experimentadas na literatura, tendem a colaborar para: (i) a geração automática de código; (ii) a manutenção da ontologia e dos demais artefatos do software; e (iii) a geração de conhecimento a partir das informações.

No que concerne à manipulação da ontologia, existem ferramentas que extraem as classes (conceitos) e as propriedades (relações e restrições) das ontologias, além de métodos e classes que colaboram para a automatização do código. Esta associação tende a garantir maior consistência entre software e ontologia, além de possibilitar mais agilidade à implementação.

A modelagem da ontologia pode ser feita com ferramentas e técnicas que tornam possível aos especialistas capturarem o conhecimento de um domínio sob um modelo formal. Isso engloba meios para formalizar o conhecimento, construir uma ontologia, avaliá-la e refiná-la, bem como mantê-la e desenvolvê-la (NIXON et al., 2011).

O processo também permite a especialização de tecnologias semânticas no desenvolvimento do software. A atividade Inserção de Tecnologias Semânticas pode ser especificada de acordo com a(s) tecnologia(s) utilizada(s), a(s) qual(is) deve(m) ser iniciada(s) nas fases de Gerenciamento e Pré-Desenvolvimento, na atividade de Análise de Tecnologias Semânticas, em que os stakeholders identificam as prováveis tecnologias para o contexto do software.

O processo OntoSoft contempla atividades referentes ao Teste, de software e da ontologia, visando associar boas práticas de verificação e validação que colaborem para a qualidade do software baseado em ontologia. Para isso, é importante que os requisitos estejam em conformidade com o domínio do conhecimento que está sendo modelado. Estas atividades ocorrem de maneira constante, uma vez que as iterações passam por revisões frequentes, a cada revisão e retrospectiva das sprints. 
A atividade Avaliação da Ontologia é uma atividade contínua, que pode ser aplicada desde a Especificação da Ontologia até a finalização da sua implementação, na fase de Desenvolvimento. A avaliação é feita por meio das diretrizes indicadas na atividade e com base no checklist disponibilizado pelo processo OntoSoft. O objetivo de começar a avaliação no início da especificação é minimizar problemas futuros e construir uma ontologia coerente e extensível.

Com o propósito de manter os compromissos ontológicos, os engenheiros de ontologia podem fazer uma avaliação interna de acordo com os seguintes critérios (GRUBER, 1995): (i) clareza; (ii) coerência; (iii) capacidade de extensão; (iv) mínimo de viés na codificação; e (v) compromisso ontológico mínimo. Para observar se os critérios são cumpridos as seguintes perguntas devem ser respondidas (GRUBER, 1995):

(i) A ontologia é clara cognitivamente?

(ii) A ontologia é coerente com as fontes teóricas?

(iii) A ontologia pode ser facilmente estendida?

(iv) A ontologia é limitada a uma representação específica?

(v) A ontologia é ligada a algum compromisso filosófico?

O ciclo das atividades do software e da ontologia ocorre simultaneamente até determinada parte do desenvolvimento, conforme pode ser visto na Figura 21. No decorrer das atividades de Projeto do Software, a Conceitualização e a Aquisição de Conhecimento já adiantam a formalização dos conceitos e dos axiomas da ontologia, de forma que no início da implementação do software a ontologia já é considerada um artefato finalizado. Além disso, a ontologia é utilizada como parte das entradas para a implementação, como facilitadora na codificação e automatização.

Figura 21 - Linha do tempo de desenvolvimento do software e da ontologia.

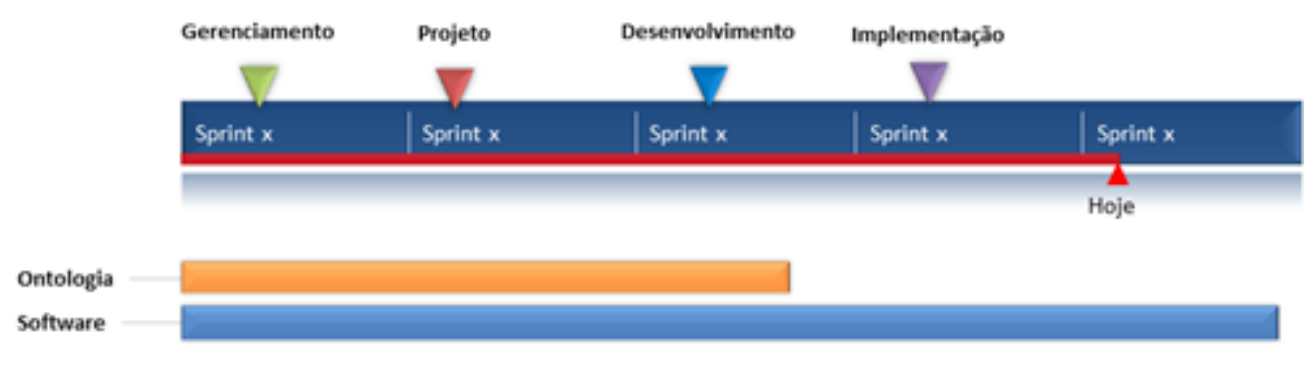

Fonte: Elaborada pela autora.

Durante o desenvolvimento do software, os artefatos já construídos são atualizados à medida em que as mudanças são identificadas nas atividades e execução das sprints. As atividades e as tarefas do Desenvolvimento são especificadas em detalhes a seguir. 


\subsubsection{Implementação do software}

Nesta atividade é iniciada a implementação do software com base nos requisitos, nas decisões tomadas na fase de Pré-Desenvolvimento e nos artefatos já desenvolvidos. Não necessariamente a implementação começará no Desenvolvimento, havendo a possibilidade de que pequenas partes do software sejam desenvolvidas já no início, de acordo com a especificação e as prioridades dos itens de backlog.

\section{Tarefas:}

(i) Implementar as regras de negócio de acordo com os requisitos e os modelos estabelecidos nas atividades.

(ii) Manipular a ontologia para extrair dados do domínio da aplicação.

(iii) Considerar os artefatos de entrada para as tarefas estabelecidas pela equipe de desenvolvimento.

(iv) Realizar as tarefas de integração utilizando as ferramentas e as tecnologias propostas pela equipe de desenvolvimento.

\subsubsection{Teste de software}

O objetivo da atividade de Teste de Software é garantir a conformidade com a especificação, considerando tanto o modo pelo qual o software é desenvolvido quanto o produto gerado (DELAMARO; MALDONADO; JINO, 2007). Esta atividade não se restringe ao produto final, mas pode e deve ser conduzida ao longo do processo de desenvolvimento do software. As tarefas são apresentadas em nível macro, a fim de direcionar as escolhas dos desenvolvedores.

\section{Tarefas:}

(i) Planejar: criar um documento de teste especificando técnicas, critérios e ferramentas que serão utilizados.

(ii) Projetar: definir os casos de teste com base nos critérios do planejamento.

(iii) Executar: executar o software com as entradas definidas nos casos de teste e coletar a saída produzida pelo software.

(iv) Analisar: verificar se as saídas obtidas são iguais às esperadas e quando forem diferentes verificar se a falha está relacionada a um defeito nos casos de teste ou ao software.

\subsubsection{Implementação da ontologia}

Nesta atividade a ontologia é desenvolvida, considerando as atividades de Conceitualização, Especificação e Aquisição de Conhecimento, as quais foram elaboradas na fase de Pré-Desenvolvimento.

\section{Tarefas:}


(i) Escolher uma ferramenta para a implementação da ontologia.

(ii) Formalizar a especificação.

(iii) Comparar versões (caso existam).

(iv) Verificar a consistência das restrições e dos axiomas da ontologia.

\subsubsection{Teste da ontologia}

Nesta atividade são feitos os testes da consistência dos requisitos e da formalização da ontologia, que deve acontecer no decorrer do desenvolvimento. Os testes acontecem durante a formalização em que os conceitos, restrições e axiomas são definidos.

O raciocinador infere novos conhecimentos a partir da base de dados semânticos, das instâncias e dos axiomas (NIXON et al., 2011). Os raciocinadores desempenham um papel essencial sempre que a inferência ou validação semântica é necessária e, por isso, atuam diretamente na verificação e no teste da consistência das ontologias.

\section{Tarefas:}

(i) Verificar a consistência do software e da ontologia.

(ii) Verificar a coerência dos conceitos de acordo com os requisitos e cenários de uso.

(iii) Iniciar o raciocinador em cada atualização da(s) ontologia(s).

\subsubsection{Inserção de tecnologias semânticas}

As áreas de Representação do Conhecimento e Aquisição de Conhecimento se concentram em capturar o significado dos dados de uma maneira processável por máquina e fornecer o contexto histórico a partir do qual a tecnologia semântica foi desenvolvida (DOMINGUE; FENSEL; HENDLER, 2011).

Nesta atividade os desenvolvedores devem inserir as tecnologias que foram analisadas e indicadas para a aplicação. Ferramentas para manipular a ontologia podem ser utilizadas para facilitar a anotação semântica, extração de conhecimento, pesquisa, modelagem e raciocínio.

\section{Tarefas:}

(i) Selecionar as tecnologias apropriadas para a aplicação.

(ii) Providenciar a instalação das ferramentas associadas às tecnologias.

(iii) Implementar a biblioteca escolhida para gerenciar/manipular as ontologias, se necessário. 


\subsubsection{Integração}

A atividade de Integração acontece ao longo de grande parte das atividades do processo OntoSoft, de modo que desde o Pré-Desenvolvimento a equipe já pode mesclar e consultar as tarefas em diferentes atividades, conforme o planejamento especificado nas sprints. Nesta atividade as primícias da aplicação são acordadas e/ou revisadas, com a finalidade de integrar os artefatos, as tecnologias semânticas e as atividades referentes à implementação. Por exemplo, a consulta de artefatos concluídos é uma prática importante para colaborar na geração de novos artefatos, assim como para manter a consistência das decisões deliberadas.

\section{Tarefas:}

(i) Consultar os artefatos de entrada sugeridos na geração de novos artefatos.

(ii) Utilizar as tecnologias semânticas indicadas nas atividades anteriores para manipular a ontologia via software.

(iii) Estimar um tempo para o aprendizado da equipe no que concerne às novas tecnologias e configurações técnicas necessárias a serem estabelecidas.

Por fim, é importante observar que a fase de Desenvolvimento acontece ao longo do ciclo de vida do software, devido aos princípios ágeis aplicados pelo processo OntoSoft. Um dos princípios refere-se à entrega contínua para o cliente na finalização de cada sprint, de maneira que a cada incremento o cliente pode visualizar os requisitos implementados nas tarefas dos desenvolvedores. Consequentemente, as atividades desta fase podem ser iniciadas em outros momentos do ciclo de vida do software, não somente na atividade de Implementação da ontologia e do software.

Os artefatos desta etapa referem-se à implementação do software e da ontologia. Além disso, os artefatos que servem como entrada para as atividades nesta fase também são utilizados e atualizados se necessário. Os artefatos que podem ser incrementados são: modelo de domínio, especificação de requisitos, glossário de termos e ontologia.

\subsubsection{Pós-Desenvolvimento}

Na fase de Pós-Desenvolvimento é feita a implantação do software, bem como o treinamento dos usuários. A atividade de manutenção é necessária para identificar melhorias, de acordo com a exigência do cliente.

A ideia é que não sejam necessárias muitas atualizações, pois as atividades de gerenciamento do Scrum permitem que inconsistências sejam identificadas ao longo do desenvolvimento, gerando correções e atualizações dos sprints em andamento ou em uma próxima iteração, antes que os incrementos sejam entregues ao cliente. Além disso, a entrega gradual do software deve 
acarretar um menor número de incoerências com os requisitos, pois o contato frequente com o cliente proporciona resultados que são gradativamente incrementados ao negócio.

As atividades e as tarefas correspondentes à fase de Pós-Desenvolvimento do processo OntoSoft são descritas a seguir.

\subsubsection{Treinamento}

Essa atividade consiste em treinar os usuários, por meio da apresentação das funcionalidades do software, entrega de manual e, se preciso, tutorial de uso do software baseado em ontologia.

\section{Tarefas:}

(i) Apresentar o software aos usuários.

(ii) Treinar as equipes dos usuários.

\subsubsection{Implantação}

Nesta atividade é feita a implantação do software para o cliente. Provavelmente, o cliente já terá uma familiaridade com o software, em virtude das pequenas entregas realizadas ao final de cada sprint durante a execução das atividades do processo OntoSoft, facilitando, assim, a adaptação dos usuários.

\section{Tarefas:}

(i) Gerenciar a instalação do software e seus requisitos técnicos.

(ii) Considerar a necessidade de ativar e desativar ferramentas que devem ser acopladas ao software baseado em ontologia (extensões se forem necessárias).

(iii) Implantar o software baseado em ontologia.

\subsubsection{Manutenção}

Nesta atividade são realizadas atualizações e modificações identificadas pelo cliente. Como o processo OntoSoft é iterativo, incremental e utiliza uma abordagem ágil de gerenciamento, espera-se que não sejam requeridas muitas modificações após a entrega do software para o cliente.

\section{Tarefas:}

(i) Identificar e corrigir as inconsistências no software.

(ii) Atualizar os artefatos necessários após as modificações. 


\subsection{Cenários para a aplicação do processo OntoSoft}

Conforme identificado na revisão sistemática, a maioria dos processos para software baseado em ontologia são genéricos, não definem atividades ou tarefas de modo detalhado e não integram as tarefas relacionadas à Engenharia de Software e Engenharia de Ontologia. O processo OntoSoft foi definido para cobrir esta lacuna de pesquisa, visando orientar o desenvolvimento de software baseado em ontologia, de forma ágil e com diretrizes detalhadas para o desenvolvedor.

O OntoSoft fornece para a equipe de desenvolvimento um guia das atividades, tarefas, papeis e modelos de artefatos na construção do software baseado em ontologia. Com base nessas definições, a partir da proposição das atividades no processo OntoSoft, verificou-se que a execução das sprints contempla distintas sequências de atividades e tarefas, que variam de acordo com o cenário correspondente para cada software ou aplicação.

De forma geral, essas diferenças devem-se à complexidade do domínio da aplicação. Além disso, a construção das ontologias pode ser considerada complexa e demandar mais ou menos tempo do que o previsto, dependendo de fatores como: (i) o contexto da aplicação; (ii) o domínio a ser especificado; (iii) e o nível de conhecimento dos engenheiros de ontologia. A partir dos indicativos da pesquisa e da definição do OntoSoft foi possível identificar que existem diferentes cenários para distintas sequências de atividades no desenvolvimento de software baseado em ontologia.

Desse modo, no processo OntoSoft foram definidos três principais cenários de desenvolvimento para aplicações que têm a ontologia como um artefato principal, a saber: cenário i: a ontologia é considerada o núcleo de uma aplicação simples; cenário ii: a ontologia é reutilizada para o desenvolvimento de uma aplicação; e cenário iii: a ontologia é utilizada para construir um framework que servirá de base para apoiar os demais sistemas de uma organização, ou seja, na construção de uma plataforma semântica. Estes cenários são sintetizados na Figura 22.

Figura 22 - Cenários de uso definidos no processo OntoSoft para software baseado em ontologia.
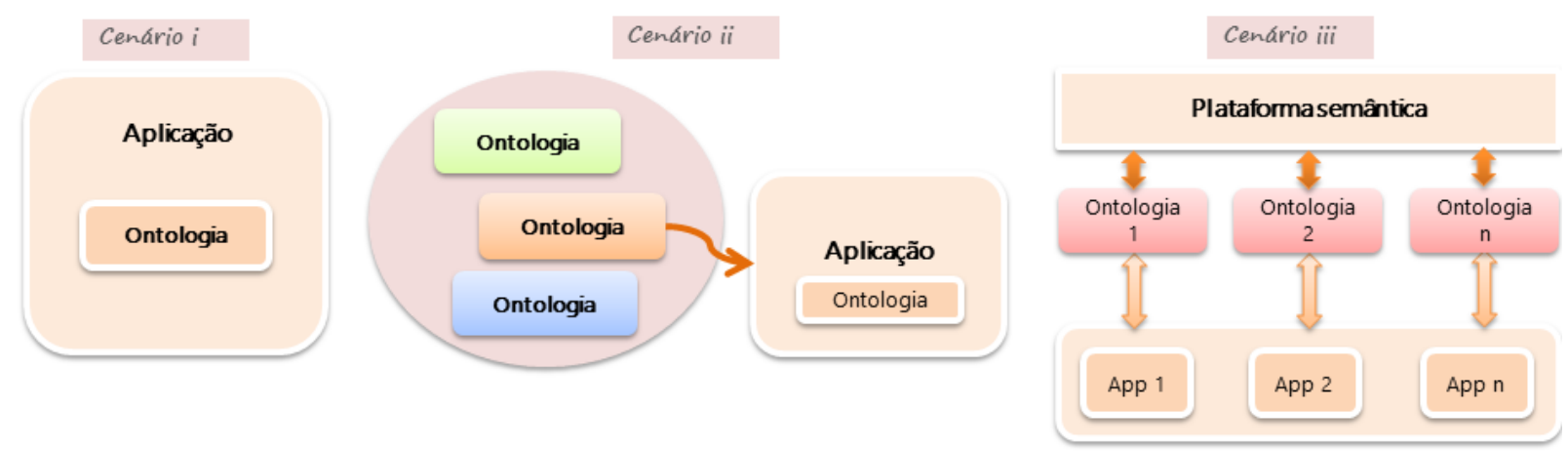

Fonte: Elaborada pela autora.

Os cenários foram definidos pois, em virtude da complexidade já mencionada, a ordem e o tempo de duração de algumas atividades acontecem de maneira distinta nas fases de Pré- 
Desenvolvimento e Desenvolvimento no OntoSoft. Além disso, algumas das atividades do projeto e desenvolvimento do software dependem do artefato ontologia. Se, por um lado, gasta-se mais tempo nas atividades relacionadas à ontologia, por outro lado, a extração de requisitos e a construção de cenários de uso são otimizadas a partir da base dos conceitos identificados na ontologia.

$\mathrm{Na}$ Figura 23 é ilustrada a relação entre as atividades do software e da ontologia ao longo da execução do processo OntoSoft. Do início ao fim há iteração entre as atividades, conforme previsto e especificado no OntoSoft. A barra laranja indica a duração das atividades relacionadas somente à ontologia e a barra verde relacionada ao software. As setas fazem referência à dependência e/ou comunicação entre as atividades e a relação entre os artefatos ao longo das fases.

Figura 23 - Iteração entre as atividades referentes ao software e ontologia no decorrer do processo.

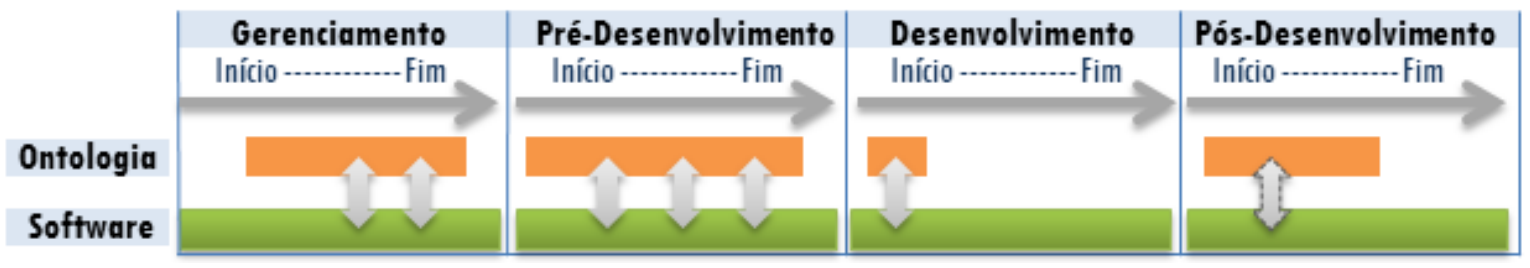

Fonte: Elaborada pela autora.

A partir da Figura 23, pode-se inferir que na fase de Gerenciamento, enquanto os principais requisitos e itens de backlog são identificados, o engenheiro de ontologias já inicia um esboço dos termos que fazem parte do domínio e que irão compor o glossário de termos. Há uma inter-relação entre as atividades software-ontologia, a partir, aproximadamente, da metade do ciclo das atividades do software.

Com relação à fase de Pré-Desenvolvimento, as atividades da equipe são subdivididas em duas equipes, uma equipe para desenvolver os artefatos do software e outra para projetar/especificar a ontologia. Por isso, a relação constante e contínua durante a fase, conforme apresentado na Figura 23 por meio das setas e dos quadros de desenvolvimento para a ontologia e para o software. À medida em que os artefatos são construídos, estes servem de entrada para outros artefatos da mesma sub-equipe ou para outra sub-equipe. Assim, os artefatos do software podem embasar os artefatos iniciais da ontologia, e vice-versa.

O quadro referente à fase de Desenvolvimento, na Figura 23, indica que a ontologia provavelmente estará finalizada nesta fase do OntoSoft. A ontologia será vinculada ao software, ou seja, será um artefato de entrada para outros artefatos, inclusive como parte do código fonte da aplicação. As associações são feitas com base nas especificações dos desenvolvedores para o domínio da aplicação e de acordo com as tarefas e tecnologias semânticas associadas.

Nesse ponto, vale ressaltar que os engenheiros de ontologia e os demais envolvidos na construção da ontologia podem ser alocados para outras atividades, conforme suas habilidades e 
a demanda que a aplicação exigir. Além disso, essa realocação de papeis na equipe de desenvolvimento tende a contribuir com a Gestão do Conhecimento no cenário da aplicação, possibilitando a otimização de tarefas e atividades na execução do processo OntoSoft.

No Pós-Desenvolvimento pode ou não haver a relação entre os artefatos do software e a ontologia. Espera-se que nessa fase a ontologia ou os requisitos não precisem ser revisados. No entanto, caso isso aconteça, serão necessárias grandes mudanças, o que pode indicar retrabalho no software. A seta tracejada sugere uma relação opcional entre os artefatos, indicando que no início da manutenção podem ocorrer mudanças que envolvam artefatos do software, inclusive a ontologia.

As alterações tendem a ser reduzidas e mais simples no software que está sendo implantado, devido às entregas contínuas que ocorreram durante as atividades do processo OntoSoft, que é iterativo e incremental. O fato da entrega ser contínua durante o processo minimiza os impactos e atualizações na implantação do software, uma vez que a relação com o cliente é mais estreita no decorrer da execução das sprints no processo OntoSoft.

Independentemente do cenário adotado pela equipe de desenvolvimento, o panorama global da construção da ontologia e dos demais artefatos do software tem o núcleo de desenvolvimento conforme foi descrito nos parágrafos anteriores. Contudo, ocorrem mudanças no fluxo das atividades para cada cenário, em conformidade com as prioridades dadas pela equipe e em virtude da complexidade do domínio da aplicação.

A abordagem de ter um núcleo comum de atividades no processo OntoSoft tem como objetivo auxiliar a equipe de desenvolvimento no momento do planejamento das sprints, por meio de uma visão global dos fluxos das atividades do processo, de forma a facilitar a indicação de prioridade dos itens de backlog envolvendo a integração dos artefatos da ontologia e do software. Na Figura 24 é apresentado o fluxo geral do processo OntoSoft, referente ao primeiro cenário, em que a ontologia é desenvolvida primeiramente, conforme será especificado na próxima seção.

O fluxo apresentado na Figura 24 corresponde ao primeiro cenário descrito no processo OntoSoft, em que a ontologia e os demais artefatos do software são construídos em paralelo. As atividades em destaque Gestão do Conhecimento, Aquisição do Conhecimento, Análise

de tecnologias semânticas, Integração e Teste acontecem continuamente no processo, como ilustrado nos quadros que indicam as fases em destaque na figura. As atividades podem acontecer em sprints distintas ou não. A equipe de desenvolvimento é responsável por seguir ou alterar o fluxo sugerido, com base no cenário e no contexto da aplicação.

Nas próximas seções os cenários são apresentados com mais detalhes e são instanciados a fim de facilitar a compreensão do fluxo das atividades propostas. 
Figura 24 - Fluxo padrão das atividades no processo OntoSoft - Cenário i.

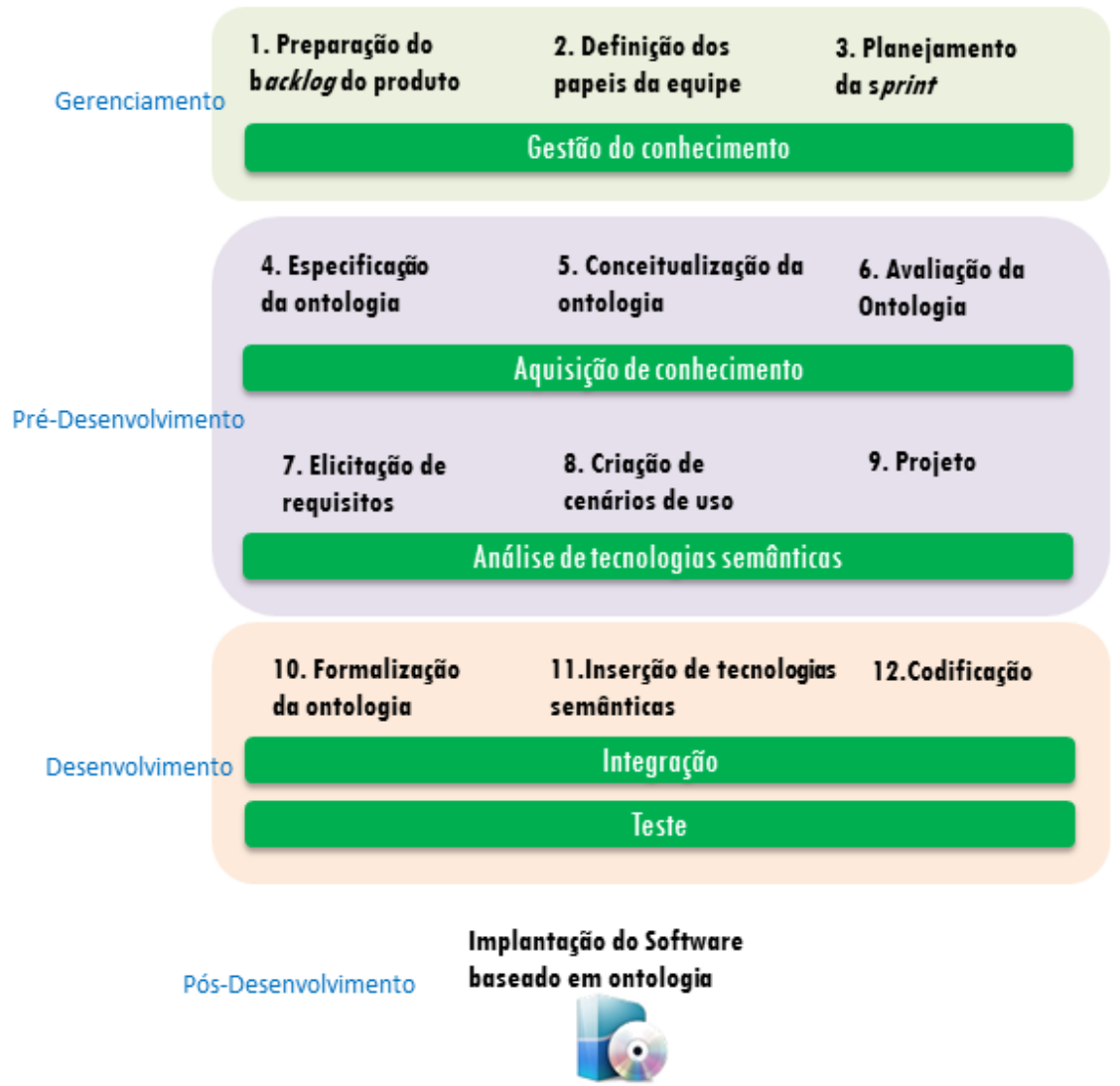

Fonte: Elaborada pela autora.

\subsubsection{Cenário i}

Este cenário corresponde ao desenvolvimento de uma aplicação de pequeno ou médio porte e independente de outras aplicações ou plataformas. Nesse caso, a equipe inicia as atividades referentes ao software e à ontologia de forma paralela. Se a equipe planejar iniciar somente as atividades da ontologia, deve-se seguir o fluxo sugerido no Cenário iii (Seção 4.5.3).

Nas primeiras atividades do Pré-Desenvolvimento a equipe é dividida e são formadas duas sub-equipes, até que a Conceitualização da ontologia seja consolidada. A reunião diária acontece nas sub-equipes; na revisão da sprint as sub-equipes apresentam seus resultados e discutem suas dúvidas, tanto relacionadas à ontologia como aos demais artefatos. Essa prática se faz necessária para que os engenheiros possam discutir e formalizar os conceitos e requisitos de de maneira mais apropriada e sem interferências desnecessárias na construção dos artefatos. $\mathrm{O}$ fluxo das atividades deste cenário é descrito na Figura 25.

Os números em destaque na Figura 25 denotam a sequência em que as atividades devem ocorrer. Após a definição dos itens de backlog, a equipe continua a Gestão do Conhecimento por meio da atividade de Aquisição de Conhecimento, que permeia todo o Pré-Desenvolvimento e acompanha a conceitualização e especificação da ontologia. 
Figura 25 - Cenário i: fluxo de atividades na fase de Pré-Desenvolvimento do processo OntoSoft.

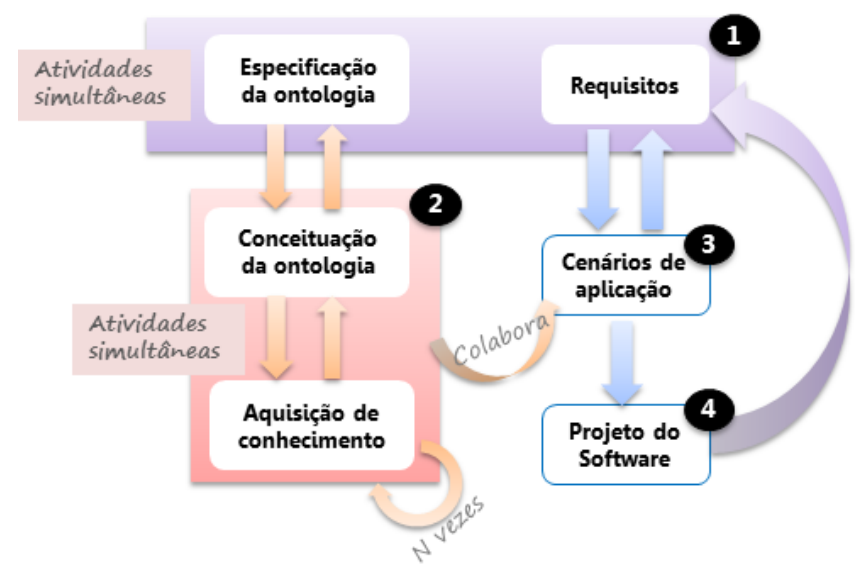

Fonte: Elaborada pela autora.

Caso a equipe não faça sub-divisões para realizar atividades simultaneamente ou decida iniciar com a Elicitação de Requisitos, o processo OntoSoft também especifica esse caminho de desenvolvimento. Além disso, as tarefas precisam ser estendidas e podem ser particionadas em conformidade com o processo e também com a realidade da equipe, que deve estabelecer as prioridades e o tempo para cada sprint. Há, portanto, duas opções para este primeiro cenário de desenvolvimento:

i. Iniciar duas sprints em paralelo: $(\mathrm{S} 1)^{1}$ para elicitar os Requisitos e (S2) para especificar a ontologia.

ii. Iniciar a sprint $\mathrm{S} 1$ com a elicitação dos requisitos e, a partir dos requisitos, iniciar a especificação da ontologia.

Ao iniciar as atividades simultaneamente podem surgir algumas objeções ou dúvidas no que se refere a inconsistências ou erros na especificação da ontologia. Conforme será visto nas análises dos estudos de caso (Capítulo 5), a ontologia pode consumir mais tempo do que o projetado para ser desenvolvida, quando a equipe não tem experiência no desenvolvimento de ontologias, além de considerar a complexidade do domínio. Como se trata da definição de conceitos, esta é uma ameaça inerente tanto para a elicitação dos requisitos como para a aquisição de conhecimento, para qualquer tipo de software, e não somente para software baseado em ontologia.

\subsubsection{Cenário ii}

Este cenário corresponde ao desenvolvimento de uma aplicação em que a ontologia será reusada, adaptada e importada para a aplicação. Nele, o processo OntoSoft comporta-se $\overline{1} \mathrm{~S} 1$ - indica a primeira sprint, $\mathrm{S} 2$ indica a segunda sprint, e assim por diante. 
de forma semelhante ao cenário anterior. No entanto, algumas atividades são acrescentadas, a saber: Pesquisa da Ontologia, Seleção da Ontologia e Avaliação da Ontologia. A Pesquisa da Ontologia acontece em paralelo à Elicitação de Requisitos, pois são atividades que se relacionam no ciclo de vida do software baseado em ontologia. Além disso, o processo OntoSoft, de maneira flexível, também permite a inversão da ordem do início das atividades, conforme os engenheiros de ontologia e engenheiros de software definirem no planejamento das sprints.

A equipe define, de acordo com os itens de backlog identificados, quantas sprints são necessárias para especificar a ontologia antes de iniciar a extração de requisitos. Neste cenário, o OntoSoft utiliza algumas das atividades propostas pelo terceiro cenário da metodologia $\mathrm{NeOn}$ (SUÁREZ-FIGUEROA et al., 2012), que é relacionado ao reuso de ontologias. São consideradas as atividades de avaliação, seleção e integração da ontologia, as quais identificam possíveis recursos ontológicos relacionados ao domínio da aplicação a ser desenvolvida. A sequência proposta para essas atividades é ilustrada na Figura 26.

Figura 26 - Cenário ii: fluxo de atividades na fase de Pré-Desenvolvimento do processo OntoSoft.

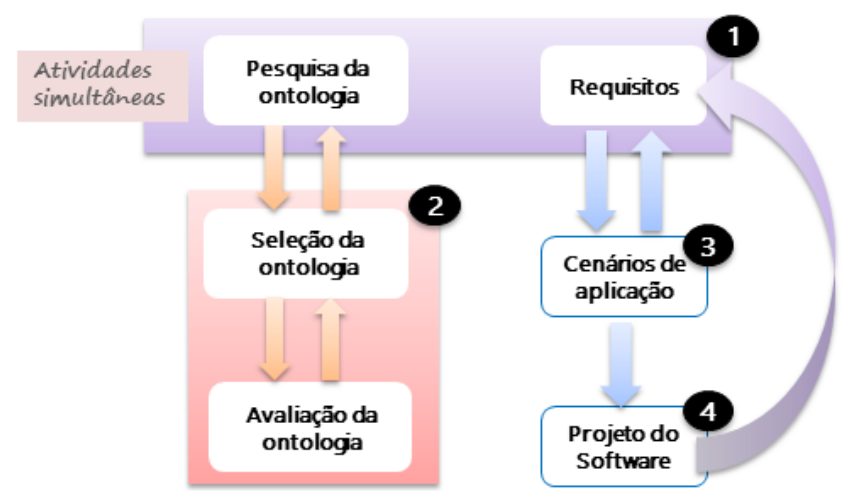

Fonte: Elaborada pela autora.

A partir da seleção e avaliação das ontologias, os conceitos podem ser discutidos e formalizados em consonância com o domínio da aplicação proposta, reutilizando o conhecimento compartilhado em uma ontologia já disponível na comunidade. O artefato glossário de termos deve ser adaptado ou incrementado para verificar se a ontologia está em conformidade com o objetivo da aplicação. Provavelmente algumas definições de conceitos devem ser revistas, a fim de evitar inconsistências e de formalizar o domínio da aplicação de forma coerente.

A Avaliação da Ontologia é feita com base na verificação dos compromissos ontológicos por meio do modelo de artefato disponibilizado pelo OntoSoft para a equipe. Os engenheiros de ontologia devem observar a clareza e a coerência das ontologias selecionadas e da ontologia reutilizada e adaptada para o contexto da aplicação. Após a seleção e importação das ontologias, as equipes seguem o fluxo padrão do processo OntoSoft. 


\subsubsection{Cenário iii}

No Cenário iii, a ontologia é utilizada como núcleo de uma plataforma que apoia os projetos de desenvolvimento da organização, desempenhando um papel essencial na composição das aplicações. Segundo Ruiz e Hilera (2006), há um grande potencial no uso de ontologias como artefatos do conhecimento, gerando benefícios para facilitar a comunicação entre os envolvidos no projeto e para evitar ambiguidades. Estas são algumas das motivações para a definição deste terceiro cenário, que foi estabelecido para organizações que utilizam uma plataforma semântica para gerenciar e fomentar seus projetos. Nesse caso, é necessário que as atividades do PréDesenvolvimento da ontologia, ou das ontologias correntes, sejam feitas de forma iterativa e antes das atividades de projeto das demais aplicações da plataforma.

Como pode ser visto na Figura 22, a plataforma semântica pode ser composta por várias ontologias e a partir delas podem ser desenvolvidas diversas aplicações na organização. Esta plataforma é similar a uma camada de apoio que envolve a modelagem do conhecimento contido nos domínios e nos contextos das aplicações. A partir da construção da base de conhecimento, por meio das principais ontologias e da especificação do núcleo dos domínios, diversas vantagens podem ser alcançadas, entre elas: (i) maior reutilização dos dados; (ii) otimização no desenvolvimento das aplicações; e (iii) padronização, automatização e gestão do conhecimento da organização.

Neste cenário de desenvolvimento, as atividades Especificação da Ontologia, Conceitualização da Ontologia e Aquisição do Conhecimento são iteradas até que os conceitos sejam considerados maduros para iniciar a fase de projeto do software. Os engenheiros de ontologia, engenheiros de software, especialistas do domínio de conhecimento, cliente e os demais papeis envolvidos na equipe de desenvolvimento reúnem-se para estabelecer os conceitos, as regras de negócio e as restrições do domínio da plataforma. Esses especialistas e desenvolvedores colaboram entre si em reuniões contínuas até que um senso comum e compartilhado seja alcançado na equipe.

Vale ressaltar, também, que as atividades Conceitualização da Ontologia e Aquisição do Conhecimento colaboram diretamente para a Especificação dos Requisitos e para a Criação de Cenários de Uso do software baseado em ontologia. Essa colaboração é consequência dos objetivos comuns a estas atividades, pois na definição dos conceitos e das restrições do domínio de conhecimento, os requisitos estão sendo implicitamente identificados. Dessa forma, o engenheiro de requisitos poderá consultar os artefatos das ontologias para esclarecer possíveis dúvidas e otimizar o estabelecimento das funcionalidades do software. Na Figura 27 é expressa a relação iterativa e incremental entre as atividades considerando o Cenário iii.

As três atividades referentes ao projeto da ontologia compõem as primeiras sprints do Pré-Desenvolvimento e podem ser iteradas quantas vezes forem necessárias, até que os conceitos sejam formalizados. A partir da Conceitualização da Ontologia, a Análise de Requisitos pode ser 
Figura 27 - Cenário iii: fluxo de atividades na fase de Pré-Desenvolvimento do processo OntoSoft.

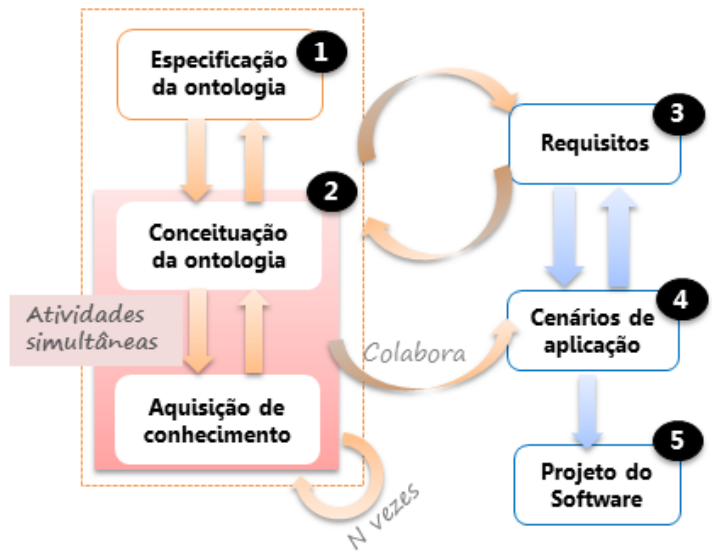

Fonte: Elaborada pela autora.

iniciada, provavelmente em outra sprint. Além disso, a equipe pode refinar, melhorar e avaliar as ontologias enquanto são feitas as atividades do projeto da aplicação. Caso algum problema seja identificado (no que se refere ao escopo), o engenheiro de software deve informar ao engenheiro de ontologia para que as inconsistências sejam solucionadas.

Assim como nos cenários i e ii, as sprints podem ser particionadas em uma ou mais, de acordo com as necessidades e o planejamento da equipe. Por se tratar da construção de uma plataforma de apoio com ontologias mais complexas, supõe-se que estas atividades iniciais perdurem por mais tempo, até que o conhecimento seja acordado entre os membros envolvidos. No entanto, como já foi mencionado, tais atividades auxiliam diretamente na execução das demais atividades do software baseado em ontologia, colaborando na criação de artefatos consistentes e coerentes.

Este é um cenário indicado para software baseado em ontologia que tem um escopo mais amplo, a fim de construir diversas aplicações reutilizando a base de conhecimento estabelecida pelos engenheiros de ontologias. Esta configuração de desenvolvimento possibilita a inserção de novas ontologias e consequentemente a criação de novas aplicações instanciadas na plataforma semântica, possibilitando a geração mais rápida, em virtude do alto nível de reúso da base de conhecimento e dos artefatos estabelecidos inicial e gradualmente.

Com base no escopo do software baseado em ontologia, os especialistas, engenheiros e desenvolvedores podem escolher o cenário mais adequado no processo OntoSoft e seguir a sequência proposta para o desenvolvimento dos artefatos do software e da ontologia. Dessa forma, os cenários foram descritos para otimizar e facilitar as decisões das equipes de desenvolvimento no que concerne ao fluxo das atividades que devem ser estabelecidas no decorrer das sprints. 


\subsection{Considerações finais}

O processo OntoSoft foi definido com o objetivo gerar software baseado em ontologia de qualidade, possibilitando o desenvolvimento do software e da ontologia de maneira integrada ao fornecer diretrizes para os desenvolvedores. Conforme foi apresentado neste capítulo, o OntoSoft foi construído com base nas boas práticas da Engenharia de Software e nas atividades da Engenharia de Ontologias, considerando características dos modelos de processo de desenvolvimento na literatura.

A fim também de promover a leveza, a transparência, a flexibilidade e a agilidade das atividades no OntoSoft, foram integradas a eles as práticas e os valores do método ágil Scrum. Tais práticas possibilitam o planejamento das sprints em ciclos curtos e entregas rápidas para o cliente. Portanto, o processo OntoSoft aborda o desenvolvimento de software baseado em ontologia de forma ágil.

Em decorrência da complexidade inerente ao desenvolvimento das ontologias, o processo OntoSoft define três cenários de desenvolvimento para guiar a equipe de desenvolvedores, identificando atividades e tarefas específicas para diferentes cenários de aplicação. Tais cenários correspondem a diferentes sequências de atividades para o desenvolvimento dos artefatos da ontologia e do software em si.

No próximo capítulo são apresentados resultados de três estudos empíricos conduzidos para validar o processo OntoSoft. O processo foi utilizado no desenvolvimento de aplicações baseadas em ontologia e foi avaliado pelas equipes de desenvolvimento nos estudos de caso conduzidos em três ambientes distintos: com uma equipe de especialistas em Engenharia de Ontologias, em uma disciplina de pós-graduação e em uma fábrica de software. 


\section{5}

\section{APLICAÇÃO E AVALIAÇÃO DO PROCESSO ONTOSOFT}

$\mathrm{N}^{2}$ Engenharia de Software as pesquisas, em sua grande maioria, objetivam averiguar como as fases de desenvolvimento, operação e manutenção são realizadas por engenheiros de software e outras partes interessadas em diferentes condições de desenvolvimento. Dessa maneira, a característica da multidisciplinaridade na Engenharia de Software a torna propícia para a elaboração e aplicação de estudos de caso (RUNESON; HÖST, 2009).

Nesse sentido, por meio da condução de três estudos de casos, o processo OntoSoft foi aplicado e avaliado em três ambientes de desenvolvimento. A primeira aplicação do OntoSoft ocorreu no grupo de pesquisa NEES (Núcleo de Excelência em Tecnologias Sociais) na Universidade Federal do Alagoas (UFAL). A segunda aplicação do processo foi conduzida em uma disciplina da Engenharia de Ontologias aplicada à Engenharia de Software, oferecida aos alunos de pós-graduação da Universidade Federal de São Carlos (UFSCar). Por fim, o terceiro estudo foi realizado em uma fábrica de software da Polícia Militar do Estado de São Paulo. Nos três estudos o objetivo foi investigar a aplicabilidade, efetividade e produtividade do processo OntoSoft no desenvolvimento de software baseado em ontologia.

O capítulo está organizado como segue. Na Seção 5.1 é apresentado o primeiro estudo de caso realizado com alunos e especialistas em Engenharia de Ontologias da UFAL. Na Seção 5.2 é descrito o estudo de caso conduzido na disciplina de Engenharia de Ontologias aplicada à Engenharia de Software na UFSCar. Na Seção 5.3 são discutidos os resultados do estudo de caso ocorrido na fábrica de software na Polícia Militar. Por fim, na Seção 5.4 são sumarizados os principais resultados e lições aprendidas no decorrer da condução dos estudos de caso elaborados. 


\subsection{Estudo de caso 1: UFAL - Boa Moradia}

O primeiro estudo de caso ocorreu para instanciar e avaliar as versões iniciais do processo OntoSoft. Trata-se de uma aplicação preliminar em que engenheiros de ontologias avaliaram as diretrizes do OntoSoft. Os participantes do estudo eram integrantes com experiência no desenvolvimento de ontologias do grupo de pesquisa NEES, da pós-graduação em Ciência da Computação da Universidade Federal de Alagoas (UFAL).

O estudo de caso ocorreu durante a execução das primeiras sprints associadas ao desenvolvimento do software Boa Moradia. Trata-se de um software de médio porte e que se enquadra no primeiro cenário de desenvolvimento descrito no OntoSoft. De maneira geral, o sistema utiliza dados de saúde, dados de segurança, dados de educação, mobilidade urbana e índice de desenvolvimento humano para produzir informações a fim de qualificar os bairros de uma cidade, por meio de dados de governo aberto, dados vinculados e ontologias para indicar ao usuário os imóveis segundo suas características buscadas.

A ontologia da aplicação foi desenvolvida pelo grupo de pesquisa, não foi reutilizada a partir de outras ontologias e não há uma plataforma semântica associada, conforme descrito no primeiro cenário do OntoSoft. O objetivo da aplicação é sugerir ao usuário imóveis e suas características, de acordo com a busca e as restrições inseridas. Na Figura 28 é apresentada parte da ontologia do Boa Moradia ${ }^{1}$. Por exemplo, o conceito RealEstate representa qualquer propriedade, como casa, apartamento ou fazenda; já o conceito Offer está relacionado a um imóvel que pode ser alugado ou vendido.

Figura 28 - Parte da ontologia da aplicação do Boa Moradia.

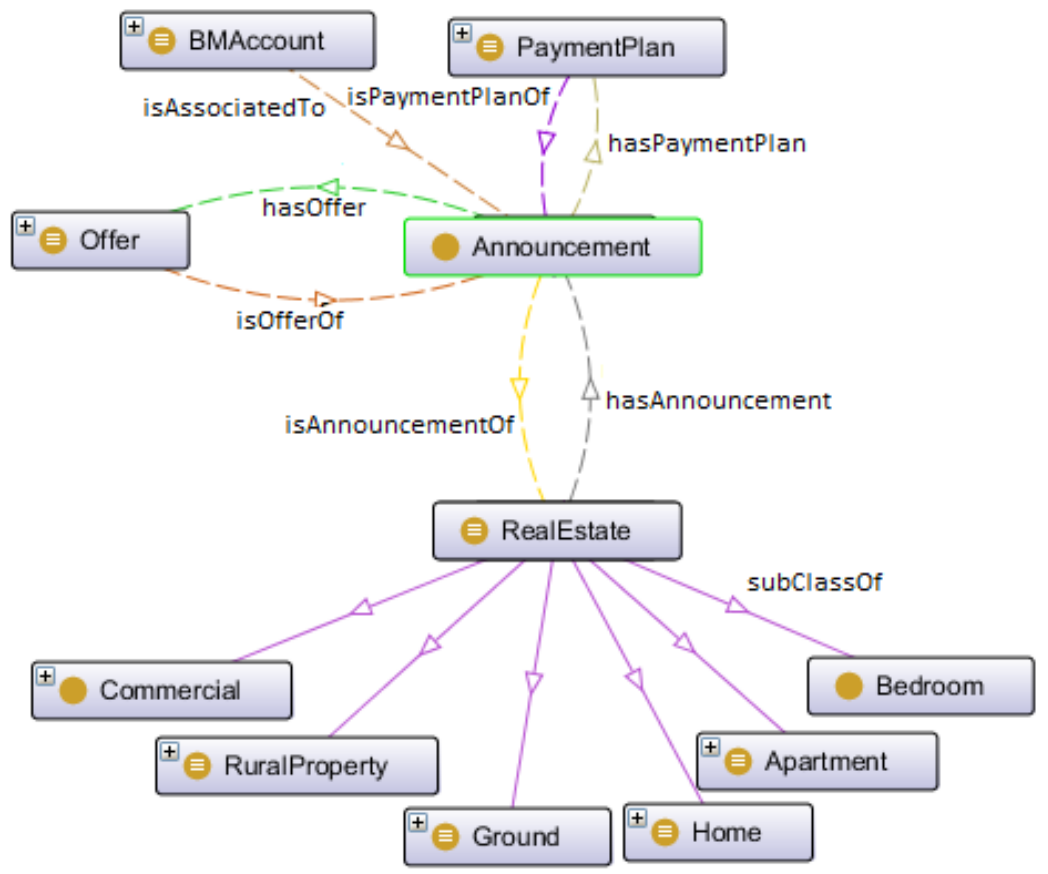

$1<$ http://nees.com.br/linkn/onto/boa_moradia/> 
Ao longo do desenvolvimento das primeiras sprints do Boa Moradia, as atividades do processo OntoSoft foram discutidas e reuniões foram realizadas frequentemente, de forma que algumas melhorias refinaram as atividades e as tarefas do processo em suas primeiras versões. Também foram estabelecidos questionários para analisar e avaliar a equipe de desenvolvimento e para extrair informações sobre a aplicação do processo. Um panorama desta iteração e das atividades ocorridas entre equipe de desenvolvimento e o processo é apresentado na Figura 29.

Figura 29 - Fluxo iterativo de avaliação inicial do processo OntoSoft.

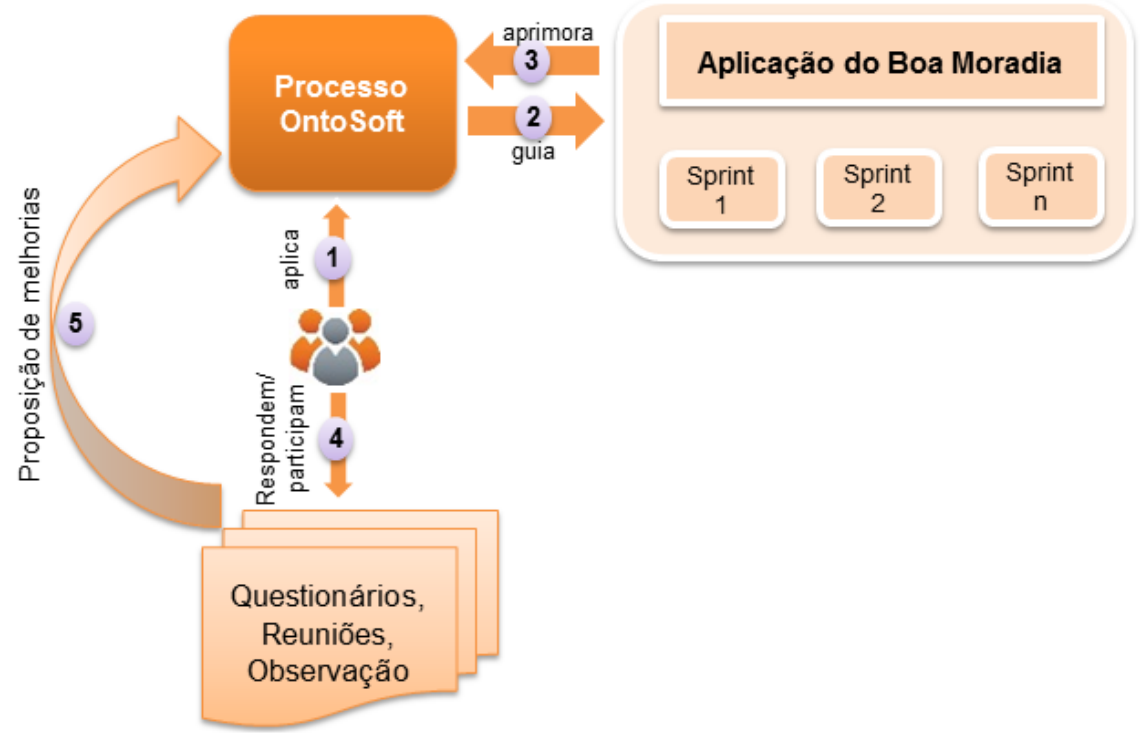

Fonte: Elaborada pela autora.

De forma geral, a equipe aplicou o processo OntoSoft e, após seguir as diretrizes propostas nas sprints, o processo era avaliado por meio de questionários. A partir das reuniões e do feedback dos participantes, algumas melhorias foram propostas nas atividades do processo. Estas foram estabelecidas para melhor apoiar os desenvolvedores e aperfeiçoar as primeiras versões do OntoSoft.

Foram realizadas três sprints no Boa Moradia abordando as diretrizes indicadas no processo OntoSoft. A equipe foi composta por quatro participantes, alunos da pós-graduação que já dominavam os conceitos referentes à Engenharia de Ontologias e Engenharia de Software. O objetivo desta aplicação foi obter ofeedback de especialistas e desenvolvedores em ontologias para melhorar e avaliar o processo OntoSoft em sua fase inicial. Na Tabela 17 são sumarizados objetivo, questão de pesquisa, hipótese e a proposição desta aplicação.

Na Tabela 18 são apresentadas algumas das questões que foram levantadas e avaliadas pelos participantes. A segunda e a terceira colunas indicam a porcentagem de aprovação considerada pelos desenvolvedores, classificadas em faixa média (de 25 a 50\%) e faixa alta (de 75 a $100 \%$ ), respectivamente. A maioria dos desenvolvedores considerou a contribuição do processo OntoSoft como efetiva para o desenvolvimento do software baseado em ontologia. A associação 
Tabela 17 - Protocolo do primeiro estudo de caso estabelecido para a aplicação do processo OntoSoft.

\begin{tabular}{ll}
\hline \hline Objetivo & Descrição \\
\hline Questão de pesquisa & $\begin{array}{l}\text { Avaliar as atividades do processo OntoSoft e observar a aceitação } \\
\text { da equipe ao processo. }\end{array}$ \\
\hline \multirow{3}{*}{ Hipótese } & $\begin{array}{l}\text { O processo estabelece a associação entre as atividades de Enge- } \\
\text { nharia de Software e Engenharia de Ontologias? }\end{array}$ \\
\hline Proposição & $\begin{array}{l}\text { 1. As atividades do processo são adequadas para o desenvolvi- } \\
\text { mento de software baseado em ontologia. }\end{array}$ \\
& 2. Os artefatos propostos atenderam às necessidades das equipes. \\
\hline \hline
\end{tabular}

entre os valores do método ágil Scrum, práticas da Engenharia de Software e Engenharia de Ontologias foi considerada $100 \%$ adequada por todos os desenvolvedores.

Tabela 18 - Exemplo de algumas das avaliações feitas pelos desenvolvedores a partir da aplicação dos questionários.

\begin{tabular}{lll}
\hline \hline & \multicolumn{2}{c}{ Nível de aceitação } \\
Proposição & Médio & Alto \\
\hline O processo OntoSoft atendeu às necessidades da equipe. & $33 \%$ & $66 \%$ \\
As atividades relacionadas ao Scrum foram incorporadas & - & $100 \%$ \\
satisfatoriamente no processo. & \multicolumn{2}{l}{$6 \%$} \\
$\begin{array}{l}\text { As tarefas foram suficientes para produzir os artefatos. } \\
\text { As atividades de Engenharia de Ontologias foram incluí- } \\
\text { das satisfatoriamente no processo. }\end{array}$ & - \\
\hline \hline
\end{tabular}

Apesar do número de participantes, o nível de aceitação é um bom indicativo de que o processo é coerente e efetivo para o desenvolvimento de software baseado em ontologia, conforme foi proposto na hipótese definida no protocolo do estudo. De acordo com os participantes, as atividades de Engenharia de Ontologias foram incluídas satisfatoriamente no processo. Além disso, a associação entre atividades de Engenharia de Ontologias e Engenharia de Software permitiu o desenvolvimento simultâneo da ontologia e do software, possibilitando a gerência das atividades desde o planejamento das sprints.

Ainda que os desenvolvedores fossem especialistas, houve dificuldades com a especificação do domínio da aplicação, em virtude da complexidade e da necessidade de estabelecer relações com outros domínios de conhecimento para desenvolver a ontologia do Boa Moradia. Esse fator é muito comum nas atividades de conceitualização e especificação de ontologias, devido ao nível de complexidade do domínio e da familiaridade da equipe com o domínio investigado, fator que pode interferir no tempo de desenvolvimento. No entanto, com o uso do OntoSoft, a equipe foi capaz de prever as dificuldades e definir as atividades e prioridades, evitando entregas tardias e cumprindo os prazos.

Vale ressaltar que este estudo de caso ocorreu quando o processo OntoSoft estava no início de seu desenvolvimento, em suas primeiras versões. Por isso, algumas atividades e tarefas que foram apresentadas e discutidas no Capítulo 4 ainda não haviam sido definidas. Sendo assim, 
os participantes nesta aplicação do OntoSoft indicaram as seguintes limitações: (i) identificar riscos e adaptar-se às equipes (pequenas, médias e grandes); e (ii) orientar as tarefas relacionadas à escolha da tecnologia semântica. Estas limitações foram consideradas e estes detalhes foram adicionados às descrições das tarefas no processo.

Além disso, os participantes sugeriram que atividades e tarefas relacionadas à implementação do software baseado em ontologia fossem mais detalhadas no decorrer da documentação do processo OntoSoft. Estas ponderações também foram consideradas para descrever a relação entre raciocinadores, ferramentas de geração de código e bibliotecas para a manipulação das ontologias. De fato, essas diretrizes mostraram-se essenciais para ajudar o desenvolvedor e reduzir o tempo de desenvolvimento.

Em geral, de acordo com os participantes deste primeiro estudo de caso, uma das principais contribuições do processo OntoSoft está relacionada ao detalhamento das atividades e tarefas especificadas. Esta granularidade faz com que as tarefas definidas contribuam para a tomada de decisões e otimização do tempo de desenvolvimento. Com base nesse feedback, o processo foi refinado e melhorado, considerando o background de uma equipe especialista em Engenharia de Ontologias. Sendo assim, ao seguir as indicações dos desenvolvedores, que colaboraram para a melhoria iterativa das atividades no início da criação do processo OntoSoft, acredita-se que as atividades foram incrementadas também de acordo com a visão prática de desenvolvimento.

\subsection{Estudo de caso 2: UFSCar - AppLucy}

Para a execução do segundo estudo de caso foi definida uma aplicação proposta por Berners-Lee, Hendler e Lassila (2001). Trata-se de um cenário clássico que ilustra a importância e a necessidade de utilizar ontologias e tecnologias semânticas no desenvolvimento de software. O escopo do problema está relacionado à marcação de uma consulta médica envolvendo o compartilhamento da agenda de três pessoas.

Basicamente, Lucy precisa marcar uma consulta para a sua mãe e levá-la ao médico, considerando a necessidade de localizar médicos qualificados e que aceitem o plano de saúde de sua mãe. Além disso, ela deve estar disponível no horário da consulta da mãe e perder o menor tempo possível com o deslocamento, ou seja, a consulta deve ser em um local próximo à casa de sua mãe. Assim, Lucy necessita configurar seu agente, para que ele considere as seguintes restrições: tratamento médico, serviços disponíveis e consultórios próximos à casa de sua mãe.

Na Figura 30 são ilustrados alguns dos recursos que podem ser utilizados no cenário apresentado. Para a resolução do problema podem ser abordados recursos de integração de ontologias, agentes inteligentes e serviços semânticos para gerar a aplicação, denominada AppLucy ao longo da explanação dos estudos de caso. 
Figura 30 - Cenário proposto por Berners-Lee, Hendler e Lassila (2001) para a inserção de ontologias e tecnologias semânticas no desenvolvimento de software.

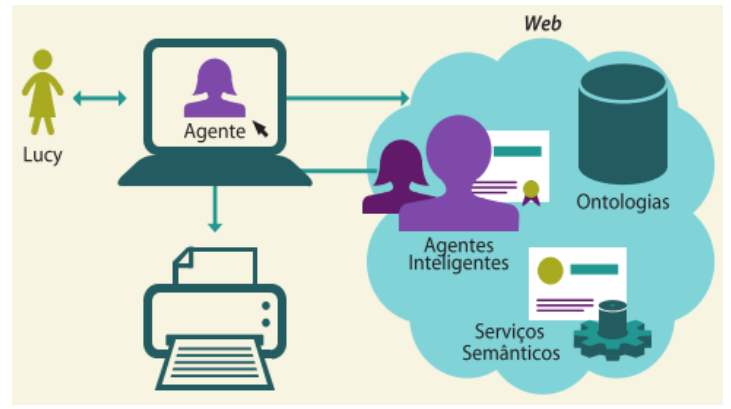

Fonte: Isotani e Bittencourt (2015).

O segundo estudo de caso envolvendo a aplicação do processo OntoSoft foi realizado na disciplina de Engenharia de Ontologias Aplicada à Engenharia de Software, no programa de Pós-Graduação em Ciência da Computação na UFSCar. O estudo de caso aconteceu em duas partes, a saber: (i) aplicação do processo OntoSoft na construção dos artefatos para a construção da AppLucy; e (ii) aplicação do OntoSoft no desenvolvimento de software baseado em ontologia, conforme proposto na disciplina.

Em ambas as aplicações, os 12 alunos da disciplina foram divididos em duas equipes (A e B) de desenvolvimento na aplicação do processo OntoSoft. A fim de facilitar o entendimento as etapas do estudo de caso são apresentadas nas seções a seguir.

\subsubsection{Estudo de caso piloto: desenvolvimento da AppLucy}

Nesta primeira parte do estudo de caso, o objetivo foi apresentar as características do processo OntoSoft e avaliar o processo identificando as vantagens e desvantagens de seu uso a partir do feedback dos participantes. Esta primeira parte pode ser considerada um estudo de caso piloto, em que um treinamento foi feito para a aplicação do OntoSoft na disciplina.

O intuito foi avaliar as atividades do processo OntoSoft e a adaptação das equipes ao processo, a partir do desenvolvimento da aplicação AppLucy, que aborda a necessidade do desenvolvimento de um software baseado em ontologia. $\mathrm{O}$ estudo foi projetado para a ocorrência de duas sprints, correspondentes a duas aulas, por meio das quais alguns artefatos da aplicação deveriam ser entregues. Para guiar e analisar o andamento do treinamento foram consideradas duas questões de pesquisa:

Q.1 Como foi a assimilação do processo OntoSoft pelos alunos?

Q.2 O processo OntoSoft supriu as necessidades da equipe? 


\subsubsection{Preparação para a coleta de dados}

Considerando o nível de conhecimento em Engenharia de Software, 67\% dos participantes caracterizam-se como intermediário. No que diz respeito à Engenharia de Ontologias, mais de $50 \%$ dos participantes indicou ter pouco conhecimento na área, pois a maioria dos alunos, até então, não havia desenvolvido uma ontologia. Por fim, com relação às práticas e valores do método ágil Scrum, 55\% dos alunos indicaram ter nível básico de conhecimento, conforme é apresentado na Figura 31.

Figura 31 - Nível de conhecimento dos participantes na primeira etapa do estudo de caso.

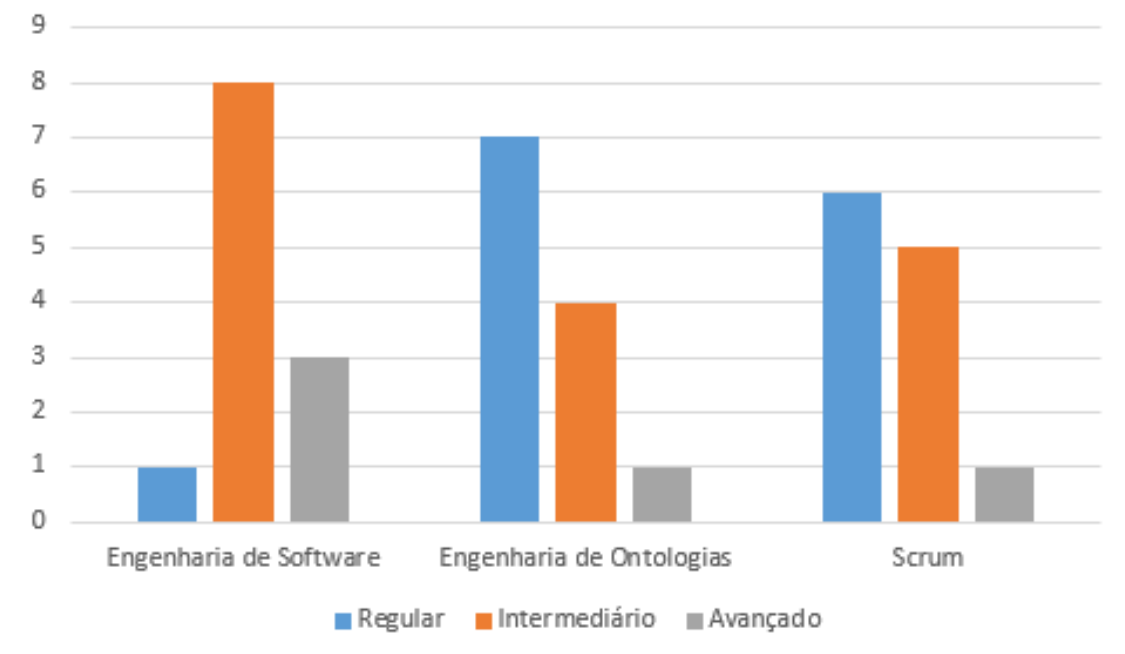

Neste estudo piloto, os participantes receberam a documentação do processo OntoSoft em um primeiro contato por $e$-mail, a fim de que a estudassem antecipadamente. No primeiro dia houve uma apresentação oral sobre o OntoSoft para explicar suas características. Logo após, foram disponibilizados a descrição da aplicação a ser desenvolvida e os modelos de artefatos esperados.

Os participantes utilizaram a ferramenta SeeNowDo ${ }^{2}$, uma ferramenta online e colaborativa para gerenciamento de equipes distribuídas e ágeis. Esta ferramenta foi escolhida, pois permite distribuir os papeis, estimar o tempo para cada tarefa e a visão das tarefas em andamento, realizadas e não realizadas. Além disso, a ferramenta apoia os princípios e valores do Scrum, utilizados no processo OntoSoft. Para a construção da ontologia foi utilizada a ferramenta Protégé ${ }^{3}$ comumente usada pelos desenvolvedores de ontologias.

Foram pré-definidas duas sprints para o desenvolvimento da aplicação AppLucy. Foram desenvolvidos artefatos das fases iniciais do processo, inclusive parte da ontologia, mas o software em si não pode ser concluído em virtude do pouco tempo disponibilizado ao estudo de caso (apenas 8 horas). Na primeira sprint, 12 alunos participaram do estudo e, na segunda sprint, nove alunos participaram (três não compareceram no segundo dia do estudo de caso).

2 SeeNowDo: seenowdo.com

3 Protégé: protege.stanford.edu/ 
A aplicação desenvolvida abrangeu a necessidade do desenvolvimento de uma ontologia, correspondendo ao primeiro cenário descrito no OntoSoft. A AppLucy pode ser considerada de pequeno porte, conforme foi descrito Berners-Lee, Hendler e Lassila (2001), na qual se apresenta a necessidade de criar uma agenda compartilhada por três pessoas. Consequentemente, uma série de ligações entre os conceitos e requisitos no contexto descrito precisa ser identificada, gerando a necessidade da modelagem de uma ontologia.

Apesar do domínio da aplicação ser considerado de baixa complexidade, as equipes utilizaram a maior parte do tempo da primeira sprint para entender o domínio do problema e ajustarem os requisitos, estabelecendo um entendimento comum a respeito do que deveria ser construído, ou seja, o objetivo da aplicação. Este fato indica que, independentemente do software a ser desenvolvido (se é baseado em ontologia ou não), um dos grandes desafios do desenvolvimento de software está em compreender corretamente o domínio e identificar os requisitos desejados pelo cliente.

Este desafio também está presente no desenvolvimento da ontologia, conforme foi discutido no Capítulo 4. Trata-se de uma característica inerente ao gerenciamento e aquisição do conhecimento no que se refere ao estabelecimento de conceitos e requisitos no desenvolvimento de software e da ontologia. O processo OntoSoft procura minimizar este desafio por meio da indicação de tarefas detalhadas em cada atividade proposta, a fim de guiar os engenheiros e desenvolvedores na geração de artefatos coerentes com o resultado esperado pelo cliente.

Como forma de avaliação e extração de feedback, os participantes responderam alguns questionários antes e depois da finalização de cada sprint. Questões relacionadas à aplicabilidade e tarefas do OntoSoft, bem como sobre a adaptação das equipes ao processo, foram definidas para motivar sua avaliação e validação. Além disso, os artefatos gerados pelas equipes também foram fonte de avaliação do processo, por meio de sugestões de melhorias. Estes resultados são apresentados e analisados na próxima seção.

\subsubsection{Análise dos dados}

O objetivo nesta primeira parte do estudo foi avaliar a adequação das atividades do processo OntoSoft e verificar a aplicabilidade do OntoSoft na criação dos artefatos para o software baseado em ontologia. A avaliação foi realizada com base em questionários, observações feitas em sala de aula, comentários dos alunos e do docente responsável pela disciplina.

A característica mais significativa do OntoSoft está na indicação clara e detalhada do fluxo das atividades no decorrer do desenvolvimento dos artefatos da aplicação. Além disso, 63\% dos participantes afirmaram que a indicação dos cenários de uso são coerentes e compatíveis com a realidade de desenvolvimento. Os demais pontos referenciados também são pontos fortes do processo e reforçam a premissa de que o OntoSoft auxilia na condução das tarefas de forma iterativa. Estes dados são sumarizados na Tabela 19. 
Tabela 19 - Características mais importantes do OntoSoft segundo o feedback dos participantes no estudo piloto.

\begin{tabular}{lcl}
\hline \hline Características & N. Participantes & \% \\
\hline Indicação do fluxo das atividades no desenvolvimento. & 9 & $100 \%$ \\
Indicação dos possíveis cenários de uso. & 7 & $63 \%$ \\
Indicação das tarefas em cada atividade. & 5 & $45 \%$ \\
Indicação das iterações e atualizações quando necessárias. & 3 & $27 \%$ \\
\hline \hline
\end{tabular}

Considerando as práticas e os valores do Scrum, na primeira sprint $100 \%$ dos participantes afirmaram ter seguido o processo e na segunda sprint $75 \%$ dos participantes. Isso pode ser decorrência do fato de que a maioria dos participantes não conhecia o método ágil e não ponderou a importância de seguir as práticas sugeridas para o gerenciamento da execução das atividades na aplicação do processo OntoSoft.

Observou-se, também, a constância da aprovação dos participantes no que diz respeito à construção dos artefatos, à indicação dos cenários de uso e às tarefas na execução das atividades da aplicação AppLucy. Mesmo tendo uma taxa de aprovação alta, na segunda sprint houve um crescimento no entendimento do processo, de forma que as especificações das tarefas foram seguidas por mais participantes e consideradas coerentes durante a execução da Sprint. A fim de avaliar esta evolução nas sprints, foram definidos cinco critérios $(\mathrm{C} 1, \mathrm{C} 2, \mathrm{C} 3, \mathrm{C} 4$ e C5) para verificar a aceitabilidade do OntoSoft. Estes critérios são apresentados na Tabela 20 e a visão gráfica deste panorama é ilustrada na Figura 32.

Tabela 20 - Observações acerca da evolução do entendimento dos participantes durante a aplicação do processo OntoSoft nas sprints.

\begin{tabular}{ll}
\hline \hline Critérios & Consideração \\
\hline C1 & Os artefatos foram desenvolvidos seguindo o processo. \\
C2 & Os Cenários de Uso foram definidos de forma adequada. \\
C3 & As especificações foram suficientes para identificar as características \\
& da aplicação. \\
C4 & As tarefas estabelecidas para cada atividade foram seguidas. \\
C5 & As tarefas descritas são coerentes com a realidade do desenvolvimento. \\
\hline \hline
\end{tabular}

Conforme apresentado na Figura 32, a taxa de aprovação aumentou consideravelmente no decorrer do desenvolvimento da aplicação. Os critérios estabelecidos dizem respeito à aplicabilidade e aceitação do processo OntoSoft. Estes foram definidos para facilitar a análise dos dados extraídos nos questionários. Na segunda sprint, os participantes consultaram com mais frequência a documentação do OntoSoft, compreenderam e aprovaram as especificações das tarefas e, consequentemente, obtiveram um maior entendimento das atividades propostas.

Concernente às especificações dos Cenários de Uso, estes foram classificados como satisfatórios para identificar as características de cada equipe. Entretanto, aproximadamente $50 \%$ dos participantes indicou a necessidade de descrições mais detalhadas. A partir dessa 
Figura 32 - Visão geral sobre a taxa de aprovação e de reprovação do processo OntoSoft com relação aos critérios estabelecidos na Tabela 20.

Taxa de Aprovação nas Sprints

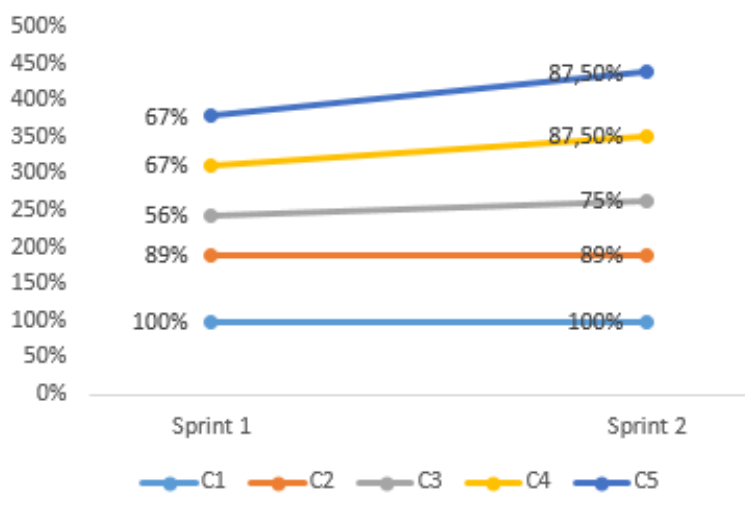

Taxa de Reprovação nas Sprints

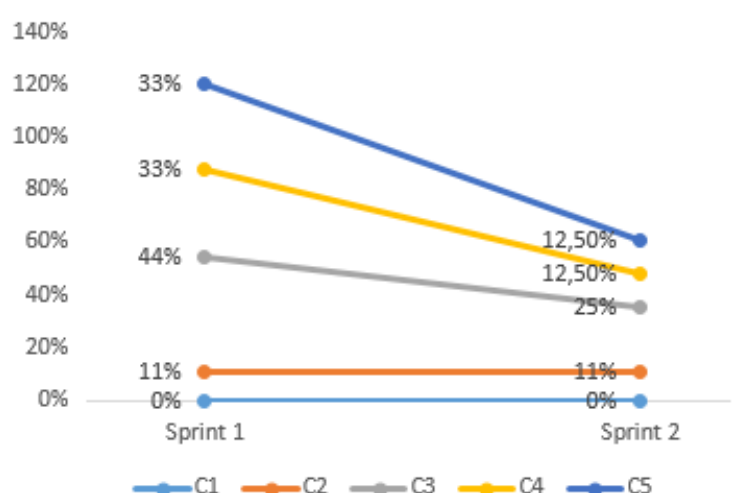

limitação, foi proposta uma melhoria do OntoSoft, a saber a criação de workflows para descrever a sequência de atividades em cada cenário, a fim de auxiliar o entendimento da equipe de forma visual e mais simplificada.

Além desses critérios, algumas considerações sobre as atividades de Engenharia de Ontologias propostas no OntoSoft também foram abordadas com base nos questionários e observações. Vale ressaltar que, apesar do estudo ser conduzido em uma disciplina específica de Engenharia de Ontologias, a maioria dos participantes não possuía experiência no desenvolvimento de uma ontologia. Todavia, a partir da aplicação do processo OntoSoft, foi constatada uma evolução nos resultados extraídos dos questionários, tanto no aprendizado dos conceitos relacionados à ontologia como na criação dos seus artefatos de desenvolvimento. Por exemplo, na primeira sprint, $78 \%$ dos participantes não elaboraram a avaliação inicial da ontologia, a partir de questões de competências genéricas, disponíveis em um dos artefatos indicados pelo processo OntoSoft. Já na segunda sprint, $87,5 \%$ dos participantes afirmaram ter feito a avaliação inicial com base nas questões indicadas.

Como mencionado na Seção 5.2, a aplicação AppLucy se enquadra no primeiro cenário de desenvolvimento (Seção 4.5.1). Em virtude da complexidade da ontologia, do domínio desconhecido da aplicação e da inexperiência no desenvolvimento de ontologias da equipe, tanto na primeira quanto na segunda sprint, o desenvolvimento da ontologia consumiu mais tempo do que o esperado pela equipe.

Em geral, os participantes seguiram o processo OntoSoft e apontaram diversas contribuições e melhorias, as quais foram realizadas para facilitar o entendimento do mesmo. Alguns fatores que se destacaram foram:

- A disposição das atividades no Pré-Desenvolvimento está de acordo com o fluxo de trabalho, todas as atividades foram consideradas na execução do estudo e não foi sugerida mudança nesta fase do processo. 
- As equipes consideraram a dependência entre as atividades, tanto relacionadas à ontologia quanto ao software, por meio da definição de prioridades no planejamento das sprints.

- Os artefatos foram construídos seguindo os modelos fornecidos e as tarefas do processo.

Ainda com base no feedback dos participantes, um diferencial do processo está em guiar e direcionar o desenvolvimento do software baseado em ontologia, alinhando as atividades do engenheiro de software e engenheiro de ontologia. Esse item pode ser particionado em três categorias: (i) guiar o desenvolvimento de forma facilitada e otimizada; (ii) manter a equipe bem direcionada; e (iii) decidir as regras de negócio com o apoio da ontologia.

$\mathrm{O}$ alinhamento das atividades permitiu identificar as especificidades e diferenças durante o desenvolvimento, guiando os participantes que ainda não conheciam software baseado em ontologia. No entanto, a inexperiência é uma ameaça à validade de construção do estudo de caso, em virtude da possibilidade de não entendimento e/ou seguimento do processo.

A maior dificuldade enfrentada foi o entendimento da ontologia, assim como desenvolver e integrá-la à aplicação. Os participantes reportaram dificuldades em: (i) entender o propósito da ontologia no contexto do projeto; (ii) especificar o que deve ser parte da ontologia e o que deve ser parte da aplicação; e (iii) integrar os membros da equipe.

Nesse sentido, observa-se que as principais limitações não estão ligadas ao processo OntoSoft, mas são de cunho conceitual, sendo categorizadas em três grupos: (i) falta de conhecimento com a metodologia ágil Scrum; (ii) dificuldade com o paradigma de software baseado em ontologia; e (iii) falta de exemplos na construção dos artefatos. Somente o terceiro item está relacionado ao OntoSoft; de fato, os exemplos se fazem necessários para esclarecer as dúvidas no desenvolvimento das ontologias para equipes que não possuem experiência.

Apesar das limitações identificadas e do pouco tempo para aprender e aplicar os novos conceitos do processo, os participantes conseguiram gerar artefatos para a aplicação, seguindo as diretrizes propostas no OntoSoft. Na Tabela 21, os artefatos são apresentados, seguidos da equipe e granularidade correspondentes.

Tabela 21 - Artefatos gerados no decorrer das duas sprints.

\begin{tabular}{|c|c|c|}
\hline & Artefato & Granularidade \\
\hline \multirow[t]{3}{*}{ Equipe A } & Produto de backlog & 5 itens categorizados \\
\hline & Glossário de termos & 5 conceitos identificados \\
\hline & Esboço da ontologia & $\begin{array}{l}6 \text { classes, } 5 \text { propriedades de objeto, } \\
3 \text { propriedades de dados e } 3 \text { indivíduos. }\end{array}$ \\
\hline \multirow[t]{2}{*}{ Equipe B } & Definição dos papeis da equipe & - \\
\hline & Produto de backlog & 7 itens categorizados \\
\hline
\end{tabular}

As equipes A e B desenvolveram artefatos diferentes, em virtude das prioridades distintas para os itens de backlog identificados e planejados, conforme pode ser observado na Tabela 21. 
Além disso, a visão dos engenheiros de software e de ontologia, bem como o entendimento do domínio da aplicação, são fatores que interferem na definição do fluxo de desenvolvimento e consequentemente nos itens entregues, como pode ser visto nesse estudo.

A Equipe A gerou três artefatos, entre eles o esboço da ontologia da aplicação AppLucy. Os participantes demonstraram entendimento na execução das atividades do processo OntoSoft e elaboraram os artefatos correspondentes à primeira e segunda sprints planejadas. Com relação à Equipe B, esta não desenvolveu a ontologia ou os artefatos relacionados, pois apresentou menor compreensão do conceito ontologia e, consequentemente, maior dificuldade modelar o problema proposto. A equipe refez o modelo inicial, pois na primeira modelagem não havia considerado a ontologia como um artefato. Esses fatores externos ao processo influenciaram diretamente na qualidade dos artefatos gerados.

No que diz respeito ao processo OntoSoft, a limitação estava na disponibilização de exemplos dos modelos de artefatos. Neste primeiro estudo de caso, os artefatos ainda não possuíam uma descrição pormenorizada dos campos a serem preenchidos ou exemplos de outras aplicações. Os participantes solicitavam mais detalhes e tiravam dúvidas quando havia oportunidade. Esta limitação foi resolvida, pois na nova versão do OntoSoft os modelos de artefatos foram descritos com mais detalhes e foram gerados exemplos a partir dos estudos de caso.

A partir dos resultados deste estudo e da visão da equipe de desenvolvimento, os principais pontos sobre a aplicabilidade do processo OntoSoft são:

- A complexidade do domínio não interferiu na execução das atividades. No entanto, a compreensão da equipe a respeito da aplicação influenciou no rendimento durante o desenvolvimento dos artefatos.

- As atividades de Engenharia de Software e Engenharia de Ontologias foram associadas de maneira adequada.

- As equipes seguiram as diretrizes (as tarefas) no processo OntoSoft em cada atividade especificada.

- Os artefatos especificados na documentação foram seguidos e utilizados pelas equipes.

- A documentação do processo foi considerada completa, no entanto, havia a necessidade de inserir mais exemplos nos modelos de artefatos.

Ainda que os participantes não fossem especialistas na área, os itens de backlog foram identificados e as sprints planejadas consideraram as ontologias a serem desenvolvidas. Além disso, a relação entre os artefatos e a precedência de atividades foram ponderadas. Considerando o tempo de desenvolvimento e a entrega dos artefatos é possível dizer que o processo OntoSoft 
colaborou significativamente para as equipes definirem as atividades e entregarem os artefatos em um curto espaço de tempo.

Na próxima seção é discutida a segunda parte do estudo na disciplina da UFSCar. O estudo foi aplicado com os mesmos participantes, mas com domínios de aplicações diferentes conforme o que havia sido estabelecido no projeto da disciplina.

\subsubsection{Segunda parte do estudo de caso: projetos da disciplina}

Após o término das sprints da aplicação AppLucy, os participantes começaram a utilizar o processo OntoSoft nos projetos de desenvolvimento de software baseado em ontologia na disciplina de Engenharia de Ontologias aplicada à Engenharia de Software na UFSCar. A proposta do processo OntoSoft permaneceu em seu formato original, pois os resultados do estudo piloto demonstraram aprovação dos participantes e corretitude no que se refere as características do processo.

O estudo de caso ocorreu durante as aulas, entre maio e julho de 2015; sendo que 10 alunos participaram do estudo de caso. Os alunos foram alocados em duas equipes e propuseram dois projetos distintos para o desenvolvimento de aplicações baseadas em ontologia. O desenvolvimento destas aplicações foi apoiado pelo processo OntoSoft, o qual também foi avaliado pelos participantes.

O objetivo do estudo foi avaliar a aplicabilidade do processo OntoSoft no desenvolvimento de software baseado em ontologia. Os participantes foram os sujeitos do estudo, os quais foram observados quanto ao seu desempenho no uso do processo, considerando a experiência e a prática no desenvolvimento de software baseada em ontologia.

A perspectiva é tida a partir do ponto de vista dos pesquisadores, ou seja, o pesquisador visa a identificar a diferença no desempenho do desenvolvimento dos projetos da disciplina, com base no histórico dos indivíduos e nas observações, por meio de questionários aplicados no decorrer da disciplina.

Desse modo, neste estudo foi feita a análise da aplicabilidade do processo OntoSoft, para verificar a otimização no desenvolvimento de software baseado em ontologia, considerando o desempenho dos participantes, a partir da visão dos pesquisadores no contexto do projeto da disciplina de Engenharia de Ontologias aplicada à Engenharia de Software.

Nas próximas seções são apresentados os procedimentos para a coleta de dados, a análise e a validação dos dados, assim como as limitações e lições aprendidas do estudo de caso.

\subsubsection{Preparação para a coleta de dados}

Para a execução do estudo de caso os participantes foram alocados em duas equipes, denominadas A e B, responsáveis por dois projetos distintos. Os participantes utilizaram o 
ambiente SeeNowDo para gerenciar as atividades e tarefas seguindo os valores do Scrum, os quais apoiam o processo OntoSoft. Foram elaborados questionários com o objetivo de verificar a aplicabilidade do processo, os quais são apresentados no Apêndice B. Na execução das sprints as respostas destes questionários serviram como base para avaliar o desenvolvimento do software baseado em ontologia. Ademais, em paralelo, as dúvidas e os comentários eram reportados durante as aulas e condução do estudo de caso.

A participação no estudo de caso foi considerada um dos requisitos durante a avaliação da disciplina. Além disso, outras tarefas foram destinadas aos participantes, que deviam entregar os artefatos correspondentes dentro do prazo estabelecido. Estas tarefas não foram relacionadas diretamente ao projeto da aplicação de cada equipe, mas tarefas globais disponibilizadas no ambiente da disciplina (Moodle) identificavam o engajamento dos participantes nas atividades e no uso do processo OntoSoft.

Dado este cenário e a natureza de avaliação de um processo, os dados coletados foram analisados de maneira qualitativa e descritiva, devido ao tamanho da amostra e aos resultados referentes as características do OntoSoft. Na Tabela 22 é apresentado o número de participantes para cada questionário durante o estudo.

Tabela 22 - Número de participantes em cada equipe e os respectivos questionários na condução do estudo de caso.

\begin{tabular}{lccccc}
\hline \hline Equipe/Questionário & Primeiro & Segundo & Terceiro & Quarto & Avaliação Final \\
Equipe A & 6 part. & 6 part. & 4 part. & 5 part. & 6 part. \\
Equipe B & 4 part. & 4 part. & 5 part. & 4 part. & 4 part. \\
\hline \hline
\end{tabular}

Nota-se que em algumas avaliações nem todos os alunos participaram, pois não estavam presentes na finalização da sprint. Adicionalmente, os participantes colaboraram respondendo a um formulário de avaliação geral do processo OntoSoft ao final do estudo. Os dados são apresentados e analisados nas próximas seções.

\subsubsection{Análise dos dados}

A fim de avaliar a aplicabilidade do processo OntoSoft, fatores como cumprimento das atividades, uso da ferramenta SeeNowDo e uso e aceitação do processo foram investigados e são discutidos nesta seção. A evolução das dificuldades e dos benefícios relativos ao processo também são sumarizados nesta seção, para fundamentar a análise descritiva do estudo de caso.

No que concerne às áreas de conhecimento abordadas, as equipes desenvolveram projetos distintos, mas com grau de dificuldade similar. A Equipe A desenvolveu uma aplicação no campo de transtornos mentais. O escopo do projeto foi definido a partir de entrevistas que eram transcritas no sistema, cujo objetivo foi identificar sintomas sobre esquizofrenia. Já a Equipe B desenvolveu uma aplicação para informar o valor nutricional de diversos alimentos associados às doenças como diabetes, obesidade e hipertensão. 
As respostas dos questionários foram manipuladas e sumarizadas em tabelas e gráficos. Os dados das duas equipes foram analisados separada e conjuntamente ao longo do estudo. Também foi calculada a média ponderada na avaliação de cada questão, considerando o número total de participantes em cada sprint. De maneira geral, os dados das principais características para aferir o objetivo do estudo de caso foram considerados. Atividades dentro do prazo, uso da ferramenta SeeNowDo, consulta do processo e coerência das atividades do OntoSoft são exemplos de tais características dispostas na Figura 33.

Figura 33 - Número total de participantes para os critérios observados no estudo de caso.

\begin{tabular}{|c|c|c|c|c|c|c|c|c|c|c|c|c|}
\hline \multirow{2}{*}{ Observação } & \multicolumn{3}{|c|}{ Sprint 1} & \multicolumn{3}{|c|}{ Sprint 2} & \multicolumn{3}{|c|}{ Sprint 3} & \multicolumn{3}{|c|}{ Sprint 4} \\
\hline & Sim & Parcialmente & Não & Sim & Parcialmente & Não & Sim & Parcialmente & Não & Sim & Parcialmente & Não \\
\hline $\mathrm{F} 1$ & 7 & 3 & 0 & 7 & 3 & 0 & 5 & 4 & 0 & 9 & 0 & 0 \\
\hline $\mathrm{F} 2$ & 10 & 0 & 0 & 7 & 3 & 0 & 9 & 0 & 0 & 9 & 0 & 0 \\
\hline F3 & 6 & 4 & 0 & 5 & 5 & 0 & 5 & 4 & 0 & 6 & 3 & 0 \\
\hline $\mathrm{F} 4$ & 8 & 2 & 0 & 8 & 2 & 0 & 6 & 3 & 0 & 7 & 2 & 0 \\
\hline
\end{tabular}

Fonte: Elaborada pela autora.

O campo observação na Tabela 33 diz respeito aos seguintes fatores: F1 - atividades dentro do prazo; F2 - uso da ferramenta SeeNowDo; F3 - frequência de consulta ao processo; e F4 - as atividades do OntoSoft supriram as necessidades da equipe. Também são apresentados dados das quatro sprints os fatores considerados. Os valores de cada coluna na tabela (Sim, Parcialmente e Não) representam o número total de participantes, considerando as duas equipes. Essas informações foram convertidas, agrupadas e são discutidas detalhadamente no decorrer da seção.

No que tange à execução das atividades, o objetivo foi avaliar o tempo de desenvolvimento e a entrega de artefatos na finalização do estudo de caso. Ao término de cada sprint as equipes realizavam entregas, porém o nível de detalhamento e o tipo de artefato eram distintos. Apesar de seguirem o mesmo cenário para desenvolvimento das aplicações, as sprints foram planejadas em conformidade com as prioridades dadas pela equipe. Por exemplo, a Equipe A entregou a primeira versão do glossário da ontologia, enquanto a Equipe B entregou o backlog da sprint. Estes dois artefatos distintos evidenciam diferentes escolhas de atividades das equipes.

Na Tabela 23 são apresentados os artefatos gerados e suas granularidades para cada equipe na respectiva sprint.

$\mathrm{Na}$ Figura 34 observa-se que a maioria das atividades ocorreu no prazo estabelecido pela equipe. Na primeira e na segunda sprints $70 \%$ dos participantes afirmaram que as atividades foram executadas dentro do planejado. Porém, na terceira sprint a Equipe A apresentou dificuldade para formalizar os conceitos da ontologia, dada a complexidade e especificidade do domínio. Por isso, cerca de $44 \%$ dos participantes indicaram que as atividades foram cumpridas parcialmente. No entanto, ao final da quarta sprint todas as atividades ocorreram e foram finalizadas conforme planejado na sprint. 
Tabela 23 - Artefatos gerados e entregues ao final das sprints.

\begin{tabular}{ccl}
\hline \hline & Equipe & Artefato(s) \\
\hline Sprint 1 & A & $\begin{array}{l}\text { Backlog do produto } \\
\text { Primeira versão do glossário } \\
\text { Definição dos papeis da equipe }\end{array}$ \\
\hline & B & $\begin{array}{l}\text { Backlog do produto, Backlog da sprint } \\
\text { Definição dos papeis da equipe }\end{array}$ \\
\hline \hline Sprints 2 e 3 & A & $\begin{array}{l}\text { Backlog do produto } \\
\text { Backlog da sprint, Cenários de uso } \\
\text { Documento de visão, Documento de requisitos } \\
\text { Modelo de domínio, Modelo da ontologia }\end{array}$ \\
\hline & B & $\begin{array}{l}\text { Backlog do produto } \\
\text { Backlog da sprint } \\
\text { Documento de requisitos, Glossário de termos }\end{array}$ \\
\hline \hline Sprint 4 & A & $\begin{array}{l}\text { Finalização da ontologia } \\
\text { Glossário de termos, Finalização da ontologia }\end{array}$ \\
\hline \hline
\end{tabular}

Figura 34 - Evolução do cumprimento das atividades no decorrer do estudo.

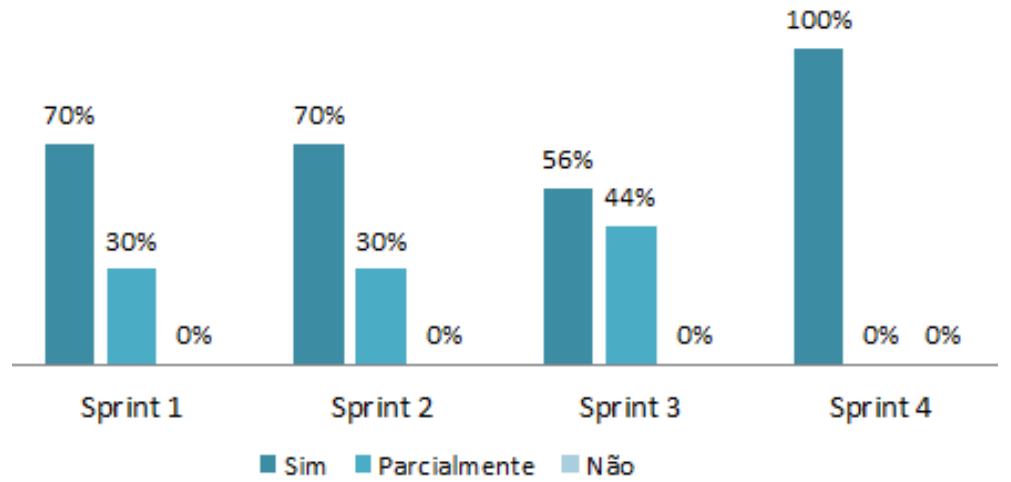

Fonte: Elaborada pela autora.

Outro fator observado refere-se ao uso da ferramenta SeeNowDo, conforme indicado na Figura 35. Somente na segunda sprint $30 \%$ dos participantes afirmaram não ter atualizado ou acessado o ambiente de gerenciamento. Nas demais sprints, todos utilizaram a ferramenta, o que possibilitou acompanhar o engajamento dos participantes e a linha do tempo de cada projeto.

O uso da ferramenta forneceu a visão geral e ampla do projeto e possibilitou conciliar as práticas do Scrum ao projeto da aplicação. Estas práticas não eram do conhecimento da maioria dos membros das equipes antes do estudo. Vale destacar que um participante de uma das equipes não acompanhou a disciplina presencialmente; o SeeNowDo, dessa forma, garantiu a integração na equipe e na designação das tarefas.

A respeito da aceitação do processo OntoSoft, observou-se uma pequena discrepância nas opiniões das equipes, ao longo do desenvolvimento das aplicações. A divergência entre as equipes aconteceu devido a fatores externos ao processo, como dificuldades para compreender os conceitos referentes à ontologia e para conceitualizar o domínio de conhecimento abordado. Além disso, a duração do projeto foi considerada muito pequena para solucionar todas as dúvidas. 
Figura 35 - Uso da ferramenta de gerenciamento SeeNowDo durante o estudo.

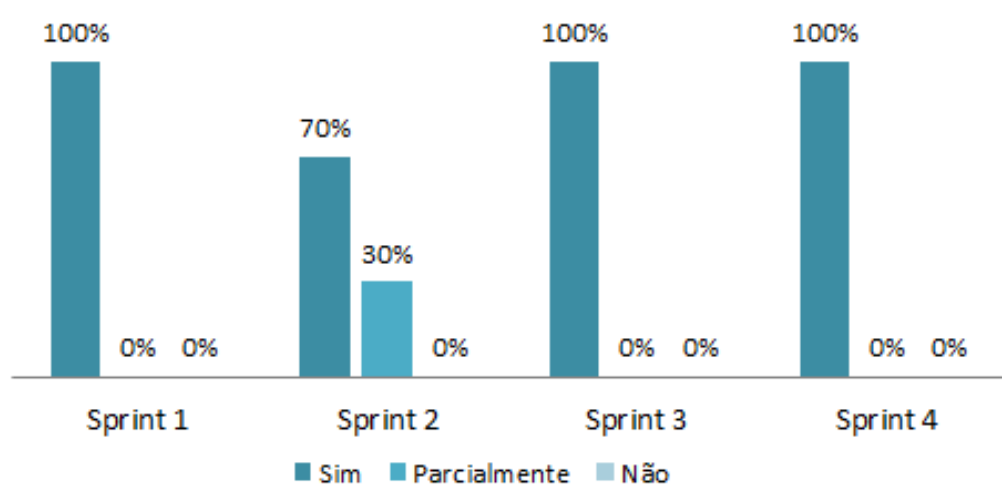

Fonte: Elaborada pela autora.

A Equipe A demonstrou um interesse mediano ao longo do desenvolvimento. Por outro lado, a Equipe $\mathrm{B}$ demonstrou uma evolução e estabilidade com relação à aceitação do processo OntoSoft, a partir da segunda sprint. Os resultados correspondente à questão as atividades do processo OntoSoft supriram as necessidades da equipe? são sumarizados na Figura 36.

Figura 36 - Análise da aceitação do processo OntoSoft no decorrer do estudo - Equipe A e Equipe B.

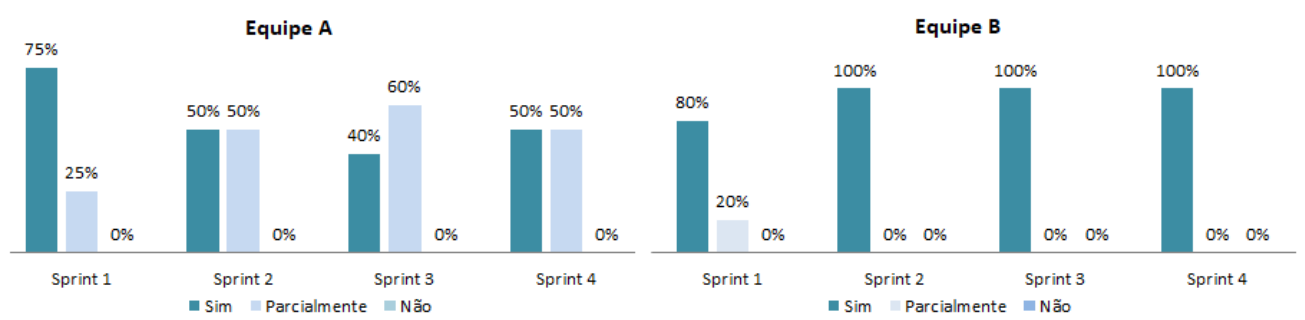

Fonte: Elaborada pela autora.

Na Figura 36 pode-se verificar que o processo OntoSoft teve um a taxa de aceitação acima da média. Quando os dados das duas equipes são considerados conjuntamente, na quarta sprint, por exemplo, a taxa de aprovação dos participantes é de $78 \%$.

No que diz respeito ao número de consultas que os participantes fizeram ao processo OntoSoft (Figura 37), houve mais consulta ao processo nas sprints inicial e final. Nas sprints intermediárias esperava-se, de fato, que os participantes consultassem o processo com menor frequência, pois as atividades estavam em andamento e a documentação do OntoSoft já havia sido estudada. Como na última sprint um grande número de artefatos foi entregue, os participantes revisaram as diretrizes e os cenários propostos no processo OntoSoft, a fim de utilizar os modelos de artefatos disponibilizados na documentação. Por isso, houve um crescimento considerável no número de acesso ao processo, aproximadamente $67 \%$ dos participantes.

Como já mencionado anteriormente, ao serem questionados sobre as dificuldades do OntoSoft, os participantes indicaram a ausência de exemplos de ontologias e a dificuldade com o Scrum como maiores limitações, tanto na avaliação inicial quanto na final. Apenas um 
Figura 37 - Análise do número de consultas dos participantes na aplicação do processo OntoSoft.

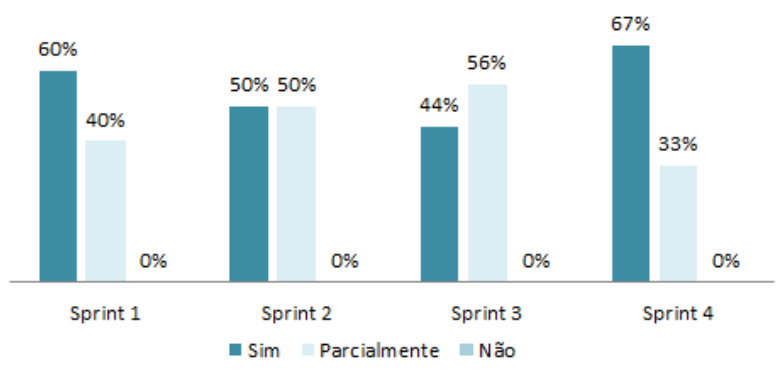

Fonte: Elaborada pela autora.

participante relatou que as diretrizes do processo estavam mal especificadas na avaliação inicial, de modo que na avaliação final esse aspecto não foi citado novamente, como é apresentado na Figura 38.

Figura 38 - Evolução das dificuldades encontradas no processo OntoSoft.

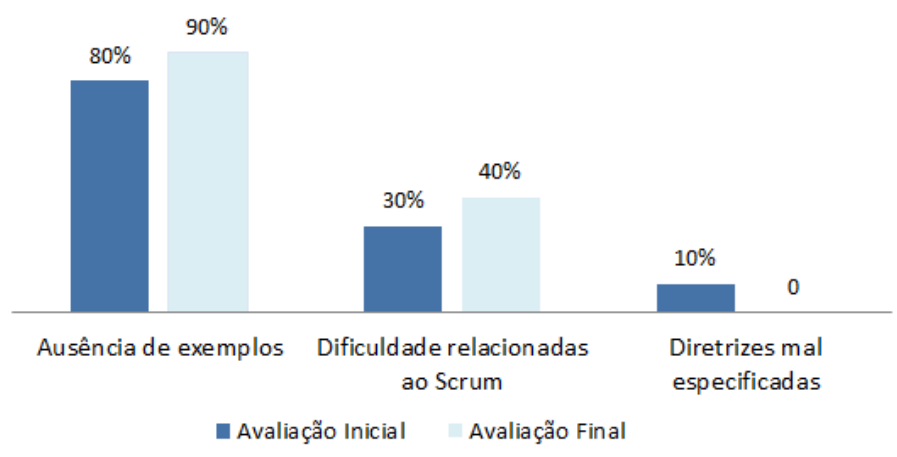

Fonte: Elaborada pela autora.

Dos três fatores de dificuldade observados, apenas um está relacionado de forma direta ao processo OntoSoft: a ausência de exemplos nos modelos de artefatos, conforme pode ser visto na Figura 38. Os participantes da Equipe A, por exemplo, mencionaram que o fato de desenvolver a aplicação e a ontologia em paralelo consumiu mais tempo do que o esperado. Além disso, para formalizar a ontologia era preciso ter acesso ao especialista do domínio, que não tinha muita disponibilidade para atender a equipe. Esse fato prejudicou o andamento do projeto, uma vez que a complexidade do domínio contribuiu para uma maior dependência da equipe em relação ao especialista.

No que se refere às vantagens do processo, os principais benefícios indicados pelos participantes estão sumarizados na Figura 39. Os participantes indicaram, a partir de uma lista fornecida no formulário, as principais contribuições referentes ao OntoSoft. De forma geral, sete critérios foram categorizados e mais citados pelas equipes, os quais são sumarizados na Figura 39.

Nota-se que os critérios (i) "tarefas bem definidas" e (ii) "fluxo iterativo do processo" se mantiveram com $80 \%$ do início ao fim do estudo de caso. Tanto na primeira quanto na última 
Figura 39 - Evolução dos benefícios identificados no processo OntoSoft durante o estudo.

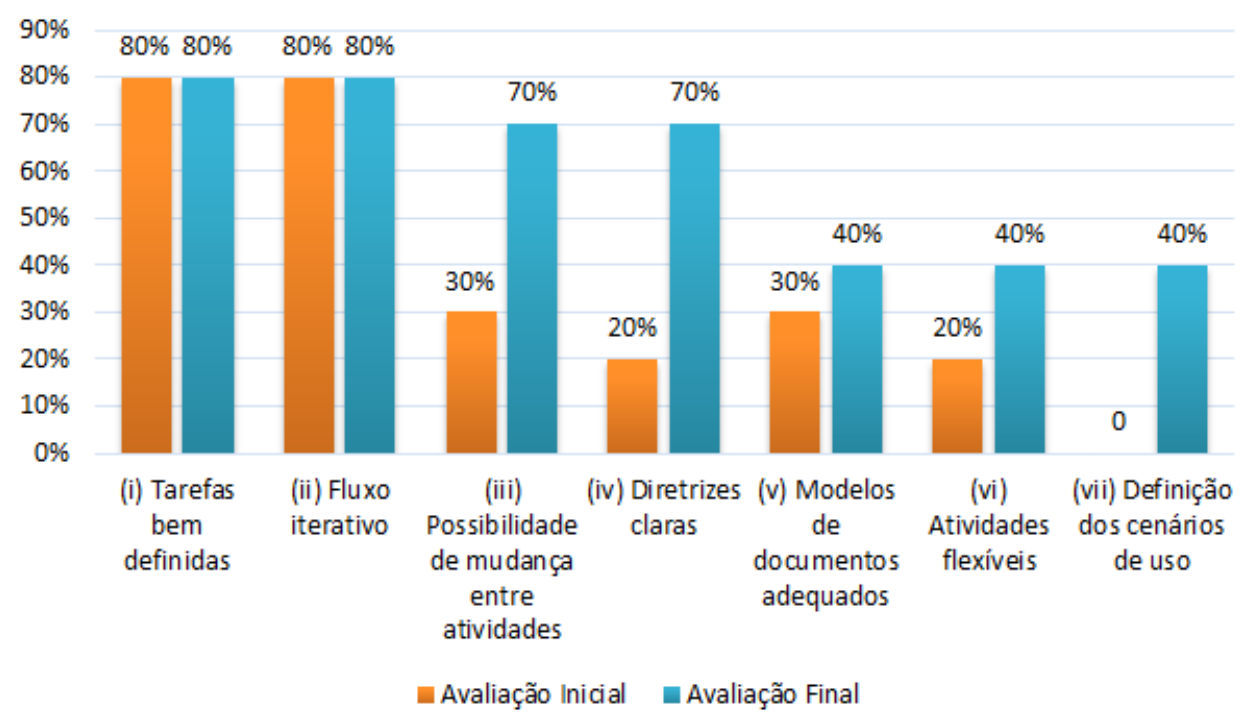

Fonte: Elaborada pela autora.

avaliação estas características se destacaram, confirmando a definição detalhada das tarefas como um dos principais diferenciais do processo OntoSoft, seguidos pelos valores ágeis empregados.

Os critérios (iii) e (iv), que indicam mudança e clareza das diretrizes, tiveram um aumento de mais de $100 \%$ na avaliação final. Os participantes afirmaram que as diretrizes estavam claras e o processo possibilitou a flexibilidade de mudança entre grandes atividades no decorrer do estudo. Essa possibilidade de mudança também é vista no item (vi), que teve um aumento significativo de $20 \%$ para $40 \%$ na última avaliação.

Além desses critérios, os modelos de documentos foram considerados adequados por $40 \%$ dos participantes e a definição dos cenários de uso também foi indicada como uma vantagem do OntoSoft por quase metade dos participantes na avaliação final.

O principal objetivo deste segundo estudo de caso foi avaliar a aplicabilidade do processo OntoSoft no desenvolvimento de software baseado em ontologias. Tanto na primeira quanto na segunda parte do estudo, o OntoSoft contribuiu para o desenvolvimento das aplicações baseadas em ontologia, guiando o projeto, o desenvolvimento e a entrega de artefatos de maneira satisfatória. Por fim, a utilização do processo OntoSoft facilitou o desenvolvimento das aplicações na disciplina e guiou as atividades dos participantes, de maneira otimizada, considerando valores e práticas ágeis para gerenciar as tarefas e as entregas de artefatos.

Além dos resultados discutidos, também foram identificadas algumas perspectivas dos participantes extraídas a partir de observações e opiniões durante a aplicação do processo OntoSoft. Nesse sentido, o propósito é apresentar uma análise qualitativa do ponto de vista dos participantes, com base nos comentários feitos nos questionários na execução das sprints. De maneira geral, pode-se afirmar que os principais benefícios concentraram-se em duas vertentes: 
(i) aplicação das ontologias e (ii) uso do processo OntoSoft.

A maioria dos participantes não possuía experiência na criação de ontologias, dos dez participantes apenas dois haviam desenvolvido uma ontologia, como foi apresentado na primeira parte do estudo de caso (Seção 5.2.1). Segundo os participantes, o maior aprendizado foi, sobretudo, no entendimento dos conceitos de ontologia e engenharia de ontologia, bem como na aplicação prática da ontologia nos projetos de desenvolvimento de software. Como demonstrado na Tabela 24, ambas as equipes elencaram este fator nos questionários de avaliação.

Tabela 24 - Observação dos participantes sobre o maior aprendizado na disciplina.

\begin{tabular}{ll}
\hline \hline Equipe & Sumarização dos comentários: \\
& - Uso de ontologias para resolução de problemas complexos que envolvem semântica. \\
& - Aprendizado do processo de construção da ontologia. \\
A & - Uso da ontologia como um artefato efetivo na implementação do software. \\
& - Os conceitos de ontologia, o uso da ferramenta Protegé e a aplicação do processo \\
& OntoSoft em sua construção. \\
\hline & - Conceitos de Engenharia de Ontologias e sua aplicação prática. \\
& - Definição e desenvolvimento da ontologia para a aplicação. \\
& - Entregas facilitadas pelo uso do processo OntoSoft no trabalho em equipe. \\
& - Validação da ontologia pelo especialista. \\
& - Utilização de um processo que integra uma ontologia à aplicação. \\
\hline \hline
\end{tabular}

Uma importante contribuição destacada pelos participantes refere-se à liberdade para criar o projeto e as entregas semanais, que motivaram e influenciaram a execução e conclusão das atividades. Esse fato é evidenciado nos comentários (Tabela 24), em que a maior parte das observações concentra-se na construção e utilização da ontologia.

Além de avaliar o processo OntoSoft, os participantes também avaliaram o formato da disciplina. Os comentários abordaram críticas e limitações, contribuições e sugestões para a disciplina, como pode ser visto nas contribuições da Tabela 25.

Tabela 25 - Observação dos participantes acerca das críticas, limitações e contribuições para a disciplina.

\begin{tabular}{ll}
\hline \hline Equipe & Descrição: \\
& Críticas/limitações: \\
& - Carência de exemplos para auxiliar no desenvolvimento do projeto proposto na disciplina. \\
& Porém, a falta desses materiais levaram ao auto aprendizado. \\
& Contribuições: \\
A & - Apresentação e formato da disciplina. \\
& - A liberdade na escolha do projeto proporcionou maior aprendizagem e pró-atividade dos alunos. \\
& - Maior motivação para aprender o conteúdo apresentado na disciplina. \\
& Críticas/limitações: \\
& - Inclusão de mais exemplos de ontologias, registros de processo e artefatos. \\
& Contribuições: \\
& - A definição do tema do projeto feita pelos alunos. \\
& - Entrega de artefatos semanalmente. \\
& Sugestões: \\
& - Fazer uma apresentação breve da equipe referente ao que foi feito durante a semana. \\
& - Maior tempo de duração da disciplina. \\
B
\end{tabular}


No que se refere às críticas e limitações, a maioria dos participantes fez referência à falta de exemplos nos artefatos, para seguir os modelos sugeridos pelo processo. Esta foi a característica que mais se destacou negativamente na aplicação do processo OntoSoft, devido à pouca experiência dos participantes no desenvolvimento de ontologias. Outra limitação indicada está na familiaridade com o Scrum, pois os participantes não conheciam as práticas e os valores propostos na metodologia ágil. Percebe-se, portanto, que parte das limitações não são próprias do OntoSoft, mas revelam a falta de experiência em Engenharia de Ontologias e a falta de conhecimento dos valores do Scrum.

Ainda quanto às limitações, em virtude do desenvolvimento de software baseado em ontologia ser um tema de pesquisa emergente, foram elicitadas as principais ameaças que podem interferir nos resultados deste estudo de caso, a saber:

- O número de participantes no estudo de caso foi pequeno. Estudos de caso envolvendo um número maior de participantes podem ser considerados futuramente.

- O estudo de caso foi aplicado em um ambiente acadêmico, como requisito em uma disciplina da pós-graduação. Esse fato pode gerar algumas intercorrências quanto à avaliação e aceitação do processo, dependendo de como os participantes/alunos reagem às atividades.

- Os resultados ainda não podem ser generalizados, dado que as aplicações desenvolvidas possuem domínios muito complexos e são de difícil replicação para outras equipes, considerando o tempo necessário para o desenvolvimento das aplicações no estudo de caso.

Independentemente das limitações e ameaças identificadas, os resultados preliminares indicaram a viabilidade de aplicação do processo. O OntoSoft foi bem avaliado pelas equipes, possibilitando uma maior compreensão do uso de ontologias na Engenharia de Software, especialmente no desenvolvimento de software. Entretanto, as limitações apresentadas devem ser consideradas para o desenvolvimento de novos estudos de avaliação.

Nas próximas seções, um terceiro estudo de caso para avaliação do OntoSoft é apresentado. O estudo foi conduzido em um ambiente real de desenvolvimento, a fim de complementar a validação do processo OntoSoft.

\subsection{Estudo de caso 3: fábrica de software - AppLucy}

A partir da aplicação do processo OntoSoft nos estudos de caso anteriores, foram realizadas pequenas mudanças no processo. De fato, não foi necessário alterar as diretrizes propostas inicialmente, demonstrando a coerência das atividades definidas. Assim como nos estudos anteriores, a meta deste terceiro estudo foi analisar a aplicabilidade e efetividade do OntoSoft, considerando a visão das equipes no desenvolvimento da aplicação AppLucy. 
Este terceiro estudo foi conduzido na fábrica de software da Polícia Militar do Estado de São Paulo. A fábrica de software localizada no Comando Geral possui mais de 100 funcionários alocados em diversos projetos relacionados à segurança e prevenção de crimes na cidade de São Paulo. Por meio de estratégias implementadas em vários sistemas computacionais, os policiais e desenvolvedores buscam soluções inteligentes e automatizadas para alguns problemas de segurança da sociedade.

O estudo foi conduzido durante três períodos de quatro horas e contou com a participação de funcionários da fábrica de software. Em razão dos funcionários estarem sempre alocados a projetos na fábrica, somente 12 pessoas foram escaladas para participar das atividades do estudo de caso, a fim de não comprometer o andamento de seus projetos. Os participantes possuíam diferentes perfis e papeis de desenvolvimento e foram selecionados por alguns líderes em virtude das funções que desempenhavam em suas equipes. Duas equipes utilizaram o processo OntoSoft e uma terceira equipe usou a abordagem de desenvolvimento empregada na fábrica de software da Polícia Militar de São Paulo.

Na Tabela 26 são apresentadas as principais características do estudo conduzido na fábrica de software.

Tabela 26 - Protocolo para o estudo de caso conduzido na fábrica de software.

\begin{tabular}{ll}
\hline \hline Item & Descrição \\
\hline \hline Objeto de estudo & O processo OntoSoft é o objeto desse estudo. \\
Proposta & $\begin{array}{l}\text { A proposta deste estudo foi avaliar a aplicabilidade do processo OntoSoft e sua efe- } \\
\text { tividade de acordo com o desempenho dos desenvolvedores durante a aplicação do } \\
\text { processo. }\end{array}$ \\
Foco da qualidade & $\begin{array}{l}\text { O principal efeito estudado foi a efetividade do processo, investigando a aplicabilidade } \\
\text { e o desempenho dos desenvolvedores. }\end{array}$ \\
Aerspectiva & $\begin{array}{l}\text { A perspectiva foi extraída a partir do ponto de vista dos participantes que utilizaram o } \\
\text { processo OntoSoft e dos pesquisadores que desenvolveram o OntoSoft. } \\
\text { Contexto }\end{array}$ \\
& $\begin{array}{l}\text { O estudo foi aplicado em três grupos de desenvolvimento na fábrica de software da } \\
\text { de uma aplicação baseada em ontologia. Na execução do estudo dois grupos utilizaram } \\
\text { o processo OntoSoft e um terceiro grupo utilizou a abordagem de desenvolvimento da } \\
\text { fábrica. O estudo foi feito com aproximadamente 12 pessoas que seguiram as diretrizes } \\
\text { fornecidas no processo OntoSoft. }\end{array}$ \\
\hline \hline
\end{tabular}

\subsubsection{Preparação para a coleta de dados}

A validação de um processo é algo desafiador. Como indica García-Borgoñón et al. (2014), os processos de software são mais complexos e imprevisíveis do que processos típicos de produção, pois eles dependem de pessoas e as circunstâncias nem sempre são controladas. Por isso, por se tratar de um estudo conduzido em uma fábrica de software, em um ambiente real de trabalho, muitas intercorrências influenciaram a dedicação dos participantes, conforme 
é discutido neste capítulo. Nas próximas seções são apresentados o contexto e as variáveis do estudo, seguindo a abordagem indicada por Wohlin et al. (2012) para formalizar o estudo.

\section{Seleção do contexto e dos participantes}

O estudo de caso foi conduzido na fábrica de software da Polícia Militar, por meio do desenvolvimento de uma aplicação baseada em ontologia utilizando o processo OntoSoft. Os participantes são engenheiros de software que trabalham em projetos distintos, com diferentes funções e que utilizam a metodologia ágil Scrum no desenvolvimento das aplicações.

O estudo também serviu como base para os participantes compreenderem a importância do processo e as vantagens derivadas de seu uso; especificamente, como melhorar o desempenho da equipe e otimizar o desenvolvimento, por meio de diretrizes do processo OntoSoft. Nesse estudo de caso a aplicação AppLucy foi desenvolvida por três equipes, sendo que duas utilizaram o processo OntoSoft e uma equipe usou a metodologia da empresa.

O objetivo foi avaliar a efetividade do processo, por meio do desempenho dos grupos, contrastando as diferenças, os benefícios e as dificuldades identificadas pelas equipes que utilizaram o processo OntoSoft e a que não usou. Neste estudo, a produtividade foi medida com base no número total de artefatos entregues. Dessa forma, o cálculo percentual para as equipes $\mathrm{A}, \mathrm{B}$ e $\mathrm{C}$ foi feito com base no número total de artefatos. A partir dessa medida, pode-se dizer que a efetividade está diretamente relacionada à produtividade no desenvolvimento do software baseado em ontologia.

Os participantes foram escolhidos de acordo com critérios estabelecidos por dois líderes da fábrica, que também participaram do estudo. No total foram 12 participantes com diferentes formações e papeis nas equipes de desenvolvimento. Algumas funções dos participantes eram: arquiteto de software, scrum master, analista de requisitos, líder de requisitos, chefe de seção, líder de sustentação, product owner, chefe de divisão de desenvolvimento e analista de sistemas.

Inicialmente, os participantes responderam a um questionário para a identificação da experiência e conhecimento nas áreas de desenvolvimento de software, método ágil Scrum e ontologia. Os participantes indicaram o nível de conhecimento considerando a escala: regular, intermediário e especialista. Dez dos 12 participantes possuíam mais de seis anos de experiência em desenvolvimento de software, sendo que cinco deles com mais de dez anos de atuação.

Quanto ao método ágil Scrum, dos 12 participantes, 11 declararam ter conhecimento intermediário nas práticas e valores propostos no método. Alguns dos participantes das equipes desempenhavam, inclusive, o papel de scrum master em seus projetos na fábrica. Na Figura 40 é apresentado o nível de experiência em desenvolvimento de software e na Figura 41 é ilustrado o nível de experiência dos participantes referente ao Scrum.

No que se refere à ontologia, a grande maioria dos participantes não possuía experiência 
Figura 40 - Experiência dos participantes em desenvolvimento de software.

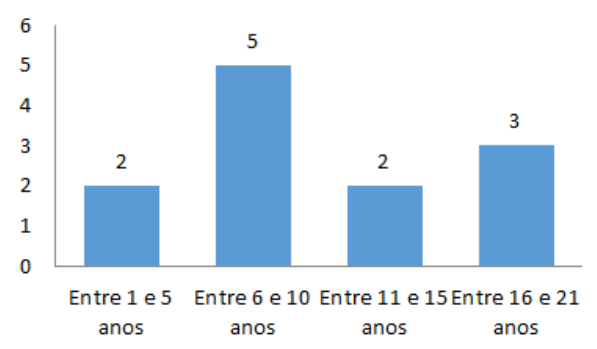

Fonte: Elaborada pela autora.

Figura 41 - Experiência dos participantes em práticas e valores do Scrum.

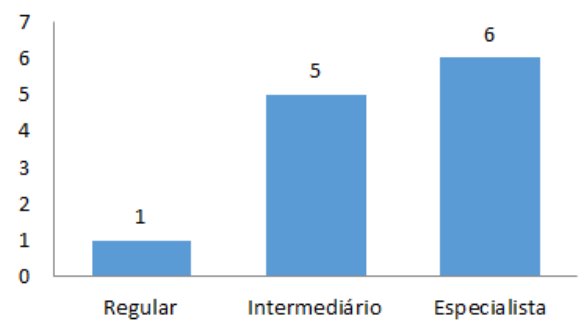

Fonte: Elaborada pela autora.

na construção e/ou aplicação de ontologias no desenvolvimento de software. Os 12 participantes afirmaram ter conhecimento regular na área. Por isso, a fim de minimizar as dificuldades referentes à construção de ontologias no estudo, um minicurso foi realizado antes do estudo de caso ser iniciado, apresentando os conceitos fundamentais relacionados à Engenharia de Ontologias.

No que se refere à instrumentação do estudo, os principais instrumentos que forneceram informações fundamentais para o desenvolvimento do software baseado em ontologia incluíram: (i) minicurso sobre ontologias e Engenharia de Ontologias para os participantes antes da condução do estudo; (ii) diretrizes descrevendo a documentação do processo OntoSoft; (iii) modelos de artefatos do processo OntoSoft para as equipes que o usaram; (iv) formulário de coleta de dados a partir da execução das sprints; e (v) formulário de avaliação no término do estudo e na entrega dos artefatos.

\subsubsection{Análise e discussão dos resultados}

Assim como nos dois primeiros estudos, neste estudo de caso os participantes responderam a diversos questionários durante a aplicação do processo. As três equipes tinham como principal tarefa especificar e desenvolver artefatos para a aplicação baseada em ontologia $A p$ pLucy, conforme foi descrito na Seção 5.2. A fim de gerar resultados comparativos, as equipes A e B utilizaram o processo OntoSoft e a Equipe C aplicou a metodologia padrão da fábrica não utilizando o processo. O estudo ocorreu em três períodos de quatro horas, em que cada equipe 
deveria desenvolver o máximo de artefatos da aplicação seguindo a metodologia proposta.

As equipes ficaram em ambientes separados e podiam esclarecer suas dúvidas solicitando a presença de quem estava conduzindo o estudo, quando necessário. Vale ressaltar que duas equipes demonstraram muito esforço ao executar as tarefas, enquanto uma equipe demonstrou resistência ao processo Ontosoft, como consequência de antigos problemas ocorridos na fábrica. Essa interferência pode ser notada nos resultados dos questionários de avaliação, sumarizados posteriormente.

Nas próximas seções são apresentados os resultados da condução do estudo considerando respectivamente: equipes A e B aplicando o OntoSoft e Equipe C sem utilizar o processo.

\subsubsection{Aplicação do processo OntoSoft: equipes $A$ e $B$}

As equipes A e B desenvolveram a aplicação AppLucy utilizando o processo OntoSoft. A Equipe A contou com quatro participantes e a Equipe B teve três participantes. Durante a execução do estudo, os participantes consultaram a documentação do OntoSoft e compreenderam a importância da ontologia e suas atividades na definição das sprints no software proposto. Notou-se que os participantes não tiveram retrabalho na execução das atividades definidas para o desenvolvimento do software, algo comum ao ambiente da fábrica de software em que atuam.

Nas primeiras atividades do estudo de caso, em virtude da falta de experiência dos desenvolvedores na criação de ontologias, houve um pouco de interferência no cumprimento dos prazos da sprint. Este fato é decorrente da falta de formação de especialistas ou até mesmo conhecedores intermediários na área de desenvolvimento de ontologias, a qual ainda pode ser considerada uma área de pesquisa emergente. Esta lacuna no entendimento da Engenharia de Ontologias já foi indicada nos estudos anteriores.

Apesar da inexperiência dos participantes, os resultados ao término do estudo demonstraram o impacto das diretrizes e tarefas do processo OntoSoft na execução das atividades de desenvolvimento do software e da ontologia. Além disso, por mais que o domínio da aplicação tenha sido diferente do contexto que normalmente é abordado na fábrica de software e os participantes não tenham background no desenvolvimento de artefatos da ontologia, as equipes puderam elaborar e entregar diversos artefatos no final da sprint, com o auxílio da descrição das atividades e tarefas do processo.

De forma geral, as equipes A e B geraram sete artefatos no desenvolvimento da aplicação. Pode-se dizer que estes números indicam a efetividade do OntoSoft, o qual colaborou na execução das sprints e, consequentemente, no aumento da produtividade das equipes, conforme apresentado na Tabela 27. A este resultado deve-se, também, o fato de que OntoSoft sugere modelos de artefatos, proporcionando agilidade na escolha e na padronização dos artefatos necessários ao software baseado em ontologia. A Equipe C, que não utilizou o processo, gerou apenas dois artefatos, conforme discutido na próxima seção. 
Tabela 27 - Artefatos gerados pelas equipes A, B e C no final do estudo de caso conduzido na fábrica de software da Polícia Militar.

\begin{tabular}{lll}
\hline \hline Artefato gerado pelas equipes & Com processo & Sem processo \\
\hline Produto de backlog & A, B & \\
Papeis da equipe & A, B & \\
Glossário de termos (iniciado) & A, B & \\
Documento de visão & A, B & C \\
Documento de requisitos & A, B & $\mathrm{C}$ \\
Esboço da ontologia & A, B & \\
Avaliação da ontologia & $\mathrm{B}$ & \\
Diagramas de projeto & $\mathrm{A}$ & \\
\hline \hline
\end{tabular}

Os artefatos produto de backlog e papeis da equipe são resultantes da visão geral das equipes sobre as principais funcionalidades que o sistema deve possuir e as competências dos participantes, respectivamente. O glossário de termos, esboço da ontologia e avaliação da ontologia são artefatos referentes às atividades de Especificação e Conceitualização da Ontologia. O documento de visão, documento de requisitos e diagramas de projeto correspondem aos artefatos gerados nas atividades Especificação de requisitos e Cenários de uso. Tais atividades e artefatos foram iniciados em paralelo pelas equipes, que definiram os itens de backlog considerando as associações entre os artefatos do software e da ontologia, de acordo com as diretrizes do processo OntoSoft.

Como o estudo aconteceu em um ambiente real de desenvolvimento e dado o pouco tempo disponibilizado para a condução do estudo de caso, a aplicação AppLucy não pode ser finalizada. Entretanto, as equipes desenvolveram os principais artefatos relacionados ao software baseado em ontologia na primeira sprint. Estes artefatos podem ser incrementados e finalizados nas sprints subsequentes. Vale ressaltar que os participantes definiram como prioridade e iniciaram o desenvolvimento dos artefatos relacionados à ontologia, com base nos itens de backlog identificados, guiados pelo processo OntoSoft.

Além do desenvolvimento dos artefatos, durante a condução do estudo de caso, os participantes avaliaram diversas características do processo OntoSoft, inclusive dando uma nota global, cujos valores são sumarizados na Figura 42. Em um contexto geral, os participantes aprovaram o OntoSoft.

Uma das equipes avaliou o processo entre sete e dez pontos e a outra equipe considerou entre três e seis pontos. Esses valores da equipe são resultados de uma aversão à sistematização da empresa. Esse comportamento dos participantes é derivado de diversos problemas ocorridos no ambiente de trabalho e da aversão ao novo, uma ameaça comum na implantação de novos processos e sistemas nas organizações. Contudo, mesmo apresentando opiniões divergentes na aprovação do OntoSoft, os participantes geraram sete artefatos no final do estudo.

Durante a avaliação também foram observadas questões sobre a disposição, a necessidade 
Figura 42 - Análise das notas dadas ao processo pelos participantes.

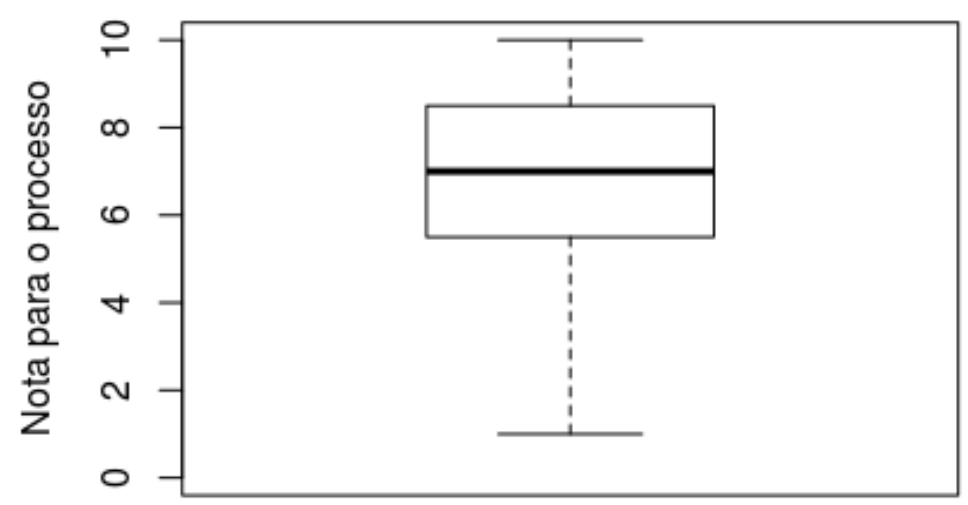

e a coerência das atividades do Pré-Desenvolvimento do OntoSoft. As equipes instanciaram a maioria das atividades da fase de Pré-Desenvolvimento, por isso estas foram enfatizadas na avaliação nos questionários. As conclusões obtidas sobre as atividades foram denominadas $\mathrm{C} 1$, C2 e C3 respectivamente e indicam se as atividades: (C1) estão de acordo com o fluxo do trabalho no processo; (C2) são consideradas necessárias para a equipe; e (C3) são coerentes com o escopo de desenvolvimento.

Nessa direção, foram analisadas as opiniões e extraídas conclusões (C4, C5 e C6) a respeito da construção das ontologia, a saber: (C4) a atividade de aquisição do conhecimento e de conceitualização foram consultadas por todos os participantes; (C5) o desenvolvimento da ontologia da aplicação consumiu mais tempo do que esperado pela equipe; e (C6) a atividade de integração da ontologia ao software foi coberta pelo processo. Tais conclusões (C1 a C6) são sumarizadas na Figura 43.

Por fim, as duas equipes afirmaram ter concluído a sprint dentro do prazo estabelecido, demonstrando que os itens de backlog foram definidos com segurança pelos participantes e utilizando as diretrizes do OntoSoft para definir e decidir suas ações. As limitações do ambiente e do processo não impediram o bom andamento do desenvolvimento da aplicação. Os cenários de uso atenderam às necessidades das equipes, que julgaram as tarefas estabelecidas como pertinentes e o apoio essencial na execução das atividades. Além disso, os modelos de artefatos foram utilizados e entregues conforme o planejado.

Com relação às limitações do processo OntoSoft, os participantes indicaram a necessidade da definição de checklists para prover uma visão global das iterações entre atividades e tarefas do OntoSoft. Esta melhoria foi adicionada ao processo e foi descrita na Figura 43, trata-se da criação dos fluxos de atividades nos cenários estabelecidos, com o propósito de facilitar a compreensão da sequência das atividades e tarefas nos cenários de desenvolvimento.

Outro ponto refere-se ao tempo destinado à execução do estudo. Esta é uma ameaça que não pode ser controlada pelos pesquisadores, pois é uma consequência de se aplicar o processo em um ambiente real de desenvolvimento, em que os participantes têm muitos afazeres e não 
Figura 43 - Observações sobre a coerência e a avaliação das atividades no processo OntoSoft.

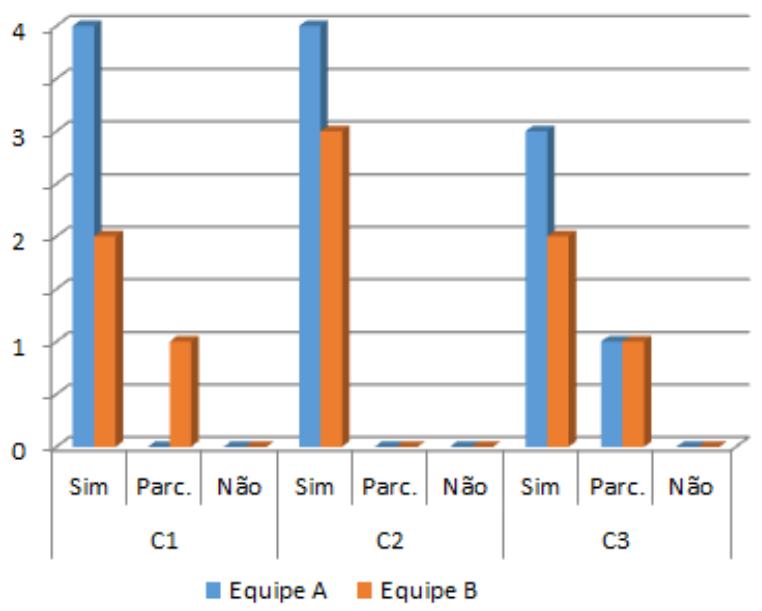

(a) Sobre a coerência.

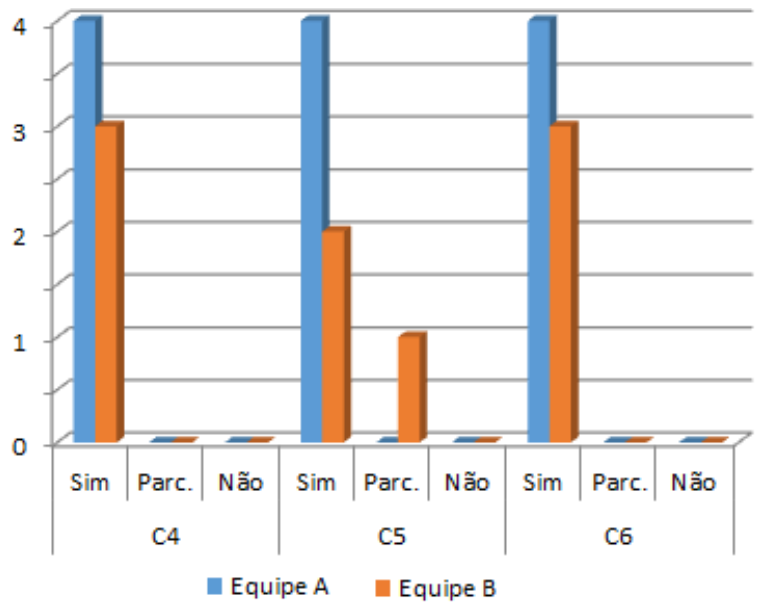

(b) Sobre a avaliação.

podem ser alocados por um longo tempo em outras tarefas sem prejudicar seus projetos. Esta característica é natural em um ambiente de desenvolvimento real e pode ser vista como um fator enriquecedor para a análise do processo OntoSoft, diante dos resultados relacionados à produtividade das equipes.

Com base nas entregas dos artefatos das equipes, pode-se dizer que o processo OntoSoft auxiliou na efetividade das equipes de desenvolvimento. Apesar do pouco tempo para a realização do estudo de caso e da inexperiência no contexto de software baseado em ontologia, as equipes A e B iniciaram e entregaram os principais artefatos da aplicação AppLucy. Os participantes seguiram as instruções e obtiveram bons resultados criando os artefatos de maneira efetiva.

Para completar a análise da condução do estudo de caso na Polícia Militar, na próxima seção são apresentadas as considerações sobre os resultados da Equipe $C$ na aplicação do processo OntoSoft.

\subsubsection{Aplicação do processo OntoSoft: Equipe C}

Durante a execução do estudo, a Equipe C não utilizou o processo OntoSoft, a fim de contrapor os resultados de todas as equipes na construção da aplicação AppLucy. A Equipe C seguiu a abordagem de rotina na empresa, ou seja, a partir da apresentação do problema os participantes procuraram delimitar o escopo e identificaram os itens de backlog do software baseado em ontologia, seguindo os valores do Scrum. Na Tabela 28 são sumarizados os principais pontos observados durante a condução do estudo pela Equipe C.

É importante mencionar que para a Equipe $\mathrm{C}$, adicionalmente à realização do minicurso, foi feita uma explanação durante a execução do estudo de como modelar e desenvolver uma ontologia, a fim de esclarecer as tarefas importantes no desenvolvimento da ontologia da aplicação. Essa ação fez-se necessária porque no decorrer do planejamento da sprint os participantes 
Tabela 28 - Observações extraídas dos questionários respondidos pelos participantes da Equipe C.

\begin{tabular}{|c|c|}
\hline Fator observado & Descrição \\
\hline Papeis da equipe & $\begin{array}{l}\text { Especialista da aplicação, especialista do domínio, engenheiro de } \\
\text { software e Scrum Master. }\end{array}$ \\
\hline $\begin{array}{l}\text { Metodologia utili- } \\
\text { zada }\end{array}$ & $\begin{array}{l}\text { Scrum associado à experiência de cada um dos integrantes no } \\
\text { desenvolvimento de aplicações. }\end{array}$ \\
\hline $\begin{array}{l}\text { Desenvolvimento do } \\
\text { software e da ontolo- } \\
\text { gia }\end{array}$ & $\begin{array}{l}\text { A equipe não abordou a necessidade de desenvolver a ontologia } \\
\text { antes ou simultaneamente aos demais artefatos do software. }\end{array}$ \\
\hline Escopo da aplicação & $\begin{array}{l}\text { A maioria dos participantes identificou a diferença do escopo da } \\
\text { ontologia, mas teve dificuldade em modelar as diferenças nos } \\
\text { itens de backlog. }\end{array}$ \\
\hline
\end{tabular}

perceberam a diferença no escopo da aplicação, mas não discutiram ou associaram o papel da ontologia aos demais artefatos do software. Após a explanação realizada, o planejamento da sprint foi refeito e os artefatos iniciados foram corrigidos e atualizados considerando a ontologia como um artefato primordial para compor a aplicação AppLucy.

Após o replanejamento da sprint os participantes elaboraram alguns artefatos, sendo dois deles entregues no final do estudo: a especificação dos requisitos e o esboço da ontologia. Assim como ocorreu na avaliação das equipes A e B, os participantes responderam alguns questionários durante o estudo, com a finalidade de extrair as dificuldades enfrentadas, as características do desenvolvimento da aplicação entre outros pontos observados.

Como a Equipe $\mathrm{C}$ não utilizou um processo para guiar as atividades, foram elaboradas questões referentes às características esperadas em uma metodologia para guiar o desenvolvimento de software baseado em ontologia. Nesse sentido, os participantes indicaram alguns pontos, a saber: maior dinamismo, agilidade e praticidade, facilidade na definição do escopo, e construção da visão global do sistema a ser desenvolvido.

O processo OntoSoft abrange a maioria das características identificadas, tais como agilidade, praticidade e visão global da aplicação. Por meio da descrição detalhada das atividades, das tarefas, dos papeis, dos cenários e dos artefatos, o processo colabora diretamente para que os fatores mencionados ocorram de maneira natural e gradativa no desenvolvimento do software baseado em ontologia. No que se refere ao dinamismo e à facilidade na definição do escopo, o OntoSoft também colabora por meio da visão geral das atividades e dos cenários de desenvolvimento. No entanto, vale ressaltar que esses pontos não excluem a importância da experiência e da dedicação da equipe.

Além disso, na avaliação final do estudo, os participantes foram questionados quanto à complexidade da aplicação proposta com relação às aplicações que estavam habituados a desenvolver. Especificamente no que diz respeito ao uso de uma ontologia, a maior dificuldade foi a falta de entendimento do conceito ontologia e de experiência na sua construção, o que tornou a aplicação mais complexa.

De forma geral, os participantes: (i) identificaram corretamente a proposta da aplicação; 
(ii) fizeram a divisão das tarefas considerando as práticas do Scrum; (iii) definiram as prioridades com base na sequência dos dados da aplicação; e (iv) definiram como primeiros artefatos o documento de visão do sistema e o dicionário de dados (ou glossário de termos da ontologia).

Contrapondo estes resultados aos resultados das equipes A e B, que aplicaram o processo OntoSoft, pode-se inferir que os participantes amparados pelas diretrizes do OntoSoft compreenderam e produziram mais. As equipes A e B não refizeram artefatos; pelo contrário, iniciaram e finalizaram sete artefatos na sprint. Por outro lado, a Equipe $\mathrm{C}$ teve retrabalho e entregou apenas dois artefatos no final da sprint. Tais indicativos demonstram que o OntoSoft apoiou de maneira eficaz o desenvolvimento da AppLucy, que se enquadra no primeiro cenário definido no processo.

\subsection{Considerações finais}

Neste capítulo foram apresentados os estudos de caso conduzidos para avaliar a aplicabilidade, efetividade e produtividade do processo OntoSoft em diferentes equipes de desenvolvimento. Apesar da dificuldade em contactar especialistas para formar as equipes, no final do trabalho foram elaborados três estudos de caso com especialistas e não especialistas da área para validar o processo OntoSoft.

O primeiro estudo de caso ocorreu na fase inicial de definição do processo OntoSoft, com especialistas em Engenharia de Ontologias, com o intuito de validar as primeiras definições do processo. O segundo estudo aconteceu em dois momentos, em uma disciplina de pós-graduação. Os participantes possuíam o conhecimento dos conceitos de ontologia e Engenharia de Ontologias, mas não possuíam experiência prática. No final do estudo duas aplicações foram desenvolvidas e o processo OntoSoft obteve aprovação da maioria dos seus usuários. O terceiro estudo foi realizado em uma fábrica de software, em um ambiente real de desenvolvimento. Os funcionários escolhidos foram remanejados de seus projetos na organização para participarem do estudo de caso. Foram formadas três equipes, duas aplicaram o processo e a terceira não utilizou uma abordagem específica. Como resultado, o processo OntoSoft foi mais efetivo e proporcionou a geração de mais artefatos.

A partir dos resultados obtidos nos estudos conduzidos observou-se que o processo OntoSoft atingiu o seu objetivo principal, que é guiar e orientar o desenvolvimento de software baseado em ontologia, associando as atividades da Engenharia de Software e Engenharia de Ontologias de forma ágil. De modo geral, também foi possível verificar que as atividades e tarefas do processo estão em conformidade com as necessidades do desenvolvimento de software baseado em ontologia. Além disso, no terceiro estudo de caso, a produtividade das equipes pode ser avaliada, indicando que os desenvolvedores que seguiram o OntoSoft produziram mais artefatos e com menos dificuldade em relação aos desenvolvedores que não o utilizaram.

Entre as melhorias a serem feitas, destaca-se a inserção de exemplos e de checklists 
na documentação do processo a fim de facilitar o entendimento do desenvolvedor e, assim, melhorar a aplicabilidade do processo. Entretanto, de forma global, as aplicações bem sucedidas do OntoSoft forneceram indícios a respeito da viabilidade de uso e adoção no desenvolvimento de software baseado em ontologia.

No próximo capítulo são sumarizadas as contribuições e as limitações gerais do trabalho conduzido, bem como as perspectivas futuras para sua continuidade. 

CAPÍTULO

\section{6}

6

\section{CONCLUSÕES}

$\mathrm{O}$

uso de ontologias na Engenharia de Software tem crescido nos últimos anos em virtude das suas características, que incentivam e aprimoram a formalização e o compartilhamento do conhecimento. Nessa mesma direção, surge o conceito de software baseado em ontologia, no qual a ontologia é tida como um dos artefatos principais, possibilitando a extração do conhecimento de maneira automatizada nas aplicações. O uso da ontologia como um artefato do software impulsiona a geração automática de código, a formalização dos conceitos, a integração contínua e a transformação de dados em conhecimento. Estas características podem ser diretamente relacionadas aos novos desafios no desenvolvimento de software e das novas aplicações na Engenharia de Software.

Como estes fatores estão presentes em várias áreas de pesquisa, ainda existem poucos trabalhos associando processos de desenvolvimento da Engenharia de Software aos conceitos da Engenharia de Ontologias. Os estudos relacionados não são detalhados e não definem uma alta granularidade das atividades, tarefas e papeis, entre outros componentes de processo de desenvolvimento, como foi apresentado na revisão sistemática conduzida neste doutorado. Estes pontos foram discutidos e definidos ao longo desta tese, que teve como principal objetivo definir um processo de desenvolvimento ágil para software baseado em ontologia - o processo OntoSoft.

O processo OntoSoft apoia-se nas boas práticas de desenvolvimento da Engenharia de Software e Engenharia de Ontologias. Ele tem como base o método ágil Scrum nas suas atividades de gerenciamento, proporcionando a entrega e avaliação contínua de incrementos do software que são elaborados iterativamente. No OntoSoft, fases, atividades, tarefas, papeis e artefatos foram definidos de maneira detalhada. Além disso, foram especificados três cenários de desenvolvimento para guiar as equipes a partir da complexidade do software a ser desenvolvido.

Para avaliar e validar a proposta desta tese foram aplicados três estudos de caso em diferentes ambientes e com equipes distintas de desenvolvimento. A aplicabilidade, a efetividade 
e a produtividade do processo OntoSoft foram verificadas, por meio das avaliações e dos resultados obtidos nos estudos de caso. As medidas de produtividade foram definidas considerando a avaliação sobre as definições estabelecidas no processo e o número de artefatos desenvolvidos. Especificamente no terceiro estudo de caso, a produtividade foi obtida por meio da comparação dos resultados das equipes que utilizaram o processo em relação à equipe não o utilizou. Como foi apresentado e discutido no Capítulo 5, as equipes que utilizaram o OntoSoft geraram mais artefatos durante a execução das sprints e compreenderam com mais facilidade as relações entre as atividades do software e da ontologia. A partir desses indicativos, observou-se que o processo OntoSoft melhorou a efetividade das equipes e apoiou o desenvolvimento do software baseado em ontologia de maneira efetiva.

\subsection{Contribuições da pesquisa}

Esta pesquisa de doutorado definiu um processo de desenvolvimento ágil para software baseado em ontologia, denominado OntoSoft, que tem como objetivo guiar as equipes de desenvolvimento na execução das atividades e tarefas, dos artefatos do software e da ontologia, por meio da associação dos conceitos da Engenharia de Software e Engenharia de Ontologias. Foram definidas fases, atividades e tarefas que acompanham o ciclo de desenvolvimento do software baseado em ontologia. Vale ressaltar que as atividades de gerenciamento do OntoSoft são baseadas do método ágil Scrum, para fomentar o desenvolvimento incremental e iterativo. Adicionalmente ao processo OntoSoft, que é a contribuição essencial deste doutorado, as seguintes contribuições também foram derivadas:

i. Caracterização do estado da arte quanto aos conceitos de Engenharia de Ontologias e Engenharia de Software. Foram identificados os principais processos de desenvolvimento da Engenharia de Software, seus benefícios e limitações. Da mesma forma, as metodologias de Engenharia de Ontologias também foram sumarizadas a fim de contribuir para a escolha das atividades e dos diferentes papeis para a equipe de desenvolvimento do software baseado em ontologia.

ii. Identificação dos processos de desenvolvimento para software baseado em ontologia. Por meio da condução de uma revisão sistemática foram identificados os processos de desenvolvimento que atuavam diretamente na construção de software baseado em ontologia, considerando a ontologia como um artefato principal do software. Os trabalhos encontrados são similares ao OntoSoft, no entanto não apresentam detalhes das atividades e tarefas, pontos que são abordados no presente processo e diferenciam esta proposta.

iii Definição dos papeis para a equipe de desenvolvimento do software baseado em ontologia. Foram definidos papeis de desenvolvimento para cada atividade, considerando as competências e as habilidades esperadas durante a associação dos papeis às atividades no 
processo OntoSoft. Assim, com base nas diretrizes e nas definições propostas no processo, a equipe pode relacionar seus desenvolvedores ao papel indicado com mais precisão.

iv. Definição de cenários de uso para software baseado em ontologia. No processo OntoSoft foram definidos três cenários de desenvolvimento para auxiliar as equipes no processo de construção do software baseado em ontologia. Para a composição dos cenários, foram consideradas, principalmente, a complexidade da ontologia e da aplicação a ser desenvolvida. Foram estabelecidos os seguintes cenários: (i) a ontologia é considerada o núcleo de uma aplicação simples; (ii) a ontologia é reutilizada para o desenvolvimento de uma aplicação; e (iii) a ontologia é utilizada para construir uma plataforma que servirá de base para apoiar os demais sistemas de uma organização.

v. Criação de modelos de artefatos para guiar os desenvolvedores. Durante a definição do processo OntoSoft foram elaborados modelos de artefatos a fim de otimizar o tempo de desenvolvimento da equipe. Alguns modelos foram criados com base em especificações e padrões já conhecidos, outros foram construídos de acordo com as definições na literatura. Notou-se ao longo das avaliações que a disponibilização dos modelos facilitou, guiou e otimizou o tempo de desenvolvimento dos artefatos nas equipes.

\subsection{Limitações e Trabalhos Futuros}

As principais limitações relacionadas à pesquisa realizada neste doutorado são sumarizadas a seguir:

i. Limitações relacionadas à avaliação dos estudos conduzidos: em virtude da especificidade do processo OntoSoft e com base nas dificuldades inerentes à avaliação do ciclo de vida completo de um software, aos resultados sumarizados não podem ser aplicados métodos de avaliação estatística, uma vez que a amostra não foi suficientemente grande. Por isso, uma ameaça à validade dos estudos conduzidos nesta tese refere-se ao baixo número de participantes. Uma provável solução para essa limitação pode ser o particionamento das atividades aplicadas em pequenos ciclos para as equipes até que todas as fases do processo sejam avaliadas.

ii. Limitações relacionadas à associação de metodologias ágeis e desenvolvimento de ontologias: existem duas opiniões de caráter consensual entre os pesquisadores, a saber: a atividade de construir uma ontologia é complexa e a formalização dos conceitos demanda tempo. Por isso, associar o método ágil Scrum ao desenvolvimento de ontologias pode gerar dúvidas e objeções. Este fato foi contornado no processo OntoSoft por meio da definição dos cenários de uso, ou seja, da determinação de sequências das atividades para diferentes cenários das aplicações. Além disso, no OntoSoft as reuniões diárias podem ser particionadas na equipe, de acordo com os papeis e as atividades que estão sendo 
executadas. Essa estratégia foi adotada a fim de minimizar o impacto da complexidade da definição dos requisitos do software e dos conceitos da ontologia.

A partir das limitações apresentadas, são sumarizadas algumas das possibilidades de continuidade deste trabalho:

i. Planejamento e condução de novos estudos experimentais: conduzir estudos experimentais com um maior número de participantes e considerando todos os cenários definidos devem ser realizados em curto prazo, a fim de colaborar para a solução de problemas em organizações e equipes de desenvolvimento que necessitem explorar um vasto domínio de conhecimento.

ii. Criação de novos exemplos de artefatos para disponibilizar às equipes: gerar novos exemplos de artefatos com base nos estudos conduzidos, para auxiliar os desenvolvedores que ainda não possuem experiência no desenvolxvimento de software baseado em ontologia.

iii. Melhorar e atualizar o processo OntoSoft com base nas experiências e nas tendências de pesquisa: melhorar as atividades e tarefas descritas no OntoSoft de acordo com as tendências nas pesquisas, considerando tanto o ambiente acadêmico como organizacional. Estudar e incentivar o uso de tecnologias semânticas e criar diretrizes práticas para sua aplicação.

iv. Estabelecer uma classificação para as tecnologias semânticas emergentes. Classificar as tecnologias semânticas identificando as características, extensões e escopo no que tange a manipulação de ontologias, a fim de apoiar as atividades do processo OntoSoft.

v. Formalizar a especificação do processo. Utilizar uma linguagem de modelagem de processo para formalizar e instanciar as definições do processo OntoSoft.

vi. Criar um sistema de controle e gerenciamento do OntoSoft. Desenvolver um sistema de software para auxiliar a aplicação do processo, incluindo as especificações das atividades e a gestão dos artefatos preenchidos online.

\subsection{Publicações}

Em decorrência das pesquisas conduzidas neste doutorado, o seguinte trabalho foi publicado em conferência internacional (Qualis CAPES/CC - A1):

- MACHADO, J. B.; ISOTANI, S.; BARBOSA, A.; BANDEIRA, J.; ALCANTARA,W.; BITTENCOURT, I.; BARBOSA, E. F. OntoSoft process: Towards an agile process for ontology-based software. 49th Hawaii International Conference on System Sciences (HICSS). 2016. p. 5813-5822. 
Em fase de submissão e elaboração:

- MACHADO, J. B., ISOTANI, S.; BITTENCOURT, I.; BARBOSA, E. F. A Systematic Review for the Identification of Development Processes for Ontology-based Software. Journal of Computer Science and Technology (submetido).

- MACHADO, J. B., BARBOSA, E. F. Ontosoft process: guidelines to support the ontology based software development. Journal of Web Semantics (em elaboração). 



\section{REFERÊNCIAS}

ABECKER, A.; ELST, L. van. Ontologies for Knowledge Management. In: STAAB, S.; STUDER, R. (Ed.). Handbook on Ontologies. [S.1.]: Springer, 2009. p. 713-734. Citado nas páginas 60,61 e 62 .

ABROWSKA-KUBIK, K. D. DevOntoCreator: An ontology-based approach to software engineering. Przeglad Elektrotechniczny, v. 91, n. 3, p. 13-17, 2015. Citado na página 67.

AßMANN, U.; EBERT, J.; PAN, J. Z.; STAAB, S.; ZHAO, Y. Introduction. In: PAN, J. Z.; STAAB, S.; EBERT, J.; ZHAO, Y. (Ed.). Ontology-Driven Software Development. [S.1.: s.n.], 2013. p. 1-34. Citado nas páginas 15, 25, 30, 31, 72, 74, 75 e 76.

BACHMANN, A.; HESSE, W. OBSE: an approach to Ontology-based Software Engineering in the practice. In: . [S.1.]: Proceedings of the 2nd International Workshop on Enterprise Modelling and Information Systems Architectures, 2007. p. 129-142. Citado nas páginas 23 e 24.

BALIYAN, N.; KUMAR, S. Adaptation of software engineering to semantic web based system development. In: IEEE-C2SPCA International Conference on Emerging Trends in Communication, Control, Signal Processing and Computing Applications. [S.1.: s.n.], 2013. p. 1-5. Citado na página 25.

BECK, K. Extreme Programming Explained: Embrace Change. [S.1.]: Addison-Wesley, 2000. ISBN 0-201-61641-6. Citado na página 36.

BERNERS-LEE, T.; HENDLER, J.; LASSILA, O. The Semantic Web. p. 1-5, 2001. Citado nas páginas 16, 117, 118 e 120.

BHATIA, M. P. S.; KUMAR, A.; BENIWAL, R. Ontologies for software engineering: Past, present and future. Indian Journal of Science and Technology, v. 9, 2016. Citado na página 40.

. SWOT Analysis of Ontology Driven Software Engineering. Indian Journal of Science and Technology, v. 9, 2016. Citado nas páginas 55 e 56.

BIYANG, X.; MIN, J. A qualitative and quantitative assessment method for software process model. In: IEEE International Conference on Software Engineering and Service Sciences (ICSESS). [S.1.: s.n.], 2010. p. 286-291. Citado nas páginas 31, 32 e 34.

BORST, W. N. Construction of Engineering Ontologies for Knowledge Sharing and Reuse. Tese (Doutorado), Enschede, 1997. Citado na página 40.

COCKBURN, A. Crystal Clear: A Human-Powered Methodology for Small Teams. [S.1.]: Addison-Wesley, 2004. Citado na página 36.

CORCHO, O.; FERNANDEZ-LOPEZ, M.; GOMEZ-PEREZ, A. Ontological engineering: Principles, methods, tools and languages. In: CALERO, C.; RUIZ, F.; PIATTINI, M. (Ed.). Ontologies for Software Engineering and Software Technology. [S.1.]: Springer-Verlag, 2006. p. 1-48. Citado nas páginas 40, 41, 42, 43, 44, 45, 46, 47, 48, 50 e 96. 
DELAMARO, M. E.; MALDONADO, J. C.; JINO, M. Conceitos básicos. In: DELAMARO, M. E.; MALDONADO, J. C.; JINO, M. (Ed.). Introdução ao teste de software. [S.1.]: Campus, 2007. cap. 1, p. 1-7. Citado na página 100.

DELINE, G.; LIN, F.; WEN, D.; GASEVIC, D.; KINSHUK. Ontology-driven development of intelligent educational systems. In: IEEE Pacific RIM Conference on Communications, Computers, and Signal Processing. [S.1.: s.n.], 2007. p. 34-37. Citado na página 26.

A case study of ontology-driven development of intelligent educational systems. International Journal of Web-Based Learning and Teaching Technologies, v. 4, p. 66-81, 2009. Citado na página 63.

DINGSOYR, T.; LASSENIUS, C. Emerging themes in agile software development: Introduction to the special section on continuous value delivery. Information and Software Technology, v. 77, p. 56-60, 2016. Citado nas páginas 37 e 38.

DOMINGUE, J.; FENSEL, D.; HENDLER, J. Introduction to the semantic web technologies. In: DOMINGUE, J.; FENSEL, D.; HENDLER, J. (Ed.). Handbook of Semantic Web Technologies. Berlin: Springer-Verlag, 2011. cap. 1, p. 3-42. Citado nas páginas 58, 59, 87, 89 e 101 .

DYBA, T.; DINGSOYR, T. Empirical studies of agile software development: A systematic review. Information and Software Technology, v. 50, p. 833-859, 2008. Citado nas páginas $17,35,36,39$ e 40 .

EMAMI, M. S.; ITHNIN, N. B.; IBRAHIM, O. Software process engineering: Strengths, weaknesses, opportunities and threats. In: 2010 6th International Conference on Networked Computing (INC). [S.1.: s.n.], 2010. p. 1-5. Citado nas páginas 30 e 34.

FERNANDEZ-LOPEZ, M.; GOMEZ-PEREZ, A.; JURISTO, N. Methontology: From ontological art towards ontological engineering. In: . [S.1.]: Spring Symposium on Ontological Engineering of AAAI, 1997. p. 33-40. Citado nas páginas 44, 47, 48, 92 e 96.

GARCÍA-BORGOÑÓN, L.; BARCELONA, M.; GARCÍA-GARCÍA, J.; ALBA, M.; ESCALONA, M. Software process modeling languages: A systematic literature review. Information and Software Technology, v. 56, p. 103-116, feb 2014. Citado na página 134.

GASEVIC, D.; DJURIC, D.; DEVEDZIC, V. Model Driven Architecture and Ontology Development. Berlin, Heidelberg: Springer Berlin Heidelberg, 2006. 109-126 p. Citado na página 25.

GASEVIC, D.; KAVIANI, N.; MILANOVIC, M. Ontologies and software engineering. In: STUDER, Y. s. S. S.; RUDI (Ed.). Handbook on Ontologies, International Handbooks. [S.1.: s.n.], 2009. p. 594-615. Citado na página 54.

GOMEZ-PEREZ, A.; CORCHO-GARCIA, O.; FERNANDEZ-LOPEZ, M. Ontological Engineering. Secaucus, NJ, USA: Springer-Verlag New York, Inc., 2004. Citado nas páginas 23, 41, 42 e 80.

GRIMM, S.; ABECKER, A.; VO, J. Handbook of Semantic Web Technologies. Berlin, Heidelberg: Springer Berlin Heidelberg, 2011. Citado na página 54.

GRUBER, T. R. Towards principles for the design of ontologies used for knowledge sharing. Int. Journal Human-Computer Studies, v. 43, n. 5/6, 1995. Citado nas páginas 23, 40, 41 e 99. 
GUARINO, N. Formal ontology in information systems. In: . Trento, Italy: First International Conference on Formal Ontology in Information Systems, 1998. p. 443-456. Citado nas páginas $24,42,57,58,79$ e 80 .

The ontological level: Revisiting 30 years of knowledge representation. Conceptual Modeling: Foundations and Applications, Springer Verlag, p. 52-67, 2009. Citado nas páginas 40 e 41.

HAPPEL, H.; SEEDORF, S. Applications of ontologies in software engineering. In: In Proc. of 2nd International Workshop on Semantic Web Enabled Software Engineering. [S.l.: s.n.], 2006. p. 1-14. Citado nas páginas 24, 30, 31, 54 e 60.

HESSE, W. Ontologies in the software engineering process. In: In Proceedings of the Workshop on Enterprise Application Integration. [S.1.: s.n.], 2005. Citado nas páginas 24,54 e 55.

HSIEH, S.-H.; LU, M.-D. Collaborative engineering software development: Ontology-based approach. In: SMITH, I. (Ed.). Intelligent Computing in Engineering and Architecture. [S.1.: s.n.], 2006. (Lecture Notes In Artificial Intelligence, v. 4200), p. 328-342. Citado na página 26.

IEEE. IEEE standard glossary of software engineering terminology. [S.1.], 1990. 1-84 p. Citado nas páginas 29, 31 e 32.

ISO, I. S. O. ISO/IEC 12207 Systems and software engineering - Software life cycle processes. 2008. Citado nas páginas 47 e 80.

ISOTANI, S.; BITTENCOURT, I. I. Dados Abertos Conectados. [S.1.: s.n.], 2015. 175 p. Citado nas páginas 41, 43, 51 e 118.

JACOBSON, I.; BOOCH, G.; RUMBAUGH, J. The Unified Software Development Process. [S.1.]: Addison-Wesley Longman Publishing Co., Inc., 1999. Citado na página 34.

KATASONOV, A. Ontology-driven software engineering: beyond model checking and transformations. Int. J. Semantic Computing, v. 6, p. 205-242, 2012. Citado na página 24.

KITCHENHAM, B.; BRERETON, O. P.; BUDGEN, D.; TURNER, M.; BAILEY, J.; LINKMAN, S. Systematic literature reviews in software engineering - a systematic literature review. Inf. Software Technology, Butterworth-Heinemann, v. 51, p. 7-15, 2009. Citado nas páginas 64 e 65 .

KOTIS, K.; VOUROS, G. Human-centered ontology engineering: The HCOME methodology. Knowledge and Information Systems, 2006. Citado nas páginas 49 e 92.

KOZAKI, K.; KITAMURA, Y.; IKEDA, M.; MIZOGUCHI, R. Hozo: An environment for building/using ontologies based on a fundamental consideration of "role" and "relationship". In:

Knowledge Engineering and Knowledge Management: Ontologies and the Semantic Web: 13th International Conference, EKAW 2002 Sigüenza, Spain, October 1-4, 2002 Proceedings. [S.1.]: Springer Berlin Heidelberg, 2002. p. 213-218. Citado na página 51.

KROEGER, T. a.; DAVIDSON, N. J.; COOK, S. C. Understanding the characteristics of quality for software engineering processes: A Grounded Theory investigation. Information and Software Technology, Elsevier B.V., v. 56, p. 252-271, 2014. Citado na página 26. 
LEVY, M.; HAZZAN, O. Knowledge Management in Practice: The Case of Agile Software Development. 2009 Icse Workshop on Cooperative and Human Aspects of Software Engineering, p. 60-65, 2009. Citado nas páginas 24, 89 e 96.

MACHADO, J. B.; ISOTANI, S.; BARBOSA, A.; BANDEIRA, J.; ALCANTARA, W.; BITTENCOURT, I.; BARBOSA, E. F. Ontosoft process: Towards an agile process for ontology-based software. In: 2016 49th Hawaii International Conference on System Sciences (HICSS). [S.1.: s.n.], 2016. p. 5813-5822. Citado nas páginas 23 e 67.

MARIETTO, M. B.; DAVID, N.; SICHMAN, J. S.; COELHO, H. Requirements analysis of agent-based simulation platforms: state of the art and new prospects. In: . [S.1.]: Springer-Verlag, 2002. p. 125-141. Citado na página 42.

MAVETERA, N. Towards a Comprehensive Ontology-Driven Software Development Approach. In: SOLIMAN, K. (Ed.). Innovation and Knowledge Management: A Global Competitive Advantage. [S.1.], 2011. p. 393-402. Citado nas páginas 26 e 54.

MEZGHANI, E.; EXPOSITO, E.; DRIRA, K. A collaborative methodology for tacit knowledge management: Application to scientific research. Future Generation Computer Systems, Elsevier, v. 54, p. 450-455, 2015. Citado nas páginas 60, 61 e 86.

MIZOGUCHI, R. Part 2: Ontology Development, Tools and Languages. 2003. Citado nas páginas $23,25,42,45$ e 50 .

MIZOGUCHI, R.; KITAMURA, Y. Knowledge systematization through ontology engineering: a key technology for successful intelligent systems. 2001. Citado na página 43.

MIZOGUCHI, R.; VANWELKENHUYSEN, J.; IKEDA, M. Task ontology for reuse of problem solving knowledge. In: . Amsterdam: IOS Press, 1995. Citado nas páginas 42 e 80.

MORO, R.; FALBO, R. A. Avaliação e melhoria de processos de software: Conceituação e definição de um processo para apoiar a sua automatização. In: . [S.1.]: VIII Simpósio Brasileiro de Qualidade de Software, 2009. p. 406-420. Citado na página 40.

NADOVEZA, D.; KIRITSIS, D. Ontology-based approach for context modeling in enterprise applications. Computers in Industry, v. 65, p. 1218-1231, 2014. Citado na página 23.

NAUR, P.; RANDELL, B. Software Engineering: Report of a conference sponsored by the NATO Science Committee. [S.1.], 1968. 231 p. Citado na página 30.

NIXON, L.; VOLZ, R.; CIRAVEGNA, F.; STUDER, R. Future trends. In: DOMINGUE, J.; FENSEL, D.; HENDLER, J. (Ed.). Handbook of Semantic Web Technologies. [S.1.]: Social Semantic Web, 2011. v. 53, p. 583-616. Citado nas páginas 58, 87, 98 e 101.

NOY, N. F.; MCGUINNESS, D. L. Ontology Development 101: A Guide to Creating Your First Ontology. [S.1.], 2001. Citado nas páginas 41, 43 e 46.

OSMAN, N. A.; HO, S.-B.; HAW, S.-C. Empirical approach in ontology engineering: An assessment on novice modelers. In: 5th Malaysian Conference in Software Engineering (MySEC). [S.1.: s.n.], 2011. p. 501-507. Citado nas páginas 43 e 55.

PAN, J. Z.; STAAB, S.; AßMANN, U.; EBERT, J.; ZHAO, Y.; OBERLE, D. Ontology-driven software development. In: Ontology-Driven Software Development. [S.1.: s.n.], 2013. p. 319322. Citado nas páginas 23, 73 e 79 . 
POPPENDIECK, M.; POPPENDIECK, T. Lean Software Development - An Agile Toolkit for Software Development Managers. [S.1.]: Addison-Wesley, 2003. Citado na página 36.

PRESSMAN, R. S. Software Engineering: practitioner's appoach. 7th. ed. [S.1.]: McGrawHill Higher Education, 2010. Citado nas páginas 29, 31, 33, 35, 80 e 92.

PRESUTTI, V.; DAGA, E.; GANGEMI, A.; BLOMQVIST, E. extreme design with content ontology design patterns. In: Proceedings of the 2009 International Conference on Ontology Patterns. [S.1.]: CEUR-WS.org, 2009. p. 83-97. Citado nas páginas 49, 50 e 92.

RODRIGUEZ, D.; GARCIA, E.; SANCHEZ, S.; Rodriguez-Solano Nuzzi, C. Defining Software Process Model Constraints With Rules Using Owl And Swrl. International Journal of Software Engineering and Knowledge Engineering, v. 20, p. 533-548, 2010. Citado na página 74.

RUBIN, K. S. Essential Scrum: A Practical Guide to the Most Popular Agile Process. [S.1.: s.n.], 2012. 482 p. Citado nas páginas 38 e 39.

RUIZ, F.; HILERA, J. R. Using Ontologies in Software Engineering and Technology. Springer Berlin Heidelberg, p. 49-102, 2006. Citado nas páginas 23, 25, 41, 57, 58 e 110.

RUNESON, P.; HÖST, M. Guidelines for conducting and reporting case study research in software engineering. Empirical Software Engineering, v. 14, p. 131-164, 2009. Citado na página 113.

SANTHOSH, J. Leveraging Traditional Software Engineering Tools to Ontology Engineering under a New Methodology. In: 2010 5th International Conference on Future Information Technology (FutureTech). [S.1.: s.n.], 2010. p. 1-5. Citado na página 44.

SCHACH, S. R. Object-oriented and classical software engineering. [S.l.]: McGraw-Hill, 2011. 1-688 p. Citado nas páginas 17, 34, 35 e 83.

SCHWABER, K.; SUTHERLAND, J. The scrum guide. 2011. 16 p. Disponível em: <http: //www.scrumguides.org/index.html>. Citado nas páginas 25, 26, 37, 80, 83, 84, 85, 88, 89 e 90.

Guia do SCRUM. Harvard Business Review, Boston, IV, p. 163-179, 2013. Citado nas páginas 37, 38, 83, 90 e 91 .

SHEN, J.; BEYDOUN, G.; LOW, G.; WANG, L. Aligning ontology-based development with service oriented systems. Future Generation Computer Systems, v. 32, p. 263-273, 2014. Citado na página 67.

SOMERVILLE, I. Engenharia de Software. 9th. ed. [S.1.]: Pearson Addison Wesley, 2010. Citado nas páginas 32, 33, 34, 36, 80 e 92.

STAAB, S.; SCHNURR, H. P.; STUDER, R.; SURE, Y. Knowledge processes and ontologies. In: . [S.1.]: IEEE Intelligent Systems, 2001. p. 26-34. Citado nas páginas 45 e 46.

STUDER, R.; BENJAMINS, V. R.; FENSEL, D. Knowledge engineering: Principles and methods. Data \& Knowledge Engineering, v. 25, p. 161-197, 1998. Citado na página 41.

SUAREZ-FIGUEROA, M. NeOn Methodology for building ontology networks: specification, scheduling and reuse. 288 p. Tese (Doutorado), 2010. Citado nas páginas 25, 49 e 92. 
SUÁREZ-FIGUEROA, M. C.; GÓMEZ-PÉREZ, A.; FERNÁNDEZ-LÓPEZ, M. Scheduling ontology development projects. Data \& Knowledge Engineering, Elsevier B.V., v. 102, p. 1-21, 2016. Citado na página 24.

SUÁREZ-FIGUEROA, M. C.; GÓMEZ-PÉREZ, A.; MOTTA, E.; GANGEMI, A. Ontology Engineering in a Networked World. In: SUÁREZ-FIGUEROA, M. C.; GÓMEZ-PÉREZ, A.; MOTTA, E.; GANGEMI, A. (Ed.). Berlin, Heidelberg: Springer Berlin Heidelberg, 2012. Citado nas páginas 80 e 109.

SURE, Y.; STAAB, S.; STUDER, R. Ontology engineering methodology. In: Handbook on Ontologies. [S.1.]: Springer Berlin Heidelberg, 2009. p. 135-152. Citado nas páginas 25, 60, 61 e 62.

SUTHERLAND, J. Scrum handbook. [S.1.], 2010. 66 p. Citado nas páginas 88 e 89.

TYRRELL, S. The many dimensions of the software process. Crossroads, v. 6, p. 22-26, 2000. Citado na página 32.

USCHOLD, M. Ontology-driven information systems: Past, present and future. Frontiers in Artificial Intelligence and Applications, v. 183, p. 3-18, 2008. Citado na página 72.

VALIENTE, M.-C.; GARCIA-BARRIOCANAL, E.; SICILIA, M. A. Applying ontology-based models for supporting integrated software development and it service management processes. Part C: Applications and Reviews, IEEE Transactions on Systems, Man, and Cybernetics, v. 42, p. 61-74, 2012. Citado na página 32.

WIEBE, A. J.; CHAN, C. W. Ontology driven software engineering. In: 25th IEEE Canadian Conference on Electrical and Computer Engineering: Vision for a Greener Future. [S.1.: s.n.], 2012. Citado na página 25.

WOHLIN, C.; RUNESON, P.; HOST, M.; OHLSSON, M. C.; REGNELL, B.; WESSLEN, A. Experimentation in Software Engineering. [S.1.: s.n.], 2012. v. 44. 249 p. Citado na página 135. 
APÊNDICE

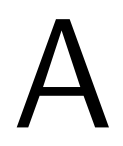

\section{ARTEFATOS PROPOSTOS NO PROCESSO ONTOSOFT}

Os artefatos definidos para o processo OntoSoft dizem respeito aos principais artefatos que devem ser elaborados em um software baseado em ontologia. Os modelos propostos no OntoSoft foram definidos com a finalidade de otimizar o tempo dos desenvolvedores e padronizar algumas práticas de desenvolvimento das equipes. Os artefatos são descritos na sequência. 


\section{Product Backlog}

Este documento deve conter a lista dos principais itens de backlog do sistema.

Responsável: [Nome]

Data de criação do documento: $[x x / y y / x x x x]$

Artefato iniciado: na atividade de Preparação do Produto de Backlog no Gerenciamento.

Artefato de entrada para as atividades: Sprint Planning.

Atualizado nas atividades: Sprint Planning.

Product Backlog - [Nome do Sistema]

\begin{tabular}{|c|c|c|c|c|c|c|}
\hline ID & $\begin{array}{c}\text { Item } \\
\text { precedente }\end{array}$ & Item de Backlog & Categoria & $\begin{array}{l}\text { Valor de negócio } \\
(0-100)\end{array}$ & Tamanho & VN/Tamanho \\
\hline & & & & & & \\
\hline & & & & & & \\
\hline & & & & & & \\
\hline & & & & & & \\
\hline & & & & & & \\
\hline & & & & & & \\
\hline & & & & & & \\
\hline & & & & & & \\
\hline & & & & & & \\
\hline
\end{tabular}




\section{Definição dos papeis da equipe}

Este documento deve conter o nome e a função de cada stakeholders na equipe, enfatizando suas habilidades e competências.

Responsável: [Nome]

Data de criação do documento: [xx/yy/xxxx]

Artefato iniciado: na atividade de Definição dos papeis da equipe.

Artefato de entrada para as atividades: Sprint Planning.

\section{Lista dos papéis da equipe}

\begin{tabular}{|c|c|c|}
\hline Papel & Responsável & Habilidades/Experiência \\
\hline Engenheiro de Software & & \\
\hline Engenheiro de Ontologias & & \\
\hline Especialista de domínio & & \\
\hline Scrum Master & & \\
\hline Cliente (Product Owner) & & \\
\hline Desenvolvedor & & \\
\hline & & \\
\hline
\end{tabular}




\section{Sprint Backlog}

Este documento deve conter a lista de cada item de backlog que é dividido em um conjunto de tarefas relacionado a uma determinada Sprint.

\section{Responsável:}

Data de criação do documento:

Sprint: [número]

Artefato iniciado: na atividade de Sprint Planning

Product Backlog - [Nome do Sistema]

\begin{tabular}{|l|l|l|l|l|}
\hline ID & Item de Backlog & Tarefa relacionada & Horas & $\begin{array}{c}\text { Total de } \\
\text { horas }\end{array}$ \\
\hline & & & & \\
\hline & & & & \\
\hline & & & & \\
\hline & & & & \\
\hline & & & & \\
\hline & & & & \\
\hline & & & & \\
\hline & & & & \\
\hline & & & & \\
\hline
\end{tabular}




\section{Cenários da aplicação}

Este documento deve conter os cenários de desenvolvimento da aplicação que são extraídos, normalmente, durante as primeiras reuniões entre o cliente e a equipe. Além disso, estes podem ser incrementados de acordo com a elicitação de requisitos e dos conceitos da ontologia feita pela equipe no decorrer do desenvolvimento.

\section{Responsável:}

Data de criação do documento:

Artefato iniciado: na atividade de Criação de cenários de aplicação.

Artefato de entrada para as atividades: Especificação de requisitos, Especificação da ontologia.

Este artefato pode ser construído de diversas maneiras, por exemplo:

- A equipe pode construir storyboards de acordo com as discussões realizadas.

- A equipe pode construir diagramas de casos de uso para ilustrar os requisitos, mesmo que de maneira informal.

- A equipe pode descrever no formato de tópicos os pontos mais importantes nas discussões.

\section{Descrição do cenário de desenvolvimento}




\section{Documento de visão}

Este documento deve conter as principais características acordadas pela equipe de desenvolvimento e pelo cliente. De forma breve e sucinta, o objetivo e as características gerais do software devem ser documentadas.

Responsável: [Nome]

Data de criação do documento: $[x x / y y / x x x x]$

Artefato iniciado: na atividade de Preparação do Product Backlog.

Artefato de entrada para as atividades: Especificação de requisitos, Especificação da ontologia.

[Nome do Projeto]

Objetivo: [Descrever o objetivo do projeto com base nas necessidades do cliente e nas decisões acordadas nas primeiras discussões.]

Problema: [Descrever o problema que será resolvido e como será abordado no projeto.]

Principais funcionalidades: [Quais as principais funcionalidades que o sistema deve ter? Qual é o núcleo do sistema? Qual o papel da ontologia?]

Escopo do projeto: [Descrever as fronteiras do sistema, deixando claro o que é parte do sistema e o que não é.]

Restrições: [Listar as principais restrições do projeto como limite orçamentário, limite de tempo, restrições de pessoal.] 


\section{Glossário de Termos}

Este documento deve conter os principais conceitos relacionados ao projeto e que serão base para a especificação da(s) ontologia(s).

\section{Responsável:}

Data de criação do documento:

Artefato iniciado: na atividade de Concepção do software.

Artefato de entrada para as atividades: Especificação de requisitos, Especificação da ontologia.

Atualizado nas atividades: Conceitualização e Especificação da ontologia.

\begin{tabular}{|l|l|}
\hline Termo & Definição \\
\hline & \\
\hline & \\
\hline & \\
\hline & \\
\hline & \\
\hline & \\
\hline
\end{tabular}




\section{Documento de requisitos}

Este documento deve conter os requisitos identificados do sistema, tanto os requisitos funcionais quanto os não funcionais devem ser descritos.

Responsável: [Nome]

Data de criação do documento: [xx/yy/xxxx]

Artefato iniciado: na atividade de Especificação de Requisitos.

Artefato de entrada para as atividades: na atividade de Preparação do Product Backlog, Criação de cenários, Concepção do software, Especificação da Ontologia.

\begin{tabular}{|l|l|}
\hline Id & Requisitos Funcionais \\
\hline RF-XX & O sistema deve.... \\
\hline & \\
\hline & \\
\hline & \\
\hline & \\
\hline & \\
\hline & \\
\hline & \\
\hline & \\
\hline
\end{tabular}

\begin{tabular}{|l|l|}
\hline Id & Requisitos Não Funcionais \\
\hline RNF-Xx & O sistema deve.... \\
\hline & \\
\hline & \\
\hline & \\
\hline & \\
\hline & \\
\hline
\end{tabular}




\section{Modelo de domínio}

Este documento deve conter os principais os conceitos do domínio do software a ser desenvolvido. Este documento pode ser utilizado para compor o diagrama de classes e para apoiar as definições dos conceitos da ontologia.

\section{Responsável:}

Data de criação do documento:

Artefato iniciado: na atividade de Especificação dos requisitos e Criação de cenários de uso.

Artefato de entrada para as atividades: Projeto, Especificação da Ontologia.

Modelo de domínio para o sistema [xxx]

Os desenvolvedores podem criar 


\section{Avaliação da Ontologia}

Este documento contém questões de avaliação genéricas e específicas relacionadas ao domínio da ontologia em desenvolvimento.

\section{Responsável:}

Data de criação do documento:

Artefato iniciado: na Especificação da Ontologia.

Artefato de entrada para as atividades: Especificação da Ontologia, Avaliação da Ontologia.

\section{Questões de Competência Genéricas}

Critérios gerais observados: (i) claridade; (ii) coerência; (iii) capacidade de extensão; (iv) mínimo de viés na codificação; e (v) compromisso ontológico mínimo.

(i) A ontologia é clara cognitivamente?
( ) $\operatorname{Sim}$ ( ) Não

(ii) A ontologia é coerente com as fontes teóricas?

(iii) ( ) Sim ( ) Não

(iv) A ontologia pode ser facilmente estendida?

( ) $\operatorname{Sim}$ ( ) Não

(v) A ontologia é limitada a uma representação específica?
( ) $\operatorname{Sim}$ ( ) Não

(vi) A ontologia é ligada a algum compromisso filosófico?

(vii) ( ) Sim ( ) Não

Os critérios que não foram atendidos devem ser revistos e melhorados na ontologia, a fim de que o mínimo esperado para o desenvolvimento de uma 'boa' ontologia seja alcançado.

\section{Questões de Competência Específicas}

Critérios específicos observados: 
APÊNDICE
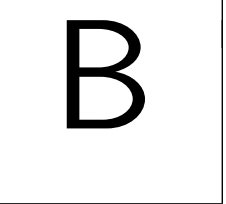

\section{QUESTIONÁRIOS APLICADOS NOS ESTUDOS DE AVALIAÇÃO}

Um conjunto de questionário foi utilizado na avaliação do processo OntoSoft na execução dos estudos de caso. As questões elaboradas para cada questionário, em seu respectivo estudo, são apresentadas nas próximas seções.

\section{B.1 Estudo de caso 1: UFAL - Boa Moradia}

No estudo de caso do Boa Moradia foram definidos dois questionários, que foram aplicados da seguinte forma:

Q1: Primeiro questionário: Aplicado ao final de cada sprint no estudo de caso.

Q2: Segundo questionário: Aplicado ao final da última sprint no estudo de caso.

As questões para cada questionário são descritas em seus respectivos questionários a seguir.

\section{Q1: Primeiro questionário}

1. Papel desempenhado na equipe:

Engenheiro de software

Especialista de domínio

Engenheiro de ontologias

Scrum master 


\section{Cliente}

2. . De que forma o processo melhorou o desenvolvimento?

Indicando as atividades e as tarefas a serem seguidas.

O processo não ajudou.

$\square$ Outra opção.

3. As práticas do Scrum são conhecidas pela equipe?

$\operatorname{Sim}$

$\square$ Não

4. As práticas do Scrum foram seguidas pela equipe?

$\operatorname{Sim}$

Não

\section{Gerenciamento}

5. As reuniões diárias ocorreram?

$\operatorname{Sim}$

Não

6. Por que as reuniões diárias não ocorreram?

Falta de organização da equipe.

Falta de gerenciamento do projeto.

Trabalhos extras da graduação/mestrado.

Reuniões e outros afazeres que mudaram a prioridade da equipe.

Outros

7. Os artefatos foram desenvolvidos seguindo o processo?

$\operatorname{Sim}$

Não

8. Como foram definidos os artefatos?

Utilizei um modelo pronto.

Não consultei os modelos propostos.

Fiz um modelo segundo os meus conhecimentos. 


\section{Pré-Desenvolvimento}

9. A disposição das atividades no pré-desenvolvimento estão de acordo com o fluxo de trabalho da equipe?

\section{$\operatorname{Sim}$ \\ Não}

10. Qual deveria ser a sequência das atividades?

11. Algumas atividades do pré-desenvolvimento foram consideradas desnecessárias pela equipe? Quais?

12. Há alguma atividade desenvolvida no Boa Moradia que não está contida no processo?

13. Quais foram tais atividades?

$\operatorname{Sim}$

Não

14. Você consultou as tarefas estabelecidas para cada atividade?

14.a As tarefas são coerentes ou precisam ser melhoradas?
Coerentes.
Precisam ser melhoradas.
Incompletas.

14.b Por que não consultou o processo quando havia dúvida?

Desinteresse.

Esquecimento.

Falta de tempo.

Falta de motivação.

15. O tempo para gerar os artefatos do software e da ontologia, em paralelo, foi coerente?

$\operatorname{Sim}$

$\square$ Não

16. Quais inconsistências foram notadas?

17. A atividade de Projeto consumiu muito tempo?

\section{$\operatorname{Sim}$}

Não 
18. Quais artefatos foram gerados na atividade de Projeto?

Diagrama de classes

Diagrama de caso de uso

Diagrama de sequência

Diagrama de atividades

Arquitetura do sistema

Definição das tecnologias semânticas

19. As atividades foram definidas de acordo com a dependência de outras atividades do processo?

$\operatorname{Sim}$

$\square$ Não

20. A atividade de aquisição do conhecimento promoveu a alteração de algum requisito ou de algum artefato relacionado ao software?

$\operatorname{Sim}$

$\square$ Não

21. Durante a atividade de aquisição do conhecimento e de conceitualização ontologias foram consultadas?

Sim

$\square$ Não

22. O engenheiro de ontologias importou alguma ontologia para reusar?

Sim

Não

23. Foi construída uma biblioteca de ontologias?

Sim

Não

\section{Desenvolvimento}

24. O desenvolvimento da ontologia da aplicação consumiu mais tempo do que esperado pela equipe?

Sim 


\section{Não}

25. Aponte as principais falhas do processo, por favor, quanto ao tempo de desenvolvimento da ontologia.

26. O engenheiro de ontologia fez a avaliação da ontologia antes de iniciar a sua implementação?

$\operatorname{Sim}$

Não

27. Na avaliação da ontologia foram considerados quais aspectos:

\section{Claridade}

Coerência

$\square$ Capacidade de extensão

Mínimo de viés na codificação

Compromisso ontológico mínimo

28. A integração da ontologia ao software foi coberta pelo processo?

Sim

Não

29. Quais foram as principais falhas na atividade de integração?

30. Quais as principais dificuldades encontradas na integração da ontologia ao código?

31. Qual ferramenta e/ou tecnologia foi utilizada para associar a ontologia à aplicação?

32. A equipe já detinha conhecimento no uso da ferramenta?

$\operatorname{Sim}$

$\square$ Não

33. A equipe concluiu a sprint dentro do prazo estabelecido?

Sim

Não

$\square$ Outros

34. Houve a inserção de tecnologias semânticas na aplicação? Quais?

35. A inserção de tecnologias semânticas interferiu na integração da ontologia? De que forma? 
36. Quais ferramentas foram utilizadas na inserção/utilização das tecnologiaos semânticas?

37. Quanto tempo, aproximadamente, os desenvolvedores levaram para adquirir o conhecimento e fazer as instalações e os ajustes necessários para o uso de tais tecnologias?

\section{Questões Finais}

38. Qual a maior dificuldade encontrada no processo até o momento?

39. Quais as maiores dificuldades identificadas no projeto Boa Moradia?

\section{Q2: Segundo questionário}

1. Papel desempenhado na equipe:

Engenheiro de software

Especialista de domínio

Engenheiro de ontologias

Scrum master

Cliente

2. Qual o seu nível de conhecimento em engenharia de software:
Regular
Mediano
Intermediário
Avançado

3. Qual o seu nível de conhecimento na metodologia Scrum:
Regular
Mediano
Intermediário
Avançado

4. Qual o seu nível de conhecimento em engenharia de ontologias:
Regular
Mediano
Intermediário
Avançado 
5. Nesta primeira etapa, o processo atendeu as necessidades da equipe de forma:

Regular

Bom

Mediano

Ótimo

6. A fase de preparação do produto de Backlog foi iniciada no gerenciamento e atualizada no decorrer da concepção do software e da especificação dos requisitos. Isto aconteceu de forma:

$\square$ Regular

$\square$ Bom

Mediano

$\square$ Ótimo

7. As atividades relacionadas ao Scrum foram encaixadas no processo de forma:

Regular

Bom

Mediano

Ótimo

8. As tarefas relacionadas às atividades foram suficientes para elaborar os artefatos de maneira:

$\square$ Regular

Bom

Mediano

Ótimo

9. Por que as tarefas não foram suficientes para elaborar os artefatos?

As tarefas descritas não foram relevantes.

As tarefas descritas foram incompletas.

As tarefas descritas não guiaram a atividade.

10. Os artefatos relacionados às atividades foram construídos de acordo com a especificação do processo?

Sim 


\section{Não}

11. Por que os artefatos não foram construídos de acordo com a especificação do processo?

Os artefatos descritos no processo não são importantes.

Nem todos os artefatos descritos no processo são importantes.

Não observei os artefatos descritos no processo, fiz por conta própria.

12. Os artefatos foram atualizados conforme a descrição do processo?

As diretrizes não foram seguidas.

As diretrizes não ficaram claras na especificação do processo.

As diretrizes foram seguidas conforme a especificação do processo.

13. Quanto às atividades de engenharia de ontologias o processo foi especificado de maneira:
Regular
Bom
Mediano
Ótimo

14. As atividades relacionadas à engenharia de ontologias e engenharia de software ocorreram de forma paralela?
$\operatorname{Sim}$
$\square$ Não

15. As atividades de conceitualização e aquisição do conhecimento foram especificadas no processo de forma:
Regular
Bom
$\square$ Mediano
Ótimo

16. As reuniões aconteceram diariamente (daily planning meeting)?

\section{Sim \\ Não}

17. Com que frequência você recorreu à especificação do processo? 


\section{Esporadicamente \\ Frequentemente}

18. Caso queira, por favor, deixe aqui suas sugestões, críticas e melhorias para o processo.

\section{B.2 Estudo de caso 2: UFSCar - AppLucy e Projeto Dis- ciplina}

No segundo estudo de caso, três questionários foram utilizados na estudo piloto e três questionários foram aplicados na avaliação do processo OntoSoft no desenvolvimento das aplicações específicas do projeto da disciplina.

\section{Questionários para a avaliação do OntoSoft na aplicação AppLucy}

O segundo questionário foi respondido ao final de cada sprint no estudo de caso.

Q1: Questionário inicial para identificação das características dos participantes no estudo piloto

1. Qual o seu nível de conhecimento em engenharia de software e/ou desenvolvimento de software?
Regular
Intermediário
Especialista

2. Qual o seu nível de conhecimento na metodologia Scrum?
Regular
Intermediário
Especialista

3. Qual o seu nível de conhecimento em engenharia de ontologias?
Regular
Intermediário
Especialista

4. Você já desenvolveu uma ontologia?

Sim

Não 
5. Quanto tempo você dedicou ao estudo da documentação do processo OntoSoft?

$\square$ Uma hora de estudo

$\square$ Duas horas de estudo

Três horas de estudo

Outro:

6. Você selecionou algumas dúvidas para esclarecer com a autora do processo?

$\operatorname{Sim}$

$\square$ Não

7. Como você considera a documentação do processo OntoSoft?

Q2: Questionário de avaliação do OntoSoft no estudo piloto

1. Papel na equipe:

Engenheiro de software

Especialista de domínio

Engenheiro de ontologias

Scrum master

Cliente

2. De que forma o processo auxiliou no desenvolvimento da aplicação?

Indicando o fluxo das atividades ao longo do desenvolvimento.

Indicando as tarefas de cada atividade.

Indicando os cenários possíveis de aplicação de ontologias.

Indicando as iterações e atualizações quando necessárias.

O processo não ajudou a equipe, pois não é intuitivo ou iterativo.

$\square$ Outro:

3. As práticas do Scrum eram conhecidas pela equipe?

Sim

Não

4. As práticas do Scrum foram seguidas pela equipe?

$\operatorname{Sim}$ 
Não

\section{Gerenciamento e Cenários}

5. Aconteceram pequenas discussões antes de iniciar cada sprint?

$\operatorname{Sim}$

Não

6. Os artefatos foram desenvolvidos seguindo o processo?

Sim

Não

7. Como foram definidos os artefatos?

Utilizei outro modelo pronto.

Não consultei os modelos propostos.

Fiz um modelo segundo os meus conhecimentos.

Outro:

8. Os cenários de aplicação foram definidos de forma adequada?

Sim

Não

9. Os cenários estão incompletos, qual sua sugestão?

10. As especificações foram suficientes para identificar as características da aplicação?

Sim, os cenários estão bem descritos.

Sim, mas faltam alguns detalhes importantes que identificamos.

Não, faltam cenários importantes.

Outro:

11. Quais detalhes foram identificados?

\section{Pré-Desenvolvimento}

12. A disposição das atividades no pré-desenvolvimento estão de acordo com o fluxo de trabalho da equipe?

$\operatorname{Sim}$

Não 
13. Algumas atividades do pré-desenvolvimento foram consideradas desnecessárias pela equipe? Quais?

14. Você consultou as tarefas estabelecidas para cada atividade?

$\square \operatorname{Sim}$

$\square$ Não

15. As tarefas são coerentes ou precisam ser melhoradas?

\section{Coerentes.}

Precisam ser melhoradas.

Incompletas.

16. Por que não consultou o processo quando havia dúvida?

Desinteresse.

Esquecimento.

$\square$ Falta de tempo.

$\square$ Falta de motivação.

$\square$ Outro:

17. A atividade de Projeto consumiu muito tempo?

Sim

$\square$ Não

18. Quais artefatos foram gerados na atividade de Projeto?

Diagrama de classes

Diagrama de caso de uso

Diagrama de sequência

Diagrama de atividades

Arquitetura do sistema

Definição das tecnologias semânticas

19. A dependência entre atividades foi considerada?

Sim

Às vezes

Não 
20. A atividade de aquisição do conhecimento promoveu a alteração de algum requisito ou de algum artefato relacionado ao software?
Sim
Não
Outro:

21. Durante a atividade de aquisição do conhecimento e de conceitualização ontologias foram consultadas?
Sim
Não
Outro:

22. O engenheiro de ontologias importou alguma ontologia para reusar?

Sim

Não

23. Foi construída uma biblioteca de ontologias?
$\operatorname{Sim}$
Não

\section{Desenvolvimento}

24. O desenvolvimento da ontologia da aplicação consumiu mais tempo do que esperado pela equipe?
$\operatorname{Sim}$
Não

25. Aponte as principais falhas do processo, por favor, quanto ao tempo de desenvolvimento da ontologia.

26. O engenheiro de ontologia fez a avaliação da ontologia antes de iniciar a sua implementação?

Sim

Não

27. Na avaliação da ontologia foram considerados quais aspectos:

\section{Claridade}


Coerência

Capacidade de extensão

Mínimo de viés na codificação

Compromisso ontológico mínimo

28. A integração da ontologia ao software foi coberta pelo processo?

Sim

Não

29. Quais foram as principais falhas na atividade de integração?

30. Quais as principais dificuldades encontradas na integração da ontologia ao código?

31. Qual ferramenta e/ou tecnologia foi utilizada para associar a ontologia à aplicação?

32. A equipe já detinha conhecimento no uso da ferramenta?

$\operatorname{Sim}$

Não

33. A equipe concluiu a sprint dentro do prazo estabelecido?

Sim

Não

34. Houve a inserção de tecnologias semânticas na aplicação? Quais?

\section{Questões Finais}

35. Quais os benefícios do processo OntoSoft durante a aplicação?

36. Quais as maiores dificuldades identificadas no projeto da aplicação?

37. Quantas vezes você consultou o processo?

Considere a escala de 0 a 7 :

Q3: Questionário de avaliação final no estudo piloto:

1. O processo atendeu as necessidades da equipe?

Nota de 0 à 10 :

2. A aplicação do processo OntoSoft fluiu de maneira:

Nota de 0 à 10: 
3. A complexidade do domínio da aplicação interferiu na execução das atividades?

$\operatorname{Sim}$

Não

$\square$ Outro:

4. As atividades de Engenharia de Software e Engenharia de Ontologias foram associadas de maneira:

Adequada

Completa

Incompleta

Confusa

5. A equipe seguiu as diretrizes (as tarefas) no processo em cada atividade?

Sim

Não

Outro:

6. Os artefatos especificados na documentação foram construídos?

$\operatorname{Sim}$

Não

Outro:

7. A documentação do processo estava completa?

$\operatorname{Sim}$

Não

$\square$ Outro:

8. Por favor, faça algumas considerações da equipe a respeito da aplicação do processo.

\section{Questionários para a avaliação do OntoSoft nos projetos da disciplina}

No segundo estudo também foram definidos questionários para avaliar o processo na execução dos projetos da disciplina, são eles:

i. Questionário para avaliar a execução das sprints.

ii. Questionário de avaliação final das sprints. 
Q1: Questionário para avaliar a execução das sprints

Este questionário foi respondido pelos participantes ao final de cada sprint durante o estudo de caso.

1. Papel na equipe:

Engenheiro de Software

Engenheiro de Ontologia

Especialista de domínio

Especialista da aplicação

Scrum Master

Cliente

2. Qual a sprint atual no desenvolvimento do projeto?

\section{Questões referentes ao projeto:}

3. As atividades do projeto estão ocorrendo dentro do prazo?

$\square \operatorname{Sim}$

$\square$ Não

$\square$ Parcialmente

4. O ambiente de gerenciamento do projeto SeeNowDo tem sido atualizado pela equipe?

$\square \operatorname{Sim}$

$\square$ Não

$\square$ Parcialmente

5. Quais foram as atividades feitas nesta sprint?

6. Em qual(quais) atividade(s) do processo OntoSoft tais atividades se encaixam?

7. Você analisou o processo OntoSoft enquanto seguia as atividades?

$\square \operatorname{Sim}$

$\square$ Não

8. Quantas horas na semana você dedicou ao projeto?

9. Quais os artefatos iniciados ou finalizados ou atualizados? 
10. Você tem consultado a documentação do processo OntoSoft para verificar as tarefas das atividades?

$\square \operatorname{Sim}$

Não

Parcialmente

11. As atividades estão suprindo as necessidades da equipe e do projeto?

$\operatorname{Sim}$

Não

Parcialmente

12. Deixe o seu comentário sobre o processo OntoSoft (sugestão, crítica, recomendação).

Q2: Questionário de avaliação final no estudo

1. Equipe
A
$\mathrm{B}$

2. Papeis desempenhados ao longo do projeto:

Engenheiro de Software

Engenheiro de Ontologia

Especialista de domínio

Especialista da aplicação

Scrum Master

Cliente

\section{Sobre o Projeto da Disciplina}

3. Você considera que aprendeu os conceitos de Engenharia de Ontologias e sua aplicação prática?

Sim

$\square$ Não

Outro:

4. Você utilizou uma metodologia para construir a ontologia da aplicação?

\section{$\operatorname{Sim}$}


Não

5. Na sua opinião, seguir uma metodologia facilitou o entendimento e o desenvolvimento da ontologia?

$\operatorname{Sim}$

Não

6. O desenvolvimento de um software baseado em ontologia difere de um software tradicional. Quais os principais aspectos que diferenciam o ciclo de vida do software baseado em ontologia?

Definição da ontologia.

Estabelecimento do pensamento ontológico.

Entendimento do que é uma ontologia na prática.

Entendimento das restrições e dos axiomas do domínio que permeiam os requisitos do software.

Entendimento da associação da ontologia aos requisitos, ao projeto do software.

Inserção de novas tecnologias de apoio à implementação do software.

Uso da ontologia como um artefato efetivo na implementação do software.

7. A definição do projeto facilitou o entendimento dos conceitos abordados?

Sim

$\square$ Não

8. 6. Qual o seu maior aprendizado nesta disciplina?

9. Por favor, faça críticas, sugestões ou contribuições para o formato da disciplina.

\section{Sobre o processo OntoSoft}

10. O processo OntoSoft colaborou para o andamento do projeto?

$\operatorname{Sim}$

Não

11. As diretrizes do processo (conjunto de atividades e tarefas descritas) foram seguidas ao longo do projeto?

$\operatorname{Sim}$

Parcialmente

Não 
12. Os artefatos indicados nas atividades foram suficientes ou outros artefatos foram criados ao longo do projeto? Se sim, quais foram?

13. Os modelos de artefatos podem ser considerados:

Adequados

Completos

Incompletos

Outro:

14. A absorção da metodologia Scrum durante o projeto pode ser tida como:

Facilmente aplicável.

Confusa.

Fácil, mas com dúvidas em algumas atividades.

Impossível de se aplicar.

15. As atividades do processo cobriram o desenvolvimento do projeto?

Sim, parcialmente.

Sim, totalmente.

Não.

Outro:

16. A utilização do processo interferiu no tempo de desenvolvimento da aplicação:

De forma positiva, devido a descrição das atividades e tarefas.

De forma negativa, pois o processo indica muitas atividades e tarefas desnecessárias.

$\square$ Outro:

17. Quais os benefícios do processo?

Diretrizes claras.

Tarefas bem definidas.

Atividades flexíveis.

Definição para os cenários de aplicação.

Fluxo iterativo.

Possibilidade de mudança entre as atividades.

Modelos de documentos adequados.

Outro: 
18. Quais as maiores dificuldades referentes ao uso do processo?

Diretrizes mal especificadas.

Tarefas confusas.

Cenários mal documentados.

Ausência de exemplos.

Dificuldades relacionadas ao Scrum.

Dificuldades quanto às atividades.

Outro:

19. Por favor, deixe suas sugestões, críticas, contribuições relacionadas ao processo OntoSoft.

\section{B.3 Estudo de caso 3: fábrica de software - AppLucy}

No terceiro estudo de caso foram elaborados diversos questionários que são descritos na sequência:

i. Um questionário geral para identificar os participantes.

ii. Três questionários para as equipes que utilizaram o processo OntoSoft.

iii. Três questionários para a equipe que não utilizou o processo.

\section{Questionário geral e inicial}

1. Nome:

2. E-mail:

3. Qual a sua formação acadêmica?

4. Função (cargo) na fábrica:

5. Você possui quanto tempo de experiência no desenvolvimento de software?

6. Qual o seu nível de conhecimento em Engenharia de Software e/ou desenvolvimento de software?

Regular

$\square$ Intermediário

Especialista

7. Qual o seu nível de conhecimento na metodologia Scrum? 


$$
\begin{aligned}
& \text { Regular } \\
& \text { Intermediário } \\
& \text { Especialista }
\end{aligned}
$$

8. Qual o seu nível de conhecimento em Engenharia de Ontologias?

Regular

Intermediário

$\square$ Especialista

9. Você já desenvolveu uma ontologia?
$\operatorname{Sim}$
Não

\section{Questionário para as equipes que utilizaram o processo OntoSoft}

O questionário B.2 foi aplicado às equipes que utilizaram o processo OntoSoft na fábrica de software. Além disso, duas avaliações foram conduzidas por meio de outros dois questionários, apresentados a seguir.

\section{Questionário de avaliação inicial}

1. Nome:

2. E-mail:

3. Equipe de desenvolvimento:
A
B

4. Papel na equipe:

Engenheiro de Software

Engenheiro de Ontologia

Especialista de domínio

Especialista da aplicação

Scrum Master

5. Qual o nível de dificuldade para especificar o escopo e o problema da aplicação? 
Mediano

$\square$ Normal

Alto

6. Qual foi sua primeira impressão do processo OntoSoft?

$\square \operatorname{Sim}$

$\square$ Não

7. Você consultou o processo durante as atividades?

Sim

Não

8. Qual a principal diferença desta aplicação para as demais que você já desenvolveu?

9. O processo atendeu às atividades indicadas?

Sim

Não

10. As tarefas do processo estão coerentes com o desenvolvimento desta aplicação?

$\square \operatorname{Sim}$

$\square$ Não

11. O que você espera para as próximas sprints?

12. Quais os artefatos criados nessa primeira etapa?

13. equipe?

Sim

Não

14. Qual a principal dificuldade enfrentada nesta primeira etapa?

\section{Questionário para avaliação final das equipes:}

1. Nome

2. Equipe de desenvolvimento:
$\mathrm{A}$
B 
3. Papel na equipe:

Engenheiro de Software

Engenheiro de Ontologia

Especialista de domínio

Especialista da aplicação

Scrum Master

4. Dedicação/disponibilidade para o estudo nos períodos:

Participei apenas 1 período.

Participei apenas 2 períodos.

Participei dos 3 períodos.

5. De que forma o processo auxiliou no desenvolvimento da aplicação?

Indicando o fluxo das atividades ao longo do desenvolvimento.

Indicando as tarefas de cada atividade.

$\square$ Indicando os cenários possíveis de aplicação de ontologias.

Indicando as iterações e atualizações quando necessárias.

O processo não ajudou a equipe, pois não é intuitivo ou iterativo.

Outro:

6. As práticas do Scrum eram conhecidas pela equipe?

$\square \operatorname{Sim}$

Não

7. As práticas do Scrum foram seguidas pela equipe?

$\operatorname{Sim}$

Não

\section{Gerenciamento e Cenários}

8. Aconteceram pequenas discussões antes de iniciar cada sprint?

Sim

Não

9. Os artefatos foram desenvolvidos seguindo o processo?

$\operatorname{Sim}$ 
Não

10. Como foram definidos os artefatos?

Utilizei outro modelo pronto.

Não consultei os modelos propostos.

Fiz um modelo segundo os meus conhecimentos.

Outro:

11. Os cenários de aplicação foram definidos de forma adequada?

$\operatorname{Sim}$

$\square$ Não

12. Os cenários estão incompletos, qual sua sugestão?

13. As especificações foram suficientes para identificar as características da aplicação?

Sim, os cenários estão bem descritos.

Sim, mas faltam alguns detalhes importantes que identificamos.

Não, faltam cenários importantes.

Outro:

14. Quais detalhes foram identificados?

\section{Pré-Desenvolvimento}

15. A disposição das atividades no pré-desenvolvimento estão de acordo com o fluxo de trabalho da equipe?

$\operatorname{Sim}$

Não

16. Algumas atividades do pré-desenvolvimento foram consideradas desnecessárias pela equipe? Quais?

17. Você consultou as tarefas estabelecidas para cada atividade?

$\square \operatorname{Sim}$

$\square$ Não

18. As tarefas são coerentes ou precisam ser melhoradas?

Coerentes.

Precisam ser melhoradas. 
Incompletas.

19. Por que não consultou o processo quando havia dúvida?

Desinteresse.

$\square$ Esquecimento.

Falta de tempo.

Falta de motivação.

$\square$ Outro:

20. A atividade de Projeto consumiu muito tempo?

Sim

Não

21. Quais artefatos foram gerados na atividade de Projeto?

Diagrama de classes

Diagrama de caso de uso

Diagrama de sequência

Diagrama de atividades

Arquitetura do sistema

Definição das tecnologias semânticas

22. A dependência entre atividades foi considerada?

$\operatorname{Sim}$

Às vezes

Não

23. Durante a atividade de aquisição do conhecimento e de conceitualização ontologias foram consultadas?

Sim

Não

Outro:

24. Foi construída uma biblioteca de ontologias?

$\operatorname{Sim}$

Não 


\section{Desenvolvimento}

25. O desenvolvimento da ontologia da aplicação consumiu mais tempo do que esperado pela equipe?

Sim

Não

26. Aponte as principais falhas do processo, por favor, quanto ao tempo de desenvolvimento da ontologia.

27. A integração da ontologia ao software é coberta pelo processo?

\section{Sim}

Não

Q20. Qual ferramenta e/ou tecnologia foi utilizada para criar a ontologia? Q21. A equipe já detinha conhecimento no uso da ferramenta?

$\operatorname{Sim}$

Não

Q22. A equipe concluiu a sprint dentro do prazo estabelecido?

$\operatorname{Sim}$

Não

\section{Questões Finais}

28. Quais os benefícios do processo OntoSoft durante a aplicação?

29. Quais as maiores dificuldades identificadas no projeto da aplicação?

30. Com que frequência você consultou o processo OntoSoft?

Sempre que tinha dúvida.

Ao definir as atividades.

Ao pensar nas tarefas das atividades.

Não consultei o processo, apenas li o seu documento uma vez.

31. Que nota você daria para o processo OntoSoft?

Considere a escala de 0 a 10 : 


\section{Questionários para a equipe que não utilizou o processo OntoSoft}

Primeiro questionário respondido por cada membro da equipe.

1. Nome:

2. E-mail:

3. Papel na equipe:

Engenheiro de Software

Engenheiro de Ontologia

Especialista de domínio

Especialista da aplicação

Scrum Master

Cliente

4. Qual o nível de dificuldade para especificar o escopo e o problema da aplicação?

Nota em uma escala de 0 a 5:

5. Qual foi a metodologia utilizada para definir atividades e tarefas da aplicação?

6. Como foi definida o desenvolvimento do software e da ontologia?

Em paralelo.

Ontologia e depois o software.

Software e depois ontologia.

Outro:

7. Qual a principal diferença desta aplicação para as demais que você já desenvolveu?

8. O que você espera para as próximas sprints?

\section{Questionário respondido pela equipe ao final do estudo de caso:}

1. Qual o objetivo da aplicação proposta?

2. Como foi feita a divisão de tarefas nas atividades?

De maneira informal.

De acordo com uma metodologia.

De acordo com as práticas do Scrum (prioridades). 
Não houve divisão de tarefas.

3. Como o escopo foi definido?

Por meio de discussões na equipe.

Por meio da extração de características no texto.

Por meio de uma abordagem específica.

4. Como a equipe definiu a prioridade das atividades?

5. Como a equipe fez a divisão dos papeis na equipe?

6. Quais os principais artefatos que devem ser gerados nas primeiras sprints?

7. Qual a diferença desta aplicação para as demais desenvolvidas na Polícia Militar?

\section{Questionário utilizado para a avaliação no estudo de caso:}

1. Dedicação/disponibilidade para o estudo nos períodos:

Participei apenas 1 período.

Participei apenas 2 períodos.

Participei dos 3 períodos.

2. As práticas do Scrum foram seguidas pela equipe?

Sim

Não

3. Como foram definidos os artefatos?

4. Como foram definidas as atividades?

Seguindo o processo de desenvolvimento atual.

Com base nas discussões realizadas durante o estudo.

Outro:

5. Qual a diferença da aplicação proposta para as demais aplicações da fábrica?

6. Quais as dificuldades encontradas durante o experimento?

7. Quais as suas conclusões sobre desenvolver o software e a ontologia?

8. Você sentiu falta de uma abordagem para guiar o desenvolvimento? Por que? 
9. O que você espera de uma metodologia para guiar o desenvolvimento de software baseado em ontologia?

10. Qual a complexidade desta aplicação em relação às aplicações que não utilizam uma ontologia? 


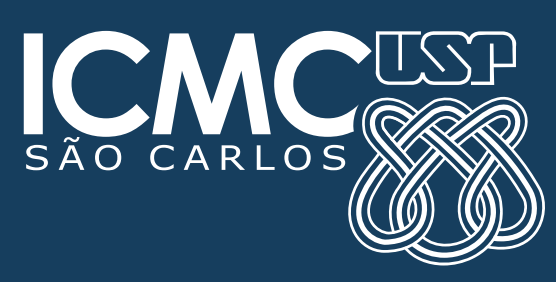

